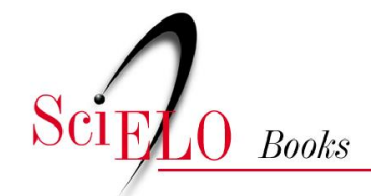

\title{
The Latin American challenge
}

social cohesion and democracy

\author{
Bernardo Sorj \\ Danilo Martuccelli
}

SORJ, B., and MARTUCCELLI, D. The Latin American challenge: social cohesion and democracy [online]. Rio de Janeiro: Centro Edelstein de Pesquisa Social, 2008, 252p. ISBN 978-85-7982-081-6.

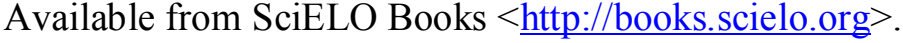

\section{@(1) (2)}

All the contents of this chapter, except where otherwise noted, is licensed under a Creative Commons Attribution-Non Commercial-ShareAlike 3.0 Unported.

Todo o conteúdo deste capítulo, exceto quando houver ressalva, é publicado sob a licença Creative Commons Atribuição Uso Não Comercial - Partilha nos Mesmos Termos 3.0 Não adaptada.

Todo el contenido de este capítulo, excepto donde se indique lo contrario, está bajo licencia de la licencia Creative Commons Reconocimento-NoComercial-CompartirIgual 3.0 Unported. 


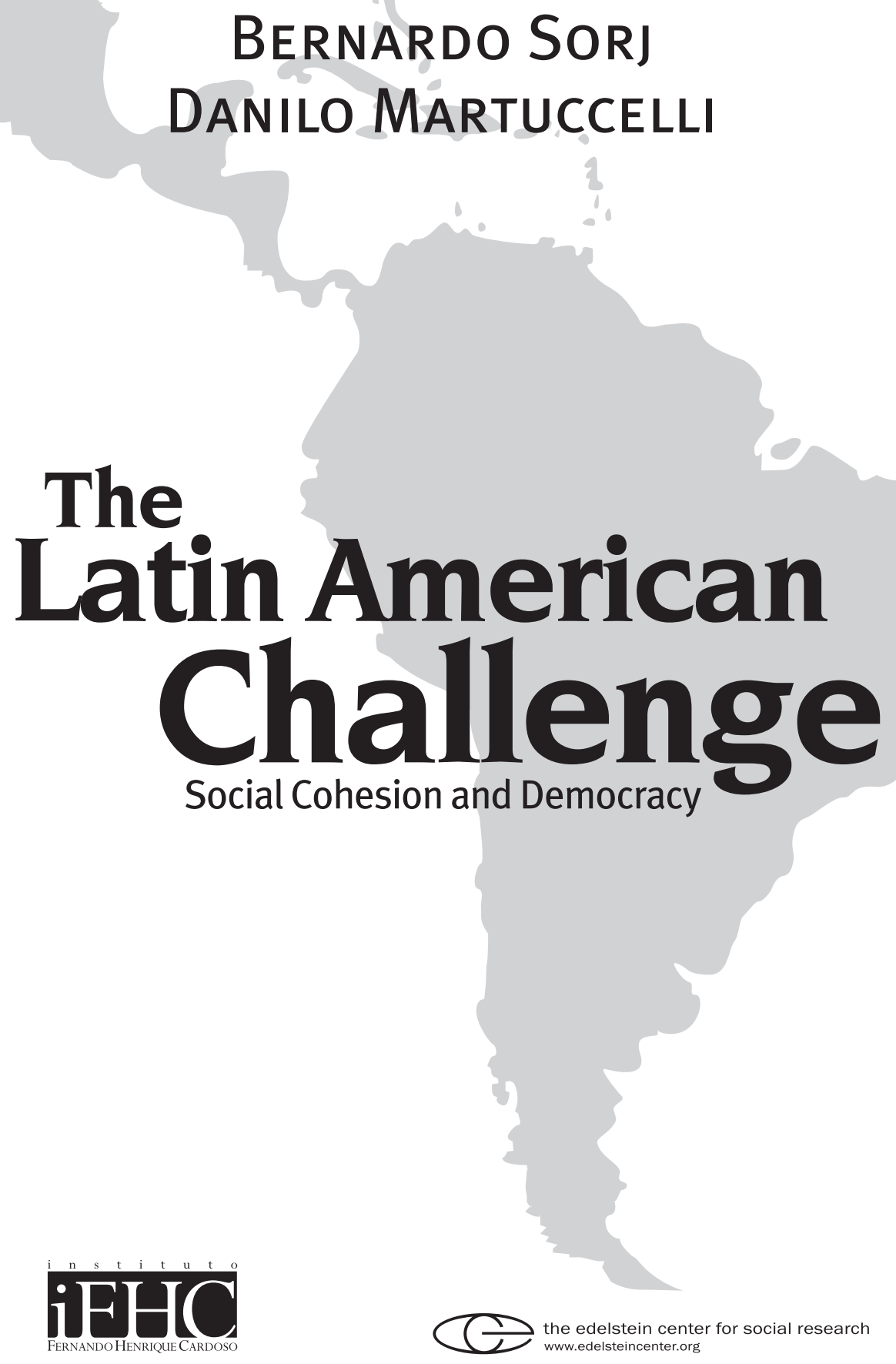


This book was written as a contribution to the New Agenda for Social Cohesion in Latin America project of the iFHC - Instituto Fernando Henrique Cardoso and CIEPLAN Corporación de Estudios para Latinoamérica. The European Union and the UNDP provided support for the project. The information and opinions expressed herein are exclusively those of the authors and do not necessarily reflect the opinions of the institutions associated with the project or entail any commitment on their part.

Project coordinators:

Bernardo Sorj and Eugenio Tironi.

Executive Team:

Eduardo Valenzuela, Patricio Meller, Sergio Fausto and Simon Schwartzman.

ISBN:

978-85-99588-32-1 (Instituto Fernando Henrique Cardoso)

978-85-99662-58-8 (The Edelstein Center for Social Research)

Translation from Spanish:

Gretta K. Siebentritt

Graphic Designer:

Domingos Sávio - Imagem\&Texto

(C) Instituto Fernando Henrique Cardoso - iFHC / The Edelstein Center for Social Research 


\section{Contents}

\section{Introduction}

Social Cohesion and Democracy: between voice and exit 7

\section{Chapter I}

\section{Transformations of the Social Bond}

1. Introduction 25

2. Religion and religiosity 29

3. Inter-ethnic relations and democratization 39

4. Urban spaces and dynamics 44

5. The media, cultural industry and social cohesion 57

6. Emigration 69

7. Conclusions 77

\section{Chapter II}

Collective actors and forms of representation

1. Introduction: noises in the formation of voice 81

2. Trade unions 83

3. Political parties 97

4. Civil society 104

5. The changing profiles of the militant 109

6. The emerging public 113

7. Conclusions 121 


\section{Chapter III}

Problems and Promises: the Informal Economy, Crime and Corruption, Norms and Rights

1. Introduction: a culture of transgression 125

2. Armed urban violence in Latin America 129

3. Drugs, organized crime and the state 136

4. The threats of corruption 143

5. The judicial question 149

6. Conclusions 156

\section{Chapter IV}

State, Nation and Politics at the Dawn of the $21^{\text {st }}$ Century

1. Introduction: State and society, a prismatic relationship 159

2. The State: continuities and challenges 161

3. Consumption: individual and collective goods 170

4. New political discourses and democracy: a return to populism? 180

5. Nation and the challenge of identities 192

6. Conclusions: from technocratic reformism to democratic reformism? 211

GENERAL CONCLUSIONS 215

\section{Annex 1}

Background to the Concept of Social Cohesion 231

\section{Annex 2}

List of contributions 241

BIBLIOGRAPHY 243 


\section{Introduction}

\section{Social Cohesion and Democracy: Between Voice and Exit}

In order to understand the dynamics of constructing social cohesion in Latin America we must bring a new perspective to approaches that focus mainly on the pervasive social problems on the continent. While it is true that disregarding these problems would be tantamount to adopting a conservative posture, we must by the same token identify the region's wealth of positive resources for integration and sociocultural creativity in order to discern how our societies generate social cohesion and how this influences democracy building. ${ }^{1}$ Our continent is generally free of strong tensions between the state and the national culture and, compared to most regions of the world, is endowed with a high degree of linguistic and religious homogeneity as well as a deeply-rooted tradition of secularism and inter-religious coexistence. The conquest, followed by the nation states, destroyed the political and religious foundations that might have fostered the emergence of political-cultural movements based on alternative values to modernity. At the same time, the peoples of most Latin American countries self-identify as mestizos, or people of mixed descent, although this has not ruled out racism in various forms. Fratricidal struggles have not occurred among ethnic or religious communities and the inter-state wars of the

1 See Annex 1 for a discussion of the concept of social cohesion as it is used in the Latin American context (Discussion of the concept of social cohesion). 
$20^{\text {th }}$ century were tangential and border conflicts largely resolved. In most countries, there is a solid national consciousness associated with shared forms of social relations, lifestyles and tastes with which the majority of the population identifies.

Few regions in the world can lay claim to a similar socio-cultural heritage. Even from the economic standpoint, the sluggish growth in per capita income during the latter half of the $20^{\text {th }}$ century did not reflect the enormous effort to increase production in many countries whose populations had quadrupled by mid-century. What is more, given the higher than average fertility rates of the impoverished populations of these countries, the fact that inequality indicators have held steady is indicative of significant processes of social mobility and wealth distribution.

In addition to these longstanding factors of social cohesion, we must understand how individuals today, within their particular contexts and life conditions - including poverty and limited opportunities - , have become producers of meaning, individual strategies and innovative types of solidarity not predetermined by history or social structures. While this assertion could be misinterpreted as one of naïve individualism, our intention, in fact, is to go beyond the old structuralist determinism. Taking into account the power vectors and social determinants within, and based on, which people define their life strategies and meaning, social analysis must discover how individuals constantly reorganize their perceptions and practices to create new alternatives and possibilities. Basically, the idea is to accept the indeterminate as a fact of life in modern societies. Social analysis reveals the past and scrutinizes the present, but it cannot predict the future.

By focusing on the richness and inclusive vitality of the social fabric in the new social processes underway in societies across the continent, we can pinpoint the contradictory dynamics they produce from the standpoint of social cohesion and democracy. We must include a caveat here with respect to the normative assessment of the progress, setbacks, and shortcomings in our societies. All of these things coexist in Latin America. If it is true that triumphalism is blind to the serious problems assailing the continent, a unilateral emphasis on our deficiencies that fails to acknowledge our achievements (which are real, if flawed) fosters a culture of collective failure and frustration that contributes to the neglect of the public space and encourages demagoguery.

Social cohesion is a comparative concept in which the present situation is compared and contrasted with the past and with other societies. While 
comparisons with European and U.S. models (oftentimes stylized and somewhat idealized) are inevitable, we must take care that such comparisons do not lead to explanations premised on our shortcomings: we are what we are because we "lack" certain qualities (Sorj, 2005a). Comparisons with the past are also inevitable. As we know, the danger here resides in idealizing the past and, most importantly, in failing to understand the new mechanisms employed by social actors, and particularly youth, to give meaning to their lives.

Maintaining a balanced perspective towards the forces of change and continuity in societies is the main intellectual and political challenge which we as social scientists are doomed to navigate. This is particularly important when we look at culture, where longstanding trends are continuously updated and adapted by the transformations in progress. It is extremely difficult to decide whether to stress only the new or affirm the permanence of the old, albeit with new trappings. In our study, we focus on the importance of autonomous individual action - somewhat on the margins of (or not directly subordinated to) the traditional social and political-cultural institutions - as the driving force behind new survival strategies and universes of meaning. At the same time, however, we are careful to point out that the space for individual initiative affects, and is affected by, structural and institutional determinants.

Finally, and cognizant of the inevitable risk of overgeneralization, we discuss Latin America as a region. Decades ago, besides acknowledging an obvious linguistic-cultural identity, generalizations about Latin America reflected a time when the political ideologies of social transformation simplified and homogenized the world and were also indicative of the state of the social sciences and the deficit in available knowledge. The opposite is true today. Political ideologies centered on the demands of specific groups fragment social perceptions, at the same time that we are gradually experiencing the inevitable and necessary specialization of social science research. In this new context, a reference to Latin America as a whole would be seemingly devoid of any real relevance. In our desire to further what we believe is the best of social thinking in the region, our project, however, defies such a dismantling. There are two reasons for this. First, we believe that a regional comparison is critical to a common understanding of the problems facing our societies. And second, we are convinced that in a globalized world, shedding light on the common processes and trends among different countries - despite their variations - is part of our commitment as social scientists to the future of the region. 
Much of the analysis concerning social cohesion in contemporary societies stresses the changes that are taking place in a fragmented world characterized by self-centered individualization. This panorama is associated with the loss of a sense of belonging to the national community, a lack of concern for the common good, the erosion of traditional reference points, and the expansion of information systems coupled with the desire for access to an increasingly broad spectrum of consumer products. What takes center stage, then, is the issue of burgeoning expectations and the capacity of distribution systems (in particular the state and the market) to respond to them.

The way in which social actors cultivate these expectations, and the individual and collective strategies employed to fulfill them, are not expressed mechanically or exclusively in terms of demands on the political system. If that were the case, given the prevailing inequality and poverty indicators in the region, democratic systems would have been completely overwhelmed by now. In order to understand the relationship between the objective situation and the strategies employed by social actors, we must take into account the proliferation of initiatives and different forms of social mediation, that is, the symbolic and associative universes that explain the complex relationship between individuals and the more abstract systems comprising the market and the State.

In the past, facing pervasive, blatant economic and political barriers, social actors associated with others based on specific class, gender or ethnic identities in order to advocate for, or defend, their interests. Hirschman encapsulates this brilliantly with the term voice. The massive influx of migrants from rural areas to the big cities, and the urban-industrial changes of the 1950s heightened expectations. Society's inability to fulfill these expectations (in terms of employment and housing, political participation and symbolic inclusion) caused an "overload" of social demands, which in turn fed authoritarian pathologies or "excesses" leading to various forms of social disorganization. In this context, collective mobilizations were at once a potential linchpin of, and a real threat to, social cohesion.

Contemporary democratization processes are not generally expressed through heightened pressure on the political system. This is only partially due to the erosion of traditional forms of collective participation and the limited effectiveness of new ones. It is also the case that many initiatives are played out on the margins (privately, at the level of individual consumption 
or collective events external to the political system), against the public sphere (various forms of criminal activity), or by leaving the country. The voice (expression/participation in the public sphere) and exit (withdrawal from the public sphere) dialectic, then, permeates our analysis. During the latter half of the last century traditional Latin American social analysis focused on the formation of voice. Today, however, there is a growing need to understand the myriad dynamics of exit.

As we shall argue in the following chapters, voice and exit must be examined together in order to understand the real state of mobilization in Latin America today. Even more so since in all likelihood the two are joined by more than one conduit: the weakness of collective actors triggers the quest for individual solutions to social problems. The way in which emigration is engraved on the collective imaginary, for instance, discourages collective participation. This provides a good illustration of the way in which the proliferation of individual initiatives covers some institutional gaps while simultaneously creating others. It is for this reason that, absent any institutional inscription and translation, there is an enormous risk that these factors could end up undermining social cohesion and the stability of democracies. At the present time, however, we are compelled to acknowledge that they also represent the promise of another more democratic and horizontal form of social cohesion.

Individuation processes are permeating Latin America, but their rhythms and forms of expression in society vary according to gender, urban and rural context, social class, education, generation, and country. Further research is required to map in more detail the ways in which these processes play out in Latin America and their correlation with specific variables. Here we will simply point out examples of how material standard of living, social and educational inequalities and institutional fragility have a powerful impact on the opportunities and foundations for individuation.

A higher degree of individuation means more individual autonomy and initiative and a constant questioning and negotiation of social relations. This leads to greater opacity between the individual subjective world and society, a topic which has been examined from various angles by the founders of sociology (alienation, anomie and disenchantment). Opacity, which leads to anxiety - fuels a vigorous therapeutic industry ranging from psychoanalysis to pharmaceuticals - and alcohol and drug use, and is also manifest in the continuous search for new forms of association and collective expression (music/dance, religion, or sports fervor). While these dynamics are not new, their significance was played down in the social 
sciences, which focused mainly on the major agglutinating social forces of the $20^{\text {th }}$ century: the labor market, trade unions, political parties, and ideologies. As the relative import of these structures has diminished, other spaces for sociability and meaning have become critical to understanding social cohesion in our societies.

The expanding space for individual action, however, does not mean that institutions simply stopped functioning. To the contrary, with the weakening of social norms, values and traditional bonds of solidarity, public regulation is increasingly in demand in domains previously regarded as spheres of private life. And this is perhaps at the heart of the drama of contemporary Latin American societies: insofar as the social sphere, increasingly penetrated by the market, is no longer sustained through social ties of dependence, favoritism, paternalism, and hierarchy, the state must increasingly assume the role of guarantor of the social pact among free and equal citizens, by means of law enforcement and social protection measures. In most countries, however, the state has responded poorly to this new social reality. Not only has the social transformation been faster and deeper than the state's, in many countries government institutions and political systems are still bastions of traditional clientelism and nepotism.

What is more, the emphasis on the growing individuation of social actors in no way precludes the need for collective discourses with which individuals can identify and find recognition and dignity. Individuation, then, is not exclusive of the state or of political discourses able to transmit to social actors an appreciation of their individual capacity and role in society. What it does signify is that individuals, in the contexts in which they find themselves, increasingly are protagonists of their own society and this, in turn, raises the need for a discourse and policy in keeping with the changing times.

Nonetheless, and even with this trend toward individuation, the statecentered patrimonialist sociability remains tremendously powerful. It undercuts the credibility of democratic institutions by breeding apathy, frustration and rejection. At the same time, it reinforces among some sectors a vision of the state as a huge treasure chest, and there is nothing for it but to wait for a leader in the tradition of Robin Hood to come along and propose distributing the spoils among the poor. Meanwhile, the other facet of the state's inability to regulate social relations is evidenced, as discussed in more depth later, in the considerable expansion of the space for illicit economic activities that foster a culture of state failure. And these strategies centered on illegality or political apathy have an equally significant corrosive effect on democracy. 
Still, the overflow of expectations is not necessarily conducive to political overflow. It can also lead to means of channeling/translating/articulating individual concerns and expectations in universes of meaning constructed on the margins of the political system, or premised on illegality or departure (emigration). Huntington's famous theory that democracies in developing countries are overwhelmed by an excess of social demands - which Gino Germani had already presaged to a certain degree in his analysis of the Argentine case - only applies to situations in which those demands find political-ideological channels capable of pressuring or backing the political system into a corner. ${ }^{2}$ As we shall see in the ensuing chapters, this is only partially true in Latin America. Not only have the old associative systems been modified, individual actors now have unprecedented room for personal initiatives.

Here it would perhaps be useful to summarize the analysis we will develop in these pages:

- Despite ongoing and significant social inequality in the countries of the region, Latin America is permeated by growing demands for equality and by the individuation of everyday sociability and expectations. Future research should map the way in which these individuation processes take on particular features and rhythms in different countries, regions, and urban and rural contexts, among different generations, and particularly, based on material standard of living, education, and income;

- The above is associated with the erosion of traditional mechanisms of social aggregation with their emphasis on the values of hierarchy, social distance, and clientelism;

- This trend is expressed in myriad ways: it is not necessarily channeled toward collective expression or direct demands on the political system, but rather toward the private realm, consumption, violence, emigration, or individual strategies to create meaning and ensure survival. It is also manifest in demands for a more transparent state, social policies that reflect greater solidarity, and more effective and universal legal institutions;

2 Huntington's basic thesis, that social and economic changes precede institutional transformations is, paradoxically, an application of Marxist thought on the relationship between infrastructure and superstructure by right-wing thinker. 
- These changes require us to reexamine the way in which we usually conceive of the Latin American reality: the democratic revolution in course must be interpreted primarily from the standpoint of the structural transformation of society and culture. Political and institutional dynamics must be interpreted through the lens of those changes.

\section{The analytical space of social cohesion}

What we have discussed so far invites us to develop an approach that elucidates the changes in social cohesion in Latin America from an historical perspective. Besides the social and cultural dynamics examined in the following chapters, it is useful to recall the traditional approach to social cohesion on the continent, based on four pivotal mechanisms, before looking at the current situation. Each of these mechanisms, which are described briefly below, have engendered specific pathologies and fears, which have recurred - and continue to recur - cyclically in the region.

First, the social bond was clearly the main vehicle for social cohesion in Latin America. We shall return to this point later, but the transition in this regard has been such that it would not be an exaggeration to refer to the end of an era. In effect, for a long time, social cohesion was regarded as self-sustaining by means of sociability. The assumption was that the social bond in Latin America was unique - in stark contrast to what occurred in developed societies - in that it could sustain itself without having to be articulated through modern political institutions. Essentially, this social bond was regarded as something less than the community bond, yet more than societal association. Less than the former, because despite the nostalgia over a "natural" relationship among actors rooted in tradition alone, politically-motivated social bonds (tutelage, clientelism, and various forms of patronage) were also very much in evidence. More than the latter because the contractual and ultimately "artificial" and "cold" nature of social relations always stood in contrast to the expectation of a personal, subjective dimension to interpersonal relations, social and economic differences notwithstanding.

While the versions varied from country to country, the emphasis was on the strength of the social bond and a tenacious sociability rooted in the cultural legacy of our unique history, whether as reflected by Gilberto Freyre, or Octavio Paz, or in Chilean writings centered on the image of 
la hacienda. In this context, the veneration of mixed heritage [mestizaje] reflected not only an oblique rejection of racism, but also a desire to affirm the permanence of the social bond on other foundations. Obviously, in such a framework anything that conspired against this "substantial" sociability was regarded as a major threat to social cohesion, beginning with fragmentation or violence and culminating in the stereotypical imaginary - one that persists in the region to this day - of a return to "barbarity" through the "invasion" of the masses.

Second, social cohesion was conceived of in terms of the role of conflicts, and particularly class conflict. To ensure social cohesion every society requires mechanisms with which to process social conflicts and organize the representation of opposing interests and social actors and in recent decades, public opinion, play a critical role in this. Various protagonists have embodied the (re)construction of social relations in Latin America, beginning with the political parties and trade unions, followed by "social movements" or "civil society", and more recently, the growing influence of nongovernmental organizations (NGOs).

In this context, efforts to build a new and authentic social cohesion have always featured cycles of enthusiasm and disappointment. Each new generation and era has brought with it the hope of democratization or "national redemption" which, together with the relevant collective actor, eventually reached one impasse after another in practice. While in other countries the institutionalization of collective action was regarded as an essential element of democratization, this process in Latin America constantly stunted by the states' phagocytic tendency to limit autonomy and absorb social actors - was more a pattern of promise followed by betrayal. Against this backdrop, it comes as no surprise that what most attracted the attention of analysts was the risk of degradation of the actors of social cohesion, who were constantly being subordinated to authoritarian leaders and to the various cooptation strategies employed by states. But here too something new and significant has been consolidated. The democratization and individuation processes underway have forced social actors to pay more attention to public opinion which, in turn - and to the extent that it is inscribed in a universe of horizontal citizenship - transforms the way interests are represented and conflicts negotiated.

Third, and this is true of other regions as well, social cohesion was envisaged from the standpoint of the legal system, or more precisely, existing laws and norms. Just articulating this premise is enough to see its obvious limitations. In contrast to other societies - and especially the United States 
where standards of conduct (and their uniquely religious underpinnings) have genuinely served to cement of society since the country's founding the effectiveness of legal standards in the region was approached solely from the standpoint of their limitations and shortcomings: the discourse stressed a powerful culture of transgression present in all social relations, which precluded them from providing a handhold for social cohesion. In contrast to what occurred with the social bond, where there was a tendency to extol a certain collective narcissism (the "sympathy" and "human warmth" of Latin Americans), the essence of the discourse concerning the law was strongly self-critical in that it repeatedly drew attention to the failure to respect agreements and commitments (in the public as well as the private realms).

Fourth, the state, together with public policy and its many forms of intervention, has been a focal point of social cohesion in the region. This is especially true since, from the outset, national states could count on a strong sense of national belonging or on the weakness of alternative regional platforms or demands. If there ever was a "we" in Latin America, it was, for a long time, at the national and state level, especially given the state's pivotal role in Latin American societies for much of the $20^{\text {th }}$ century.

The above notwithstanding, both the state and the nation exhibited weaknesses which today are seriously criticized for several reasons. First, ethnic grievances have been a constant in countries with large native populations. Despite a seemingly united front, national identity has always been a theater of divergent and even opposing positions. Moreover, despite its protagonism in the public scene, the state was often hampered by its limited capacity to respond and to the bureaucratic weight of an administration lacking the resources or the capacity for social spending. The relative inefficiency of the state apparatus was a constant and brought with it the risks of social breakdown associated with a return to anarchy or government mismanagement.

The importance and influence of these mechanisms in the region have been such that they have largely shaped the political debate. Leaving aside their internal divisions, the major political families can be viewed, through the optic of the subject at hand, as a unique combination of these mechanisms of social cohesion. In the same way that social cohesion cannot be dissociated from a political vision, the political sphere is inseparable from a certain conceptualization of social and power relations. Following the proposed order, and at the risk of a certain oversimplification, each political family appears at the intersection of two of these mechanisms: 
- The "conservatives" on the continent espouse a vision of social relations based on an original or native form of sociability, which stresses traditional normative agreement over legal recourse;

- For their part, "liberals" upheld the importance of freedoms and therefore laid their bets (more in rhetoric than in practice) on the necessary association between normative-institutional regulation and the existence of autonomous social actors;

- The "populists," in contrast and almost antithetically, underscored the need to reestablish the old (hierarchical, asymmetrical) social bond on new foundations (revolving around the figure of "the people"), all of this contingent upon the vigor of a centralizing national state;

- Lastly, when it came to social cohesion, the "socialists," with significant variations from country to country, were defined throughout the $20^{\text {th }}$ century by the search for a viable combination of state and collective mobilizations.

Clearly, an assessment of this nature cannot do justice to the many other factors that are purveyors, at least virtually, of a promise of growing social cohesion in Latin America in the framework of democracy: a wide array of individual strategies actively engaged in the creation of universes of meaning which cannot be reduced to the mechanisms outlined above.

\section{The recomposition of social cohesion}

The Latin American reality - whether due to the shortcomings of the State, the lack of observable autonomy in collective mobilizations, or the limitations of the legal framework - was such that our unique form of social cohesion was envisaged as revolving around a self-sustaining social bond (along with a certain conservative nostalgia). Despite the simplified presentation, to some extent, this notion informed academic thought in the social sciences throughout the region. Social cohesion in Latin America was rooted essentially in the social bond, in contrast to a country like the United States, where solid normative underpinnings accord a central and uncontested role to institutions or continental Europe which, depending on the situation, historically opted for a model of social cohesion based on a republican, Jacobin state or else a social democratic or social Christian model of commitments and negotiation. The best of Latin American writing, whatever its limitations, entertained this imaginary and ultimately upheld this premise. 
In a social context in which, as we shall discuss in Chapter 1, the traditional social bond is in crisis, what analytical substitute should we draw on to describe the social cohesion we observe on the continent? The debilitation of the principal social, cultural and political mechanisms of societal integration invites us to turn our attention towards individual capacity for action and initiative and the potentially virtuous impact this might have on institutions. Paradoxical as it might seem at first glance, the individual and his or her search for autonomy - and by implication, the emphasis on personal initiative rather than resignation - is increasingly becoming the cement of society. This is contingent, however, on a clear understanding that this individual is not at the origins of society, as suggested in traditional liberal thought, but is instead the product of a particular way of making society (Martuccelli, 2007). While its presence may not be radical news in the region, the concept of the individual was conspicuously absent from past representations, to the point that social scientists approached social actors virtually exclusively from the collective or political standpoint. In this sense, the individual is a novel idea in Latin America and, curiously, one that lends itself to a fresh examination of the past in our societies even as it opens the door to a series of new possibilities for social cohesion, particularly in the framework of democracy.

Let us examine this assertion further, as it might come across as paradoxical. For a long time, the social sciences in the region assumed that "individuals" existed in the countries of the north - in the United States and Europe -, their raison dêtre sustained by institutions and social representations. In Latin America, in contrast, the stress was on groups and the community in Latin America and this - together with a stubbornly politics-centered analysis - meant that the notion of "individuals" in our societies was disregarded or even rejected outright (in terms of theoretical acknowledgment). The premise of the present study is that such a reading is completely erroneous. True, the individuals observed in Latin America are the fruit of a different and unique individuation process, but as actors, they are no less individual for all that. To the contrary, as we shall discuss in detail below, in many ways they might even be considered "more" individual than actors in many other societies in the sense that they must face and solve for themselves the sorts of social problems that are processed by institutions elsewhere.

The chapters that follow demonstrate the richness of this viewpoint through a reexamination of each one of the major mechanisms of social cohesion in the region. Each chapter is organized in the same, three-part 
format: (a) an introduction that describes the specific characteristics of each mechanism, (b) an exposition of their problems and their promise in the current context, illustrated with specific examples, (c) a conclusion pointing out observable forms of social reorganization from the standpoint of individual practices. But we will begin by briefly reviewing the main thrust of the argument that will be developed in the ensuing chapters:

- The crisis of the traditional social bond creates an opportunity to recognize interpersonal ties which, while insufficient in and of themselves, contribute to an understanding of how the social geography is shaped based on mutual help and new types of solidarity. The latter is no longer confined to community bonds or fixed collective identities, but relies increasingly on affective, elective, or revisited traditional ties (family, youth, immigrants, etc.) in which new technologies play an important role. Most importantly, as the imaginary of the old social bond fades from view, it is necessary to accept the growing importance of horizontal social relations in the region.

- The relative weakening of social actors invites us - without disregarding traditional contestatory or associative participation to focus on new forms of individual initiatives. These should not be regarded in opposition to the actions of past social movements, but rather as a sort of recomposition of them (as is the case of the NGOs to a certain extent), and a consolidation of new militant profiles that redesign the public-private connection on a different footing. This also means recognizing the growing and unprecedented influence of public opinion in the representation and negotiation of social conflicts.

- With respect to legal standards, we will demonstrate a growing tendency to seek legal recourse, despite the inherent limitations (such as pervasive and intense feelings that of abuse and derision in many national contexts). Here again - and this trend does not solely apply to the realm of individuals but is reflected in the actions of collective actors as well - the very fact of citizens demanding their rights is extremely important. The fight against corruption and the defense of human rights are among its noblest expressions today, even when the Latin American experience is held up to that of other regions of the world.

- Lastly, with respect to the state, we will see how the current times fit along the continuum of historical avatars of nation 
state and democracy in the region, and how new challenges in terms of freedoms, policies, or economic regulation calls for a gradual transition from an exclusive system of participation or representation to one that facilitates generalized access to public services, consumer goods, and symbolic inclusion.

The foregoing enables us to better elucidate the crux of our thesis. For a long time, the concept of the individual - and growing individual expectations - in the region was mostly approached as a threat to social cohesion. The reasoning was as follows: awash in foreign cultural influences, Latin American societies engendered individual and collective expectations that were impossible to fulfill. This, in turn overwhelmed the political system, creating myriad social frustrations. In a nutshell, the revolution of expectations gave rise to subjective wishes and desires among actors which society was unable to regulate and which were at odds with each actor's real and objective capacity to realize.

In contrast, our research underscores that the current revolution of expectations is accompanied by a tangible increase in individual initiatives which have become the main democratizing force in contemporary societies. This is not to say, of course, that individuals can be conceived of "outside" or "against" society since their initiatives, if they are to come to fruition, require cultural and institutional resources. Furthermore, when institutions and public policy are weak, these initiatives may unfold on the margins of, in opposition to, or to the detriment of, the institutions themselves.

To summarize: the revolution of expectations and the ensuing irruption of the masses has been regarded as both a democratizing factor and a very real risk to social cohesion in a democracy. Today the proliferation of individual initiatives in a context of heightened expectations has introduced a new dialectic between institutions and social actors: while individual initiatives are contingent upon institutional resources, they also correct and complement them, and ultimately may compound or exacerbate institutional deficiencies. It is not therefore, always a virtuous circle. Yet it is certainly an active way of generating new forms of social cohesion that hold promise for democratization. 


\section{Conclusions}

The issue of social cohesion in democracy poses an enormous challenge for social scientists in the region. In recent decades, the subject of social conflict as a source of progress and social change - which meant sweeping structural transformations - predominated in the social sciences. It is increasingly clear, however, that democracy advances not so much by leaps and bounds but through the cumulative effect of small changes and that the conventions of everyday life are just as important as the conflicts.

Social classes have lost their protagonism in contemporary forms of social conflict and State-citizen relationships lack the outward transparency that ideological models once conveyed. New and extremely flexible social networks have expanded along with civil society organizations which have become increasingly active, although their effectiveness is not always obvious. Meanwhile, traditional modes of exercising power (economic, political, and cultural) have lost their edge along with their capacity to transmit or impose values and decisions, which is not to say they have disappeared. What we have, then, is a set of complex dynamics between power centers and social networks, which interact in oblique ways that prove difficult to unravel analytically.

While growing thematic and disciplinary specialization has enhanced empirical rigor in the social sciences in the region, it has also contributed to the abandonment of the classical tradition of Latin American social thinking. Classical social thought was sensitive to the diversity of national histories and the need for comparative studies and dialogue among disciplines to grasp the complexity of social dynamics and it was willing to introduce new concepts and hypothesis to give meaning to local realities. One of the aims of this study is to recover that tradition and to adopt a more daring intellectual approach, which may on occasion include essayism as an intellectual style.

Over the past decade, the concept of multiple modernities in the social sciences helped consolidate the notion that modernization does not imply a single path or destination. This approach, which has already been developed in the most relevant work on dependency theory, has the virtue of recognizing the importance of the diversity of historical experiences and the unique ways in which each society integrates the political and cultural innovations of the contemporary world. Nonetheless, the concept of multiple modernities poses its own set of specific problems, particularly when it leads to a generalized relativism. When, for example, it is asserted 
that all cultural experiences are equivalent in the name of respecting diversity, or the flip side of this, when culture is essentialized to the point of concluding that democracy is only viable in very specific contexts.

With the relative failure of structural reforms to reduce inequality and transform institutions, the issue of multiple modernities began to penetrate the world of policy-makers. International agencies were compelled to acknowledge the importance of diversity and the uniqueness of historical and socio-cultural contexts. And yet to date, this acknowledgment has yielded only timid analytical offerings. The approach taken here contends that there is broad consensus in Latin America over what constitutes a desirable world, namely a democratic social order that ensures liberties and public order, reduces extreme inequality and poverty, and increases transparency in the use of public resources. But the process to construct this new order must take into account diverse historical experiences and the dominant social, political and cultural patterns. In this sense, we are talking about resuscitating the classical agenda of Latin American social thought. In other words, we need to understand how the dominant trends in the international system play out in our societies today so that we can identify the problems and barriers that separate who we are from who we would like to be. This exploration must take into account the inevitable tension between the real and the desired world, and between the major historical tensions that emerge in hegemonic centers and the ways in which they have evolved in the region.

An approach to social cohesion as a concept that must be constructed through a dialogue among different disciplines (economics, sociology, political science, anthropology and history) heightens the diversity and complexity of the issues to be examined and the attention that should be accorded different national realities. The objective of this study is to develop an analytical perspective of contemporary Latin American societies that is not intended to be a systematic or exhaustive study of the myriad facets of social life in the region. Certain issues, such as social movements, for example, are touched on only in passing here and should be included in future, more in-depth research. We highlight issues associated with emergent trends that are germane to social cohesion and frequently have not been sufficiently developed, in some cases because they are not as seemingly straightforward and transparent as the organizations associated with political and ideological discourse. And even within these points, we have had to limit ourselves to a few examples, leaving aside other areas essential to social cohesion such as transformations in the family, gender 
relations, education, the development of public opinion, the labor market (which we only discuss from the standpoint of trade unions), the informal sector, new media heroes, the formation of intellectual and entrepreneurial elites immersed in rapid globalization processes, and sports, which are frequently the main outlet for feelings of national identification.

Globalization is a crosscutting issue and therefore is not addressed in a separate section. International relations are only discussed in the analysis of organized crime networks, emigration, and the new populism. We do not examine emerging trends in inter-state relations, which is a particularly relevant topic as new tensions begin to spread across the continent, threatening the relative peace to which we became accustomed in the $20^{\text {th }}$ century. The growing interdependence of infrastructure, energy sources and economies strengthen regional integration and simultaneously exacerbate tensions. While only a short time ago, nationalization processes meant disappropriation and conflicts with corporations from developed countries, nowadays nationalized companies increasingly belong to a Latin American neighbor. The dependency of bordering countries on energy resources has been used for political ends, examples of this being Bolivia's refusal to sell gas to Chile or Paraguayan and Bolivian politicians stoking animosity towards their more powerful neighbor, Brazil. Similarly, many border areas have been transformed into battlegrounds due to migratory flows or trafficking in contraband (including weapons and drugs), while the issue of environmental protection is producing inter-country conflicts, such as that between Argentina and Uruguay over the pulp and paper industry. In sum, Latin America may be losing one of its greatest resources as a region, namely: the harmonious coexistence among countries, as xenophobia is used as a political tool to pit neighbor against neighbor.

In the chapters that follow, we offer a vision of the social dynamics of the continent - conscious that it is only an initial glimpse - based in large part on 20 studies produced especially for the project, "A New Agenda for Social Cohesion in Latin America", organized by the Institute Fernando Henrique Cardoso and CIEPLAN, with a grant from the European Union and the UNDP. While these contributions, which are cited in each section, were central to the preparation of this text, the authors are not responsible for the ways in which their work has been edited and used. In some cases their points have been transcribed literally, while in others they have been expanded upon in our analysis or the original argument has been modified. We are grateful to these authors and exonerate them completely from any 
errors or discrepancies of interpretation herein. ${ }^{3}$ This study would not have been possible without their collaboration. The body of knowledge available and necessary for an undertaking of this nature is such that a proposal to offer a synthesized depiction of changes in social cohesion in the region exceeds the capacity of any researcher (or two researchers). In each section, therefore, we have relied heavily on their opinions and evaluations, and most importantly, on their vast knowledge as renowned experts in their specific areas.

Finally, we would like to thank Juan Carlos Torres, Sergio Fausto and Simon Schwartznan for their comments on an early draft of this book. We likewise are indebted to the participants at the seminar organized by CIEPLAN in Santiago, Chile - in particular those who discussed the various chapters - and the conference organized in Buenos Aires by the Institute of Advanced Studies of the University of Bologna, for their critiques, which contributed to the final version. 


\section{Chapter I}

\section{Transformations of the Social Bond}

\section{Introduction}

Despite significant social and cultural divisions and inequalities, Latin America was long considered to possess a unique form of social cohesion revolving around the way in which its social bond was forged. Central to this social bond was the structural tension between hierarchy and equality (Martuccelli, 2002). While in a naively evolutionist conception it would appear to have established itself somewhere in between "community" and "society," it was, in fact, an innovative experience that emerged in the specific context of expanding capitalism and the formation of modern societies. In contrast to a more homogeneous aspiration to egalitarian interaction and the attendant horizontalist ideal, in a dual system of this nature, individuals demonstrated an aspiration of egalitarianism and an affirmation of individual autonomy, while simultaneously corroborating the "natural" permanence of hierarchical elements and personal dependence. Beginning with independence, then, Latin American countries developed their own unique forms of hierarchy and egalitarianism, of individuation and dependency.

Without the referent of inherited aristocratic or meritocratic status, hierarchy was established mostly through economic and political power, while individualism was expressed more through deviations from the norm 
than through the assertion of individual rights enshrined in the constitution or legal systems. It was a universe of ambiguity that has been admirably depicted with respect to the rural world in the rich store of Latin American literature, and was foretold for the urban milieu in the tango "Cambalache," in the first cosmopolitan city in the region.

While not exclusive to Latin America, this type of social bond, played a powerful role on the continent at the practical and symbolic levels (to the point that this tension is at the heart of the debate over the legacy of the experiences of conquest and colonization). Nonetheless, while this model could be considered a product of a combination of structural tensions, the latter are not merely a functional adaptation of the contradictory demands of individuation and hierarchy. Rather they reflect original and creative forms of sociability, ways of being and relating that are valued as marks of national identity and take on distinct profiles in each country. Darcy Ribeiro referred to them as new "civilizatory" forms.

There is no better illustration of the power of this model than the fact that despite its inherent tensions, it has become the underlying premise for the notion of a self-sustaining social bond. Its imprint is found on all types of social relations: workplace hierarchies (patronage, labor relations in the formal sector, and trade unions), gender, intergenerational or, significantly, interethnic relations, in addition to the interactions that may occur in the public and civic spheres, and obviously the religious and traditional aspects that constitute its symbolic underpinnings.

Inherent to all of these relationships was a specific game through which the future would be constructed. The trick was to preserve, in a single move, a certain hierarchical verticality, while simultaneously making progress in the establishment of more horizontal, egalitarian relationships. The tension generally was played out through a combination of moments of cordiality and powerful, palpable subordination processes with their frequently paternalistic overtones (Nugent, 1998). Strangely, this dual social bond was experienced as at once stable and solid and constantly at risk and in flux. Social relations were submersed in a silent interactive tension in the quest for certain connivance between open abuse and discreet defiance. Behind the façade of respect for hierarchy, a myriad of everyday questionings were concealed.

Notwithstanding the national and regional variations of this model, the important thing is that this type of sociability with its contradictory shades of presumed domesticity and the longing for equality produced a social bond that was perceived as particularly solid for a very long time. We 
repeat: if social cohesion was a problem in Latin America, it was essentially under the dual and paradoxical threat of "barbarity" (the fear that it would be ruptured by grassroots sectors) and "civilization" (individualism and the contractualism promoted by the elites). It was in between these two extremes - where everyone found his or her "natural" space - that society was possible.

The national variations are, of course, considerable. In some countries or regions, the social bond is more or less equidistant between the two imperatives. One example is Brazil, where social life evolved in the midst of an irreducible ambiguity (Da Matta, 1978; Buarque de Holanda, 2006), at least until recently (Sorj, 2000). In other situations (such as in Andean countries), the social bond tends toward the vertical, in which a "double code" in social relations allows for the simultaneous expression of discrimination and challenge (UNDP, 2000). Sometimes the tension is inscribed in a framework that retain some hierarchical elements, despite being essentially egalitarian. Such a case is Argentina where the famous, "you don't know who you're talking to," and the inevitable "Why should I care?" neatly sums up the tension underlying social relations (O'Donnell, 1984). Meanwhile, countries such as Chile or Uruguay tend to accentuate - at least as the relational ideal - the importance of respect for law and standards (Araujo, 2006).

The relative equidistance between equality and hierarchy, between individualism and ties of personal dependency, gradually mutated over the course of Latin American history under the influence of an increasingly urban and better educated population, workers' movements and socialist ideologies, communications systems and the growth of vast metropolis with their anonymity and sub-cultures. But even though Latin American societies showed tremendous capacity to change while simultaneously retaining their ambiguities, the existing equilibriums have eroded rapidly in recent decades, giving way gradually but irrevocably to growing demands for equality and individuation.

Latin America is currently undergoing an active process of democratization (demands for equality and individuation) in all areas of social relations. Everywhere the horizontality of the social bond is becoming a core demand. There are many reasons for this, ranging from the unquestionable contribution of expanded educational coverage or the mass media, the consolidation of an egalitarian yearning conveyed by the city, the affirmation of the human rights discourse as the dominant semantic field, the feminist movement and the cultural affirmation of women, ethnic 
minorities or youth, without overlooking, of course, the impact - as we shall see in the next chapter - of a culture of mass consumption and political changes. Here too we should include recent struggles for democratization, as well as the new economic model which, by emphasizing the market's role in the generation of wealth and fiscal responsibility, has increased public awareness that citizens are the main source of state resources, with the attendant effect of delegitimizing the universe of relations rooted in a state whose aureate floats somewhere high above society. This constitutes perhaps one of the most sweeping transformations in the history of the continent.

This genuine and profound democratic revolution is not manifest, however, at the institutional level; at least not yet. As we will see, the political system itself remains particularly fragile in some countries and, on more than one occasion, the democratic aspiration has had a destabilizing effect on our institutions. Hence the difficulty encountered by those who focus solely on the political sphere and therefore fail to grasp the relevance of the change in progress. At the moment, the democratization process begins and ends with individuals, with their expectations and their initiatives. This clearly is not enough and there is an enormous risk that without the institutional channels to formalize and translate them, these factors will have a negative impact on social cohesion and on the stability of democracies. At the present time, however, they clearly represent the promise of another type of more democratic and horizontal social cohesion.

In any event, the outcome of this silent democratic revolution will not be long in coming. Transformations are visible in many social settings, starting with gender relations - a high profile issue in recent decades (and rightly so) and therefore accorded less attention here - as is the revolution of expectations and their paradoxical egalitarian dynamism, which has been the driving force behind consumption in recent years.

In this chapter we will outline the main consequences of the changing social bond for religion, inter-ethnic or race relations, urban dynamics, culture, the imaginary conveyed by the media, and emigration. All of these areas contain a patent, albeit varied and sometimes contradictory, affirmation of the growing desire for equality. It is a process that lends itself to ambivalent readings. The egalitarian demand - whose main standardbearers today are individual actors - destabilizes the old social relations and their influence vis-à-vis the hierarchy. From this viewpoint, the social bond is no longer that sphere of co-presences that lent itself to a conception of social cohesion as self-sustaining. Moreover, beyond institutional or 
contractual space, this egalitarian project requires the development of a new sociability among individuals, one that is more horizontal and less abusive than that which has been experienced on the continent until very recently.

\section{Religion and religiosity ${ }^{4}$}

Religion, or perhaps we should say religiosity, is probably the main source of ontological security, moral support and hope, particularly among the poorest sectors. It would be difficult to explain the capacity to endure adversity, sustain ethical mores, or trust in a better future without taking into account religious beliefs. Most commonly observed, however, are unique forms of religiosity, meaning that individuals are often sustained by personalized and often syncretic or hybrid beliefs: the protection of a certain saint or some variation of Marianism, for example, rather than an active and obedient observance of instititutionalized customs and authorities. Catholicism, the continental hegemonic religion that was imposed on the indigenous and African slave populations, displayed an enormous capacity to absorb and syncretize local religions, despite its efforts to repress and eradicate them, which persist to this day in some areas, albeit to a lesser degree than before. A vernacular facet of Latin American religiosity, traditional religious syncretism now features a new twist. Previously rooted almost exclusively in large social group contexts, the spiritual makeover increasingly reflects a tendency towards more individualized recompositions.

Latin American institutional religion and religiosity are a fundamental source of social cohesion not only because they offer individual support, but also due to their role in the construction of culture and politics. As indicated by its etymological roots, religion (religare $=$ to bind) is a powerful unifier in Latin American societies. The cultural base of mestizo America is sustained to this day by grassroots forms of religiosity that combine Christianity with ancestral beliefs and rituals, whether from the Quechua, Mapuche, or Maya, or various African traditions. In Catholic churches, town squares, or on beaches - where each year millions of people pay homage to Yemanja, the African goddess of the sea - the mix of traditions produced the unique

4 This section is based on the work of Ari Pedro Oro, "Religião, coesão social e sistema político na América Latina”. 
cultural phenomenon of a common religious substratum upon which the most diverse versions and traditions coexist, in many cases peacefully.

This particular ability to live with diversity went hand in hand with another virtuous process, namely the successful laicization of Church-State relations. This clearly has not been a homogeneous process, as illustrated by Mexico's Cristiada rebellion in the 1920s, during which more people were killed than during the Revolution of the preceding decade, or by the powerful influence of the Catholic Church hierarchy in $20^{\text {th }}$ century Argentine politics. In general, however, Latin American societies have been exempt from religious wars and the separation of Church and State and the secularization of politics are well established.

In recent years, this universe has been transformed by the growing presence of evangelical churches, many of them native to the region. Extremely enterprising and with a tremendous capacity for proselytizing, these churches have installed themselves on several continents and built communications empires. Paralleling the growing presence of evangelical religions and cults primarily among the working classes, other religions and spiritual or self-help movements have proliferated among the middle classes in particular, feeding new trends such as the massive presence of "whites" in Afro-Brazilian cults or the preponderance of evangelism among Mexican and Guatemalan indigenous peoples. This transformation has been spurred by the erosion of tradition as a source of identity formation, which ultimately transfers to each individual the task of defining his or her religious identity.

This movement, as a whole and as a sum of its many parts, must be taken into account when evaluating the role of religion in social cohesion in our countries. We will therefore employ a circular reasoning process in our discussion. We begin with the vitality of religious affiliation to underscore the continued relevance and force of the Catholic faith alongside growing religious differentiation. We then examine the mechanics of the relations between the state and religion, and the role of politics therein. Only after examining, albeit briefly, all of these factors, in the last section we discuss their ramifications for social cohesion in democracy.

\section{The universe of religious affiliations}

In the past as well as today to speak of religion in Latin America was to refer mainly to Christianity. In effect, Christianity is impregnated in Latin American societies. It is woven into the social fabric of everyday life on the subcontinent in the sense that numerous collective events and activities, 
national, regional, and local holidays and religious symbols - which are widely visible even in public places - reflect the Christian tradition and are guided by its liturgical calendar. Besides Christianity, however, other religious practices and rituals associated with grassroots religions, which may involve mediumistic trances, esoterica, neopaganism and so forth, shape a uniquely sacred territoriality comprising traditional sacred spaces (churches, temples, centers, oratories, chapels, pilgrimage and festival sites, cemeteries) as well as private spaces that have a religious function. Some examples of this are the homes of healers and intercessors, pastors of small Pentecostal churches, leaders and members of evangelical groups "cell churches," mediumistic centers, spirits or therapeutic centers, charismatic and meditation groups.

One might argue, in the tradition of Maurice Halbwachs, that all religious celebrations and rituals, including holidays and the entire religious geography described above, are important to reinforce the collective religious memory, but they are also effective social attractors, which fosters social integration and by extension, the cohesion of social groups. In other words, beyond strengthening collectively shared symbolic universes, religious practices and sacred spaces are also venues for social gathering and for solidifying social bonds. The integrating aspect of Latin American religiosity is likewise apparent in the vast array of churchsponsored assistance projects - school-based programs and health clinics, or services for orphans, the elderly, the homeless, the poor, migrants and other disadvantaged groups - which are often carried out in conjunction with government authorities to promote social solidarity and address the problems of the neediest people.

A survey on religious identification in 20 Latin American countries showed that Catholicism and Christianity continue to be the leading religions. Catholicism accounts for $79 \%$ of religious self-identification and is the institution in which Latin Americans place the greatest trust. According to the polling firm Latinobarómetro, from 2003 to 2004, the degree of confidence expressed in the Catholic Church rose from $62 \%$ to $71 \%$. The countries with the highest proportions of people who identify themselves as Catholic are Venezuela, Ecuador and the Dominican Republic.

Meanwhile, 12\% of Latin Americans report belonging to an Evangelical faith and of these, $70 \%$ are members of the Pentecostal church. Guatemala (39\% of the population) and Honduras (28.7\%) are the most heavily evangelical countries on the continent. Catholicism and Christianity then, are no longer synonymous in the region, as they were in the past. 
Nonetheless, 91\% of Latin Americans identify themselves as Christians of some sort. The remaining smaller percentages are identified as belonging to mediumistic (African American, spiritist, or Ayahuasca) religions, eastern faiths, Judaism, mystical or esoteric streams, and the non-religious.

The extraordinary expansion of Pentecostalism in Latin America is one of the most significant religious phenomena of the past thirty years. North American in origin but possessing a tremendous capacity to adapt to the diverse religious, social and cultural realities of the subcontinent, Pentecostalism has penetrated different social strata, although its main client base is found among the poorest and most disadvantaged urban dwellers. As a conversionist religion, it has a profound influence on the subjective experiences of its followers, who tend to adopt a new lifestyle and find new meaning for their existence. Although this occurs to varying degrees depending on the dictates of each church, most require a puritan sort of behavior, which means abstaining from "worldly pleasures," such as cigarettes, alcoholic beverages, and irreverent parties, and espousing a new morality that condemns abortion, adultery, and homosexuality, all in the context of a symbolic break from the "world."

Being a Pentecostal Christian - whether by birth or conversion - brings with it certain therapeutic benefits, such as alcoholism and drug abuse recovery, and a "family and work ethic" associated with saving, valuing success, and earning money "with God's help." This has an effect on gender relations and leads to a new form of sociability. Church-centered social networks become a key source of information about job opportunities, including those available outside of the country, where Catholics frequently "convert" to Pentecostalism in order to approach the Pentecostal churches where their compatriots, and solidarity networks, can be found.

This latter point is important: as with other faiths, Pentecostal religious practice is not confined to the sphere of subjectivity. It has many repercussions for daily life, building solidarity and becoming a purveyor of meaning and collective identification. Oftentimes, however, the more mundane facet, which is quite modern in its use of the communications media, has lent itself to a negative external vision of the church. An example of this is the systematic tithing requirement which in some cases has enabled pastors to enrich themselves to the point of amassing vast fortunes. While these issues may be present in some denominations, they do not overshadow the enormous impact that the ascent of Pentecostal groups has had in many countries, in terms of bringing discipline to, and integrating, the poorest of the poor. 
Religions in Latin America

\begin{tabular}{|c|c|c|c|c|}
\hline Country & Catholics (\%) & Evangelicals (\%) & $\mid$ Others (\%) & Non-religious (\%) \\
\hline Argentina & 88 & 8 & 2 & 2 \\
\hline Bolivia & 93 & 7 & & \\
\hline Brazil & 73.6 & 15.4 & 3.6 & 7.4 \\
\hline Chile & 89 & 11 & & \\
\hline Colombia & 81.7 & 15 & 1.4 & 1.9 \\
\hline Costa Rica & 76.3 & 15.7 & 4.8 & 3.2 \\
\hline Cuba & 40 & 3 & 7 & 50 \\
\hline $\begin{array}{l}\text { Dominican } \\
\text { Republic }\end{array}$ & 95 & & 5 & \\
\hline Ecuador & 94 & 3 & 3 & \\
\hline Guatemala & 60 & 39 & 1 & \\
\hline Haiti & 80 & 16 & 3 & 1 \\
\hline Honduras & 60.3 & 28.7 & 11 & \\
\hline Mexico & 88 & 7 & 5 & \\
\hline Nicaragua & 72.9 & 16.7 & 1.9 & 8.5 \\
\hline Panama & 85 & 15 & & \\
\hline Paraguay & 90 & 10 & & \\
\hline Peru & 88 & $8-10$ & $1-2$ & \\
\hline Uruguay & 52 & 2 & 11 & 35 \\
\hline Venezuela & 96 & 2 & 2 & \\
\hline
\end{tabular}

Prepared by A. P. Oro, Op. Cit, based on the following sources: Ministère des Affaires Etrangères - France, http://www.diplomatie.gouv.fr/, CIA - The World Fact Book, https://www.cia.gov/cia/ publications/factbook/fields/2122.html, the U.S. Department of State, http://www.state.gov/g/drl/ rls/irf/2001/5594.htm, apud Ari P. Oro, Op.cit.

The "other" religions observed in Latin American countries include Judaism, Islam, indigenous faiths, eastern faiths, African American religions (Candomblé, Umbanda, Santería, Voudun, etc.), spiritism, and an array of religious beliefs referred to in the literature as "popular religions," "mystic esoterica" or "new religious movements." They are minority religions from the demographic and political standpoints. Some are experiencing a certain decrease in their following (African Americans), while others resort 
to various forms of syncretism as a strategy for preserving their autonomy as religions (spiritualism, Eastern and African American faiths). Other streams (mystic esoterica) have a growing number of followers, but given the low percentage, remain statistically insignificant in the breakdown of religious beliefs in general.

\section{Religion and State}

While the study of religion and politics in Latin America points up numerous variations in the relationship between Church, State, and society, the presence of religion in the public sphere in most countries, and in the political realm in some, indicates that Latin American societies and cultures are imbued with a certain tolerance for, and recognition of, religion and various religious practices as vehicles for mobilization and social life. This contrasts sharply with the modern secular European republics which tend to confine religion to the realm of the subjective and private sphere.

As a result, religion in Latin America today is still an institution that produces and/or reproduces social cohesion - along with others that operate in a similar manner - and it continues to influence the political realm, although this plays out differently depending on the country and the religion. As we will see, several studies have shown that the link between religion and politics is in some cases very strong, and the boundaries between the two realms can be quite porous.

The spectrum of institutional relations between Church and State in Latin America is evidenced in an examination of national constitutions, which can be grouped into three categories of legal regimes: countries that adopt an official Church system (Argentina, Bolivia and Costa Rica - obviously the Catholic Church in all cases); countries that provide for the separation of Church and State, with certain provisos concerning the Catholic Church (Guatemala, El Salvador, Panama, the Dominican Republic, Peru, Paraguay and Uruguay); and countries that adopt a model separating Church and State (Mexico, Haiti, Honduras, Nicaragua, Cuba, Colombia, Venezuela, Ecuador, Brazil and Chile).

At least half of Latin American countries, then, are legally established as secular, modern, and liberal States that purport to accord the same legal status to all religious groups by espousing equal treatment for all religious organizations and guarantees of religious freedom for all citizens. This is still more an ideal than a reality, however, since Catholicism continues to pervade cultural life. 
Systems of Church - State Relations in Latin America

\begin{tabular}{|c|c|c|c|c|c|}
\hline $\begin{array}{l}\text { Has an } \\
\text { official } \\
\text { church }\end{array}$ & $\begin{array}{l}\text { God in the } \\
\text { Constitution }\end{array}$ & $\begin{array}{l}\text { Separation } \\
\text { of Church } \\
\text { and State } \\
\text { with certain } \\
\text { privileges for } \\
\text { the Catholic } \\
\text { Church }\end{array}$ & $\begin{array}{c}\text { God in the } \\
\text { Constitution }\end{array}$ & $\begin{array}{l}\text { Separation } \\
\text { of Church } \\
\text { and State }\end{array}$ & $\begin{array}{l}\text { God in the } \\
\text { Constitution }\end{array}$ \\
\hline Argentina & Yes & Guatemala & Yes & Venezuela & Yes \\
\hline Bolivia & Yes & El Salvador & Yes & Ecuador & Yes \\
\hline \multirow[t]{8}{*}{ Costa Rica } & Yes & Panama & Yes & Honduras & Yes \\
\hline & & Peru & Yes & Nicaragua & Yes \\
\hline & & Paraguay & Yes & Brazil & Yes \\
\hline & & $\begin{array}{c}\text { Dominican } \\
\text { Republic }\end{array}$ & No & Colombia & No \\
\hline & & Uruguay & No & Chile & No \\
\hline & & & & Cuba & No \\
\hline & & & & Mexico & No \\
\hline & & & & Haiti & No \\
\hline \multirow{2}{*}{ TOTAL 3} & $Y=3$ & \multirow{2}{*}{7} & $Y=5$ & \multirow{2}{*}{10} & $Y=5$ \\
\hline & $\mathbf{N}=\mathbf{0}$ & & $\mathbf{N}=\mathbf{2}$ & & $\mathbf{N}=\mathbf{5}$ \\
\hline
\end{tabular}

An analysis of five Latin American countries using data obtained mainly from working class sectors reveals the broad spectrum of relationships between Church and State, between religion and politics, and at the level of religious representations. ${ }^{5}$ Briefly, the Argentine grassroots imaginary associates the concepts of religion and nation: the Catholic faith is regarded as a "national asset." Moreover, the Christianity of many Argentines is practical, and its practice is political. This is to say that it seeks to influence

5 In many western European countries, religion is much more closely tied to the state than in Latin America. In Ireland, all of the Catholic schools are state subsidized while different religions in Holland are part of the supply of public education. Of course there is the Anglican Church of England, not to mention the strong ties between the state and the Russian Orthodox Church. 
the social order and therefore, political and religious imaginaries overlap and are interrelated. This link between political and religious imaginaries is also observed in Brazil, where religious beliefs are expressed in political language and conversely, views on the political organization of society are expressed in religious terms. Religious life in both of these countries - whether official or not - leads to collective interaction due to the powerfully ritualistic aspect of religious practices and to the social and assistential networks they have established.

The situation is somewhat different in Mexico, where the established religious and the political imaginary are less embedded, particularly among the disadvantaged. This is indicative of social distrust towards religious as well as political life. At the other end of the spectrum, in Venezuela the credibility of religions, and the trust vested in political institutions and the State, is high. It is no coincidence that Venezuela is among the most Catholic countries in Latin America and one of the most sensitive to a type of political discourse that marshals religious symbols and images. Uruguay bears a resemblance to Mexico in this regard, although with its own unique characteristics, having undergone a protracted and profound process of laicization, which featured the "de-Catholicization" of all religious symbols in the public sphere, in spite of the more recent reshaping of the public sphere which allows at least a limited display of religious symbols and practices.

\section{Religion and politics}

Religion in Latin America informs culture, permeates the public realm, and is influential in social aggregation. It operates in close proximity to politics in a relationship that varies among countries and religious institutions. Historically, the Catholic Church often became involved in political life, and did so through the most varied ideological leanings. More recently however, following the edicts of the Catholic hierarchy, the Church has tended to withdraw from politics except when what it regards as fundamental ethicalreligious principles (abortion and the use of contraception, for example) or human rights are at stake. The Church's social doctrine is supposed to serve as its inspiration, and that of Catholic politicians, in the quest for social justice and the defense of human rights.

In contrast, evangelical Christians have a different relationship with politics in some Latin American countries (Brazil, Chile, Guatemala, Peru), where certain movements, particularly the Pentecostals, have insinuated 
themselves into institutional political life in such a way that political parties cannot disregard them.

Wielding symbolic-discursive arguments (to exorcize political "demons" such as corruption and misappropriation of public revenues for example) or more practical ones (hoping to benefitas an institution), evangelical Christians, and particularly Pentecostals, assimilate some of the characteristics of Latin American political culture, such as political action "on behalf of the grassroots" and political clientelism. In this way, Pentecostals recreate in politics the model for action they practice on a daily basis in the religious sphere, where there is tremendous competition due to the "religious market" that has taken root in Latin America. Because of this "market," however, it is virtually impossible for religions to act proactively in politics, except, as we have indicated, when it comes to certain specific moral issues. This has two important ramifications: first, it belies suspicions that what is occurring in Latin America is a "fundamentalist" attempt at the "religiosization" of politics and second, it invites us to consider that the churches have, to some extent, become venues for political learning, while not threatening or undermining democracy.

\section{Religion, democracy and social cohesion}

Religion is an inescapable aspect of social life in Latin American societies, albeit to varying degrees depending on the density of the religious culture in each individual country. In other words, the predominant trend in Latin America is that beliefs are not confined to the sphere of subjectivity: they are not exclusive to a particular faith system, but rather are embedded in the spheres of experience and action. They are, therefore, shared collectively and extend into the public realm through the rituals practiced by each religion, regardless of its legal or institutional status. In this way, religions create social ties and symbolic forms of belonging and both are critical for creating a sense of social cohesion. It goes hand in hand, however, with other social practices, institutions, and entities that inform meaning to varying degrees depending on the social group and the circumstances, such as the family, politics, school, art, sports, the sciences, institutions, and so forth.

Because of its unique historical and cultural qualities, then, the Latin American reality does not emulate the European secular republican ideal premised on an almost radical separation between the private (where religiosity is inserted) and the public (where the political reigns), despite the diversity of its institutionalized relations. Interactions between the 
public and private spheres and between politics and religion in the region, are fraught with crisscrosses and alleyways, points of proximity and tradeoffs. This suggests the possibility and/or existence of a democracy that must take into account - or would be hard-pressed to disregard - the religious sphere in general, and religious institutions in particular. Religion and politics are intertwined in one way or another in each of the five countries mentioned. They associate in Argentina, overlap in Brazil, and separate and mutually acknowledge each other in Uruguay. They are brought together by an immanent view of politics and religion in Mexico, and by a transcendent vision of religious life and political life in Venezuela. In Latin America, then, religion is not relegated to the private life of individuals. Rather, individuals carry it into the public sphere where it influences social relations and interfaces with other social institutions and with politics. ${ }^{6}$

Significant cracks have appeared in this continuum, however particularly in light of the political impact that religion has always had on the continent. Three of them in particular should be highlighted. First, the traditional religious syncretism that ensured the hegemony of Catholicism is confronting a somewhat larval inter-church competition that is relatively unprecedented in Latin America. Secondly, in recent years, the association of different churches with authoritarian or democratizing processes has hinged more on national political circumstances than automatic alignments between belief systems and ideological positions. Third, as is true in many other places, religion is gradually becoming privatized and giving way to more individualized practices. Believers are tending to distance themselves from many aspects of the church's authority (separation, contraception) and individuals (not just social groups any more) areleaning towards singularized spiritual forms expressed in increasingly customized combinations. Indeed, and contrary to what was believed in the past, religiosity has overtaken religion. And this religiosity is an amalgam of more or less personalized beliefs, accepted ecclesiastical dogmas, expressions of the "enchanted" world, as Weber would say, intense common experiences, and various other sorts of ties (and support systems) that are critical in societies where the level of vulnerability is massive.

But one aspect in particular is fundamental to the subject of this chapter and that is the social bond. Religion was never a parallel sphere to the state

6 We should add Chile here, where the Catholic Church has a strong institutional role, the Christian democratic party is strong, and the Catholic University is government subsidized much like the public university. 
in Latin America, due to its matricial role in the culture of the continent and its constant presence in the political realm. Having said that, contemporary religion also appears to have been deeply permeated by the democratic revolution.

Although the "naturalization" of the hierarchies of the past found a staunch ally in religion (particularly in rural areas), the religious matrix has gradually opened itself up to the influence of equality. This has not, as we have discussed, kept some religious representatives from lending their political backing to authoritarian regimes or from engaging in blatant attempts to influence people's consciences and moral practices through methods reminiscent of the old tutelary mechanism (this has been particularly visible in policies concerning sexuality). But it is impossible not to conclude that a profound change has taken place. Ensconced in the protracted and now largely consolidated process of normalization of Church-State relations, the social bond is no longer transmitted through religious beliefs (and their implicit naturalization of the hierarchy) but rather by the political matrix of democracy. The former no longer defines the meaning of the latter; instead politics have established the parameters - the equality - in which religion is inscribed.

\section{Inter-ethnic relations and democratization}

The transformation of the social bond is particularly visible in the context of inter-ethnic relations. Inextricably linked to diverse public policies that are at once the cause and consequence of these transformations (which are discussed in a subsequent chapter), the decline of the dual social bond and the rise of egalitarian aspirations has enormous consequences for inter-ethnic relations as well for everyday sociability. Here our discussion focuses specifically on indigenous peoples and their rights, particularly in the Andean context.

\section{From societal dynamics to individual aspirations ${ }^{7}$}

Over the past few decades, the transformations wrought by the political and economic crisis of the developmentalist national model became the catalyst

7 This section is based on the work of Antonio Mitre, "Estado, Modernización y Movimientos Étnicos en América Latina". 
for the eclosion of indigenous movements (leaving aside for a moment the variations in different local contexts). This phenomenon corroborates the correlation between indigenous movements and modernizing reforms observed throughout Latin American history, which we will discuss in the next chapter. A comparison of the liberal reforms of the $19^{\text {th }}$ century, and more recently, those of the $20^{\text {th }}$ century, however, reveals a number of significant differences.

In addition to advocating rights premised on individualistic conceptions, the substance of the proposals found in present-day reforms and demands opens up a rich space for the legitimization of traditional forms of governance, communal justice, and collective representation. The structural reforms advocated from the 1980s onward also proposed a decentralization of the state apparatus to accommodate longstanding demands for greater autonomy. This agenda clearly strengthened the allegiance of indigenous populations to the new state model, which came to be regarded as the guarantor of an ancestral pact in the sense of legitimizing traditional uses and customs.

In the case of Bolivia, for example, the combined effect of processes dating back to the 1952 revolution and reforms associated with globalization has thrust the indigenous population onto the political stage, exposing traditional communities to the frontal impact of national crises. Here we should note the significant levels of migration from indigenous communities. These migrants have maintained their social, economic and family ties to their countries of origin and they are demanding from their authorities protection of their rights abroad. It is likewise important to note the role of international cooperation and international NGOs in promoting indigenous groups, which frequently find that international forums offer a platform for expression not always available in their own societies.

Modernization has had an impact on the whole of the indigenous population insofar as its expectations and demands - which are accentuated by the demonstration effect - are currently organized around new horizons of consumption and political participation. Such phenomena, as they are inserted into the international dynamics, have increased the dependency of indigenous populations on state resources and institutional channels. This dependency will no doubt be a difficult bridge to cross for ethnic or regional chiefs demanding greater autonomy for their communities or those who espouse a more extreme, separatist agenda. Even more so since the need to process the explosion of increasingly diverse and heterogeneous demands ultimately will reinforce the state's protagonist role nationally and 
internationally. The ethnic question, in this context, will continue to be activated as a political resource by various opposing forces. In all likelihood, however, it will become less relevant as a national issue, particularly for the indigenous movements themselves, as they become incorporated more fully into the state matrix and enjoys greater access to the civic sphere from which it had been excluded since the founding of the republics. Which is not to say, of course, that ethnic identities, as they become a source of specific benefits, will not become increasingly consolidated and give rise to self-reproducing interests.

It should be noted that the demands of indigenous groups affect a substantial portion of the population in only a few countries. A satisfactory response to such demands in other countries, then, is just one aspect, albeit an important one, of democracy-building. Just as it should not be undervalued, a unilateral over-emphasis on the issue of ethnic diversity should not be allowed to veil the broader matter of a nation-building project for the $21^{\text {st }}$ century that takes into account the different social sectors.

The impact of these structural transformations - which we will discuss in more depth later on - is not confined to the political sphere. They have set in motion other crucial changes in social relations as the previous verticality of the social bond (with its impenetrable mix of economic inequality and racial denigration) is buffeted by new democratizing pressures.

\section{Social inequality, social bond, and the ethnic question in the Andean world ${ }^{8}$}

Andean societies are culturally and socio-economically heterogeneous and this heterogeneity became the historical underpinnings of "arguments" to justify the exclusion and inequality that constitute an obstacle to democracy and social cohesion today.

Inequality in the political culture and in everyday social relations and socio-economic inequality are mutually reinforcing. A focus on its cultural dimensions, however, by no means implies a vision of inequality as natural or culturally determined. In reality, deeply ingrained and extremely complex behavior patterns and dynamics "reinvent" forms and mechanisms of inequality depending on the historical contexts. In the pre-colonial period,

8 This section is based on Alicia Szmukler, "Culturas de desigualdad, democracia y cohesión social en la región andina". 
Andean societies were quite heterogeneous and culturally diverse, with relations of dominance between ethnic groups. It was not until after the colonization, however, that ethnic identity became the main argument for exclusion, arbitrariness and inequality: and this ethno-racial "reason" endures and is manifested in many different ways in these societies today.

Discrimination toward indigenous and mestizo (mixed-race) populations has been a matter of course, beginning with the racist ideology of the colonial powers and the hacienda system, which deemed such groups to be inferior based on their ethnic origins in order to exploit them economically. Prejudice against non white or Creole Spanish identities became the basis to legitimize the economic and cultural abuse of these groups. Truly hierarchical and racialized relations developed in this context.

Inequality based on ethnic origin persists today, although with different features. The national revolutions and nationalist governments of the latter half of the $20^{\text {th }}$ century embarked on a path to rectify many of the factors of inequality affecting majority mestizo and indigenous groups in Andean societies. Democratic governments since the early 1980s have done much to broaden and strengthen citizenship. Today, legal recognition of the equality of these groups is a fact and a remarkable achievement of democratic consolidation and of the struggle waged by indigenous and cultural movements. Inequality still persists, however, in daily social interactions and practices and in the political culture.

In the latter half of the $20^{\text {th }}$ century, the national revolution in Bolivia and the national-populist governments in Peru and Ecuador promoted a developmentalist economic model leading to the political inclusion and expanded social rights of broad sectors of the population heretofore excluded from citizens' rights. These policies benefited peasant sectors, which were also indigenous. The class category, however, subsumed the identitary one and cultural heterogeneity was therefore subordinated to national unity. Moreover, while these governments made valiant efforts to further social and cultural equality, they also reproduced mechanisms for exclusion by rejecting those who thought differently or who rejected the clientelistic networks through which the ruling parties obtained political allies in exchange for posts and perks.

In recent years, poverty and the ability and opportunities to access markets have changed the face of inequality in day to day interactions. Acute economic inequality in the Andean region is now the objective substratum underlying the rejection of the "other." Rising expectations of access to consumption and public goods (spurred by globalization processes, the 
broader reach of the mass media and information technology, and increased educational coverage) come up against harsh limitations in terms of the actual possibilities of fulfilling those expectations and achieving upward mobility.

The transformation has nonetheless been profound from the standpoint of the social bond. Throughout the region, extremely hierarchical relations have given way to genuinely dual ones: the tension between hierarchy and equality is palpable and the emergence of truly egalitarian relations is increasingly observed. Of course, this latter aspiration acquires concrete cultural forms to the extent that it is accompanied by the state's affirmation of a national-indigenous identity (as is the case, in part, in Bolivia) or when it emerges as the result of a new urban, mestizo and grassroots culture (as illustrated by the changing meaning, increasingly positive, of the word cholo in Peru).

Of course in view of the cultural and social heterogeneity of these societies - and the lingering effects of hierarchy that continue to influence everyday social relations and the political culture they reflect - it is worth asking ourselves exactly what conditions are in place to deepen more democratic and pluralistic ties that could produce consensus around renewed principles of social cohesion?

In this context it would appear necessary to propose new principles upon which to reconstruct an idea of nation and a sense of belonging. The principle of different but equal is currently the basis - and one that is not without difficulties and contradictions - for efforts to address demands for justice based on the principles of a democratic State.

Despite persistent and serious difficulties, it is important to stress, however, that progress has been made in terms of legal and civic equality. Bolivia, Ecuador and Peru, all countries with high percentages of indigenous and mestizo populations, have taken enormous steps forward in terms of legal recognition of indigenous and gender rights. This has been the result of the mobilization and political reorganization of social actors, in the case at hand, indigenous people and women in particular. But these achievements in the area of rights - and the opportunities for expression accorded to their advocates - are also linked to the deepening of the democratic system in the region. And both of these things ultimately have had a concrete and visible influence in day to day social interactions. For example, abuse by "superiors" is increasingly criticized, even as the latter attest to being victims of "abuse" by their "subordinates" (an example of this being repeated complaints of an achoramiento ["scofflaw" culture ] in Lima 
society). Paradoxical as it may seem, in this context one should not discard the notion that the deregulation and generalization of inter-ethnic conflicts, even when they have racist overtones, may also be a normal expression of the democratization of everyday life.

Of course, these distinct planes are not isomorphic. The conditions that give rise to unequal social relations do not change merely because legal advances have been achieved. Similarly, while such advances are certainly important, particularly in terms of symbolic and political inclusion, they do not cause longstanding stereotypes and prejudices to disappear overnight. Between the legal responses and indigenous demands on the one hand, and the tepidity of the dual social bond on the other (since there are those who persist in placing more weight on what they regard as the "natural" hierarchy), the dialectic is subtler and doubtlessly more sluggish than some would like. While one is not a substitute for the other, favorable legislation on ethnic identities raises awareness about particular rights and spotlights situations of inequality affecting these groups. At the same time, the quest for more egalitarian social relations in everyday life encourages new legal and political aspirations. For this reason, even though legal recognition, while absolutely necessary, is insufficient to establish equality in social bonds, the affirmation of ethnic rights contributes actively to the democratization of social relations. Cultural changes and the democratization of everyday life travel on slower tracks fraught with tensions and conflicts, as is the case with any process of change. But here again the break from the dual social bond is evident.

\section{Urban spaces and dynamics ${ }^{9}$}

We are living in what some authors have described as a period of symbolic mutation and while no one can really know where it is leading us, we can point out some of its new forms of expression. Manuel Castells (1998) describes one of these phenomena as a "deterritorialization" process, which

9 This section is based on Luis Alberto Quevedo, "Identidades, Jóvenes y Sociabilidad - Una vuelta sobre el Lazo Social en Democracia"; George Yúdice, "Medios de comunicación e industrias culturales, identidades colectivas y cohesión social”; Ruben Katzman y Luiz Cesar de Queiroz Ribeiro, "Metrópoles e Sociabilidade: reflexões sobre os impactos das transformações sócio-territoriais das grandes cidades na coesão social dos países da América Latina”; Enrique Rodríguez Larreta, "Cohesión social, globalización y culturas de la democracia en América Latina." 
he rightly accords a strategic relevance. The crisis of modern territories is a fundamental aspect of the changing times. Territories can no longer be reduced to the geography of nation-state, meaning the physical borders that demarcated countries. Instead, institutions, values, beliefs, ideologies, and public and private spaces are what define political and social, and family or personal territory. Indeed, while they have not dissolved completely, the everyday points of reference that gave shape to society - its symbolic frames of reference and understanding - have certainly lost their stability and this is especially visible in metropolitan urban settings.

In Latin America, progress (and setbacks) in the modernization/ globalization process are experienced as a malaise, sometimes explicit and sometimes diffuse, but persistent over time. Individuals become mutually distrustful. According to some interpretations, in this process the "other" comes to be regarded as a threat. A single watchword appears to traverse all areas of social life: "insecurity." The threats are manifold. The "erosion of norms of civility" (Lechner, 1999), is a consequence of a modernization/ globalization process that exacerbates social differentiation while weakening the notion of a collective order and alters behaviors and perceptions with the attendant impact on social coexistence. Before exploring further this extremely important point, we will review some of the main transformations in contemporary urban Latin America.

\section{The city as a setting for modernization and cultural fragmentation}

Urban cultures today comprise over $70 \%$ of the Latin American population. They are made up of culturally hybrid groups that are residentially fragmented and destabilized, and simultaneously homogenized by the information generated by the mass media. Contemporary modernity, or the culture of post-modern capitalism if you will, impregnates every one of the cultural hybridization processes observed in cities in particular.

A sensual, pleasure-driven circuit fed by money is one of the most obvious poles in large Latin American cities, which are hubs for tourists and middle classes sectors with access to fashionable restaurants, nightlife and entertainment. In these highly concentrated mediatic cities entertainment also has its geography: restaurants, bars, cinemas, theaters and concert halls are confined to a narrow strip of the city.

Countless everyday tensions surface alongside this growing diversity. The consolidation of significant forms of urban violence (which are 
discussed in a separate chapter), consumer frustrations and expectations, political apathy and disenchantment, the scant opportunities available to vast numbers of urban youth - who create their own often music-centered spaces for entertainment - are becoming permanent fixtures of the new Latin American city even in societies with a relatively more integrated tradition of urban life, such as Montevideo and Buenos Aires.

Modes of sociability take on different meanings in these new contexts. The family at the center of social life is still part of the ideology of daily living and of the social imaginary in the region. And yet, internal hierarchies and gender identities are undergoing profound changes particularly under the influence of new types of mass communication. Social differentiation and individuation processes derived from modernization are changing the moral economy of the family. While access to new universes of education and consumption, of comparison and contrast, does not destroy family-

\section{Victimization and Firearm use (urban centers)}

\begin{tabular}{|c|c|c|c|c|c|c|c|c|}
\hline $\begin{array}{l}\text { In the past } \\
12 \text { months: }\end{array}$ & Argentina & Brazil & Chile & Colombia & Guatemala & Mexico & Peru & Average \\
\hline $\begin{array}{l}\text { Someone } \\
\text { entered the } \\
\text { house to } \\
\text { steal }\end{array}$ & $13.70 \%$ & $9.80 \%$ & $18.90 \%$ & $11.90 \%$ & $12.20 \%$ & $12.20 \%$ & $19.70 \%$ & $14.00 \%$ \\
\hline $\begin{array}{l}\text { Someone } \\
\text { robbed } \\
\text { him/her on } \\
\text { the street }\end{array}$ & $25.40 \%$ & $24.30 \%$ & $28.70 \%$ & $23.00 \%$ & $35.20 \%$ & $24.80 \%$ & $41.00 \%$ & $28.60 \%$ \\
\hline $\begin{array}{l}\mathrm{He} / \text { she was } \\
\text { physically } \\
\text { assaulted by } \\
\text { someone }\end{array}$ & $6.90 \%$ & $4.40 \%$ & $10.40 \%$ & $9.10 \%$ & $10.60 \%$ & $10.40 \%$ & $15.50 \%$ & $9.40 \%$ \\
\hline $\begin{array}{l}\text { Was } \\
\text { threatened } \\
\text { with a } \\
\text { firearm }\end{array}$ & $17.00 \%$ & $7.00 \%$ & $13.20 \%$ & $16.00 \%$ & $24.80 \%$ & $14.90 \%$ & $16.30 \%$ & $15.20 \%$ \\
\hline $\begin{array}{l}\text { Believes } \\
\text { having a } \\
\text { firearm in } \\
\text { the house } \\
\text { is justified } \\
\text { to defend } \\
\text { oneself }\end{array}$ & $33.50 \%$ & $15.10 \%$ & $43.40 \%$ & $29.30 \%$ & $41.00 \%$ & $41.20 \%$ & $43.10 \%$ & $34.60 \%$ \\
\hline
\end{tabular}

Source: ECosocial, 2007 
centered socialization as a moral model and material infrastructure, it does transform it significantly.

As the more harmonious and homogeneous era of national cultural integration has become a thing of the past, we are compelled to acknowledge an urban space that reflects differentiated, heterogeneous societies. This urban space, however, does not emerge as a genuinely public space, because the practices associated with it are frequently on the margins of law enforcement. This is observed not only in the more obvious fight against gangs or organized crime, it is also evident in collective expressions such as dances in poor neighborhoods, where the music might blare until dawn at intolerable volumes for neighbors hoping to get some sleep.

In any event, Latin American cities have a key role to define due to their new position in cultural production and forms of sociability in the context of globalization. Beyond the issue of who controls the urban space, it is critical to recognize the existence of a diverse range of actors who are actively creating new forms of sociability. The national state is no longer the only actor on the stage and Latin American statist nationalism has acquired a distinctly anachronistic, anti-modern air. The negotiation of conflicts among NGOs, the media, and civil society organizations is part the decision-making process and one that is necessary for the effective functioning of contemporary democracy. A certain "disorder" in this regard is part of the essential pluralism and a democratic pedagogy of negotiation could become the terrain for new forms of social integration capable of counteracting apparently anomic trends. The fact is that identities and forms of participation are not a priori affairs, nor do they develop outside of the more general processes underway in our societies. A public identified with democratic values is the result of, rather than the premise behind, the democratic game. And this democratic game relies on participation, debate, and confrontation in the public space, and in the territory of institutions.

\section{The city and social exclusion}

New forms of capitalism influence, and in general weaken, cities in their capacity as hubs of civic life. In addition to modes of production, transformations in this sphere reshape patterns of consumption and social reproduction, and this has an enormous impact on social interaction in large cities. Indeed, opportunities for face to face interaction between socially different and unequal individuals have been greatly reduced in the 
workplace, in residential areas, and in the institutions that provide essential services for collective living.

Unskilled workers have experienced the most dramatic change in the labor market. The dramatically higher qualifications levels required to access stable, protected jobs exclude these segments of workers from mainstream economic circuits. Many urban micro-enterprises were $o$ harmed by the gradual penetration of large-scale, globalized capital in the service industry and in the production of consumer goods directly related to the social reproduction of the poorest sectors of the population. The changing labor market shattered many of the dreams of upward mobility held by unskilled manual and nonmanual laborers, whether that meant entry into the urban world of stable, protected employment, or into the urban petite bourgeoisie. Moreover, new labor market trends accentuate the historically unjust income distribution structure, situating the winners of new modes of capitalism in strata dramatically set apart from the rest of society in terms of relative income as well as their ability to adopt globalized cultural models.

The social organization of space in big cities, which is associated with rising violence, has accentuated the territorial division between sectors excluded from the dynamic labor market and the rest of the city. The territorial gap widens as excluded sectors are displaced to outlying areas of the city, and to increasingly precarious low-income housing in declining downtown areas including squatter settlements [villas-miseria] or low-income tenement buildings [conventillos] and the like. A parallel phenomenon is the urban flight of the "winning" social strata, which choose various means of territorial self-isolation (private condominiums, country condominiums, gated communities and the like). Such socialterritorial organization patterns in large cities reduces opportunities for social interaction among the different and unequal, whether in the streets or in the context of geographically-based services such as schools, health care, transportation and recreation.

Various mechanisms are at work to segment collective services. One of them is the impact of residential segregation on the ability of different social groups to finance such services through their tax contributions. The concentration of poor people in peripheral municipal areas is often accompanied by lower quality local collective services used only by those population sectors. At the same time, the middle class sectors that have most benefited from new forms of accumulation turn increasingly to the market for basic services such as education, health, pension plans and 
public security. This reinforces urban flight, further limiting opportunities for interaction among the different and unequal.

Another relevant phenomenon that affects the quality of social interaction in the city is the rapid rise in expectations as material and symbolic consumption patterns serve as sources of social differentiation. Here the mass media play an important role, as do universal educational coverage and widely disseminated political rhetoric proclaiming the universality of social rights. These processes spotlight class disparities in the consumption of goods and services that define social status and lead to unfulfilled expectations and aspirations among the urban population, which also inhibits social interaction in big cities.

The revolution of aspirations combined with the desertion of spaces where people learn how to coexist in differential, unequal settings rends the social fabric in large cities. These two general trends, however, leave us only on the threshold of grasping the impact of new forms of capitalism on models of sociability in large Latin American cities. We must explore three additional angles to more fully grasp what is happening. The first enables us to distinguish between cities based on the influence of models of historical domination; the second examines levels of unequal distribution of wealth; and, the third points up the seriousness of trends towards residential segregation and the segmentation of collective services.

These trends reduce opportunities for interaction among social classes and isolate them from each other. This has many repercussions for the social fabric. In contrast to the city that provided the origins of modernity, this city is no longer a sphere of social experience in which people learn to live together in their differences and inequality. When encounters between classes are rare or nonexistent, it is less vital that urban sociability create common codes, develop a sense of moral obligation, or foster the construction of associative norms to regulate the negotiation of conflicting interests. To the contrary, the simultaneous separation of these two venues for social interaction - housing and services - fosters stereotypical inter-class perceptions that hamper dialogue and preclude the objective evaluation of the intrinsic merits of one or the other group.

Social isolation is particularly problematic in neighborhoods with large concentrations of unskilled workers with fragile ties to the labor market. Compounding their poverty of access to information and contacts, these workers now have fewer opportunities to interact with others who might have useful information and contacts to facilitate their access to the market. 
Even more importantly, however, criminal groups often exercise control in such poor neighborhoods, a tangible symptom of the State's failure to ensure basic human rights. Terror and fear reign in gang-dominated neighborhoods. The law does not emanate from the state in the criminalcontrolled slums [favelas] of Río de Janeiro (where traffickers or self-styled militias "keep order" by levying different types of "taxes"). In some favelas, certain colors of clothing might be prohibited as being associated with rival gangs, and the same sort of censorship might be applied to songs that mention favelas dominated by other bands. These groups directly resolve their local conflicts, including theft or any other act that might attract the police. Penalties include torture, death, or a bullet wound. They also enforce expulsions or restrict movement, directly control certain services (such as gas distribution, since the companies refrain from entering certain areas), and compel businesses to close as a sign of mourning when a trafficker is killed by the police. They also forbid people to circulate between favelas or sectors of favelas controlled by enemy factions, which in some cases means that relatives or friends literally wishing to cross the street are obliged to take a bus. A mandatory law of silence ("I didn't see anything or hear anything. I don't know") is in effect and those who disobey it, or merely are suspected of disobeying it, often pay with their lives.

But even in this context of social exclusion, where the price of poverty is paid in human lives, individual initiatives abound in the form of urban invasions, unauthorized building, diversion of electricity, water and cable $\mathrm{TV}$, informal commerce and drug trafficking, as well as constant efforts to organize community life, sometimes with the support of NGOs. The villas miseria are a paroxysm of a society in which individual initiative is not state regulated, where the legal system does not support or regulate individual and social relations.

\section{Urban space and virtual communication channels}

Even as housing construction and transportation systems segregate, the mass media create and unify new spaces of communication. Radio and television initiated the process of creating virtual communication worlds shared by the most diverse social sectors, including the illiterate. In the past, however, such media outlets were characterized by their verticality and virtual lack of interactivity. This situation changed dramatically with the spread of cellular phones and the Internet (although as we will see later, the latter has had little impact among grassroots sectors). 
In most Latin American countries, telephone networks never really penetrated low income sectors, where people traditionally relied on public telephones, the local store, or a privileged neighbor to make a call. This has begun to change over the past decade, with the exponential growth in cell phone use.

The spread of the cellular telephone cannot be dissociated from the unequal distribution of wealth and does not extend into the poorest rural

\section{ICT Statistics by Country}

\begin{tabular}{l|c|c|c|c|c|c|c|c}
\hline & Argentina & Bolivia & Brazil & Chile & Colombia & Costa Rica & Cuba \\
\hline $\begin{array}{l}\text { Internet users } \\
\text { per 100 people }\end{array}$ & 16.10 & 3.90 & 12.18 & 27.9 & 8.94 & 23.54 & 1.32 \\
$\begin{array}{l}\text { Land-based } \\
\text { telephones per }\end{array}$ & 22.76 & 6.97 & 23.46 & 21.53 & 17.14 & 31.62 & 6.78 \\
$\begin{array}{l}100 \text { people } \\
\begin{array}{l}\text { Cellular } \\
\text { telephones per }\end{array}\end{array}$ & 34.76 & 20.07 & 36.32 & 62.08 & 23.16 & 21.73 & 0.67 \\
100 people & & & & & & & \\
\hline
\end{tabular}

\begin{tabular}{l|c|c|c|c|c|c}
\hline & Ecuador & El Salvador & Guatemala & Honduras & Mexico & Nicaragua \\
\hline $\begin{array}{l}\text { Internet users } \\
\text { per 100 people }\end{array}$ & 4.73 & 8.88 & 5.97 & 3.18 & 13.38 & 2.20 \\
$\begin{array}{l}\text { Land-based } \\
\text { telephones per }\end{array}$ & 12.22 & 13.42 & 8.94 & 5.57 & 17.22 & 3.77 \\
$\begin{array}{l}\text { 100 people } \\
\begin{array}{l}\text { Cellular } \\
\text { telephones per }\end{array}\end{array}$ & 34.44 & 27.71 & 25.02 & 10.10 & 36.64 & 13.20 \\
100 people & & & & & & \\
\hline
\end{tabular}

\begin{tabular}{l|c|c|c|c|c|c}
\hline & Panama & Paraguay & Peru & Dominican Rep. & Uruguay & Venezuela \\
\hline $\begin{array}{l}\text { Internet users } \\
\text { per 100 people }\end{array}$ & 9.46 & 2.49 & 11.61 & 9.10 & 20.98 & 8.84 \\
$\begin{array}{l}\text { Land-based } \\
\text { telephones per }\end{array}$ & 11.85 & 4.73 & 7.49 & 10.65 & 30.85 & 12.78 \\
$\begin{array}{l}\text { 100 people } \\
\begin{array}{l}\text { Cellular } \\
\text { telephones per }\end{array}\end{array}$ & 26.98 & 29.38 & 14.85 & 28.82 & 18.51 & 32.17 \\
100 people & & & & & & \\
\hline
\end{tabular}

Source: APC.org - Monitor Políticas TIC y Derechos en Internet en América Latina y El Caribe. Available at: http://lac.derechos.apc.org/es.shtml?apc=se_1 
sectors where infrastructure is lacking. In contrast, it has penetrated massively in metropolitan areas. There are a number of reasons for this. First, the availability of lines (in many countries landlines required a long wait or had to be purchased on parallel markets at a high price), for which the only cost is the purchase of the telephone itself at a price usually subsidized by the service provider. Second, there is no fixed cost to maintain it, which means that one can stop using it to make calls for a period of time without risk of charges or complications associated with service interruptions, as occurs with landlines. Third, the portability of the cellular telephone, which goes wherever the user goes, increases its utility (for example, working parents can be located wherever they happen to be and the logistics of service industry and informal sector workers are facilitated since they can be readily located by their customers).

The dissemination of the cellular telephone among the poorest sectors was made possible by the pre-pay system. While the per minute cost of communication is much higher than for those who purchase a monthly subscription, the poorest sectors develop their own systems to minimize costs. Basically the telephone is used to receive calls (at no cost to the receiver) while outgoing calls are placed from public telephones or landlines, or else kept very short. The main cost, then, is the purchase of a card that offers a certain number of minutes and is valid for a certain time period, which entails periodic card purchases. Therefore, while the quantity and quality of communication is income dependent, this in no way nullifies the enormous revolution brought about by the advent of the cellular telephone.

The cellular telephone has had a profound impact on social relations. Landline telephones, even among the upper classes, are a product for family consumption. The whole family shares a single telephone number: one answers the phone with the classic, "who is calling?" and "with whom do you wish to speak?" In this sense it was conducive to powerful social controls, in particular by parents over their children, but also between spouses, or in the workplace or by the department head over subordinates. The cell phone, in contrast, is for personal consumption (one would suppose that the person on the other end is calling for one, and the only possible control question is "where are you?"). This strengthens the horizontality of relations and individuation (particularly of children in relation to their parents). ${ }^{10}$

10 This assertion refers to the current state of the technology. In the future, new locator and tracking devices will curtail the freedom currently supplied by the cell phone. 
Parents who give their children cell phones in order to keep track of them rapidly discover that the only thing they have actually accomplished is to bolster the latter's communications autonomy.

In some cases the strong penetration of the cellular telephone is associated with emigration. El Salvador, poorer than Costa Rica and Panama, and with the highest communication costs, features the highest cell phone penetration levels, due to the remittances sent by their emigrants and the communication possibilities available in the destination country. In the case of Ecuador, which sends large numbers of emigrants to Spain, a telephone company headquartered in both countries offers special plans in response to the new international telecommunications market for low income sectors.

Criminal groups also rapidly discovered the potential of the cellular telephone and the Internet. Telephone tapping is routinely used by traffickers in the favelas - especially in confrontations with the police - to monitor calls from local residents in order to make sure that they do not inform or collaborate with the police. Traffickers also attempt to control the use of local cybercafés, in particular when they suspect that someone may be sending information or complaints. The cellular telephone enables imprisoned leaders of criminal bands to remain in constant contact with the outside world, for the purpose of organizing drug distribution or "virtual kidnappings." This type of criminal operation has reached epidemic proportions in San Pablo and Río de Janeiro. It works like this: all of the landlines in a particular area (usually a middle class neighborhood) are called systematically and the person who answers hears a distant voice crying, immediately followed by a demand for payment of a particular sum of money within one half hour or else the kidnapped individual (presumably a son or daughter) will suffer the consequences. The Internet is also used to distribute drugs among the middle classes or - as occurred in a recent case in San Pablo when criminal groups conducted a series of attacks - to disseminate fictitious news in order to intensify the panic.

The Internet is increasingly permeating society, although to a large extent, the residential divide continues to parallel the digital divide. ${ }^{11}$ Even so, low income sectors gradually are obtaining access to Internet use whether in the workplace, at the home of friends, and especially in cybercafés. The latter, the vast majority of which are private microenterprises, have become

11 See Sorj and Guedes (2006) for an analysis of the relationship between space and digital exclusion. 
the main source of Internet access for low income sectors in many Latin American countries, transforming the pioneering initiatives of NGOs or even governments into relatively minor players. $s^{12}$ The digital inclusion process could accelerate rapidly with the advent of interactive Internet and the new combined communications systems. This might have the effect of strengthening the barriers to access by the poorest sectors. We must not forget that electronic products used to be educationally neutral (in other words, no particular educational level was required for their use) and there was no cost associated with having them (except for electricity). In contrast, the new media devices generally have a strong reading and writing component and require some sort of monthly or per use payment.

As in the case of cellular telephones, here too there is an enormous gap in the amount of communications time available to the rich and the poor, and among those with different educational levels (a critical variable in Internet use among the poorest sectors). Access to connectivity is not synonymous with exploiting the Internet's vast information potential, which varies tremendously according to educational level and the potential social network of the user (Sorj and Guedes, 2006). In any case, whether for games or schoolwork (for teenagers and young adults) or to send a curriculum vitae and job hunt, the Internet has become a unifier in the realm of communications. And like the cellular telephone, it is an individualizing product in the sense that the family (or the boss) forfeits social control over its members (or subordinates).

\section{The city, reticence and social cohesion ${ }^{13}$}

Alongside cultural modernization and spatial segregation, several important phenomena have emerged associated with violence and crime, which we will discuss in more depth later on. This has brought to the fore a new sort of relational sentiment. Various terms have been suggested to describe it: fear, uncertainty, insecurity. While these expressions may be apt in many ways, they have the downside of painting a perhaps overly dramatic picture of urban social bonds. To us, therefore, it seems more appropriate to refer simply to a constant feeling of alert and of reticence.

12 See Finkelievich and Prince (2007) for a discussion of cybercafés in Buenos Aires.

13 This section is based on Luis Alberto Quevedo, "Identidades, jóvenes y sociabilidad. Una vuelta sobre el lazo social en democracia". 
In reality, we are embarked on a process in which much is new, but there is also some continuity. For example, our societies already were marked by social heterogeneity in the 1960s, but the institutional framework and individual action has changed profoundly. And just as we debate in Latin America today the ambiguous simultaneity of globalization and localization trends, as far back as the $19^{\text {th }}$ century, and to an even greater degree in the $20^{\text {th }}$ century, the ambiguous dissolvent effects of modernization were being discussed. Individuals who emancipated themselves from traditional ties also forfeited the support those ties had afforded them. This was the case, in part, for instance, of religious secularization. Just as people then turned to the secular "religions" of political ideologies seeking expressions of their need for social ties, young people today attempt to construct social ties and communities in ways that are generally more distanced from the public space.

The city, then, caught up in a two-pronged operation, a pincer maneuver that threatens to dissolve its modern configuration: on one side, there is spatial segregation of a new sort, which requires a redefinition of the concept of "neighborhood" and by extension the types of relationships that develop there. On the other, there is cultural self-segregation, that is, a de-centering of cultural practices and consumption patterns, which no longer use the city as a point of reference, but instead are locally inscribed and based on new global configurations, particularly among the middle and upper classes.

The city recedes not only as a space where identities are constructed, but also as an equalizer of the symbolic possibilities available to its residents. In gathering places such as the block, the café, or the club, the local development association, and the political committee, differences were mitigated by proximity. In this model, the school was an important mechanism for integration and for equalizing opportunities to urban access. But the city has changed and insecurity has dramatically altered neighborhood sociability. The combination of all of these factors (segregation and self-segregation, new urban fears, the differentials produced by globalization in some sectors of the city, and so forth) led to a de-urbanization process (García Canclini) due "in part to insecurity and also to trends, driven by electronic communications, towards a preference for at-home culture piped in via radio, television and video over going to the movies, the theater or sports events that may require traveling long distances and through dangerous areas of the city." ${ }^{14}$

14 As cited in A. Quevedo, Op. Cit. pp. 33-34. 
Neighborhood living, the experience of insecurity, the impact of the media, the widening economic gap and new phenomena of social exclusion and segmentation create a very different panorama of people's lives. What are its main features?

- The perception of the public space as risky, especially for more vulnerable citizens such as children, youth, the elderly and, in particular, low income sectors.

- The proliferation of huge shopping centers and supermarkets which alter consumption habits. The decline of neighborhood "mom and pop" establishments.

- Fewer opportunities for face to face interactions in the goods and services market.

- Changes in movie consumption: decline of the old neighborhood exhibition halls (now converted into evangelical churches) and emergence of expensive state-of-the-art cineplexes owned by international distribution chains and featuring multiple small theaters and a food court packed with large screens.

- Retreat of the family into the home (cut off from its surroundings by bars and protected with alarms or private security guards). The home is at once isolated from its immediate surroundings (the neighborhood) and very connected to the outside world through technology.

- Proliferation and personalization of domestic screens and monitors (televisions, computers, cellular phones, notebooks, iPods, videogames, etc.)

- Transformation of the typical venues to see and be seen, or meet up with others, namely, the local bar or café. No longer are they routine stomping grounds where one might stop in without knowing in advance who might be there.

- Changes in relational aesthetics and styles (from the owner tending bar to the restaurant-bar staffed by post-modern youth with little interest in service or the connection). Many of the "old style" bars manage to survive by being declared sites of cultural and historical interest in the city.

- Local proliferation of U.S.-style fast-food establishments, with standardized aesthetics, products, and service mechanisms. The television is prominently located and always on.

- Emptying out of the city on weekends by residents who literally are able to escape it. Permanent congestion on roadways in and out of the city. 
In brief, where the old dual social bond - hierarchy and equality, with the former predominating - assigned each actor a clear position in the social space, dictating his or her behavior and restricting the spectrum interactive transgressions, in the new framework of sociability that is more horizontal and more demanding in egalitarian terms, interactions with strangers are universally perceived as less structured. Even more so since the egalitarian imperative occurs in the framework of segmented urban experiences and tremendous cultural pluralism. This does not transform "all" social relations into "uncertain" interactions, nor does it magnify a generalized "fear" towards others or even unleash an obsessive "insecurity." What it does exact in retaliation, however, is a constant sense of vigilance, of alert, indeed a broad spectrum of attitudes of constant reticence and strategies of enclosure and privatization.

Cities, as we know, are a blend of "streets" and "houses." When the streets are perceived as being dangerous, the only option is retreat into the houses. And even more so now that new cultural props (Internet, DVDs, etc) and the growing availability of home-based services and commercial delivery, encourage this type of reclusive, long-distance sociability.

\section{The media, cultural industry and social cohesion ${ }^{15}$}

Do the communications media and culture industry (CM \& CI) help to maintain or erode social cohesion? This is not an idle question. Cohesion is generally produced through the actions of the state, institutions, and civil society. At present, all of these actors are relatively weak in Latin America and the main traditional factors of cohesion based on reciprocal relationships (religiosity, leisure pursuits, fraternity, strong family ties, political parties, trade unions) are undergoing major processes of mutation, erosion, or abandonment, as we will discuss.

In this context, the $\mathrm{CM} \& \mathrm{CI}$, along with culture in the broader sense (from arts, literature, music, and traditional crafts to anthropological phenomena known as "intangible heritage," encompassing religion, festivals, rituals, language, cuisine, etc.), play a very important role in the new social make-

15 This section is based on George Yúdice, "Medios de comunicación e industrias culturales, identidades colectivas y cohesión social"; Luis Alberto Quevedo, "Identidades, Jóvenes y Sociabilidad. Una vuelta sobre el Lazo Social en Democracia”. 
up. Throughout the $20^{\text {th }}$ century the media were a powerful catalyzing agent of collective identity. The CM \& CI will acquire even greater protagonism as technological advances increasingly channel culture into the digital convergence (television, Internet and telecommunications). According to some observers, however, these changes are already causing modifying relations of reciprocity. Many - perhaps most - people see this as negative, although for some it might seem promising. Once again, as we will see, what is at stake is the endurance or erosion of the dual social bond and the advent of more egalitarian relations.

\section{A new ligature of social cohesion?}

In the pessimistic view, if traditional symbolic lubricants and glues are diluted in an atmosphere in which neither the state, institutions, nor civil society are playing the "proper" cohesive role, other agents will have to emerge to fill in the gaps. The future, then, might bring powerful, charismatic caudillos capable of averting disorder, but only at the price of submission and tyranny. Alternatively, new interactive media might revolutionize the unidirectional transmission of our culture and render it truly interactive, recreating at the virtual level phenomena similar to presential rituals in traditional communities. In this scenario, new communications media would be conducive to the flowering of democracy, one that is interactive, rather than representative. A third possibility, of course, is that the current discouraging, but not disastrous, reality will simply continue.

But something is missing in both lines of reasoning. While the CM \& CI play a significant role, society is not automatically better or the worse for them. Of course, access to CM \& CI could improve, which would have an effect on the quality of participation. But the CM \& CI cannot be singled out from other social factors as if they, in and of themselves, could lead the way to a more cohesive society. The CM \& CI have to be understood in their intersection with other spheres of social life. While it would be of little use to take an apocalyptic or all-encompassing view of the contribution of the CM \& CI, this does not mean we should not try to understand its effects, to fine-tune its relationship with other aspects of social dynamics. In any event, it is important to bear in mind that its effects are varied and ambivalent.

The CM \& CI, for example, comprise a highly creative sector with tremendous potential for transversal expansion that can enhance performance in other areas of activity (e.g. the contribution of the arts 
to urban revitalization and reintegration or the incorporation of artistic creativity in software innovations). This is critical in today's information and knowledge-based economy. According to recent studies, the contribution of the CM \& CI to Latin American economies is as high as 7\% of the GDP in some countries.

We bring this up because the transversality of the CM \& CI vis-à-vis the so-called creative industries and education gives us to understand that its role in society today may not be to "produce cohesion," at least in the traditional sense, but rather to create synergies, which could benefit organized crime as much as globalized economic and social sectors, the integration of rural communities, or poor urban-dwellers.

The question, then, is how the CM \& CI can contribute to the synergy of building social cohesion in democracy? We must first understand that the new CM \& CI and contemporary culture in general are oriented toward individuals and their interactions in loosely constructed, shifting networks. The very notion of community has been transformed. According to network theory, a community can be defined as a dense network in which the same actors are found everywhere, as is the case in small towns where everybody attends the same school, the same church, frequents the same park, and so forth. Information and communication technologies, however, together with the territorial complexity of cities and the ease of transportation, extend the radius of connectivity; thereby rendering the networks ever more diffuse (something that, as we shall see later on, is very significant in contemporary migration processes).

The change has been profound. By empowering individual possibilities, the CM \& CI literally alter the meaning of social cohesion. No longer a flow exclusively from "society" toward "actors," it takes shape as a cluster of networks of greater or lesser density that change in function of the moment or the activity and can sustain themselves in, or activate, divergent identitary, affective, ethnic or familial elements. In this sense, it could be said that a growing number of individuals are, in effect, the protagonists of their own social cohesion. Each person, from different positions and using different resources, interweaves different networks. And if one takes a closer look, the most important thing is not so much their "density" (as in the number or longevity of the contacts) as their consistency, in other words, the differential solidity of the various relational scaffolds.

Some networks are voluntarily diffuse; we might say their importance lies in their ability to evaporate. The individual feels inserted into society based on a series of labile interchanges. Peer-to-peer exchanges of audio 
recordings and videos are a tangible illustration of contacts so diffuse as to be imperceptible. Similarly, socialization or "social networking" sites such as MySpace, Orkut and YouTube - with growing participation by young people from slum communities - facilitate the creation of diffuse, but no less enthusiastic, "communities" built around certain tastes and participatory consumption. (It is obvious from the interactive modus operandi of such sites that they are not about passive consumption as in the previous culture of mass consumption.)

One initial reaction to this reality, especially from those of us who are wed to the notion of stable "communities," is to condemn the diffuse bonds of the CM \& CI, arguing that such volatility cannot possibly beget solidarity. The contention is that the mass culture of the $19^{\text {th }}$ and first half of the $20^{\text {th }}$ centuries, with all of its problems, fostered the development of national communities and subsequently the welfare state in developed countries. In Latin America, the traditional CM \& CI projected an imaginary national community in which everyone was represented - examples of this being the rancheras or the Cantinflas or Sandrini shows - despite the disjunction in traditional mass culture between the consumption of such images and actual participation. Nonetheless, the cinema and radio of the 1940s and 1950s transmitted and translated people's dreams, fears, and aspirations.

Not enough empirical research is available to compare the cinema and music from that period with contemporary CM \& CI. Today sensationalism reigns, particularly in the violence and individualism that is daily fare on reality shows. What are the effects of this predilection for the sensationalized lives of others? It is hard to say for sure. Besides, the press and news programs broadcast ad infinitum images of young people who are gang members, or foreigners, or slum dwellers, or at risk, or drug traffickers. When in the late $19^{\text {th }}$ century, Durkheim wrote that "crime brings together upright consciences and concentrates them," he was saying that crime had an integrating function in that it illustrated or dramatized the way in which norms create cohesion among those who comply, or imagine themselves complying, with the law. In other words, there is no better cohesive agent than the "public temper" of those who seek each other out to "talk of the event and to wax indignant in common." (1995: 76). This process also created scapegoats, however: those who did not subscribe to the norms or who were "not like us" for reasons such as race, religion or sexual orientation (Jews, homosexuals, "dandies," and so forth).

Could it be true that the new exhibitionist societies are eroding social cohesion? As many empirical studies have shown, it is not that the CM 
\& CI incite their audiences to violence, but they do contribute to the atmosphere of fear that pervades most Latin American cities, including places like Montevideo or San José, where levels of crime and violence levels are more comparable to those of European countries. And fears have their ramifications. As we have pointed out, people retreat into their homes, what was once public space is privatized (the street, squares), private security agencies are contracted or people move to gated communities. It is not that the CM \& CI create this situation, but they do aid and abet it by encouraging the real dynamics and fears produced by social distancing.

It is not all negative. The CM \& CI (especially, but not exclusively, nonhegemonic ones) have been at the forefront of initiatives to transform imaginaries and influence systems that propagate racialization and criminalization. In Brazil, groups such as Afro Reggae and the Central Unica das Favelas, are popular in the media, but they have also mobilized to change police treatment of youth, especially young people with AfricanAmerican features from poor neighborhoods. Likewise, some newspapers have bowed to the petitions of organized groups to change the way they cover crime. The goal is to change the current connotation of insecurity derived from the fear instilled by criminality.

Moreover, while the CM \& CI in general tend to stereotype the poorest social groups, they have also at times promoted interculturality. Examples of this are world music on the international scene or participatory and inclusive websites such as Overmundo, which provides virtually across the board coverage of Brazilian culture and promotes new virtual networks which, while not communities in the traditional sense, certainly create a basis for bonds of solidarity. ${ }^{16}$

The CM \& CI of yesterday and today probably have one thing in common. In this context, it would be remiss not to draw attention to the irreducible ambivalence they convey. On one side, they transmit a cultural plurality that profoundly transforms the universe of signs permeating our societies. A relatively homogeneous and unique national culture is assailed by a plethora of diverse microcultures that are at once global and national, national and local, local and generational, and so forth, in a virtually endless chain. In this sense, the CM \& CI emerge as an important vector of cultural division and fragmentation particularly, as we have noted, in the midst of large cities swept up in rapid and intense urbanization and segmentation

$16 \mathrm{http} / / /$ www.overmundo.com.br/ 
processes. On the other side however, despite their plurality, the CM \& CI serve as a relevant agent of social cohesion insofar as they transmit a common collective imaginary. This affirmation is only paradoxical on the surface, and depends in large measure on the society being examined. The main contribution of the CM \& CI to Latin American societies has been to transmit across social classes and regions a series of common fictional intrigues and media heroes. Dances, for example, are events of mass appeal and participation and song lyrics play a key role in developing the discourse and self-awareness of youth.

Of course the new CM \& CI no longer play their former role of building the imagined communities that were nations. But this is not to say that they no longer transmit certain shared principles, new ways of being, or world visions. In effect, despite their multiplicity, most of them convey elements generally associated with cultural modernization and steadily rising expectations (an aspect which, as we will see later, is particularly relevant in its intersection with consumption).

But what is the unifying principle transmitted by the plurality of the CM \& CI? Equality. Or to put it more aptly, an individualized aspiration toward equality. The principles conveyed are globally distanced from the vision that attributed the durability of the social bond to a naturalized version of hierarchy and reflect instead a tangible and growing relational equality. Generation-specific interactions more than gender relations - and power or labor relations to an even lesser degree - are clearly the preferred target for this virtual pedagogy and even so, their relevance cannot be discarded (even in the transmission of norms as we discuss later).

Obviously, this cultural opening can create aspirations with contradictory results, depending on whether the demonstration effect or the fusion effect prevails. In Germani's famous interpretation, in the previous context of politically stifled societies, the fusion effect prevailed triggering the emergence of mass societies, followed by populist or authoritarian military regimes. Today, in contrast, the demonstration effect appears to be insinuating itself globally. The reason for this is found in the proliferation of initiatives actually available to individuals who are in a position to accomplish more things practically speaking and process more elements intellectually speaking, and who feel symbolically more included in the modern world. The process is, of course, fragile and gives rise to numerous frustrations. We will examine some of these in detail in our discussion of the consumption paradox. Here, however, how could we fail to note the democratizing power of the fictional intrigues circulated by the CM \& $\mathrm{CI}$ ? 
The penetration of the dreams they crystallize and ultimately the yearning for equality they introduce into social life? If, on the one hand, urban segregation is conspiring against the ability of individuals to feel as if they belong to a society, the CM \& CI, in contrast - and not without some degree of ambivalence - are contributing to the expansion of a common imaginary.

We should reiterate here that the process is an ambivalent one since the audiences that watch some programs, would never watch others. This is characteristic of multiple programming. For example, in their study of the Second Festival of Mexico City, (1991) Nestor García Canclini and his research team found that those who enjoy one particular genre of music will not listen to anything else, even when diverse offerings are available in the same space. Alejandro Archondo studied two television programs in Bolivia: The first was "Sábados Populares" (the competition of a similar program entitled "Sábado Gigante") hosted by "Don Francisco" Mario Kreutzberger and the second was "De Cerca", a talk show - a Bolivian version of sorts of France's acclaimed program "Apostrophes" - whose guests include public figures, writers, politicians, economists, artists and so forth. The first program courts a more grassroots audience with the Bolivian music - chicha - preferred by Aymara listeners - and rap. By adding lambada and some young couples, however, it was able to transcend its primarily "cholo" audience (in the words of host, Don Paco) in La Paz and El Alto and make it all the way to Santa Cruz where it joined a television network with better infrastructure. Similar to the approach adopted by some radio stations, the program uses a mixture of "popular, subcultural wisdom" to circumvent the law of differentiated audiences. As presenters began to moderate their speech and more salsa was played (popular among Santa Cruz residents) the program was evaluated as having served as an effective mediator.

The other program, "De Cerca", compromises none of its principles to achieve popularity. Here the host "has intellectualized a normally dramatic medium and hasimposed the preeminence of argumentation over exhibition." The elites have sustained this program, which otherwise would have gone under. The coexistence of these two programs points to a demographic divide or one of "diverse communities imagined through screens and microphones" that should interact at the symbolic level to build a truly intercultural society. Despite this divide, however, the media "have fueled an accelerated political development in which people have become accustomed to talking about issues with total freedom." There is no univocal conclusion. 
If, despite their limitations, the CM \& CI participate in the construction of a public sphere built around interculturality on the one hand, this only occurs in the midst of a real division of audiences or publics. In the final analysis, however, the point of convergence is found in the transmission of a common and more egalitarian imaginary of the social bond.

\section{Youth identities and cohesion in the age of the media ${ }^{17}$}

Even if one acknowledges that the CM \& CI play an important role in transmitting a common modern imaginary, this is not to say that they are not also a powerful factor in cultural division, as we have seen. Indeed, when classical institutions of modernity lost their monopoly over the production of meaning, what ensued was a proliferation of identities. Within this process, the growing social diffusion of the $\mathrm{CM} \& \mathrm{CI}$ led to an extraordinary proliferation of every possible type of relation and tie, multiplying in turn the number of identities available to individuals, institutions, groups and social movements.

How does social cohesion develop amid this abundance of signs and messages? Essentially by means of individual strategies or at best, those of very small groups, which negotiate identities in the framework of what has been referred to as "glocalization": individual "identifications" are mediated by consumption and (reinvented) as particularist group identities. Indeed, what we are witnessing is the crafting of the local, including the re-creation of neighborhood features, using transnational cultural inputs. The result is a re-creation of the social bond that is no longer filtered, at least initially, through the institutional matrix. Instead, the $\mathrm{CM} \& \mathrm{CI}$ become the structuring realm between individual experiences and collective processes. Of course, the emergence of new social and cultural practices does not erase national traditions (or loyalty to symbols and values dating back to the formation of nation states). It merely complicates these things and exposes their strengths and weaknesses in everyday practices.

It is important to point out the age-related aspects of this process. Young people are not only the ones who experience more directly the deficit of meaning in the modern institutional fabric, they are also the ones who, most forcefully and out of the greatest need, create the interstices that

17 This section is based on Luis Alberto Quevedo, "Identidades, jóvenes y sociabilidad. Una vuelta sobre el lazo social en democracia”. 
filter and combine new sources of identity. And they are also the most vulnerable. They struggle the hardest to obtain good jobs, benefit the least from public policy, must eke out their own spaces in the cultural landscape, and are the most exposed to insecurities in the public space - which has become hostile, aggressive, dangerous and hard to predict, particularly for the youngest - and to pressures to turn to crime.

Young people emerge as protagonists in CM \& CI driven identitary recreation processes. We should be clear that we are not talking about the mere resurgence of latent identities heretofore suppressed by the coercive force of the institutions that forged national identity (a common interpretation in the political sphere). Nor is this a case of the inertial resistance of traditional community forms to the expansive trend of modernity, according to the modernization theories disseminated from 1950 to 1970 (which found fertile ground in the Latin American social sciences). To the contrary, what we are observing is the genuine production of locality, in other words, the creation of new, often virtual, spaces for sociability. This production of locality - or these "reterritorializations" - takes on many different forms with respect to history and tradition and sometimes, and this is particularly true of youth, it means breaking away from them.

But the important thing is not mobilized cultural diversity, but rather the contemporary role of these identifications as social adhesives: "a function of paradoxical belonging and therefore of stabilization" (Marramao, 2006: 173). Marramao is right to refer to a paradoxical function. While it would not seem evident on the surface that (individual) consumption could function as a social adhesive, CM \& CI consumption often restores a sense of belonging to those who share tastes, aesthetics, or identify with each other in the mass-mediatic enjoyment of certain stories. In this way, the television primarily, and radio and Internet to a lesser degree, insert the individual into a sphere of sociability (communities of meaning) that give him or her a certain sense of belonging in an increasingly complex, strange, and incomprehensible world

There is no better illustration of this than the evolving notion of the neighborhood - "el barrio" - particularly in youth culture. Interestingly, despite the many transformations and new behaviors we have described in the urban and domestic spaces, it cannot be said that the barrio model of sociability is simply a thing of the past. The "values of the barrio" (face to face social relations, solidarity, reciprocity, mutual assistance) are restored and reinvented by certain cultural productions which - in Argentina at 
least - surfaced with a vengeance at the peak of the country's (economic, institutional and representational) crisis at the beginning of the $21^{\text {st }}$ century. This "return" to neighborhood values of solidarity was very much in evidence in cinematography - Luna de Avellaneda was emblematic of the genre - and in music. "National rock" appeared on the scene with an gregarious and festive aesthetic that was, at the same time, moralistic and appealed to a "tribal" and Dionysiac identity. This had occurred before, in the early 1990s, when people began to listen to global music products, and it had engendered phenomena of localization (as well as reterritorializations) and group subjectivities.

But the barrio was also reinvented on the TV screen. Several widely viewed Argentine programs ("El sodero de mi vida", "Gasoleros", "Campeones", "Son de fierro") featured different versions of middle class families facing the economic crisis and recycled depictions of the national ethic of defending traditional values. For vast sectors, and particularly for the middle classes, the barrio has left off being a hub of socialization and of those early forays to discover the world beyond the front door of the family home. Those unable to "retreat" to safer enclaves find their place of residence marked by urban decay, distrust, and insecurity. The urban transformation we have described calls into question the image of the middle class neighborhood as the "matrix" or ideal model of social cohesion and mediation between the public and the private spheres.

This process also occurred in the 1990s with the birth of a rock subgenre that inspired a number of bands, many of which became extremely popular (or perhaps it would be more apt to say extremely visible, since in quantitative terms it wasn't the music most young people listened to). ${ }^{18}$ Although the subgenre has been described in disparate terms (rock "chabón", rock barrial, rock futbolero), the lyrics consistently evoke the difficulties youth face in envisioning their future due to the lack of job opportunities. In a distrustful, crisis-battered society, such expressions helped define identitary enclaves that provided refuge, shelter and protection by extolling values of belonging, loyalty, and group fraternity. They essentially reinvent the barrio with a dose of nostalgia, more romanticism than illustration. In effect, these bands sing of neighborhood streets, neighborhood friends, neighborhood girls, soccer, and drug use, elements that construct the inner face of these

18 “Los Piojos", "La Renga”, “La Bersuit Vergarabat", "Viejas Locas”, “Intoxicados”, “Jóvenes Pordioseros", "Los Gardelitos", "Dos Minutos." Groups that helped young people deal with the bitter pill that was the Argentine crisis of the early 2000 s. 
groups. The songs are full of allusions to the "other side", for example, the upper echelons: the chetos or "high society snobs" who side with the yuta (police) and, above all, the corrupt politicians, "the enemies of the people... Allusions may also be horizontal: there are the traitors (the one who "went to the other side of city" and, as in the local cumbia style of music, those who turned "snob" or went over to the police). ${ }^{19}$

This imaginary and eminently nostalgic resurrection of the barrio in musical and audiovisual cultural productions is very significant. Especially since beyond simply expressing or reflecting through fiction the lifestyle of certain social sectors, these television programs reinvent their values and create from them a place of identification. This reaffirms the notion of "unanchoring" (Giddens, 1990), in other words of social relations that become uncoupled from their local contexts and reconstitute themselves in indefinite spatial-temporal intervals. It indicates too that mass culture continues to play an important role in social cohesion and inclusion. To do justice to the main change that has taken place when examining (the aesthetic) of popular music, "it is not a matter of how a particular piece of music or a performance reflects the people, but how it produces, how it creates and constructs an experience - a musical experience, an aesthetic experience - that we can only understand by assuming a subjective as well as a collective identity." (Simon Frith, 1977: 109).

This is an important distinction. If the goal of the analysis is to establish some sort of relationship between material living conditions and the musical forms that give expression to them (in the classic model of a determinant relationship between base and superstructure), there is a real risk of reaching a conclusion that only confirms the fragmenting role of youth culture: when this type of evidence is encountered, it tends to be interpreted in terms of "subcultures." In this way, there would be a sort of preconstituted social identity that latches onto a particular form of musical expression. But this is by no means evident in the practice of those who produce and listen to music, much less in the cultural practices of youth in urban spaces. To the contrary, it is the cultural supply - which is more interactive than representative - that co-produces the experiences of

19 An example of this is the "you aren't the same anymore" theme in the CD "Puente Alsina" by the Dos Minutos band: "Carlos let his mustache grow/and he's got a nine millimeter/and he never went back/to Fabian's bar/and he forgot about playing/Sundays on the field./He knows full well a bullet/is waiting for him out there/ at night, on the street." The police (yutas, ratis), are always featured as the eternal persecutors of the rockers and cumbieros. 
collective identification, but it does so based on elements which have been experienced in profoundly subjective ways.

Indeed, in a country like Argentina a deep attitudinal schism can be observed when it comes to musical tastes and preferences. One group favors popular or mass culture selections while another is more inclined toward more segmented alternatives. In the former category are those who prefer tropical music and cumbia (including the villera), which is gaining ground among province dwellers, people under 34 years of age, and the lower classes. The other major musical preference is rock (national rock or pop music), which is also spearheaded by young people from all over the country, as well as the middle and upper classes. More segmented musical preferences include: folklore, tango, salsa, Brazilian music, disco, opera and classical, jazz/blues and techno, each of which has a unique support base.

In other words, it is necessary to acknowledge the existence of a double frontier. On one side is the divide between young people and adults - not to exclude a transformation of the patterns associated with "being an adult" and the pressure on "mature" individuals to remain open to "youthful" ways and appearances - and on the other, the various strongly divergent cultural expressions observed among youth. This internal differentiation, however, cannot be compared to traditional social divisions except in the very roughest sense.

Groups of more or less ephemeral cultural sociability form around "listening regimens" (chosen for symbolic reasons and indicative of subjective imaginary inclinations) capable of producing collective identities that extend beyond their place of origin and the industrial circuits that produce them. Rock as a global/local phenomenon is a good example of this. It was perhaps the first musical genre with a readily identifiable public based on age (adolescents and young adults) rather than territory. It sparked a global cultural enthusiasm that enable it to quickly shed its local roots. This segmentation is not completely explained by the industrial creation of a "niche" to take advantage of the consumer power of young people. Far from a response to the demand or to the commercial strategies of the record industry, the rock music of the 1960s was the driving force behind it all. Clearly a paradoxical way of producing age-based social cohesion - ephemeral, segmented, at times hermetic, multiple - and yet capable of creating a genuine sense of collective belonging. A sense that, despite the distance and anonymity, the "we" is forged by the intensity of the subjective experience and by acknowledging it in the other person - which ultimately is an acknowledgment of his or her equality. 


\section{Emigration ${ }^{20}$}

A major receiver of immigrants in the first half of the $20^{\text {th }}$ century, Latin America has since become a population-exporting continent. There are many and varied reasons for this: natural disasters, the armed conflicts in Central America and Colombia, exiles created by authoritarian regimes in the Southern Cone, severe economic crises such as those in Argentina and Uruguay, but most importantly, the inability of economies to offer sufficient opportunities to obtain a decent job. It is imperative to understand this in all of its many facets. International emigration traces a new "frontier" in Latin America, one that has replaced the previous internal frontier of rural to urban migration. Much like the frontier in United States history, it diverts initiatives from their narrow path to social conflict and rechannels them towards exit - to borrow a term from Hirschman - and emigration processes. It is a broadening of horizons that accompanies and deepens a developing egalitarian imaginary increasingly looks to global patterns of consumption and well-being as its yardstick.

\section{Emigration: a few figures}

Emigration levels in Latin America have risen sharply in recent decades:

Latin American population re-censused in the U.S.A. based on origin and growth base

Raw numbers

Growth base $(1960=100)$

\begin{tabular}{l|c|c|c|c|c|c|c|c|c}
\hline & $\mathbf{1 9 6 0}$ & $\mathbf{1 9 7 0}$ & $\mathbf{1 9 8 0}$ & $\mathbf{1 9 9 0}$ & $\mathbf{2 0 0 0}$ & $\mathbf{6 0 / 7 0}$ & $\mathbf{6 0 / 8 0}$ & $\mathbf{6 0 / 9 0}$ & $\mathbf{6 0 / 2 0 0 0}$ \\
\hline $\begin{array}{l}\text { South } \\
\text { America }\end{array}$ & $\begin{array}{c}74964 \\
\text { base 100 }\end{array}$ & 234233 & 542558 & $1,028,173$ & $1,876,000$ & 312.46 & 723.75 & 1371.55 & 2502.53 \\
$\begin{array}{l}\text { Central } \\
\text { America }\end{array}$ & $\begin{array}{l}624851 \\
\text { base 100 }\end{array}$ & 873624 & $2,530,440$ & $5,425,992$ & $9,789,000$ & 139.81 & 404,96 & 868.36 & 1566.61 \\
Caribbean & $\begin{array}{l}120608 \\
\text { base 100 }\end{array}$ & 617551 & $1,132,074$ & $1,760,072$ & $2,813,000$ & 177.4 & 512.03 & 938.63 & 2332.34 \\
\hline
\end{tabular}

Source: Prepared by Angelina Peralva (op.cit.) based on Pellegrino (2003).

20 This section is based on Angelina Peralva, "Globalização, migrações transnacionais e identidades nacionais". 
Emigrants do not only head towards the United States. In recent years, Latin America has increasingly exported migrants to continental Europe, particularly Spain. Data from that country's National Statistics Institute reflect that 2,672,596 foreigners were living in Spanish territory at the beginning of 2003, accounting for $6.26 \%$ of the total population. Ecuador has overtaken Morocco as the main country of origin of foreigners in Spain, and Morocco is followed by Colombia, the United Kingdom, Romania, Germany and Argentina. Latin Americans now account for $38.61 \%$ of all foreigners living in Spain (Gil, 2004).

A total of $1,665,850$ Peruvians, $51.7 \%$ of them women, migrated abroad from 1990 to 2005. Emigration rates accelerated beginning in 2001, when the number of passports issued tripled relative to previous years. The six main countries of destination were: the United States (30.9\%), Spain (14.3\%), Argentina (12.6\%), Chile (10.5\%), Italy (10.4\%), and Japan (3.8\%). Over $70 \%$ of this migration is transcontinental and $42.9 \%$ of migrants lived in Lima immediately prior to migrating abroad. Students are the most numerous group, followed by service sector workers (IOM, 2005; INEI, IOM, 2006).

Unlike past migration patterns, this migratory movement is more individual than family-based and men and women are represented in virtually identical percentages. Where they are not officially received, migrants work illegally (one would think, in fact, that the immigration policy of developed countries, the United States in particular, is to promote "undocumented" labor). This type of migration is frequently more of an "experiment" rather than a definitive decision to leave the country of origin. One favorable aspect of modern migration is that contact with loved ones left behind is no longer a matter of mail (which can delay weeks or months). Instead, it has become instantaneous and ongoing owing to the new forms of telecommunications and their drastically reduced costs. Contemporary migratory movements actually reflect a double movement: one of individualization and personal autonomy and another of enduring ties facilitated by transportation and communications systems. ${ }^{21}$

Latin American emigration follows the universal pattern of modern migration flows, from poorer to richer countries. Some of this takes place within the region, with Bolivian and Paraguayan emigrants traveling to

21 The physical mobility of the undocumented emigrant, however, is limited by the fear of not being able to return. 
Argentina and Brazil, or Central Americans heading towards Mexico. In some cases, the Latin American recipient country is but a stepping stone to other countries; this is particularly true of Mexico and the United States. Geographical factors clearly influence migratory flows. Mexicans and Central Americans tend to head to the United States because of its proximity, while South Americans usually turn toward Europe. Pioneering emigrant groups play a significant role in these flows by weaving social networks that attract their compatriots.

While we will not focus on the economic impacts of migration flows, it is important to note that remittances are of utmost importance worldwide and, as shown in a recent World Bank study, are absolutely essential to some countries. ${ }^{22}$ According to estimates, remittances for Latin America and the Caribbean surpassed 53.6 billion dollars in 2005, making the region the largest remittances market in the world. This amount exceeded, for the third consecutive year, the combined totals of all direct investments and official development assistance to the region, and this does not take into account money sent through informal channels.

Remittances account for over 50\% of Haiti's gross domestic product and for between $10 \%$ and $20 \%$ of the GDPs of Jamaica, El Salvador, the Dominican Republic, Nicaragua, Honduras and Guatemala. While the percentages are lower in Ecuador, Barbados, Colombia, Paraguay and Mexico, remittances still have a significant impact on the standard of living of vast swaths of the population, especially the most impoverished sectors.

It is safe to say that in general there is a certain correlation between the percentage of remittances in the gross national product and the percentage of emigrants relative to the total population. Obviously the poorer the country, given equivalent figures for population and emigrants, the greater the weight of remittances in the GNP. Likewise, the longer the emigrant population has been outside of the country, the greater the tendency towards a decline in remittances (owing not only to weakening ties but also the tendency to start a family and incur more expenses locally). This has been the case, for example, with Uruguayan emigrants and, to a lesser degree, Mexicans.

22 Pablo Fajnzylber and Humberto Lopez "Close to Home: The Development Impact of Remittances in Latin America,” World Bank, 2007. 


\section{Migratory flows of individuals, networks and cultures}

Emigration affects more than economic flows. The type of migration also changes, as migrants assimilate the technical supports that made globalization possible. Contemporary migrations, then, are no longer international: in other words, they no longer involve a nation to nation transfer of populations under the auspices of two States, as was the case until recently. Population movements now occur independently - and, in part, despite States - and shape their own transnational territories. A transnationalization of contemporary migration has occurred.

Long distance communications technologies have made it possible to build multiloci networks. This opens up to migrants a supranational space to build social relations based on principles that articulate various types of identities, endowed with different resources for action and/or insertion in the global market. Identity may revolve around territory of origin (the municipality of Arbieto, Esteban Arze province in Bolivia, for example), or may be based on a culture featuring crafts with market value (such as the typical weavings studied by Kyle, which are created by rural Ecuadorians originally from the highlands and marketed in London, Paris and New York).

Emigrants bring with them their labor force, but also their culture, and the latter often becomes a source of income, whether in the form of artistic production (from private shows to street musicians) or "ethnic" food. Another example of this is "capoeira", a fighting/dance style originally developed by native slaves in Brazil and often introduced in the racialist U.S. market as being of African origin.

Migratory flows also carry with them their belief systems and many native Brazilian evangelical churches have expanded their clientele through emigrants from Brazil or from other countries where these churches were already established. They operate as job information hubs and this, in turn, attracts other compatriots.

International circulation is a permanent and pervasive fixture of contemporary experience that transcends race, class or religion. Not only the elites travel. Those of the most modest means also circulate. In the latter case, the income gaps between countries become an important resource to be leveraged for individual and/or collective purposes, based on principles analogous, albeit without legal protection, to those that today determine the volatility of capitals. This type of circulation circumvents the territorial sovereignty of States, inasmuch as it involves economic transactions unfettered by any sort of controls. This may include illicit trade in licit - or 
illicit - products and infrainstitutional forms of social regulation based on principles of word of mouth, which are exempt from the written rules of a contract and therefore subvert the operational foundations upon which $20^{\text {th }}$ century democracies were built.

Many observers explain the intensity of these migratory flows as a result of the difficult living conditions migrants face in their countries of origin. While these conditions might explain why migration appears on the horizon of future migrants as a possibility at a given moment, they cannot account for the autonomization of migratory movements in relation to the specific circumstances that gave rise to them. A case in point is that of Brazilian migrant workers or dekasseguis in Japan. Their migration process began during the crisis that swept Brazil in the 1980s and persists today in the form of constant back and forth travel that has stabilized into a circulatory territory demarcated by the intensity of the exchanges between the two countries. The same is true of Ecuadorian migration flows originally triggered by the economic crisis in the late 1990s, which have continued unabated since that time. By all indications, the cumulative experience of migrants will be conducive to ongoing migration, which will become increasingly consolidated as a social dynamic. It is a dynamic that involves a growing number of women, whose migration experience has become autonomous from that of men, with the attendant impact on gender relations. Higher rates of violence against women has accompanied their increased autonomy. And while this violence cannot be regarded as specific to migratory situations, the two phenomena are often interrelated.

Luiz Lopez (2007) studied Mexico - U.S. relations in the border city of Tijuana whose social ambit, while situated in Mexican territory, extends to the outskirts of Los Angeles. Although there had been successive migratory waves dating back to the 1940s, demographic growth accelerated over the past 25 years, during which time the city's population grew from 400,000 to $1,500,000$. Spurring this unprecedented growth were the new jobs which opened up in the maquiladoras or assembly plants for various types of devices - in Tijuana mainly televisions - made with parts currently being manufactured mainly in Asia. Women play a particularly relevant role in this labor market, where they are recruited based on traits that presumably make them better suited than men to production demands. Some authors have proposed the notion of "productive femininity," to describe a form of domination geared toward exploiting the traditional feminine identity to the benefit of production. The living conditions of these women are fraught with the difficulties associated with precarious jobs, lack of adequate 
childcare and educational infrastructure, an equally precarious home and a rigid market poised on the threshold between legal and illegal. At the same time, however, women have staked out their own territory in terms of economic initiative and they have developed strategies of resistance to the domination experienced in labor relations. Similarly, they have carved out a space for collective action in the transnational framework. For example, several of their environmental mobilizations have found an echo in the United States. In this context, women's access to autonomy due to their work in the maquiladoras caused a true "moral panic" in Tijuana associated with the subversion of traditional representations of feminine identity. The city and the press are rife with virulent public criticism levied against the women workers, who are deemed "whores" and "irresponsible mothers," and this in turn has created fertile ground for gender-based violence.

\section{Emigration and social cohesion}

Emigration has had a contradictory impact on social cohesion and it is easy to overstate its positive and its negative aspects. We will merely list the most salient impacts:

1) One important downside associated with emigration as a collective phenomenon is the sentiment that the patria is unable to offer alternatives that would allow its children to stay home. It is a feeling of failure, of economic unviability. It is the missing horizon that weakens the collective will to cast its lot with the future of the country. The undocumented emigrant's experience as a social pariah is perhaps the most painful phase of this process. Despite this, however, emigration has served as an escape valve that has a "regulating" effect on social conflictiveness in migrant-producing national societies.

2) Migration should be included in labor market and social mobility studies, which are usually confined to national contexts. It represents job opportunities for an often considerable segment of the population. And for those emigrants who return, sometimes with a certain amount of capital or new skills, it represents a path to social mobility to which they would probably never have had access had they remained in their home country.

3) Remittances are an important expression of the social ties operating in Latin America at the level of primary relations. Remittances help 
mitigate poverty. Since emigrants are young and mostly single, a significant portion of remittances are directed toward their parents: older people with greater impediments to generating income.

4) On the other hand, emigration is often associated with the breakdown of families or the departure of a spouse who might remain abroad for a protracted period or might never return. But this aspect should not cause us to overlook the underlying cause of emigration (and often the reasons behind its duration): the desire of so many men - and an increasing number of women - to emigrate so that they can fulfill their parental role to support their families. The process restructures family ties in the countries of origin (where grandparents or other relatives assume the parental role) even as it accentuates the autonomy of women's migration.

5) While emigration constitutes a brutal drain of human resources, those who do return often bring back new professional qualifications. In other cases, however, emigrants become involved in gangs and other criminal organizations and when they return (often deported by the local authorities) bring with them a culture of violence and international crime networks. There is some discussion as to what percentage of remittances actually represents laundered assets and financing from criminal activities.

6) Finally, we must point out the creation of a new "nation," a transterritorial space consisting of the nation-state and its "diasporas." This includes the vast physical infrastructure or "highway" of people, goods, information, and communication. How this new transterritorial "nation" affects the self-images of different peoples is a topic that should be studied carefully in the coming years.

\section{The political challenges of migration flows}

Migrants today account for a relatively minor, albeit significant, percentage of the world's population (2.5\%). Their presence has provoked a major nationalistic backlash and a harsh crackdown by law enforcement in the countries of the "north." Migration, therefore, has become an extremely risky undertaking with a high human cost. Paradoxically, what attracts migrants toward the principle poles of globalization is the certainty that they will find attractive opportunities for economic insertion, often 
informal and precarious, but well compensated nonetheless. The countries of the north close their doors to migrants and yet open them up at the same time. They close the doors on regular migrants who are considered undesirable as potential beneficiaries of social protection policies in rich countries, while leaving them open a crack for underground migrants who may be employed with no rights whatsoever. Qualitative studies detail these delicate transactions, in which the overlapping interests of migrants from the south and capitalist entrepreneurs from the north cause borders to become porous, even as the states of the north insist unconvincingly on their desire to close them.

Crossing borders requires access to information concerning travel conditions, which is frequently available through private companies, such as, for instance, the travel agencies that have proliferated in recent years in downtown Cochabamba, Bolivia. In addition to selling airline tickets, particularly to Spain, at prices set to undercut the competition, these companies show movies about the trip and how to navigate the different airports. Ávila (2006: 90-91) provides a word for word transcript of radio advertisements by Bolivian travel agencies promising successful illegal entry into several European counties, with a guaranteed refund of the ticket in the event of failure. Migration to Japan by Brazilians of Japanese descent, while legal, is strictly managed by entities that are part travel agency and part temporary employment agency. Based in La Libertad, the Japanese "neighborhood" of Sao Paolo, these agencies handle the migrant's transportation from Brazil to Japan and guarantee a job and housing upon his or her arrival (Perroud, 2006). This is an indication of the extent to which individual emigration is indivisible from a host of collective resources.

Today, transnational migrations confront the nation state with a number of challenges arising from the combined phenomena of mobility and sedentarism. These include the organization of movements and political activity in territories where migrants pass through or settle. This occurred in Morocco with the Sub-Saharan African movements that emerged in 2005 and in the United States, which experienced significant Latin American migrant mobilizations in 2006. In light of such phenomena, the issue of social cohesion in democracy requires Latin American countries (and others as well) to rethink the very real disconnect between a democratic social dynamic in which mobility is an exercise of individual freedom, and a democratic institutional structure built on essentially sedentary, national foundations.

According to ECLAC, from 1990 to 2003, over 3,000 people have died in their attempts to cross the Mexican-United States border. Other sources 
indicate that since 1998, 7,180 people have perished on the thresholds of Europe, while traversing the desert or attempting a sea crossing. This figure appears to be mounting as more and more people attempt such crossings, departing the African Coast for the Canary Islands in precarious vessels. The human cost of contemporary migration processes is even more shocking as the barriers erected to stop migrants prove incapable of stanching a flow spurred by the opportunities that are, in fact, available for insertion into a globalized economy. The porosity of borders and volatility of capital cannot be examined in isolation from each other. They are two facets of the decay of the democratic social models that enjoyed considerable legitimacy in the recent past, but were premised on a powerful correlation between the sovereignty of the people and the (territorial) sovereignty of states.

In this sense, the six South American conferences on international migration held from 2001 to 2006 - and the bilateral agreements recently signed between Ecuador and Spain - were organized to reflect on the rights of foreign populations and to regulate population flows taking into account the inevitability of contemporary mobility. At the same time, as Seyla Benhabib has observed, it would appear that emergent forms of citizenship, this time founded on a local territorial basis, are tending to broaden the spectrum of social and political rights through the partial uncoupling of the relationship between citizenship and national identity.

By all indications, then, the responsibility of nation states with respect to social cohesion and population management can no longer be premised on nationality and requires the consolidation of more efficient post-national agreements and international cooperation procedures to guarantee an entire range of citizens' rights to moving populations. Moreover, while it would not eliminate the contemporary phenomenon of international mobility, the reduction of international asymmetries through the implementation of policies to jump-start development in "southern" countries would probably rein in the volatility of capitals, thereby improving guarantees of social rights in general.

\section{Conclusions}

The five topics discussed in this chapter are very different, not only because they refer to distinct social phenomena, but because they point to varying types of evolution from the standpoint of this study. Nonetheless, they all flow into a single channel towards a growing and widespread expectation 
of equality in society, coupled with the proliferation of new individual initiatives. The result is the same, whether we are discussing trends in religiosity where collective syncretism gives way to more individualized combinations; or the framework of interethnic relations and the break from the traditional social bond they represent; or emergent urban dynamics that transmit a principle of relational equality (at the moment die-cast as disorder and fear); or the CM \& CI that unite and divide social actors based on a shared imaginary; or emigration and the ways in which it expands horizons. Social and cultural differentiation, and the institution of equality as a horizon of inter-relational expectations, do not conspire against social cohesion, but rather create it on a different basis.

Naturally, this new social bond may seem weak and ephemeral when compared to the "solidity" of the traditional social bond to which we had grown accustomed in Latin American thought - a bond ensured by the naturalization of the hierarchy and ties of personal dependency. This relational universe stopped being the reality many years ago and a functional substitute emerged in its stead: a dual social bond, an amalgam of equality and hierarchy which, through the pendulum swing from one to the other, demarcated and regulated social relations amidst economic inequalities, cultural barriers, and ethnic differences. The social and economic democratization of the 1960s and 1970s, and the consolidation of the middle classes, was only the beginning of the transformation of everyday sociability.

The remaining vestiges of the hierarchical order have vanished into thin air in recent decades. Equality has insinuated itself all over in the realm of social and symbolic representations. Of course, actual social relations often do not match that ideal and individuals have experienced numerous frustrations in their relationships at various levels, whether in the workplace, in the city, or in family life. This produces a pervasive sense of interactive fragility, as if individuals no longer know what they can mutually expect from each other. But underlying this experience, and through it, lies what may be the most important democratic revolution on the continent. The kind that, as de Tocqueville admonishes us, is inscribed in the very nature of social relations. The "hierarchy" is clearly insufficient to regulate the resulting interchanges. What will be required - indeed is already required - are more contractual agreements and strengthened observance of rules and norms. Which is to say, new demands on political institutions and entities at a time when, as we will see, both exhibit tangible signs of social reorganization. 
A greater challenge is in the works: it will be necessary to reestablish authority based on a horizontal social bond. The evolution of authority from hierarchy to equality is only possible through an acceptance of criteria of civility premised on merit and respect for the norms. When traditional forms of authority are eroded, and a democratic authority is not established in its stead, the sense of mutual respect is lost and incivility permeates all relations.

It is impossible to predict the future. For the moment, however, a significant transformation of the mechanisms of social cohesion can be observed. Social cohesion is no longer premised on the "naturalness" of the traditional social bond and must put down new roots in a pluralistic form of sociability based on more horizontal and democratic principles. And based too on a reworking of the types of ties that Latin Americans have with norms and the law. At the present time, as we will see in the following chapters, this objective is still a long way off. 


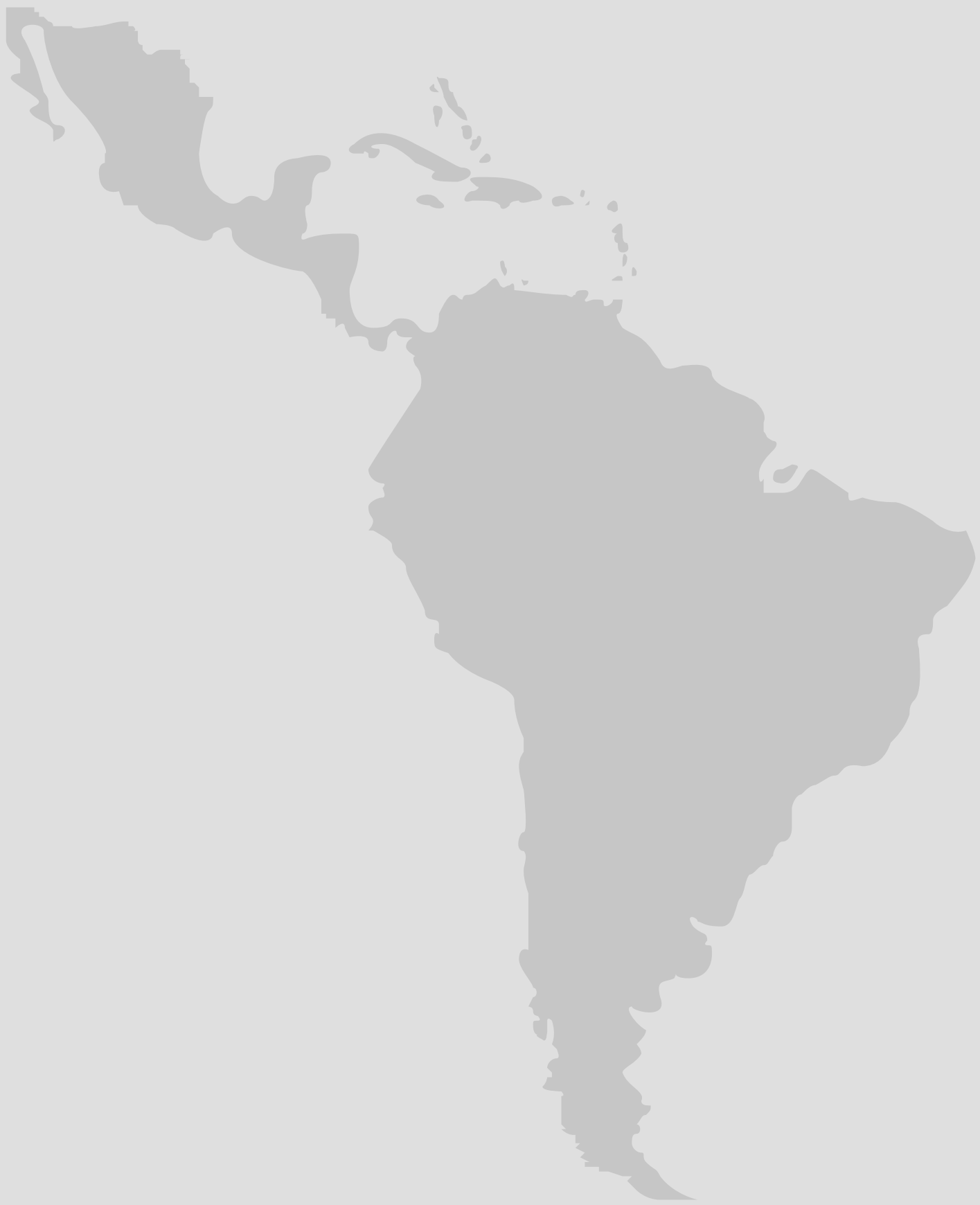




\section{Chapter II}

\section{Collective Actors and Forms of Representation}

\section{Introduction: noises in the formation of voice}

Citizen participation and State action are made possible by organizations and their infrastructure, and by material and symbolic resources including the government apparatus, the media, trade unions, political parties, social movements and NGOs, to name the main ones. Social cohesion cannot be dissociated from these institutional mediations through which individuals weave together - and are woven into - the myriad of interests that tie us to a given national citizenship. And while sentiments may be the same or at least similar, interests tend to diverge. For this reason, the way in which a society processes its social conflicts and organizes the representation of opposing interests through different institutions is at the core of its social cohesion.

If we are to fully understand the contemporary dynamics of constructing a sense of belonging, we must examine the various types of mediations that socialize, integrate, and confer meaning on - even through social conflicts - the sense of being a citizen of a country. In this chapter we will focus on forms of mediation directly linked to political and associative participation. In order to narrow our discussion, we have excluded a number of other dynamics that affect the sense of belonging in its various expressions. We will not discuss, for example, the two-pronged trend of the massification of universities and their waning influence, whether as a political actor or in 
their role in forming the power elite who hold key government positions (and have become internationalized by the growing tendency to study abroad and/or work in transnational companies and agencies).

Forms of citizen participation have changed drastically in recent decades. Trade unions, which were critical to $20^{\text {th }}$ century processes to integrate and dignify workers, are losing density. While they continue to play an important role in defending their corporativist interests, in most countries they have lost much of their former protagonism as political actors and as constructors of collective identities. Political parties are also in crisis and often are ad hoc structures that serve as vehicles for individual circumstantial ambitions.

New ways of organizing participation have shifted over to civil society embodied, as we shall see, by professional organizations of social activists (NGOs) devoted to advocacy or social interventions on diverse human rights and environmental issues. In the course of this process, a new type of social activist has emerged, representing a departure from previous forms of political militancy. Most importantly - and this is due to the growing influence of the CM \& CI in the representation of our societies - we are witnessing a profound transformation in the grand scheme of intersecting interests in the region. Public opinion has become a leading actor in social life; another indication of the individuation process underway.

Moreover, alongside organized civil society, more or less spontaneous explosions occur periodically (such as "pot-banging protests" and street demonstrations). Such episodes, which are usually associated with dissatisfaction with the government over a traumatic situation such as an economic crisis, corruption scandal, or crime, have triggered impeachment processes against several presidents as well as other measures to address the issue at the root of the particular complaint. Taken to an extreme, such demonstrations are an expression of dissatisfaction with the political system and the way in which representative institutions are operating. This state of affairs is starkly illustrated by the slogan "out with them all" ["que se vayan todos"] referring, of course, to the politicians.

The vacuum created by the crisis of the old forms of representation is filled with new types of participation and demands, which are not expressed in the form of national projects, or even collective ones for that matter. They emerge instead as the visions of actors whose identities are defined at the infra or supra national levels and who promote interests which, while legitimate, do not always strengthen the construction of a common space in society. 


\section{Trade unions ${ }^{23}$}

\section{Introduction}

Latin American trade union movements bore little resemblance to the somewhat stylized or idealized European model of an autonomous working class organized from the bottom up - although this did occur in many Latin American countries prior to the populists governments - whose demands for social rights pervaded much of society (Sorj 2005a). This is not to say, however, that they have not played a key role (mainly in urban areas) in the development of labor laws and in advocating for the dignity and defense of workers.

The inclusion of the working classes in the social dynamics and political regimes of the continent was mainly accomplished through the labor market regulation. The establishment of legal guarantees gave workers a voice in the public arena, ensured them a modicum of relief in situations of unemployment, and provided a social safety net for them and for their children, among other things. The regulation of the labor market was the vehicle for inclusion under the import-substitution industrialization model and workers harbored real hopes of being included in the regulatory universe.

It is true that the formal labor market never included them all. The informal sector is ubiquitous in Latin America, its ranks swelled by the many workers who lost their jobs. But the expectation of inclusion always played an "inclusive" role in the region. And that expectation was occasionally met because of traditionally high levels of job turnover, which meant that workers might enjoy periods of formal employment. For this reason, the formal labor market and its regulations became one of the most important, if not the most important, cohesive institutions on the continent.

At the same time, trade union victories, especially those achieved in the public service and state-owned enterprise sectors, contributed to social segmentation and created a situation that could only be sustained by preserving an increasingly obsolete industrial structure. As the ranks of informal sector workers and the unemployed swelled, it became clear that formal sector workers did not constitute the poorest social strata of

23 This section is based on Adalberto Cardoso y Julián Gindin, "Relações de Trabalho, Sindicalismo e Coesão Social na América Latina". 
society and that ultimately, public policy would have to shift its priorities toward those groups. The gradual policy shift towards the poorest sectors of the population, coupled with privatization initiatives, meant that public resources could no longer be allocated, at least not in the same proportions, to support trade union demands. The unions were therefore obliged to revisit their modus operandi. This was the backdrop for the emergence of technocracy whose discourse and social policy targeted the poorest sectors of the population, far from the realities and demands of the labor market.

The labor crisis of recent years, brought about by structural adjustment programs - which in their efforts to extract the State from the economy wreaked havoc on traditional centers for the construction of social, collective identities - ultimately broke the promise of inclusion represented by the formal capitalist economy and formal labor market. Fearful of losing their formal employment and benefits, workers acquiesced to labor relations with fewer rights than before. This slowed the momentum for collective action and with it, the power to safeguard the rights won prior to the reforms. Unemployed, landless, homeless and without rights, poor workers burst onto the scene, demanding some sort of social inclusion from the sidelines of traditional means for the representation of interests.

Latin American trade unions traditionally pursued two overlapping avenues to build their legitimacy and social profile. The first was through their ties to the political system, whether in the form of associations with political parties or through their direct subordination to the State in corporative agreements. The second was direct action in the labor market, which sometimes complemented - and on other occasions supplanted - political action as a factor in the construction of collective identities. Attempts to bargain collectively in labor markets plagued by high levels of unemployment and informal employment (brought about by the profound transformations to productive structure that reduced the momentum to strike along with membership levels) led to fragmentation, a weakening of the topics under negotiation, and collective bargaining agreements with less coverage.

\section{Structural reforms and the decline of trade unions}

Over the past 20 to 30 years, workplace relations systems (WRS) in Latin America have been altered dramatically by transformations in productive and technological structures and work relations management, as well as globalization processes. These transformations, linked to the adoption of 
a set of reforms commonly referred to as the "Washington consensus," dismantled the import-substitution industrialization model and with it, the physical underpinnings of the social order consolidated throughout the $20^{\text {th }}$ century. To varying degrees depending on the country, these economic changes impacted labor laws, the trade union structure, collective action, capital-labor negotiation models and the State's role in those relations. In short, they had a profound influence on the model of class relations and social cohesion that had operated on the continent for the past century.

In recent years, then, with the partial depletion of the model introduced on the continent in the 1950s, the workplace's role in the construction of cohesion has taken various forms and posed new challenges for trade unionism. The latter has never recovered its protagonism under the previous model and, to date, has been unable to reinvent itself in keeping with the changing times.

Most Latin American countries consolidated their workplace relations systems in tandem with the economic development process based on state controlled import-substitution industrialization. Perón, Vargas, post-Cárdenas Mexican leaders, post-Ibáñez Chileans, and Venezuelan leaders after 1958, strengthened and/or regulated workers even as they expanded government bureaucracies, subsidized industry, created stateowned companies in strategic sectors, established controls over foreign investment, closed domestic markets to foreign competition, and so on. State bureaucracies - which were often closed to political competition due to intermittent experiences with authoritarian regimes - were central agents in these scenarios.

"Developmentalism" as the raison détat meant exactly that: economic growth with social peace. And social peace was only possible through varying degrees of authoritarian control, which was more or less inclusive of the demands of organized labor depending on the country. In these terms, the inclusion of labor - in a more or less subordinated position depending on the case - was at the heart of nation-building projects across the continent from the 1920s on. And this pact proved durable. It persisted virtually unchanged for decades in most countries, and for 70 years in the case of Mexico.

Despite being introduced, in most cases, in an authoritarian manner, with time labor laws began to shape the expectations and practices of capital-labor relations in increasingly intense and profound ways over the course of the $20^{\text {th }}$ century. The law traced the battlefield and the horizon for the actions of organized labor in Brazil, Mexico, and Chile (up to the 
Allende administration when the legal boundaries were swept away), as well as Argentina and Venezuela. The trade union struggle was oriented toward enforcing existing law more than anything else. In this sense, worker identities in countries such as Mexico and Brazil, for instance, were constructed through the mediating influence of labor rights and within the bounds of their own horizons (French, 2004; De La Graza, 1990). In this way, labor rights largely define workers in our societies.

The economic restructuring that commenced in the 1970s in Chile and spread from there to other Latin American countries changed the face of labor relations and social cohesion on the continent. Restructuring programs varied from country to country in terms of the timing and objectives, and the depth and internal coherence of the measures taken. Even so, and taking into account the inevitable risk of oversimplification, one could argue that it represented a continent-wide plan for the relative depolitization of the economy. In other words, it essentially reduced, if not eliminated, the role of the state as organizer of economic dynamics, planner, financier of productive investment - and frequently an entrepreneur too, through state-owned enterprises - , and mediator of capital-labor relations.

Behind the scenes of this depolitization process, the mechanisms for public intervention and economic regulation were genuinely transformed. To disregard this aspect leads to an "economicist" reading of the changes in recent decades in Latin America. The important role of the Washington consensus in this process has oft been pointed out. We must not, however, disregard the extent to which changing capital-labor relations was essentially the result of the inversion of power relations among social actors in the context of a broader international reorganization of the capitalist economy, which included the emergence of new actors such as China and their impact on the competitiveness of the continent's industries. This is a complex process, one that has involved, at different points in time, international financial institutions, changes in the productive base, and entrepreneurs and political leaders at the national level who perceived in these changing alliances greater opportunities for personal initiatives, something which has been particularly visible in the neo-populist governments of the 1990s (Martuccelli, Svampa, 1997 and 2007).

The liberalization of labor markets, products, services and capitals, together with reforms to the State apparatus and the divestiture of much of the government's productive machinery were the pillars of the reforms 
that swept the continent. ${ }^{24}$ At the same time, in countries where the reforms occurred in the context of hyperinflation, trade union struggles were focused on a race against the decline of the purchasing power of workers' wages. Reining in inflation meant actual income for the poorest sectors of the population and this accounts in part for their passive, if not active, support for the economic policies of the period.

In Venezuela, Chileand Argentina restructuringmeant deindustrialization - the "competitive shock" that internationalized capital ownership and reduced industry's role in the GDP and in job creation. This deepened industrialunemployment, informaleconomicactivityand theprecariousness of ties to the labor market, all of which had a significant impact on the strength of organized labor. In Mexico and Bolivia the manufacturing structure was either modified or transferred to other areas of the country boosting employment in this particular sector (even as a percentage of overall employment). ${ }^{25}$ At the same time, however, unemployment rose and the informal sector absorbed much of the labor force in many important regions, as was the case, for example, in the Metropolitan Region of the Federal Mexican Capital. ${ }^{26}$ Poverty also rose in southern Mexico and in many of its major cities. At the same time, productivity increased and, in contrast to the economies of Brazil and Argentina, Mexico's economy became heavily dependent on exports, mainly to the United States. ${ }^{27}$

24 There is an abundance of literature on the content of the Washington Consensus, which in large part guided the reforms, particularly in the 1990s. See, for example, Dupas (2001) and Stiglitz (2002).

25 In Bolivia, the population working in the manufacturing industry more than doubled from 1989 to 1997 , but nearly $3 / 4$ were concentrated in small family businesses, and semi-enterprises with low productivity levels, primarily in clothing (Montero, 2005; Kruse y Pabon, 2005). Employment in the mining industry, which constituted the heart of the labor movement, declined from 86,000 jobs in 1980 to 69,999 in 1985 . This decline has since continued, but the most significant change has been in the composition of the sector, with the growth in cooperativism and the emptying out of state-owned mines (Montero, 2003). And while trade union activity is difficult in the Bolivian mining sector, the situation is even more critical in the new modern manufacturing industries, where it is tacitly understood that organizing is prohibited (Kruse y Pabon, 2005).

26 Informal sector workers nationally accounted for $75.2 \%$ of the population in Bolivia, (2002), 54.2\% in Brazil (2004), $51.1 \%$ in Venezuela (2004), 37.0\% in Chile (2003), 69.0\% in Guatemala (2004), 50.1\% in Mexico (2004) and $42.5 \%$ of the urban population in Argentina (2003) (Gasparini et al. 2007).

27 The depth and scope of the restructuring process were remarkable. The very structure of capital distribution was altered dramatically and in the same direction: basic urban services, industry, and retail and wholesale operations changed hands, and domestic capital became 
The structural reforms had an extremely destabilizing effect and financial crises swept the region (Mexico in 1994, Asia and Russia in 1997, and Argentina, Uruguay and Ecuador fell one after the other in the wake of the 1999 Brazilian crisis). While we are unable to discuss this fragility in depth here, suffice it to say that the effects of pro-market policies were neither even nor linear. Argentina experienced economic growth almost until the end of the 1990s, but paid a price in terms of greater income concentration and inequality. Unemployment rose in Mexico until the mid 1990s, only to drop consistently after that. In Brazil, poverty levels declined abruptly following the 1994 introduction of the monetary stabilization plan, plateaued in 1998, and then declined once again. In Chile, the costs of the initial restructuring (in the 1970s) were enormous and led to a substantial rise in poverty - which peaked at $40 \%$ of the population in the mid 1970s - situating the country among those with the highest levels of social inequality in the world. While the recovery of the late 1980s reduced poverty to 1960s levels, this same was not true of inequality and unemployment. ${ }^{28}$

Many analysts concur that, although economically efficient in terms of monetary stabilization, and despite improved living conditions associated with curbs on inflation, the restructuring model adopted in Latin America also damaged the social fabric. We must not forget that in most countries, hyperinflation had deepened social inequality and caused substantial losses in the wage worker and retiree sectors. Legitimacy and governability were undermined in favor of speculative sectors. Structural reforms helped control inflation, which boosted the purchasing power of wage-earning sectors. Because of this, organized labor did not universally oppose the measures and its reaction to them varied in form and intensity. This was especially true since, while the thrust of the restructuring process was generally the same, it played out in different contexts in each country.

Indeed, the structural reforms occurred in very diverse settings from the standpoint of the strength of organized labor. In Argentina, Venezuela and Mexico, the traditionally hegemonic labor movement - a key source of support for the political regime and ally of the governing party - lent

international capital in a very short period of time. In Brazil, for example, the composition of capital in the automobile spare parts industry shifted from 52\% national capital in 1994 to 78.4\% foreign capital in 2002 (and 80\% in 2006). See http://www.sindipecas.org.br.

28 Although industrial employment in Chile recovered slightly in the 1990s (from 14\% in 1982 to $16 \%$ in 1996) this was not enough to restore 1970 levels, when $24 \%$ of this population was employed in industry. See Campero (2000). 
institutional support and legitimacy to adjustment programs. As a result, it lost support from among its bases and its social power and capacity for collective action waned. Chile's labor movement was simply silenced as a political actor. Meanwhile, labor opposition in Brazil gradually petered out due to the effects of market liberalization policies and the privatization of government enterprises, which had undermined one of the pillars of the traditional labor movement. Something similar occurred in Bolivia, but in an atmosphere of acute social crisis during which the labor movement lost legitimacy, opening the door to more rigid antilabor policies. One of the main consequences of the reforms in every country was that organized labor lost the power it had consolidated in the preceding period.

Put another way: the structural reforms adopted as a solution to the crisis of the previous development model involved reducing any "impediments" to the free play of market forces, including the labor market. From this standpoint, established systems of labor relations were treated as simply another obstacle to be removed. This included organized labor as an agent capable of influencing the policies that directly affected its support base.

Governments attempted to either attract this agent or exclude it from the playing field. In the three instances of labor support for the reforms, the labor movement had undergone either a profound (Venezuela and Mexico) or significant (Argentina) deterioration in terms of its social presence. As a coparticipant in the power pacts in the three countries, it received its share of the blame for the crisis. In this sense, support for the adjustment measures must also be viewed as a reaffirmation of the labor movement's role as coparticipant, and therefore a reaffirmation of traditional power alignments and of the hegemony of the most relevant past trends in the organized labor market. In the new context, the trade unions fell victim to their own former alliances.

Nonetheless, the losses in the labor market (due to privatizations and flexibilizations) were offset by the ability of the workers federations (Confederación General de Trabajo - CGT of Argentina, the Confederación de Trabjadores de Venezuela - CTV, and the Mexican Congreso de Trabajadores - CT) to maintain their control over the trade union structure. Organized labor was weakened - it lost members, resources and capacity for action - yet there were no significant changes to its internal power structures or its relation to the State. In Brazil, Bolivia and Chile trade unions were generally excluded from the political playing field, although for different reasons. In Bolivia, the veto power of a radicalized labor movement blocked the adoption of measures to surmount the crisis. In 
cases where the miners could not be defeated, some mines were shut down in revenge. The trade union movement was also strong in Brazil and in a sense had exercised veto power over previous stabilization policies (Salum Jr, 1996). The Fernando Henrique Cardoso administration, therefore, faced off with the trade unionists, in particular affiliates of the Central Unica de los Trabajadores (CUT) with ties to the Partido de los Trabajadores, while simultaneously seeking support for its measures from another trade union sector (Força Sindical). But none of this reached the extremes observed in Argentina or Mexico, where the hegemonic central was essential to any political agreement. And in Chile under Pinochet, exclusion was simply absolute.

\section{The situation today}

Now that the most acute phase of the structural reforms is over, the region is seeking new paradigms, or at least "adjustments" to the model. This is even true of Chile, where an advisory council to the Presidency on "Work and Equity" was formed in August 2007. ${ }^{29}$ There is even talk of a new era in Kirchner's Argentina, meaning a total shift in the prevailing development model and accumulation system towards a neo-Keynesianism in economic policy and a new appreciation of trade unions as critical agents of social cohesion. ${ }^{30}$ Some analysts even allude to the emergence of a "segmented neocorporatism" in class relations (Etchemendy and Collier, 2007), and the resurgence of the tripartisanism typical of the Peronist period, this time, however, confined to specific sectors of the formal labor market.

Venezuela and Bolivia give the most radical indications of a return to statism. This is being accomplished through the extensive nationalization of privatized (or never privatized) companies and the reinstatement of workers' protections or the establishment of new guarantees, with the support, or cooptation, of trade unions and rural cooperatives in Bolivia, or of unorganized rural and urban populations in Venezuela. Brazil, Chile and Mexico are examples of the more general rationale of the reform program (in sum, preserving macroeconomic stability through checks on inflation and public accounts). This course, however, involves the cooptation of trade union leaders in the State apparatus and concessions to trade unions. While 
it may have been possible to construct a Latin American labor relations model in the previous phase, the current situation is one of enormous structural diversity among countries.

In other words, in this post-reform period on the continent, one cannot speak unequivocally of trade union - state relations, or of a trade union position vis-à-vis economic and labor policy. While trade unionism in general was weakened during the reform period, subsequent shifts in economic policy (where they occurred) do not appear to have reinvigorated the labor movement, the two important exceptions to this being Argentina and Bolivia.

The Mexican and, paradoxically, the Argentine experiences reflected continuity. In the latter case, profound changes to the development model did not extend to the relational model between Peronist trade unions and the state apparatus. Despite its pronounced institutional fragility, trade unionism has recovered some of its former protagonism on the Argentine political scene. In contrast, substantial changes have occurred in Bolivia, where for the first time since the revolutionary events of the 1950s, the labor movement is participating in the formation of a grassroots style government. This has breathed new life into the Central Obrera Boliviana - COB given up for dead at the start of the millennium - although not enough to convert it into a key agent of the new government. Social movements rather than trade unions, comprise the social base of the Movimiento al Socialismo - MAS. In Brazil, labor leaders became co-participants in public administration, even as adverse national circumstances have kept the trade unions themselves from gaining strength. The pre-reform legitimacy enjoyed by trade unions appears to be far from the horizon.

The situation has changed considerably in Venezuela, but in the other direction. The Chávez government has excluded the traditional trade union movement and encouraged a new, pro-government sort of trade union activity. Meanwhile, the redemocratization of Chile has finally created space for trade union activity, although its evident fragility has kept it from playing a relevant role on the new political scene (which, by the way, has preserved the macroeconomic model of the previous administration).

The trade union structure in many countries on the continent is still encumbered by the historical administrative and/or political control exercised by State officials and political parties. Despite the democratization processes that have taken place in several of these countries in the 1970s and 1980s, and more recently in Mexico, trade unions must still contend with the legacy of more or less heteronomous relations with the state, whose 
influence affects everything from internal organization to fundraising, and from legitimacy to the potential for collective action. Across the continent, moreover, the burgeoning informal sector has become a barrier to trade unionism, despite the efforts of trade union centrals (in Bolivia and Argentina for example) to extend their membership base beyond formal salaried workers. ${ }^{31}$ Peasants affiliated with the COB in Bolivia, or unemployed members of the CTA in Argentina (the most successful examples) have become important organizations in their own right - autonomous from the trade union centrals. Internally, however, there have been power struggles with formal salaried employees and they do not always manage to develop a common agenda for mobilization.

During the reform period, each of these countries exhibited a general trend toward the fragmentation of the trade union structure, whether at the level of leadership, the grassroots, or in some cases, from top to bottom. What is most significant, however, is that the "changing times" did not necessarily help to reverse this fragmentation process. In Chile, the grassroots were pulverized, while in Venezuela, the trade union leadership and locals have proliferated. In Mexico, fractures have been observed mainly at the level of trade union centrals, similar to what has been occurring more recently in Brazil, although in the latter case, the labor movement had been fragmented from the start.

Bolivia is an example of the potential reversal of the general trend toward fragmentation, as the $\mathrm{COB}$ regains ground in the trade union movement. It is nonetheless obliged to coexist with a myriad of other social movements now competing for the loyalty of the workers, particularly in the informal sector. For its part, Argentina has undergone a national reconstruction process encompassing traditional institutions such as the CGT and the Partido Justicialista. The CGT, however, shares the space for labor disputes with the CTA and new social movements, although it is currently spearheading a movement towards the partial reconcentration of collective

31 The Central Obrera Boliviana (COB), made up of federations and confederations, is known for accepting affiliates from grassroots organizations, student groups and academic sectors as well as salaried workers. One of its main organizational affiliates today is a peasant confederation: the Confederación Sindical Única de Trabajadores Campesinos de Bolivia (CSUTCB). This opening up to peasant groups dates back to the 1970s (Zapata, 1993). Even so, the statutes ensure that a miner will lead the Central. The Central de Trabajadores Argentinos (CTA) has promoted the individual affiliation of workers and encouraged the formation of a powerful nontrade union organization: the Federación de Tierra y Vivienda [Land and Housing Federation] which represents the unemployed. 
bargaining. As with other areas, however, it is still premature to evaluate the longevity of current trends.

Beyond the structure of organized labor, economic changes had a considerable impact on the power of the trade unions, measured in terms of affiliates and the capacity to carry out actions such as strikes and collective bargaining. The decline in membership is probably the most telling indicator of this trend, although data of this nature are not always reliable or totally comparable. Having said this, in all of the countries under study the overall trend is too strong to ignore. In Argentina, the percentage of affiliates dropped from $60 \%$ of the Economically Active Population (EAP) in 1975, on the eve of the military coup, to $36 \%$ in 1995 and $24 \%$ in 2002 - an overall decline of more than $60 \%$. A country with historically low affiliation rates, Mexico showed a similarly significant decline from 14\% of the EAP in 1992 to $10 \%$ in 2002. Affiliation levels remained relatively constant in Brazil, but at a very low level, fluctuating between $18 \%$ and slightly under $20 \%$ of the EAP from 1988 to $2005 .{ }^{32}$ In Chile, affiliation rates rose steadily to reach $21 \%$ in 1991. This was followed by a gradual drop, which leveled off at $15 \%$ of the so called "dependent population" ${ }^{33}$ until 2005 (14\% in the metropolitan region of Santiago). Significantly, under the Allende administration, trade union affiliation in Chile had peaked at 32\% of the EAP (Roberts, 2007: 24).

Venezuela and Bolivia appear to have experienced the heaviest losses in the shortest time frame. In the former case, the affiliation rate among the employed population dropped from $40 \%$ at the beginning of the 1980 s to $28 \%$ in 1999 (Gasparini et al, 2007: table 6.a), with estimates placing it at approximately $15 \%$ in $2004 .^{34}$ In Bolivia, the affiliation rate dropped from a high of $25 \%$ in the early 1980 s to under $9 \%$ at the end of the 1990 s (Roberts, ibid.). ${ }^{35}$

32 The data for these three countries are drawn from Cardoso (2004: 22). The 2005 figures for Brazil are calculated directly from the national household survey: Pesquisa Nacional por Amostra de Domicilios (PNAD).

33 This includes salaried employees and workers in the service industry, excluding public administration. See Dirección del Trabajo (2006: 9). Note that the EAP is the reference population for the three cases mentioned. In Chile it refers to the employed population, excluding public servants.

34 Information available at http://www.venezuelanalysis.com/articles.php?artno=1151

35 There are discrepancies in the data for Bolivia. Montero, for example (2003) reports a drop from $25.6 \%$ in 1989 to $19.7 \%$ in 2000 , with a decline from $17 \%$ to $10 \%$ in the unskilled workers segment. According to Gasparini et. al. (2007) affiliation declined from $30.9 \%$ in the mid1990 s to $22.5 \%$ in 1999 . While the figures differ, however, they all point to a significant decline in trade union density in the country. 
The four countries for which reliable statistics on strikes were available (Argentina, Brazil, Chile and México) reflect a similar downward trend in strike activity during the adjustment period. Now that the storm is over, however, the inclination to strike has not recovered its previous levels. A possible exception to this might be Argentina under Kirchner, although not enough time has transpired to speak of a new strike-oriented cycle in the country. The same has been true of collective bargaining. In general, declining membership and capacity for collective action has hampered the ability of trade unions to run interference, through collective bargaining, on the two labor flexibilization measures typical of productive restructuring processes in the context of economic adjustment: internal or functional flexibility and external flexibility.

In Brazil, Argentina and Mexico the trade unions either failed to negotiate job continuity issues or were ineffective in their efforts to do so. In many cases, the bargaining process itself served as a means to reduce workers' rights and narrow the scope of regulations governing job conditions issued under the law or through collective agreements. Argentina appears to be the exception in this regard, with the introduction of new subjects into the bargaining guidelines under the Menem administration. Here too, however, negotiations over job security were nonexistent.

With the most acute reform period over, Argentina and Brazil are showing a relative reversal in the trend toward deteriorating wage and job conditions. There has been a turnaround in the previous downward curve in employment and real wages, while poverty and social inequality have declined. In Chile, although the job situation was already in recovery mode by the end of the Pinochet government, this trend has continued and deepened under the "concertation" governments, particularly in the past few years, with a rise in real wages and decreases in inequality. In Mexico, in contrast, real wages have continued to decline or are stuck at levels 33\% lower than the figures preceding the 1994 crisis (Salas y de la Garza, 2006), although unemployment rates remain quite low. The panorama is more complex in Venezuela where poverty and unemployment rose early on in the Chávez administration, followed by a reversal of these trends more recently.

The transformation of the productive system and economic reforms of the 1980s and 1990s heightened insecurity in the job market. According to Latinobarómetro 2006, even with the turnaround in the economic growth forecast (with 2007 being the fifth consecutive year of positive figures), 67\% of all Latin Americans reported that they feared losing their jobs sometime 
in the next twelve months. This figure 70\% in Bolivia and 68\% in Brazil. According to the International Labor Organization's Global Employment Trends 2006, self-employment, unremunerated jobs, or domestic work accounted for $40 \%$ of existing employment. These workers are not covered by social protection benefits under labor laws or collective bargaining agreements.

\section{Perspectives}

Whether they chose a path of subordination to governments with respect to structural reforms, or opted for confrontation (and ultimately defeat), Latin American trade unions reflected the political limits inherent to their traditional association with a certain economic development model. When the crisis of this model demanded a profound shift in direction, the unions revealed themselves to be essentially conservative structures, incapable of adapting to the new realities of increasingly globalized economies and demands for fiscal stability. They were therefore hampered in their ability to participate in the quest for new directions in their societies. Faced with increasingly vociferous criticism of the inefficiency and political manipulation of state-owned enterprises, and the often inappropriate protection of obsolete industrial companies and sectors, the labor movement was unable to propose new alternatives. Some of this conservatism (a typical feature of trade unions in most countries) is tied to the inability of the leftist parties with which they frequently were associated to adjust their programs in response to the changing times.

The combination of these divergent trends - persistent or mutating institutional pacts and economic transformation, albeit in different directions in different countries - do not lend themselves easily to generalizations. It would seem that the enormous challenge for social policy to promote social cohesion on the continent is to recognize that people whose lives depend on their capacity to work are entitled to the rights associated with that capacity, rather than unjust or violent exploitation or deprivation. The main issue is how to reorganize the regulation of the workplace in a context in which job and company stability is increasingly scarce and fluidity is a sign of the times.

Different approaches and strategies have been gradually taking shape since the reform program rendered the main elements of the old model of government-trade union relations obsolete. Particularly called into question is the tradition in which improved economic and employment conditions 
are contingent exclusively on State arbitration. A union's capacity to exert political pressure no longer seems to be the only tool of organized labor, all the more so since its present role in economic policy-making is particularly modest (mainly due to the new social alliances forged in the 1990s).

Ironically, this transformation opens up virtual space for the autonomy of organized labor and for a redefinition of trade unions as social actors with a relevant role in the internal life of companies, in the negotiation of working conditions, and in job preservation. It is a role, however, that requires trade unions to distinguish the reality of professional relations from political strategies - and ultimately from the viability of a model that consisted of leaving the former to management for all practical purposes and focusing labor struggles solely in the area political pressure. In many cases, trade unions have begun to operate in other arenas, in particular the professional recycling of the unemployed, and this has enabled many former workers to reestablish themselves as microentrepreneurs or work in some capacity in the informal sector. Because of this situation, which has been further complicated by the informal sector, purely economic, or purely political strategies are no longer productive. This poses a challenge which, at least at the moment, the trade unions have not dealt with successfully.

Even as we acknowledge that trade unions in Latin America frequently were either distanced from the poorest sectors or politically co-opted (and sometimes even corrupted by that cooptation), we should not underestimate their historic relevance or the need for a collective defense of workers. Obviously the challenge is how to update these mechanisms in the context of globalization, technological changes, and individuation. It has become increasingly vital to leave behind the vision that confines social policy to the poorest sectors and idealizes a market devoid of adequate labor laws. A new social model for the region must be developed through a dialogue involving the public technocracies responsible for social policy (which tend to focus on the neediest sectors made up mainly of non-wage earners who are less sensitive to labor market conditions), economic policy-makers (whose main goal is often to preserve macroeconomic equilibriums, efficiency and competitiveness), and workers and trade unions. 


\section{Political parties ${ }^{36}$}

We begin with the obvious and that is the widespread dissatisfaction with political parties in Latin America. Public opinion surveys situate political parties squarely among the institutions that inspire the least trust in the population. Pervasive political disaffection with traditional parties leads people to become increasingly receptive to "antiparty" appeals. This has weakened, if not totally transformed, the party-dominated landscape that described the political scene in the latter half of the $20^{\text {th }}$ century. In this context, our analysis could focus on changes at the ideological level (nationally and internationally) and in society that have eroded the constituencies of the traditional parties or on the institutional reforms that influenced the functioning of the political party system and could potentially rechannel its actions in the near future.

\section{From the crisis of representation to institutional reformism}

Institutional reformism, which along with economic structural reforms was high on the Latin American public agenda, was geared toward rebuilding the representational connection and restoring the ties between civil society and political parties. The catchphrase was simple and persuasive: bring the representative closer to the represented. A whole battery of measures was proffered with this goal in mind, foremost among them political decentralization, expansion of the electoral supply, and the democratization of the parties.

A general evaluation of the reforms implemented yields a decidedly ambiguous balance. While it is true that, as in Bolivia and Ecuador, heretofore unrepresented sectors found a voice - and this is certainly positive - the most pronounced cracks in the social structure were refracted towards the political parties, weakening their capacity for political coordination and governance. Even a cursory examination reveals that the reforms opened the doors to elected authoritarianism, gave expression to deep societal fissures, and further destabilized governments, which were hard-pressed to remain upright amidst the social and political tremors that followed the institutional reforms.

36 This section is based on Ana María Mustapic, "Del malestar con los partidos a la renovación de los partidos"; Luis Alberto Quevedo, "Identidades, jóvenes y sociabilidad: una vuelta sobre el lazo social en democracia." 
Let us look briefly at the principal reform initiatives, which took on different hues in each country:

a) Political decentralization focused on establishing new representational spaces at the local level. The attendant redistribution of political power impacted political parties in several ways. It contributed to the collapse of the traditional party system and the emergence of outsiders in Venezuela and Peru, to political and territorial polarization in Bolivia, and to the fragmentation of the party system in Colombia y Ecuador.

In the Peruvian case, for instance, against a backdrop of profound economic crisis, President Alan García launched a regionalization process in 1988 that required the election of subnational authorities. In doing so, he sought to decompress the difficulties besetting his administration and hold onto spaces of power for his party, the Partido Aprista Peruano, which was unlikely to prevail again in the next presidential elections. The initial decentralization process - termed chaotic by some analysts - was also short-lived: Alberto Fujimori's April 1992 self-coup dissolved the regional governments and replaced them with provisional regional administration councils under central government jurisdiction. The Toledo administration later reactivated the decentralization process in what some observers qualified as an improvised and precipitous manner. As a result, political forces were left fragmented and the ties between local and national organizations were extremely tenuous.

b) The expansion of the electoral supply was accomplished through more lenient laws on the establishment of political parties and nominations. Colombia and Argentina showcased this measure. The resulting proliferation of parties and slates brought with it two negative consequences: first, elections fraught with confusion and opacity, which undermined citizens' right to cast an informed vote, and second, party leaders who were increasingly focused on internal nomination processes and competition.

Decentralization measures were initially introduced in Colombia in 1988 under the conservative government and one of their earliest manifestations was the election of mayors. The 1991 constitutional reform deepened the process by adding elected governors, the nomination of independent candidates, and Senate elections based 
on a single national district. At the same time, traditional political parties were becoming atomized by more lenient regulations that allowed and encouraged individual political parties to present several slates for a single post. The proliferation of slates, coupled with the personalization of political rivalry, left the party system fragmented and anarchical. Another political reform was instituted in 2003 to bring some order to this complicated scenario by discouraging the trend toward fragmentation.

c) The opening of primary elections to nonparty members was intended to democratize the internal life of parties and weaken their oligarchical machinery. Where this measure was implemented - and the Partido Revolucionario Institucional (PRI) in Mexico offers a good illustration -, it had a paradoxical effect: increased participation did not lead to the nomination of more popular or competitive candidates in general elections. This was hardly surprising since primaries usually give voice to those with the strongest preferences - the militants - who, when it comes time to vote, tend to place more weight on their traditional ideological leanings than on the expectations of public opinion.

\section{Perspectives on the dissatisfaction with political parties}

The democratization of the party - citizen link has turned out to be far from the panacea promised by the institutional reforms. The formulas used to envision representation in party - citizen terms have not lived up to expectations. There are two explanations for this from a schematic perspective. The first has to do with the unevenness of the reforms: what was achieved in one area was lost in another. The second is more general and relates to contemporary sociological realities that conspire against the expressive function of political parties: increasingly fragmented social sectors, new interests and preferences, the media's agenda-setting role, and an ever more alert and informed public opinion.

In a panorama such as this, we believe that the conventional approach to representation should shift from its exclusive focus on the party - citizen link to examine of party - government relations. The justification for this new perspective lies in the convergence of three elements. The first is drawn from a principle of democratic theory: since the counterpoint to the mandate to govern is the obligation of governors to be accountable, it follows that the 
exercise of power is part of the representative link. The second is derived from political sociology: at this stage of their historical trajectory, political parties have shed many of the characteristics usually associated with the ideal model (representation, mobilization, the development of platforms and a vision for the future, and the ability to articulate the interests of broad social groups), while retaining one that is critical to democratic life: the power to choose who will exercise political power on behalf of citizens and to establish a government. The final element to buttress this proposal comes from empirical observation: a close look at public dissatisfaction reveals that it is nourished, more than anything else, by complaints about the performance of the authorities.

We should begin our examination of the party - government relationship by pointing out a distinction. While the party - citizen relationship must be evaluated in terms of how eloquently parties articulate interests and preferences, party - government relations must be examined in terms of the level of cohesion in party interactions with elected officials. The level of cohesion has ramifications for representation inasmuch as it strengthens government performance. In effect, where cohesion is strong, the party acts as a shield to protect the government from the maneuverings of the opposition. It also helps to close the information gap by acting as a conduit for public policy. Moreover, it raises the political bar for government action and reinforces the latter's credibility by conveying its support for official decisions. These sorts of contributions show that parties not only count when it comes to getting votes, but are inherently key instruments for the consolidation of government capacity. Their status as key instruments depends on the level of cohesion and traces potential courses to follow in strengthening party - government relations.

One such course is situated in the electoral sphere: the ideal number of parties matters. An excessive number of parties is negative for various reasons. First, it does not help simplify the options available so that the voter can make an informed, useful decision. Second, it does not facilitate the role of filtering demands, and finally, it dilutes accountability for government actions by making it harder to identify and weigh the influence of those involved in the decision-making process. At the same time, the minimum number of parties - two - poses the risk of excluding some sectors from representation and can foster occlusive practices intended to keep out new competitors. In terms of electoral systems, the quest for greater cohesion in party - government relations places more emphasis on the collective - party component over the individual one. 
Another course has to do with the way in which parties are organized. Some have adopted a model that distances the party from governance issues. This is based on the principle establishing the incompatibility of holding elected office while simultaneously exercising a leadership role in the party. In this way, for example, the government leader - or an opposition leader in the parliament as the case may be - may not play a leadership role in the party. Such a practice or rule introduces a factor of tension and competition between the two leaderships and the first one to suffer the consequences ends up being the government leader and his or her ability to govern. In the long term, however, the damage extends beyond the government to the party as well.

These two courses of action have to do with institutional conditions which, in principle, favor cohesion in party - government relations. In order for this virtual objective to become real, a third element must be introduced into the equation. It involves the type of interactions between government policy-makers and sectors with varying degrees of proximity to the party ranging from legislators to affiliates and sympathizers. What is important here is the creation of informal opportunities for participation through which different groups can engage the policy debate.

The combination of these three factors helps shape party - government relations and encourages cohesion, paving the way for public policymaking with more resources. There is a corollary to this picture: improved government administration by political parties can bolster voter support. To state this in terms of the distinction we have been using, the effects of cohesion in party - government relations can narrow existing gaps in party - citizen relations.

The approach proposed here is not without limitations. It has the merit, however, of recognizing that, in the framework of contemporary sociological realities, gaps in representation are hard to bridge; a rapprochement between political parties and citizens is an ever-elusive goal, as the outcomes of institutional reforms have shown. Party - government relations are, in this sense, a potential strategic locus in the quest to support and relegitimize party organizations and as such, may constitute a promising alternative to address the prevailing dissatisfaction with representation.

\section{Beyond political parties?}

However important this course of institutional reconstruction - the future of which is uncertain at present - may be, however, we must stress another 
major reason for the crisis of political parties today. Since, as so many analysts have pointed out, we are living in a time when legitimacy - an essential ingredient for policy-making and the basis for state intervention in democratic societies - is scarce, perhaps the overriding concern of the ruling classes in our countries revolves around renewing their pacts of meaning with citizens, rather than creating an institutional framework associated with the classical ideal model (political party system, institutional mediations, strengthened parliamentary structures, and so forth). All of this in the framework of societies that have witnessed a mutation of the classic political panoramas of modernity towards other types of interlocutors (video politics, new leadership, social movement activity, etc.).

In the area of political representation, however, many analyses prefer to cling to some sort of "institutional reconstruction" as if it were a perpetually latent civic demand. Following this train of thought, we would find ourselves before a definite shortage of the democratic institutions typical of the $20^{\text {th }}$ century, in the context of $21^{\text {st }}$ century capitalism and cultural and symbolic practices. Yet although citizens may experience a certain amount of discomfort at the absence of points of reference that restore a sense of security, it is difficult to imagine that most of our societies harbor any nostalgia for the institutional past. What is more, many Latin American countries have never had solid, long-lasting institutions or political party systems. Citizens seem more inclined to adapt to the cultural and political codes of neocapitalism even though they miss, of course, the long-term social securities promised by the capitalism of the last century.

Indeed, behind the current crisis in representation, a mutation is in progress: the search for other "links in the political community characterized by the central role of mediatic leadership in the construction of political identities or by the direct presence of citizens who in some circumstances seem to prefer to represent themselves" (Cheresky, 2007: 12). An extreme case, and one that is clearly problematic at the moment, is embodied by social actors - and frequently individuals - who place so little trust in the existing political party system as to have the deeply-rooted conviction that the latter is incapable of representing them in the diversity of their interests.

One of the underlying questions (and a recurrent one in recent political analysis) consists of understanding how these structural transformations impact the political cultures of our countries. It is hard to pinpoint a single answer. The political arena is muddied by the proliferation of conflicts and by specific, immediate demands that frequently take an extra-institutional route and an "all or nothing" approach that precludes any possibility of 
a negotiation of interests. Imagine intensifying social protests whose protagonists often display a steely intransigence in their positions. Or "indignant communities" that moralize and personalize public issues propelling onto the scene an active, but anti-institutional citizen who, while not to be discounted, seems much more conscious of her rights than her duties, distrusts the state, politicians ("let's get rid of them all") and institutional structures, and takes refuge in the media.

But this too, could be the basis for a new type of relationship with political institutions. One in which, as in many other places, the demands for representation or participation give way to a democracy subject to strong mediatic oversight (including the new electronic media) and in which public opinion - with its moods and instability - reinforces its particular brand of influence. This is a growing trend in countries which have never had a political party tradition to speak of, or those in which the institutionalized party system has, in fact, collapsed in recent years.

As important as these trends are, at the moment it is impossible to imagine that political parties will disappear. For this reason, and despite the intensity of these anti-institutional moods, the cohesive role of political parties must be revisited from a different standpoint. In any event, it is in this joint evolution that legitimization by means of the party - government (as opposed to the traditional citizen - party) route could be a fruitful strategy. Parties ultimately will be evaluated less for their capacity for social representation (a function increasingly assigned, as we will see, to the CM \& IM) than for their ability to make available a varied political supply and to actually serve as effective agencies for the rotation and selection of leadership teams. In all likelihood, the future of political parties lies in their enhanced organizational efficiency, in their capacity to offer political proposals, and in their protagonism in improving institutional governance in our countries.

The current is not flowing universally in this direction. And yet we must stress that in recent years, and despite their shortcomings, the political leaders of the region have succeeded in managing severe - even extremely severe - crises without undermining the space for democracy. Suffice it to recall recent experiences in Argentina, Ecuador, Bolivia, Venezuela, Peru, and even Colombia). In many of the countries mentioned, it was the very system of democratic life that was in dispute in various ways. And in all of these cases, with variations and sometimes operating on the edges of legality, political solutions were negotiated. This does not auger a regeneration of parties - as indicated by their scant legitimacy in public opinion - or their improved organizational structure. But it is a significant indication of 
a new capacity for regulation in the framework of democratic party politics in the region and of the fact - unprecedented in recent decades - of the return of the military to their barracks.

\section{Civil society ${ }^{37}$}

Civil society came to embody solidarity and social change in the post Cold War public sphere. Due to its power of evocation and its potential to articulate the hope for a better, world, the notion of civil society has tremendous influence over the structure of public perception and over the role different social actors confer upon themselves. Above and beyond its evocatory power, we must address certain unremitting political questions: what is civil society's actual impact in the realm of its social development activities? What is the nature of the relationships between national and international civil society? To what extent, and within what parameters, can it act as an intermediary between individuals, social groups, and political power structures?

\section{Civil society and the political system}

After a century of dormancy, "civil society" returned to vogue in the context of the struggle against authoritarian military regimes in Latin America and against totalitarian communist regimes in Eastern Europe. ${ }^{38}$ In these contexts, civil society constituted an extremely heterogeneous array of actors united around the common goal of struggling for the democratization of political regimes. By all indicators, once this had been accomplished, civil society would prove to have been an ephemeral phenomenon. To the contrary, it has become a core concept in the political life of societies in the developed and developing worlds alike.

What happened? The power of civil society in the social imaginary is an expression of, and a response to, the crisis of representation in contemporary democracies, in which political parties have lost their drawing power and

37 This section is based on Bernardo Sorj (2005b), "Sociedad Civil y Relaciones Norte-Sul: ONGs y Dependencia”, Centro Edelstein de Investigaciones Sociales, Working Paper 1, Rio de Janeiro, http://www.centroedelstein.org.br/espanol/wp1_espanol.pdf

38 The notion was commonly employed in the $18^{\text {th }}$ and $19^{\text {th }}$ centuries, beginning with Adam Ferguson. 
their capacity to produce innovative visions for society. This is particularly, but not exclusively, true of parties associated with socialist utopias.

In developing countries, civil society is regarded as a sphere capable of short-circuiting state institutions (which are considered corrupt and inefficient). This makes them attractive to international institutions such as the World Bank, the International Monetary Fund, and the United Nations system, which have come to regard the NGO community as an ally in the development of a transnational agenda designed to break the nation-state monopoly in channeling international cooperation.

Civil society has thus been resurrected by very different international ideologies and actors. It is however an autonomous actor tailored neither to rightwing thinkers who believe such associations will contribute to a reduction in the state's role (and social expenditures) nor to the leftist model of a radical breach in relation to the market and state.

Nongovernmental organizations, NGOs, are the main actor in contemporary civil society. What are the NGOs? Civil society associations (cultural and sports clubs, professional and scientific societies, Masonic lodges, philanthropic organizations, churches, trade unions, etc.) were present throughout the $20^{\text {th }}$ century. They directly represented a specific constituency. Contemporary NGOs, in contrast, assert their legitimacy based on the moral force of their arguments rather than their representativity. This is something new: a group of organizations that promote social causes without having received any mandate from those they purport to represent.

Traditional philanthropic organizations characteristically do not represent their public either, but then again, they have never claimed to be the voice of their clientele. The church, for its part, operates on the premise that its mandate comes from God. Revolutionary parties viewed themselves as the vanguard with which the working class ultimately would identify and affiliate. Moreover, although they were motivated by powerful humanitarian moral values, the original intent of the precursors to contemporary NGOs - the Red Cross, Action Aid and Oxfam, for example - was to aid their beneficiaries, not to become their mouthpiece.

In this sense, the NGOs constitute a genuine revolution in the domain of political representation. Their precursors are the organizations and individuals who fought against slavery, or later advocated on behalf of consumer rights. But even taking into account these antecedents, the representation of public causes and public debate in the $20^{\text {th }}$ century was channeled mainly by trade unions and political parties, in other words, by representative organizations. 
The NGOs, this new phenomenon of representation without delegation - or more aptly, self-delegation without representation - channel the creative energy of social activists towards new forms of organization which are separate from the public whose needs they purport to represent, or at least do not establish a very clear link with that public. The most obvious examples of this are NGOs in developed countries that support social groups and causes in developing countries.

Based on a human rights (and ecological) discourse, NGOs situate themselves as demanders of governments (and of international organizations) rather than as vehicles for access to state power. In this sense, they express and reinforce a political culture peripheral to, and distrustful, of governments, setting themselves up as ethical agents before a pragmatic state, or a moral conscience before an amoral system. As such, they are simultaneously voice and exit, a mechanism for participation that tries to avoid being contaminated by political interests and power plays.

Lacking the direct support of the community they purport to represent, NGOs rely on external resources. In contrast to most traditional civil society organizations that operate with a volunteer base, NGOs are directed by professional teams and constitute a significant source of employment. And because they lack a stable, homogeneous social base able to exert political pressure through direct mobilization, they frequently work through the media to advance their agendas. In sum, they are professional groups engaged in social critique - without the explicit delegation of any broader social group - expressed through activities whose impact is contingent on media coverage.

While many NGOs in the developed world receive a significant portion of their funding through voluntary contributions, dependence on foreign funding has become a critical issue for most NGOs in developing countries. NGOs are, in fact, an important channel for international cooperation. But this type of funding also imposes restrictions. The NGO world can only be understood as a link in a more extensive chain in which funders play a crucial role. Whether directly or indirectly, donors are key players in the development of NGO agendas. And while the latter have the capacity to influence their funders, the struggle for survival compels them to accommodate the donors' agendas. 


\section{NGOs in Latin America}

The universe of NGOs began to diversify in Latin America beginning in the late 1960s. Established by means of external support, their main objective was to participate in the resistance against authoritarian regimes. In recent decades, the proportion of European funding of Latin American NGOs has decreased, with the exception of the poorest countries, and tends to be more concentrated in Africa and Eastern Europe. At the same time, local public funding sources have increased.

In several countries, such as Brazil, NGOs and corporate sponsored foundations proliferated and, influenced by the socially responsible business discourse, became increasingly involved in social projects. In other instances, the state began to make ample use of NGOs, more often than not to support organizations with direct links to partisan groups or individual politicians. This sort of support frequently has erupted in corruption scandals whose demoralizing effect ultimately erodes the credibility of all such organizations. In any event, the independence of NGOs is ultimately circumscribed by the need for funding, which is always tied to some sort of conditionality.

International NGOs also have a strong presence in Latin America. These organizations became relevant political actors in the struggle to influence national agendas in specific areas, such as the environment, indigenous rights, and human rights. Most national (and multinational) NGOs are based in developed countries, where they obtain most of their funding and where many of their associates reside. The agendas of northern NGOs reflect the priorities of their own societies. The difference is that most southern NGOs depend on support from outside their countries. It is not, then, a network of equals, but rather an NGO world founded on an asymmetrical power structure. Even the smallest northern NGOs are in a position to act on the international stage, while the main southern NGOs only obtain support to act nationally. ${ }^{39}$

The assertion that Latin American NGOs became a substitute for the state and its social policies is unsustainable, since the capacity of NGOs to distribute public goods is extremely limited. The stronger the economy of the

39 In this sense, the world map provided in The State of Global Civil Society 2003 (Mary Kaldor et al.: 2004), shows that civil society overall reflects the north-south bias, insofar as it is mainly driven by advanced countries: the main criteria for estimating the density of global civil society relate to the existence of international NGOs (Helmut Anheier and Hagai Katz, 2003). 
country, the more this argument is confirmed. In Brazil, Argentina, Chile, Colombia, and Mexico, to cite only the most important economies of the continent, it is not reasonable to argue that NGOs are situated to substitute state policy. Governments generally contract them to implement local services, while the most creative among them develop innovative practices which, if absorbed by the state, can have an impact on society. Obviously, in order to pursue such an innovative function, these groups cannot simply operate as project generators with foreign funding and budgets removed from the local realities which ultimately are extinguished when the funding pipeline is cut off. The situation is different in the poorest countries such as Haiti, Nicaragua or Bolivia, where NGOs channel essential international cooperation to the poorest sectors.

As instruments of social development, the challenge in Latin America is not whether NGOs have the potential to replace the state, but rather how to empower them to become autonomous partners of the state equipped to administer innovative projects that can be articulated as social policy and to engage in a more transparent relationship with the political system and social movements.

As disseminators of causes, advocacy NGOs had, and continue to have, a significant impact. Success stories include the policy to combat AIDS in Brazil, one of the most successful in the world, or the struggle to preserve the memory of the disappeared in Argentina. The success of these initiatives is explained in part by the fact that, in both cases, they directly mobilized mainstream social sectors. Their more diffuse influence in human rights and environmental protection also cannot be underestimated.

International foundations or NGOs have espoused certain causes whose political and social impact, if not the cause itself, could be challenged, at least in terms of their ideological underpinnings and priorities. While the environment is clearly an important cause, national priorities should be determined by means of domestic public debate rather than by a foreign headquarters. The same goes for support provided to indigenous movements in Central America and Andean countries or, as we will see later, the black movement and racial quotas policy in Brazil. In other words, along with good intentions, political agendas and visions that have not been subject to internal public debate in the "receiver" country are often exported indiscriminately.

We must not forget that NGOs are impregnated by the local political reality. Their role and relevance in democratic systems depend on the degree of democratization in a particular society and its political system. 
The less democratic the society, the greater the potential that the NGOs will isolate themselves from the political system and national institutions, will be silenced, or will become instruments of authoritarian sectors.

\section{The changing profiles of the militant}

Dissimilar as they may be, the three types of transformation we have described can be interpreted from the standpoint of political/citizen militancy and the attendant individuation process. In essence, citizen participation is premised on certain archetypes found in the intersection of the observable behaviors, idealized collective representations, political ideologies, and sociological models that comprise the main profiles of commitment. The latter, in turn, at their own level and in their own way, inform the evolution of collective action and beyond that, a certain link with political life or "doing politics."

At the risk of being somewhat formulaic, one can observe in the aforementioned transformations the metamorphosis of the profile of citizen commitment. The old profile of trade union militant or revolutionary gives way to a more immediate, pragmatic brand of activism grounded in communication and networking skills. The old single-minded and absolute commitment is diffracted into myriad forms of intersection between the public and the private, which are more temporal and professionalized. In many cases, this commitment leaves open the possibility of withdrawal: voice, then, is interspersed with an unprecedented capacity for exit.

\section{The demise of the classic militant}

The profile of the Latin American trade union militant never really fit with that of the leftist political party militant. While the latter were usually volunteers, the trade unionist rapidly became a professional. The former frequently faced off with the latter inasmuch as there were significant differences between the interests, generational backgrounds, and social origins of the two groups. And yet they had something in common. Both were highly politicized and their commitment - even if it was only actually put into practice during a finite biographical phase - was experienced as a total "vocation" to which one "dedicated one's life."

We reiterate: there has always been an enormous gap between trade union militants (and their perpetual dependence on political leaders and 
parties) and leftist political party militants, whose visions of society were - in very different ways depending on the country - more ideologically autonomous and less socially embedded. In the 1960s, however, this very real disparity was blurred by the emergence of a new group of militants, many of whom were coming out of the middle classes and universities and defined by a nationalistic revolutionary option. This type of militancy was so cloistered in some cases that it would have been excessive to speak of "ideology," to the point that the interpretive systems it produced were not at the service of any specific social actor (Touraine, 1988).

The political experience of these militants unfolded in structures with varying degrees of organization, usually quite closed, and always hierarchical. Personal life often became little more than an extension of militant life. A strongly biased political formation led to a discourse saturated with references to the leader (in the populist tradition) or to doctrinal texts (in the Marxist-Leninist tradition, subsequently reinterpreted by Maoism and Fidelism). The formation of "cadres" was a crucial element in revolutionary militancy and a core element of its "mystique:" it embodied a commitment that was, or was purported to be, permanent and radical. For many of these militants, who were strongly influenced by the Cuban revolution, the horizon seemed to expand with limitless opportunities for social change that was customized at will, to the point that it seemed as if militant determination and political leadership alone could set the course of history.

This notion was brutally eclipsed. In some cases it vanished as a result of military repression (military dictatorships in some countries of the southern cone essentially cut off the transmission of militant memory between generations). In other cases it was the result of the professionalization of political parties or of social changes in the 1980s and 1990s that reduced the space for political volunteerism in the region.

In any event, the first big change - which in a way set the others in motion - was nothing more than a gradual acceptance of the exigencies of democracy by a new generation of militants. This process remains ambiguous among some militants, as evidenced by the recent return to populist temptations (which we will discuss later) and the persistence of a certain revolutionary ideal. Nonetheless, between the figure of Che Guevara and the approach of Sub-comandante Marcos, or between Fidel and Chávez, a profound metamorphosis of form and substance has taken place.

With the restoration of democracy in the 1980s, many of the old-school militants embarked on a painful transition process. Clashes between exiles, former prisoners, the new activists and the militants who had remained 
in their country of origin created situations in which many struggled to find their place. In some cases, a gradual purging of the ranks occurred within partisan organizations. In others, and even more overtly, the past and the present collided and many trade union activists discovered that the old ways of operating, pressuring and negotiating politically had been depleted. Essentially, what was occurring was not only this new generation's failure to adapt, or its readaptation, but also the crisis of its militant profile. In the Latin America of the 1990s, there was little space left for the leftist or revolutionary militant.

\section{The pragmatic activist}

The individuation process underway is also evident at the level of citizen participation. There are many reasons for this evolution and they vary from country to country, but in general a new social activist is taking shape. One observes in many instances a rationalization of political commitment, in which more weight is assigned to the professional role; in other words, individual skills are put to work in support of a particular cause in exchange for economic remuneration. To borrow Max Weber's famous distinction, the "vocation" of yesterday's militant is juxtaposed with the "profession" of the new activist. This new profile has a number of characteristics that distinguish it from the figure of the past: political activism is an incomegenerating pursuit; more credibility is assigned to professional expertise; there is more concern over actual results and the services provided to adherents; networking skills take precedence over the ability to build vertical organizations; and, of course, communication skills definitely prevail over ideological rhetoric. In some cases, certain material and status-oriented incentives have replaced those associated with ideological identity. ${ }^{40}$

The income-generating aspect, or at least the larger dose of pragmatism in activism, accentuates the widening gap between parties, trade union activities, associations, NGOs, and citizens. This marks an important distinction with the situation in the 1970s when the militant had ties (albeit often only at the level of discourse) to a social movement, a trade union, or at the very least, a neighborhood association. In this context, any

40 We should point out, however, that many university and party militants still carry out their partisan activities without remuneration. And we should not forget that in the past, many registered party members or grassroots militants pursued and obtained public posts, which is a different sort of income-generating power for a militant. 
action in the public sphere was automatically regarded as political. Today the boundaries between social spheres, while still porous, tend to be more clearly defined: new activists are more "pragmatic," less ideologized, and more inclined to circulate among political-degradable organizations and even, as we have just seen, among NGOs defined more by their moral or assistential activities than purely political conflicts.

Thenew activist profile, then, is defined by economic professionalization and pragmatism. The latter is manifest in its rejection of all or nothing ideological visions in favor of more immediate, tangible results. This is observed in the proliferation of neighborhood associations or women's groups where, once the objective is achieved - access to electricity, potable water, a specific demand - the mobilization tends to disperse. In Argentina and Venezuela this phenomenon has come to involve middle class sectors heretofore unaccustomed to such protests. But it is also visible in areas previously considered bastions of revolutionary militancy. Despite the presence of partisan groups in university politics, for example, in many countries of the region, activism has become autonomized in its leanings and students' associations focus increasingly on specific university-centered problems.

Added to this is the awareness, among many young people as well as some trade unionists, that political activity can be nothing more than a transitory phase unless it is converted into a professional, income-generating activity. Activism is regarded more lucidly and without false illusions as a transitory and specific practice. A change that can only lead to the conclusion that there has been a crisis in the militant commitment, even more so since the democratic experience facilitates, just as in so many other places, a privatization of individuals, particularly youth. What is happening, most likely, is that the individuation process underway in the region has compelled an acceptance of more space for personal and family life, which can no longer be sacrificed for a political commitment. In the wake of this process, a necessary separation of spheres is taking place. And despite its evident limitations, this is an important means of fortifying democratic culture. Even more so when this equilibrium is sometimes sought by militants, such as in the case of feminism, have politicized the personal sphere.

A different profile of public commitment is taking shape. It is marked not just by the decline of the public figure or waning political passions, but by the emergence of new ways of connecting to the public sphere that may be less absolute, less demanding, but are by no means less active. Some involve the professionalization of activism, while others reflect a desire for participation, association and solidarity. Despite their differences, however, 
both of these avenues for involvement are united by a desire to dissociate personal life from civic commitment or to associate the two realms in the context of a particular lifestyle (in areas such as alternative consumption or in family relations). Individuation processes subterraneously reinforce this transformation. To the point where many actors value their participation in a movement no longer as a "vocation" per se, but as a venue in which to develop skills, carry out initiatives, discover personal traits, and assert rights. In sum, they feel like citizens, but with a different profile. What separates yesterday's militant from the activist of today is a tangible ideological and political crisis, alongside an individuation process that has nourished new forms of citizen involvement.

\section{The emerging public}

Transformations in the sphere of collective action have significantly changed representation in Latin American societies. As in many other regions, the relative decline of social mobilizations and socialist ideologies, coupled with the representational crisis of the political party system, has caused a shift in representation in the direction of the mass media. In the preceding chapter we examined the role of the CM \& IM in transforming social bonds in the region. Here we will discuss their new role in political cohesion and representation in our societies. In any case, the fading influence of social mobilization has been more than offset by the advent of new media-centered mechanisms for the representation of interests and identities.

It is not only through collective mobilizations that a society processes its conflicts and divergent interests. It also does so through an expanded public sphere in which the role of the CM \& IM is increasingly relevant. In this sense, Latin America has not been exempt from one of the sweeping transformations of the late $20^{\text {th }}$ century, namely the consolidation of an increasingly active, diverse, and autonomous public sphere that encompasses the principal self-representations produced by contemporary societies. A public domain in which it is necessary to distinguish between an opinion, a space, and a dynamic.

\section{Public opinion}

At once industry, show, mediation, reflection, debate and language, the CM \& IM are the main vector for a public opinion that has become the 
springboard for the expression of social divisions and differentiations. We experience social cohesion in large part because the CM \& IM transmit an image of society to us, its debates, and its conflicts.

This is not the place to introduce what reception analysis has taught us over the past fifty years, but the point is important enough to at least provide a general framework. In Latin America, as in many other regions, public opinion is susceptible to all sorts of suspicions (since it is susceptible to control or influences). This sentiment is even more powerful in Latin America than elsewhere because distrust was based on a dual social bond in which it was stylish for the "natural" hierarchy to perpetually condemn "the masses" for their incapacity to develop their own opinions and for their propensity to be "manipulated" or "alienated." It does not matter that empirical studies have failed to corroborate the thesis of the direct influence of the CM \& IM on individual opinions: it has been the underlying assumption from the start and, as such, is unshakable.

Of course, public opinion in the region, as in other areas, is subject to an array of controls, ranging from insidious or publicity-driven propaganda, to the desire of political authorities to exercise varying degrees of direct control over broadcasts, or to the powerful monopoly of large, private economic groups over the mass media in the region (suffice it to recall the role of the Globo system during the military dictatorship in Brazil, or Televisa in Mexico). And yet despite these evident influences, public opinion remains an arena in which multiple, opposing, antagonistic visions jockey for position, are represented, circulate, and are debated, increasingly on the Internet. ${ }^{41}$

In light of the individuation process underway we must be more vigilant about the actual processes that shape public opinion. Avenues of persuasion are less linear. Messages are decoded based on diverse social experiences, which are becoming more diverse by the day. Public opinion, no matter how evanescent, is the fruit of the perpetual collision of representations in which social actors vie for influence and to make their voices heard. The notion of a sole transmitter broadcasting coherent and homogeneous messages to a shapeless mass of isolated, captivated individuals does not correspond to any real social situation. Individuals predate cultural and informational broadcasts. Different social groups perceive and interpret

41 Although this should not be idealized as a public space on the margins of the realities of society and has even posed its own challenges for the construction of the public sphere. See Bernardo Sorj, 2006. 
ideologies, messages and codes in different ways, in function of their class, gender, generation, cultural formation, place of residence, and so forth. This process has been sharply accentuated by higher educational levels and the diversification of the CM \& IM in the region.

In Latin America, however, if one leaves aside important studies by certain experts, this more conflictive conception of public opinion has fallen - and falls - short because the classic thesis of the social atomization inherent to the masses (and the "ideological availability" this would imply at the level of individual consciences) was perpetuated by a dichotomous vision that pitted "decent" folk against the "rabble" or the "aware" against the "alienated" (by definition passive and incapable of critical opinion). The fact that individuals in the region are important consumers of programs (particularly television programs) or that the inhabitants of suburban working class neighborhoods purchase a television ahead of most other consumer items, generally has been interpreted as an unequivocal sign of their alienation. The individuation process forces us to revisit this thesis. This is absolutely not to say that in Latin America, as in other regions of the world, individuals are not influenced by the CM \& IM, but rather that this influence is complex, even more so when the very process of influencing is subject to social struggles. It is a work in progress involving an enormous number of actors with diverse interests (journalists, owners, consumers, politicians, and so forth).

Under the influence of publicopinion, one observes a tendency towards the uniformization of thought and lifestyles alongside a growing individualism. The communities of the past see their restricted identifications weakened by a plethora of images and messages targeted towards individuals. Of course, this paradoxical process of standardization and singularization does not engender equality. The CM \& IM maintain or reinforce social and cultural inequalities, and while lifestyles are constantly being recreated under their influence - with different rhythms for different social actors - , the fact remains that the uses to which the messages are put are fundamentally unequal. Be that as it may, as we alluded to earlier, the CM \& IM ultimately create "publics" with different cultural sensibilities which, in their diversity, accentuate the mosaic of interests and identities that make up contemporary societies. An identitary diversity that complicates, obviously, the capacity for representation of social actors through established conflicts, to the point that individuals seem to be more mobile than group identifications.

This process has been reinforced in recent years by the advent of the Internet and cable and the proliferation of channels (to which many social 
categories have access, sometimes even through illegal means which in some countries involves up to nearly $40 \%$ of low income sectors). Still the CM \& IM, and television in particular, are one of the most powerful factors of national cohesion. Television is where the crux of the political debate is organized, where the main national collective emotions are played out (need we even mention those lay rituals of communion that are the soccer selection?). Of course this process is more open today than before, producing a more reflexive vision of nation, one that is constantly held up for comparison with other nationalities and social contexts, but no less cohesive for all that.

\section{The public space}

If the CM \& IM are involved in the formation and expression of public opinion, it is because the latter lends itself to being expressed in a particular domain that has expanded decidedly in recent decades. A genuine public space has been constructed where society can air its issues and expose them to debate and discussion. The mechanisms through which this occurs are many and the effects may be counterproductive, particularly when the media agenda imposes its rhythms on the political agenda. The public space in the region has nonetheless become a critical sphere of democratic life. It would be futile to take an optimistic or pessimistic view of this here. The important thing is to gauge the magnitude of the transformation. Let us not mince words: the change has literally been enormous in a lapse of barely thirty years.

The tension between opinion and representation is as old as democracy. Parallel to the legitimacy obtained at the voting booths is another more tenuous one: that of public opinion. For a long time this opinion came from the "street," from "pamphlets," from certain prestigious commentators, or from police reports. Today it "is expressed" in opinion polls which sometimes comment on, and sometimes precede, political decisions. Of course, this sort of opinion can never be the pure manifestation of an actual opinion, since it is always crafted by experts and star communicators. Opinion is determined by the nature of the questions (and ultimately the power of the one doing the asking) and by the commentary of those who "interpret" the polls. In this sense, the public space is an arena where we are not so much told what to think, but rather which things we should be thinking about. The power lies in the hierarchy of the topics of debate. But this is not to say that the public space is merely a domain perverted by the powerful. It is a 
perpetual battleground, although the barriers to entry are not the same for every actor.

The CM \& IM also have radically transformed democracy in the region. The transition has been faster in Latin America since political party democracy has always been weak, to the point that populist leaders were frequent and the consolidation of a democracy of opinion ultimately a reality that insinuated itself like an inevitable next step. And yet the change happened. The old charisma of certain populist leaders is being replaced by the growing personalization of power around figures whose aura generally derives more from the office held than from any exceptional characteristics they might possess. The democracy of opinion profoundly changes the politician's job description. Communication skills become critical: one must "appear" on television and know how to make a good "showing." One must have an appealing face and voice. One must master the "sound bite" (which a key group of experts is constantly working to refine); one must learn to communicate with different audiences. The downsides are well known. Political programs disappear or cede ground to the polls. The essence of the political game is concentrated in the election of the candidate. The short attention span of opinion prevails over the long time span of reforms. A sphere of power is woven by the connivances among journalists, media magnates, and political leaders. Politics becomes a show and images are its inevitable weapon.

Many of these criticisms are valid. And fair of course, if they are judged in relation to a rational and autonomous subject. They resonate less, however, when examined from an historical standpoint. In Latin America the formation of public opinion in the strongest, broadest sense of the term coincides with this mediatization and ultimately, with the construction of this public space, accompanying it, and feeding on it. Public opinion is more active in the region today than it was in the past. It encompasses more actors and ensures that new voices are heard and through new channels. This sometimes has a destabilizing effect on traditional social actors who often have no other choice but to express themselves on behalf of the "excluded," since the latter air their views through other mechanisms. Sometimes, as we have seen, this exacerbates the trade unions' representational difficulties since informal or unorganized sectors are able to make their voices heard and are even manipulated by other social actors.

While an informal worker would naturally have less political information than someone with a college education, he or she is more informed now than in the past. What is more, the authorities are increasingly taking note 
of public opinion, a signpost of the democratization underway in the region. Public debate is structured around it: it is in front of that virtual reader or studio audience that options are compared and contrasted. The objective of many collective mobilizations is to obtain visibility in the public space, to make sure that the CM \& IM cover their petitions, so as to broaden the radius of discussion surrounding their cause. Moreover, as we have indicated, this process changes the profile of political militants because public opinion requires new skills and because the public space implies and imposes a new rationale in the selection of candidates.

\section{The public sphere}

From some perspectives, the affirmation of public opinion and the public space can be said to have occasionally followed a unique course in Latin America. From the standpoint of the recomposition of the public sphere as a whole - and the resulting dynamics in terms of the representation of culture and interests -, however, connections can be drawn with comparable evolutions in other societies (Dubet, Martuccelli, 2000).

The main change is easily summarized: despite the differential influence of each actor, from this point forward, no one actor can impose its will in the public sphere. Today neither the political system sensu stricto (states and parties), social mobilizations (trade unions, NGOs), nor public opinion (surveys, CM \& IM) can unilaterally guide the social debate. Of course the essence of political negotiation remains under the purview of governments and leadership still carries considerable weight. There is, nonetheless a trend toward the gradual autonomization of social actors (as exemplified not only by the consolidation of civil society in the region, but also by the independence imposed on certain trade unions by the economic turnaround). Above all, however, the public space currently wields an unprecedented degree of influence that enables it to expose the incongruities between electoral expression (the forces represented in parliament or representative entities) and the more volatile state of public opinion.

This interplay transforms - albeit with significant variations among countries - the way in which the region's societies represent and negotiate conflicting interests. By employing a very schematic approach and examining each of these domains successively, we can discern the dynamics at the core of the processes underway. What we are witnessing is a new equation between the power of action and the power of representation. 
a) The political-institutional system retains its decision-making capacity even though it is no longer the only actor endowed with the legitimacy and instruments necessary to impose certain decisions. At the same time, however, its capacity for social representation and analysis is sharply diminished relative to social mobilizations and in particular the shift towards the CM \& IM and public opinion experts. Of course the modernization of administration and tangible progress in the production of technically more reliable national statistics somewhat mitigate this assertion, while not essentially altering the course of the power shift.

b) From this standpoint, collective mobilizations are in an unprecedented position. On the one hand, their capacity for direct intervention has evolved unevenly, diminishing in some instances (as we have seen with the trade unions) while expanding in others (NGOs). At the same time, and this is a substantive change, their rationale for action has been transformed. Their role is no long limited to the defense and representation of certain interests or identities: collective mobilizations are increasingly directed towards alerting public opinion and eventually the establishment. Although ultimately their target audience is always the political system, collective mobilizations increasingly function as alternative channels of representation and alert through the CM \& IM.

c) The CM \& IM are characterized by an imbalance of power that is virtually the inverse of that observed in the political system. While their capacity for action is limited (contrary to what many journalists believe, press-driven information campaigns often never yield a practical result), their capacity to represent society surpasses by far that of the political system. It is through the CM \& IM that our societies know or fail to know each other, the implication being that citizens are more actively engaged, even if only in terms of their growing capacity to comment on current events.

This recomposition of the public sphere accounts in large part for the overlapping ills observed among members of each of these domains. Actors in the political system fear society as an unknown and unfathomable quantity (hence the reign of opinion polls and communications experts, which have stepped in to allay this fear) - and, when confronted with unexpected social mobilizations - as ungovernable. Many of these actors even blame their current difficulties on the media, whose sensationalistic 
tendencies supposedly incite all social actors to vie for visibility. This panorama is complicated by the fact that the media also paradoxically encourage, whether directly or indirectly, a reduction of the public space, as people's retreat en masse into the private, personal realm. It should come as no surprise then, that studies on the indifference, depolitization, apathy, cynicism, and lack of participation of "low intensity citizenship" (as O'Donnell asserts) or the "precarization of citizenship" often lay the responsibility for this on the doorstep of the mass media, particularly in urban areas.

Changes in their relative import or influence have fostered a sense of ambivalence among actors in social mobilizations: politicians do not listen to them nor are they audible in the CM \& IM, and yet they persist in their efforts to "influence" the former and "be covered" by the latter. Even more so since the alliance between the media and the targeted, emphatic protest of social mobilizations plays out in what is, in fact, a media-dominated terrain.

Lastly, the important thing in terms of the principal actors in the CM \& IM is to affirm their differential capacity to represent society as they constantly confront the political powers with their practical limitations, whether by underscoring the perpetual gap between promises and actions or by monitoring their actions and denouncing acts of corruption. In other words, the media, in its critical activism - including campaigns fueled by powerful economic interests - should not forget its origins: the power differential between its considerable capacity for representation and its relatively weak capacity for action. Its impact is relative, to the point that even the CM \& IM's constant condemnation of acts of public corruption ultimately has the effect of banalizing corruption itself.

In any event, this structural transformation has enormous consequences that simultaneously support and magnify the current individuation process. Collective mobilizations and political parties are no longer the only pole of expression for conflictiveness in society. Moreover, their capacity for identitary representation has eroded considerably. At times, we appear to be witnessing the divorce of the domain of the functional representation of interests (which continues to correspond to political institutions and representative actors in the literal sense such as trade unions and parties) and the figurative representation of society (in which the CM \& IM play a decisive role). Of course, not all individuals have the same capacity to maneuver in these domains. For many people, particularly those of more modest means, protection is still found in collective mobilizations. But 
even among those sectors, the defense of interests is tendentially distinct from the expression of identities, and their knowledge about the societies in which they live has tended to increase and no longer depends on a single source. Some engage the debate or articulate an opinion, while others display no interest whatsoever in the debate, and still others are doubtlessly incapable of making a decision about many issues. But everyone is being transformed significantly. Previously, one was either an actor or lived in alienation. Today, everyone participates either as actors or spectators and frequently, as actors, spectators and commentators of public life.

\section{Conclusions}

Social cohesion is indivisible from a society's capacity to organize dialogue and conflict among opposing interests. This was traditionally the role of trade unions and political parties (excluding those associated with revolutionary or fascist ideologies), which channeled and dealt with social problems through the intersection of the social and the institutional. Trade unions and political parties clearly played a unique role in Latin America since, as we will see in the final chapter, the preponderance of the state was such that social actors were usually weak or dependent on the activities of the state.

But despite the evident historical continuity, this sort of assessment does not do justice to the contemporary situation, which is characterized by something other than the mere accentuation or deterioration of secular trends. As we have seen, underlying the economic and political shifts of recent decades, the very nature of trade unions is being questioned, together with their role as mixed agents of public co-regulation and collective contestation. Caught in the global inversion of the balance of power between capital and labor (and the consolidation and occasionally the expansion of the informal sector), facing new public technocracies which view them with caution and the emergence of political leaders who have found it necessary to dismantle the former labor power structure in order to impose their own, trade unions are finding it difficult to define their new role.

The balance is even more negative when it comes to parties - and especially to politicians - which are widely distrusted by citizens, sometimes to an extreme. It is a sentiment that the sweeping reforms of recent years have yet to truly eradicate. Their capacity for social mobilization has been 
significantly eroded and this, more than anything else, has transformed them from militant-based organizations to professionalized groups serving as channels to government office. (This is even the case of the Partido de los Trabajadores in Brazil which had promised to be a renovating force.) In this context, their dual role of representation and participation has deteriorated considerably. Nonetheless - and because they will continue to be an essential agent of public administration for the foreseeable future - efforts to improve their organizational effectiveness may be the key to revitalizing their role in social cohesion.

In recent decades, the nebula of civil society and the NGO community has joined these two traditional actors on the Latin American stage. While their relevance is often overstated, their presence has nonetheless transformed the institutional life of many countries. As we have described, they play the curious role of relegitimizing collective action while simultaneously delegitimizing government action, particularly in countries with less developed government infrastructures. This frequently spurs different actors to step up their initiatives which, when carried out through extragovernmental channels and often featuring explicit criticism of government inefficiency - fosters a sense of trust towards these associations and distrust toward the state.

Such transformations have contributed to the decline of certain forms of political participation while simultaneously triggering the emergence, under the more general imprimatur of the individuation process, of a new activist profile. One that seeks an equilibrium between the public and the private based on new foundations. One in which the objective of participation is also interpreted from the standpoint of personal experience and most importantly, one which recognizes, if only implicitly, the wellfounded need for a separation from the domains of personal life.

But the most significant change registered has been the consolidation of a more dynamic and diverse public sphere. It is impossible to underestimate the importance of this. Conflicts and politics, while still the virtual monopoly of certain social groups, are increasingly a matter of debate - and with no possibility of backtracking given the publicity involved. It is necessary to debate and rebut, to appear in public and withdraw from the public eye, to attempt to influence public opinion and be constantly ensnared by it. But above all, in such unequal societies in terms of power, to be able not only to express one's voice through the vote, but to be sought out by the powers that be, conveys a new sense of citizenship at the level of the imaginary. Here too the profundity of the democratization and individuation processes in course 
is manifest. Growing legitimacy is accorded public opinion - granted, this refers more to the middle classes than low-income sectors at the moment. In any event, it is no longer possible for any particular actor to be unaware of its influence.

It is interesting to contrast these manifestations of collective stances or mediatic expression (voice) with the individual emigration strategies (exit) examined in the preceding chapter. Dissimilar as they might seem, both are part of the same process through which actors confront social difficulties. This is doubly true since, as we have discussed, underneath its façade of "individualism," emigration cannot be dissociated from an entire spectrum of collective resources and frequently emerges - thanks to migratory networks - as a form of belonging to an ethnic or regional group. Most importantly, however, and above and beyond the differential of emigrant statistics from different countries, as emigration takes root in the imaginary of the region, it opens up an escape valve, a "frontier," that discourages collective mobilization and participation.

As stated in the preceding chapter, the idea is not to pit "individuals" against "society" but rather to understand the often ambiguous role that the palpable increase in individual initiatives plays in social cohesion. While it was long believed that growing expectations would lead inexorably to an institutional blockage or overflow, today it is important to acknowledge the broader spectrum of responses that actors find, collectively or individually, to address social problems. These initiatives, however, are not viable unless they are translated at the institutional level.

There is no clearer illustration of this than the consolidation of a significant informal sector in many Latin American countries. While it has facilitated - facilitates - the "individualized" management of a societal deficiency, it is likewise impossible not to acknowledge the many "crisis" elements inherent to such a solution. It is not helpful in this context to offer dubious ideological praise for the virtues of individualism. To the contrary, once having recognized the proliferation of individual initiatives in the region, what is required, far from a certain collectivist nostalgia, is the development of public policy and collective actions capable of accompanying and sustaining these expanding capacities. In the absence of such policies, and sometimes without any horizon at all before them, actors will increasingly turn to individualized solutions and continue to feel alienated from the establishment. On this point, the future of social cohesion requires a departure from the contemporary dialectic between a shortage of voice and an excess of exit. 


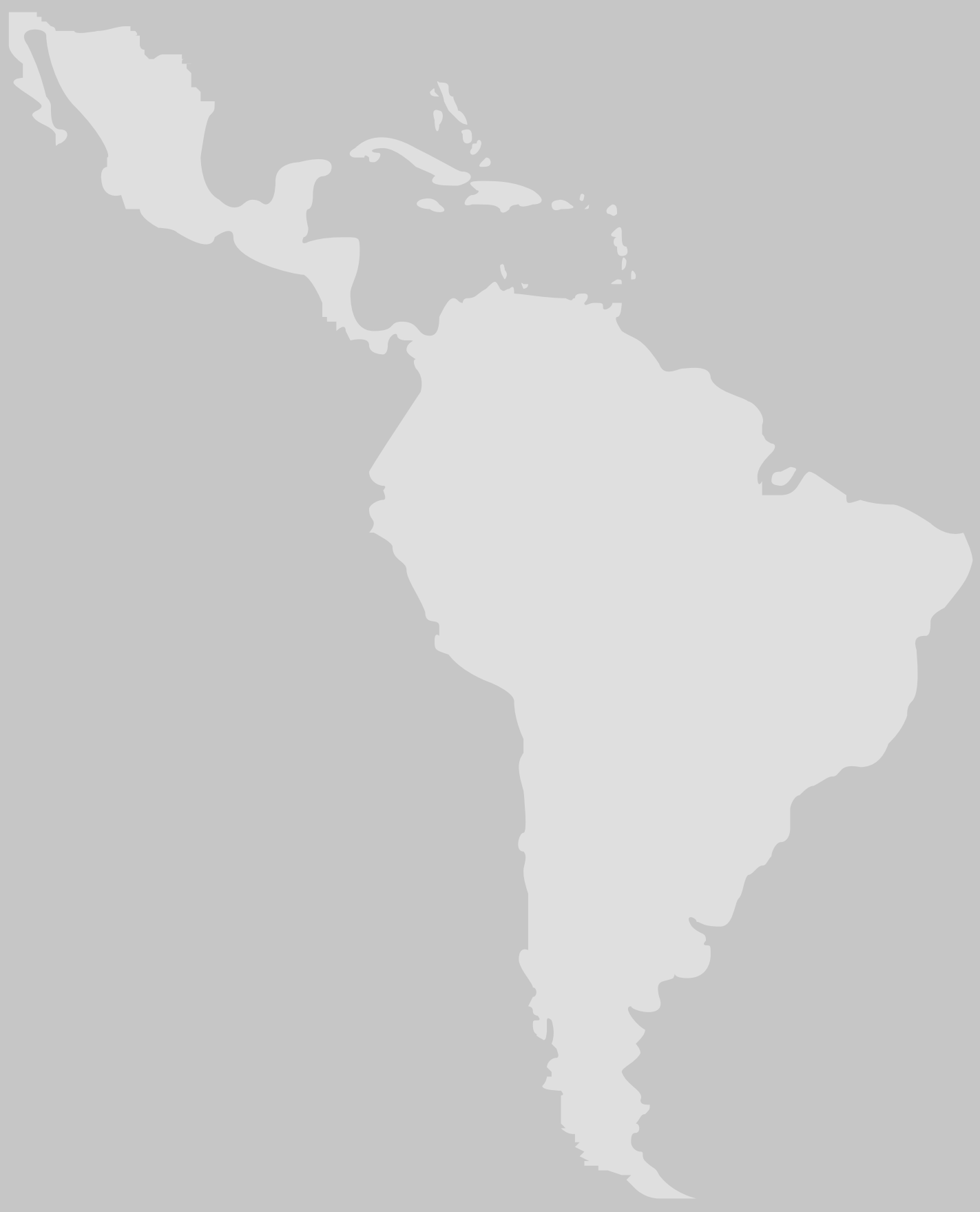




\section{Chapter III}

\section{Problems and Promises: the Informal Economy, Crime and Corruption, Norms and Rights}

\section{Introduction: a culture of transgression}

Social cohesion is unthinkable without respect for rules and norms. All societies establish norms and, transgressions notwithstanding, tend to adhere to them. But national societies exhibit considerable differences in this exercise. In some cases, individuals acquiesce to transcendental traditional or religious norms, especially if social controls and community sanction of disobedience are strong. In contrast, in cases where secularization and detraditionalization have been more intense, respect for the rules derives in large measure from personal ethical beliefs, rational calculations about the need to respect (more or less freely) accepted contractual agreements, and the degree of willingness to risk punishment.

Latin America is no exception to this. As we shall see, however, its historical self-perception and the magnitude of the challenges facing its societies are influential, and indeed, inter-related factors in this area. The prevailing image of the traditional relationship to the norms in Latin American societies intensifies feelings of being overwhelmed by the expansion of criminal phenomena. The individual experience of this is perhaps less a feeling of living in a truly anomic society (one that is devoid of rules, as Durkheim asserted in the late $19^{\text {th }}$ century) than of being condemned to navigate in societies where the law has two faces: it is applied differently 
depending on the person involved. There is an old Brazilian saying: "for my friends, justice, for my enemies, the law."

A unique culture of transgression exists in Latin America (Nino, 1992; Girola, 2005; Araujo, 2006). It is a culture of generalized attitudes of transgression - to a greater or lesser degree - that reflect countless perversions of social life: a legalistic tradition; an establishment that holds its citizens in contempt (in direct proportion to their lack of economic or political power); and a tolerance - and even a collective sense of satisfaction - towards violations of the rules. Some forms of transgression, especially those committed through the harsh imposition of raw economic, political or bureaucratic power, are met with revulsion, while other everyday transgressions are experienced as positive signs of understanding, sensitivity, and a willingness to help out. If we ignore the latter aspect - which regards the "blind" application of universal norms without taking into account personal circumstances as inhuman and rigid - we will be hard-pressed to understand how the culture of transgression has so thoroughly penetrated our way of being.

This culture is an amalgam of arbitrary behaviors and "turning a blind eye." One of harsh punishment for some and the "law of the funnel" for others (the wide part for me, the narrow part for everybody else). Tolerance of the powerful can be present to an extreme, since many still equate power with the right to abuse, as if it is simply a matter of fate and there is nothing to be done about it. In many countries, "cleverness" is not only tolerated, it is an acknowledged feature of the national "temperament," although this attitude is slowly changing, as we will see later on. While there is less tolerance towards "every day" citizens, abuses are accepted because the thinking basically goes that "it isn't fair that they punish some and not others" and that "it isn't fair" to send an "educated middle class" person to a prison where the conditions are usually infrahuman. In any case, the law is not applied in the same way to everyone. Moreover, for the power elites in particular impunity is virtually guaranteed since they have every opportunity to use economic power to ensure that the law will act in their favor or if not, to simply corrupt some public official in charge of the proceeding.

This state of affairs frequently has its roots in the colonial legacy: in the gap - if not the abyss - between the de jure country and the de facto country, or between what the law prescribes and the social reality actually allows (the famous "it is respected but not obeyed" from the colonial era). The traditional disconnect between "law" and "habit" is such that it sometimes seems as if the laws have no other vocation than to facilitate "featherbedding" 
and corruption. This is particularly true of the most rigorous laws, which are, for that very reason, unenforceable (except to punish or blackmail a particular individual). The end result is the proliferation of attitudes which, from this perspective, citizens regard as "hypocrisies." It is difficult, nonetheless, for anyone to completely escape playing the game, especially since there is no expectation that the authorities (police, judicial officials) will adequately enforce the law ("he who doesn't pay, pays").

But that is just one side of the coin. Morality, of course, exists in Latin American societies, but it is elastic and ambivalent. Although everyone is convinced that the rules are necessary, anyone who obeys the law has got to be a "fool," "slow," or an "idiot." A transgression may be held up for public admiration ("clever," the "scam", but sooner or later is inevitably debunked as "cocky" or even a "screw up"). Indeed, some would consider transgression itself to be legitimate since "no one has any respect for anything" in society. As shown by an empirical study on Peruvian youth, this relationship with transgression is most aptly described as ambivalence: it is at once rejected and admired (Portocarrero, 2004, Ch. 3). If we fail to take into account this final point, we risk interpreting the culture of transgression as some sort of cultural or psychoanthropological constant inherent to Latin Americans, while forgetting the extent to which these traits were informed - and to a degree are still informed - by a model of social domination.

This bears repeating: we are not dealing with inherently virtuous or vicious agents. Private interests colonize the state in search of spectacular, risk-free gains. Individuals from across social sectors develop survival strategies within the realm of possibilities determined by pre-established practices vis-à-vis state institutions in a generally perverse dynamic. While police corruption is considered repulsive, few would hesitate to take advantage of it to benefit or protect a loved one who has ended up on the wrong side of the law. And even though slum dwellings erected by means of land invasions lack adequate infrastructure and services, residents often oppose legalizing the holdings if it means paying municipal taxes. Similarly, while the so-called informal sector of the economy exhibits enormous creativity, it is frequently built on semi-criminal regulatory systems and operates through a system of payments to tax and fiscal authorities.

We cannot, however, fall into the anachronism of projecting onto the past the categories of the present. While transgression is a constant in Latin American history, it has undergone a constant recomposition in form and substance. Only today - when individualized forms of sociability have proliferated and the political horizon increasingly comprises a democratic 
state at the service of the public good - is it possible to appreciate the range of past and present forms of transgression.

The past - based on hierarchical, authoritarian class relations and the patrimonialist use of the state - is essential to understanding how we arrived at the present. At the same time, it is insufficient to explain the complex network of relations that modern Latin American societies, particularly urban ones, have woven around transgressions of the law. This network comprises a system in which the poor and the rich participate unequally but often in combination. The police officer whose low salary is the excuse used to justify the payment of a bribe (often extorted) from a middle class driver, or the residents of the poorest neighborhoods who "divert" water or electricity, or the wide range of illegal practices found in the informal sector, cannot be reduced, by our "guilty consciences," to byproducts of history or to the bad example set by the elites. Beneath the apparent generosity of those who redefine the acts committed by the poorest groups as symptoms of their victimhood lies an elitist paternalism that has failed to grasp the enormous transformation of our societies and the range of behaviors and values that permeate different social groups. To paraphrase an old Latin American leftist slogan: either "everyone is held responsible or no one will be responsible."

As with all historical phenomena, the characteristics and currency of such practices are beginning to change. Alongside the transformation of the social bond discussed earlier and the consolidation of a more open and frankly egalitarian ideal, there is increasingly less tolerance for transgression, especially in the public sphere. At the same time, growing relational equality - as social and hierarchical distances between actors have been reduced in the context of profoundly urban societies cut off from their former community controls - has led to the emergence of an uneven assortment of transgressive or criminal practices.

Let us take corruption, for example. Previously one of the perks or "rules of the game" enjoyed by power elites sheltered by their social distance, the public increasingly regards corruption as a criminal act (even though it is not always treated as such in practice). In any event, in recent years it has provoked social outcry and produced a tacit demoralization of democracy. This is not an innocuous matter. The gradual but persistent expansion of the state's fiscal capacity in most countries, in which the direct tax base is made up of a narrow swath of formal sector employees and business people, can engender new forms of polarization between those who feel that they benefit from state action - generally the poorest sectors that use public health and education services - and those who feel as if they 
receive "nothing in exchange" (even the responsibility for security is, in practice, transferred to middle class citizens whose cost of living rises as they pay for private transportation for their children or for building or home security services). This frustrating situation is intensified by political corruption scandals, which members of the middle class view as personal "robbery" since they are the ones paying higher taxes, and which deepens their dissatisfaction with democracy. ${ }^{42}$

The spread of such phenomena strongly conspires against social cohesion in democracy. We examine several of them in the pages that follow: the unprecedented explosion of armed urban violence in the region; the consolidation of organized crime - often associated with drug trafficking - which quite literally compromises the neutrality of the state apparatus; acts of corruption met increasingly with public protest, which is ultimately a rejection of impunity and judicial inefficiency; and, at the same time, a growing number of citizens seeking legal recourse through the justice system. While these issues are clearly linked to extreme social inequality, today they have taken on a life, and a relevance, of their own that deserves specific scrutiny.

In the sections that follow we will discuss the problem of transgression with a focus on several issues in particular. In Latin America we are a long way from having a developed sociology of transgression, one that would enable us to understand its different manifestations and the complex avenues through which ordinary transgression gives way to legal transgression given the enormous deformations of the "law and order" system. This is necessarily an interdisciplinary effort, and in particular requires introducing a discussion of legal studies into the social and political reflection.

\section{Armed urban violence in Latin America ${ }^{43}$}

International lexicon defines "conflict" in very narrow terms. "Conflicts" relate to politics and to the paths intended to overcome them. When associated with the category of "war" they can be termed "just" or "unjust." Negotiation

42 According to a study conducted by Bernardo Sorj during the most recent Brazilian presidential elections, one of the fastest growing virtual communities (which reached 15,000 members, mainly middle class youth) was "We want a coup now."

43 This section is based on Pablo G. Dreyfus y Rubem Cesar Fernandes, "Violencia Urbana Armada en América Latina -otro conflicto." 
processes serve as the counterpoint to the violence of conflicts: even in the most terrible cases, a legitimate space for interlocution can be found.

The issue we are looking at is altogether different: it is a violence for which we do not even have an adequate name. It is referred to as "crime," a term that is wholly inadequate to express the complexity of the phenomenon. It poses a challenge not only at the level of semantics, but also in terms of ideas and available policy choices. This "other conflict" translates into extremely high rates of violent homicides, a staggering number of which are committed with firearms (WHO, 2002: p.30). According to some studies, Latin America accounts for $42 \%$ of homicides caused by firearms worldwide (Small Arms Survey, 2004: p. 176).

\section{Burgeoning violence}

By way of illustration, let us look at four countries: El Salvador, Guatemala, Venezuela and Brazil. Despite their differences, they lend themselves to comparison, as they have several common features related to our examination.

The Central American armed conflicts of the Cold War era ended during the 1990s and yet intentional injury death rates remain high in several countries. At present, the homicide rate in El Salvador, for example, is 40 deaths per 100,000 inhabitants and in Guatemala, it is 46 deaths per 100,000 inhabitants (from León and Sagone, 2006: p.188; Acero Velásquez, 2006: p.7).

Venezuela and Brazil began the 1980s with promising prospects for development and democratization. Homicide rates, however, spiraled in Venezuela in 1989 (the year of the "Caracazo") and this trend has continued unabated. Venezuela's homicide rate climbed from 9 to 51 deaths per 100,000 inhabitants in 2003 (Briceño León, 2006: pp. 317-321; Acero Velásquez, 2007: p.6). ${ }^{44}$ In Brazil, the rate of homicides by firearm tripled in two decades, rising from 7 such deaths per 100,000 inhabitants in 1982 to 21 in 2002 (Phebo, 2005). ${ }^{45}$ Clearly then, the problem began to expand in the region in the 1980s or 1990s, depending on the country, and by 2000 , it had reached critical levels.

44 The Venezuelan office responsible for reporting crime statistics (Cuerpo de Investigaciones Científicas Penales y Criminalísticas - CICP) has not made homicide statistics public since 2004. Therefore the figures after that date are based on estimates.

45 The growth trend in the curve was barely interrupted in Brazil en 2004, which was attributed, at least in part, to the impact of new public security policies including stepped up firearms control. See Ministry of Health 2005 and Fernandes (coord), 2005. 
This process has also undergone a significant displacement, shifting from the endemic violence considered typical of rural areas to a mainly, although not exclusively urban violence. The homicide rate per 100,000 inhabitants in cities such as Recife (65 in 2004), San Salvador (78 in 1998), Caracas (107 in 2006), Cúcuta (60 in 2006), San Pablo (38 in 2004) and Río de Janeiro (51 in 2004) far surpasses national averages (Acero Velásquez, 2006: p.17).

Fernandes and de Souza Nascimento (2007) have extensively documented these ratios. The following graph is taken from a 2002 study carried out in 5,507 Brazilian municipalities:

\section{Homicide Rate in Brazilian Municipalities, according to the Rural/Urban Gradient (Number of cases per 100,000 inhabitants)}

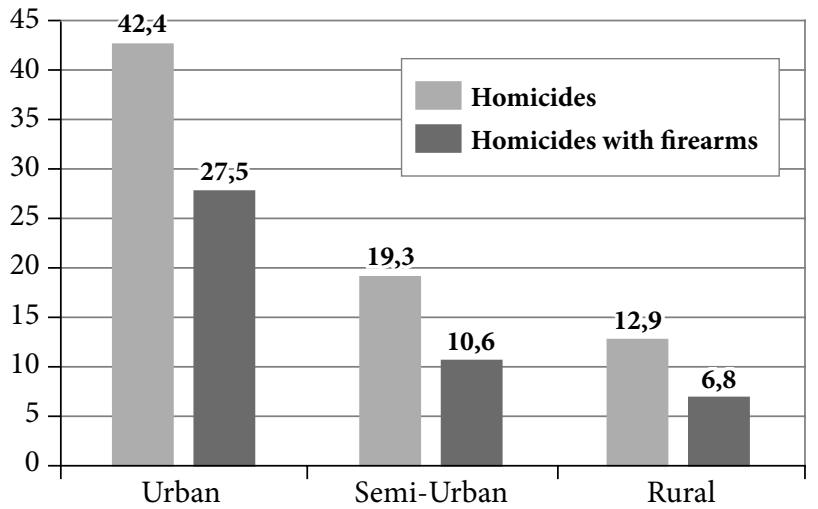

Source: Fernandes and Nascimento Sousa, 2007

Briceño León (2002: pp. 39-40) offers a fair interpretation of this transition: "The homogenization and inflation of expectations among the second or third urban generation occurs simultaneously with a downturn in economic growth and in the possibilities for social betterment, creating a chasm between aspirations of a certain quality of life and the real possibilities of achieving them. This clash, this dissonance between the individual's expectations and his or her inability to meet them through the means prescribed by society and the law, breeds violence by creating an incentive to turn to crime as a means of obtaining by force what cannot be achieved through formal channels." 
We will return to this point, but let us stop for a moment to examine the social logic at the heart of this process. This form of violence is not essentially produced by immigrants who lost their traditional controls by moving from the countryside to the city. To the contrary, as Briceño León rightly points out, it is the fruit of second or third generation youths, city born and bred and living lives of acute frustration. A phenomenon in which it is essential to underscore two contradictory elements: (a) first - as Merton's classic analysis pointed out decades ago - this criminal violence is the fruit of a clash between growing expectations and the dearth of formal channels through which to meet them (to paraphrase the preceding chapter: such phenomena exemplify the dissociation between higher expectations and actual individual capacity); (b) this phenomenon, despite its inherent violence and illegality, also expresses, as we have seen in previous chapters, a process of homogenizing expectations and communion around a common imaginary; (c) lastly, and this is very important, increased expectations, heretofore channeled towards the political system (giving rise to the populist phenomena of the 1950s and 1960s), today are more likely to take the shape of individual aspirations and attempts to satisfy them in ways that are peripheral to the political arena and/or illegal.

The dissonance between expectations and capacity is reflected, as we have seen, in an urban map marked by radical inequalities. Risk factors accumulate in certain areas and in inverse proportions to protection factors. "Poverty," from this standpoint, has become synonymous with chronic vulnerability to the proliferation of risks to individuals in the urban setting.

In Río de Janeiro, for example, social and institutional protection mechanisms against the risk of violence are concentrated in the southern zone of the city. That is where the middle classes live, sandwiched between the mountains and the ocean. The northern and western zones, in contrast, are situated beyond the mountains in the poorest region, rarely visited by foreign tourists. The table below compares homicide rates in neighborhoods of the southern, northern, and western zones of the city. The homicide rate in Ipanema, a famous neighborhood in the southern zone, is 43 times lower than the Bonsucesso neighborhood in the northern zone. Using the tunnels that now crisscross the city, one can travel from Ipanema to Bonsucesso in 30 minutes. The distance between the two, however, is considerably greater in the Human Development Index (HDI) ranking. If Ipanema were to freeze at its current HDI level, while that of the Complexo do Alemão, the largest favela (precariously erected slum neighborhood) in Bonsucesso, 
continued to grow at the same pace of the past 30 years, it would take the latter 100 years to catch up with Ipanema. The map of Río de Janeiro below, color-coded by HDI rankings, illustrates this point (Fernandes and de Souza Nascimento, 2007).

Rio de Janeiro - Homicide in the Geographical Context

\begin{tabular}{l|c|c|c|c|c|c}
\hline \multirow{2}{*}{ Neighborhood } & \multicolumn{2}{|c|}{ Homicides } & \multicolumn{2}{c|}{ Population } & \multicolumn{2}{c}{ Homicide rate } \\
& 2003 & 2004 & 2003 & 2004 & 2003 & 2004 \\
\hline $\begin{array}{l}\text { South region } \\
\text { Ipanema }\end{array}$ & 8 & 5 & 47.106 & 47.739 & 17 & 11 \\
\hline $\begin{array}{l}\text { North region } \\
\text { Bonsucesso }\end{array}$ & 79 & 93 & 19.421 & 19.682 & 406 & 471 \\
\hline $\begin{array}{l}\text { West region } \\
\text { Pedra de Guaratiba }\end{array}$ & 26 & 24 & 9.755 & 9.886 & 267 & 246 \\
\hline
\end{tabular}

Source: Fernandes and de Souza Nascimento, 2007

Human Development Index, by Neighborhood in Rio de Janeiro, 2000

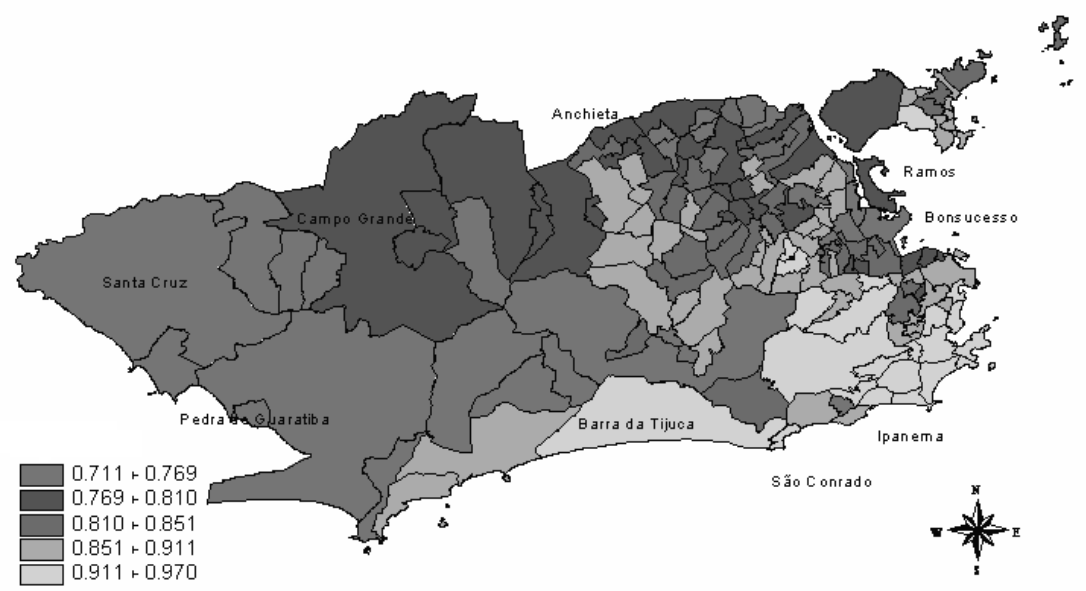

Source: Fernandes and de Souza Nascimento, 2007 


\section{Victimization and at-risk groups}

But even in poor neighborhoods, victimization does not affect everyone equally. According to 1999 World Health Organization (WHO) estimates, violence was the primary cause of death among youths (over 15 years of age) in the region (Briceño León, 2002: p34). Young people are affected so disproportionately by this type of crime that Lisboa and Viegas (2000) propose age as the structural variable for a sociological interpretation of the problem. The common denominator of "100,000 inhabitants" masks the true impact of the various factors on youth as a specific demographic group and therefore, the usual "rates" estimates based on the general population fails to include relevant information on the variants of violence and its associations.

Data on education are consistent among the four cases under examination. The at-risk group is composed of urban youths familiar with the city and its wiles, who attended and subsequently dropped out of school. Although not illiterate, neither are they equipped to surmount the obstacles to integration in formal society. They are halfway between the illiteracy more typical of their parents' generation, and the level of education required by the market. Here we encounter a criterion with which to determine the dimensions of the at-risk group in Latin American urban centers. In Venezuela, 27\% of young men aged $15-18$ are neither working nor in school (Briceño León, 2002: p.38). In Brazil, $13.8 \%$ of youths ages $15-24$ are not working or studying and the percentage rises to $19.6 \%$ among those who did not finish their eight years of basic education (PBAD, 2005). These are alarming figures for a generation seemingly condemned to the risks of the informal economy, a fertile breeding ground for criminal activity.

Along with violence, sexuality is practiced freely and at a precocious age among this generation, regardless of any adults who may be in the picture. In Central America, 25\% of heads of household are young women on their own; this circumstance is more prevalent in urban areas. In Brazil, where equally significant figures are cited $(27 \%)$, there is a positive correlation between the percentage of families headed by young women and the rates of lethal violence by firearm (Fernandes and Sousa do Nascimento, 2007). According to a study by the Institute for Education on Sustainable Development -IEPADES-, 38\% of young women involved in gangs are already mothers (de León and Sagone, 2006: p.182).

Although this is an urban phenomenon, hierarchies and loyalties have a powerful influence on individual behavior. Gangs or "factions" establish 
hierarchies tailored to hostile conditions and tuned to uncertainty. They affirm identities, mark out territories, and mobilize wills around radical options. In reality the powerful organic and internal cohesion of these criminal bands, and the strict respect accorded their norms and codes of honor, contrast sharply with the relative weakness of their ties to other sectors of society or to its criminal dimension.

Although very local, their origins rooted in the internal variables of each society, these new criminal groups are connected to international networks and symbologies. Guatemalan and Salvadoran gangs have evolved in the context of transnational relations. In Brazil and Venezuela, illicit business dealings involve internal and external connections segmented into multiple networks. It makes sense, then, to consider strategies to fight crime and violence that target the links between the local and the global (Fundación Arias, 2006: p.4; Carranza, 2005: p.210).

The illicit drug business, the niche of criminal entrepreneurism, along with easy access to firearms - the source of parallel powers - are the main vectors of the problem assailing the region (Dreyfus, 2002). The United States' liberality when it comes to the small arms business impacts the entire region, which then provides justifications and support to anti-gun control pressure groups and, paradoxically, strengthens drug trafficking. Compounding this, Latin America is also home to major arms and ammunition producers such as those in Brazil, Argentina and Mexico.

The death of each and every one of these youths has an indirect economic impact on societies in which the man continues to play a central role in supporting the family. They are the husbands, boyfriends, sons, and brothers who help feed their families. Violence among armed men has an indirect impact, then, on the main social nucleus. Added and multiplied, it acquires even greater proportions. In 2003, the cost of armed violence in El Salvador was estimated at U.S. $\$ 1.717$ billion. This figure is equivalent to total tax revenues for that same year, double the education and health budgets combined, and equivalent to $11.5 \%$ of the Salvadoran GDP (Luz, 2007: p.4). Similarly, the direct and indirect costs of violence are estimated at $11.8 \%$ of Venezuela's GDP, while the same percentage in Brazil is 10.5\% (Briceño León, 2002: p. 42 and 44). The annual cost of hospital admittances due to firearms alone is estimated at U.S. \$36 - \$39 million (Phebo, 2005: p.35).

In synthesis, the violence we are referring to is characterized by the intensive use of firearms by criminal groups comprising young men (1529 years old), from low-income sectors. They are born in unstable families further weakened by the frequent absence of a father figure. While they are 
not illiterate, they lack the academic qualifications they need to thrive in the institutions of greater contemporary society. Their access to the formal market blocked, they avail themselves of the opportunities available in the illicit market where illegal drug trafficking is rampant. Easy access to the illicit arms market strengthens their control over certain territorial or economic segments. While these groups operate throughout society, they consolidate their dominion in the poor areas of large cities, where they are able to thrive by feeding on the endemic fragility of institutions and public services. This situation occurs in the cities of countries not presently at war (such as Caracas, San Salvador, Río de Janeiro, Guatemala City and Tegucigalpa), as well as in countries engaged in political armed conflicts, although generally in urban areas far from rural combat zones between government and insurgent forces (Cali and Medellín in Colombia, for example).

Exploding rates of urban, armed violence conveys the sense that the state is incapable of ensuring the physical integrity of its citizens. The impact this has on social cohesion is immediate and profound. Insecurity and fear desensitize the middle classes. The latter distance themselves from the circumstances of the poorest sectors, which they come to regard with distrust, particularly if they are young men and even more so if their physical appearance classifies them as mestizos, Indians, or blacks. This further reinforces a strategy, particularly among youths from poor sectors, to use violence or incivility as a means of combating their invisibility. This perverse dynamic is at the root of that unnamed "other conflict." And beyond the telling statistics (to which other crime indicators could be added), the important thing is the general wound it inflicts on society. Security is one of the fundamental freedoms that states must guarantee their citizens - all of their citizens - and its inability to do so conspires against solidarity among individuals, and against its own legitimacy.

\section{Drugs, organized crime and the state ${ }^{46}$}

While urban armed violence is an important indicator of state impotence and the expansion of a culture of transgression and crime, it is not the only factor that conspires against social cohesion. Though the two are often

46 This section is based on Luiz Eduardo Soares and Nizar Messari, "Crime organizado, drogas corrupção pública -observações comparativas sobre Argentina, Brazil, Chile, Colômbia, Guatemala, México e Venezuela." 
related, the drug trafficking phenomenon is critical enough to warrant a separate analysis. Even more so when its expansion gives rise to new patrimonialist pressures and enormous corruption risks, thereby increasing public disaffection towards institutions and the state.

\section{Drug trafficking and delegitimization}

The redimensioning of Latin American - U.S. relations around the drug trafficking phenomenon did not yield very positive results. Despite heavy financial investments to fight drug production and drug trafficking, over the past fifteen years, total narcotics production in the countries of the region has not declined significantly, nor has consumption in the North American market. The fight against drug trafficking also led to the criminalization of a particular product - coca - which had an enormous impact on a broad swath of the region's low income population.

In many countries, the regional increase in drug trafficking strengthened armed groups, which took control of urban and rural spaces creating a destabilizing panorama that calls into question the state's capacity to perform its basic duty to monopolize the use of instruments of violence.

Comparative Table

\begin{tabular}{l|c|c|c|c|c|c|c}
\hline & Colombia & Guatemala & Venezuela & Argentina & Chile & Mexico & Brazil \\
\hline $\begin{array}{l}\text { Organized } \\
\begin{array}{l}\text { Crime with } \\
\text { Drugs }\end{array}\end{array}$ & YES & NO & NO & NO & NO & YES & YES \\
\hline $\begin{array}{l}\text { Public } \\
\text { Corruption }\end{array}$ & YES & YES & YES & YES & NO & YES & YES \\
\hline $\begin{array}{l}\text { State monopoly } \\
\text { over coercive } \\
\text { methods }\end{array}$ & NO & NO & NO & NO & YES & NO & NO \\
\hline $\begin{array}{l}\text { Societal } \\
\text { privatization } \\
\text { of coercive } \\
\text { methods }\end{array}$ & YES & YES & NO & NO & NO & YES & $\begin{array}{l}\text { YES } \\
\text { of militias } \\
\text { the cased by } \\
\text { the police } \\
\text { forces) }\end{array}$ \\
\hline
\end{tabular}




\begin{tabular}{|c|c|c|c|c|c|c|c|}
\hline & $\mid$ Colombia $\mid$ & Guatemala & $\mid$ Venezuela $\mid$ & Argentina & Chile & Mexico & | Brazil \\
\hline $\begin{array}{l}\text { Politicized } \\
\text { or partisan } \\
\text { appointments } \\
\text { to government } \\
\text { posts, or their } \\
\text { political- } \\
\text { corporative- } \\
\text { ideological } \\
\text { cooptation } \\
\text { (confusing } \\
\text { government } \\
\text { with state) } \\
\end{array}$ & NO & NO & YES & YES & NO & YES & $\begin{array}{l}\text { NO } \\
\text { and } \\
\text { YES }\end{array}$ \\
\hline $\begin{array}{l}\text { State induced } \\
\text { privatization } \\
\text { of coercive } \\
\text { methods }\end{array}$ & YES & NO & YES & NO & $\mathrm{NO}$ & NO & NO \\
\hline $\begin{array}{l}\text { Public security } \\
\text { is a major } \\
\text { issue in public } \\
\text { perception }\end{array}$ & YES & YES & YES & YES & YES & YES & YES \\
\hline $\begin{array}{l}\text { Public security } \\
\text { is a major issue } \\
\text { according to } \\
\text { crime statistics }\end{array}$ & YES & YES & YES & NO & NO & YES & YES \\
\hline $\begin{array}{l}\text { Are there } \\
\text { pockets of } \\
\text { sovereignty } \\
\text { or loss of } \\
\text { territorial } \\
\text { control on the } \\
\text { part of the } \\
\text { state? }\end{array}$ & YES & YES & YES & NO & NO & YES & YES \\
\hline $\begin{array}{l}\text { Are these } \\
\text { pockets } \\
\text { associated with } \\
\text { the dynamics } \\
\text { of drugs? }\end{array}$ & YES & YES/NO & NO & ---- & --- & YES/NO & YES \\
\hline $\begin{array}{l}\text { Do current } \\
\text { national trends } \\
\text { reflect an } \\
\text { expansion of } \\
\text { democratic } \\
\text { control, } \\
\text { stabilization, or } \\
\text { deterioration }\end{array}$ & \begin{tabular}{|} 
expanded \\
democratic \\
control
\end{tabular} & $\begin{array}{l}\text { stabiliza- } \\
\text { tion of the } \\
\text { current } \\
\text { panorama }\end{array}$ & $\begin{array}{c}\text { deterio- } \\
\text { ration of } \\
\text { the current } \\
\text { panorama }\end{array}$ & $\begin{array}{l}\text { expanded } \\
\text { demo- } \\
\text { cratic } \\
\text { control }\end{array}$ & \begin{tabular}{|} 
expanded \\
demo- \\
cratic \\
control
\end{tabular} & $\begin{array}{c}\text { stabiliza- } \\
\text { tion of the } \\
\text { current } \\
\text { panorama }\end{array}$ & $\begin{array}{l}\text { deterio- } \\
\text { ration }\end{array}$ \\
\hline
\end{tabular}


As shown, we cannot really refer to regional or general trends when it comes to violence and drugs. While some issues such as corruption, police violence and a sense of insecurity are common to all of the countries, there is considerable variability in other areas, such as the credibility of police institutions and the homicide rate. Finally, drug trafficking and consumption have had a wide range of impacts on the societies and the political climate of the countries examined. Indeed we can distinguish two groups: Brazil, Colombia and Mexico, where drug trafficking has had an enormous impact - felt mainly in the social sphere in the case of the former, and in the political sphere in the latter two instances. This issue does not have the same impact or repercussions in the other four countries studied (Guatemala, Venezuela, Argentina, Chile). But even so, there are discrepancies between the countries in this regard. Colombia seems to be resolving its security problem and shifting drug trafficking away from center stage. In Mexico, in contrast, the influence of drug traffickers and the challenges they pose for society and for the political system have increased palpably.

While not a drug producing country, over the past fifteen years, Mexico has become a springboard for drug exports to the United States. Powerful groups of drug traffickers have established themselves in the country, causing tremendous insecurity and uncertainty. These groups use sophisticated weapons that surpass those of the Mexican and North American police in terms of technology and firepower, and they operate with enormous audacity, causing grave concern and insecurity in Mexico and the United States alike. The particular brand of cruelty practiced by drug traffickers is exemplified in sensationalist and grisly murders, in some cases involving the torture and decapitation of the victims. Yet even as rampant corruption in the Mexican police force and its antidrug apparatus pointed clearly to the ineffectiveness of its antidrug policy, the U.S. executive branch persisted in certifying Mexico, asserting that its southern neighbor was, in fact, collaborating in the war on drugs.

\section{Organized crime and the perversion of social cohesion}

Organized crime has reached such proportions in the region that it is important to recognize the enormous paradox, and challenge, it poses for Latin American societies. Whatever its negative import, violence is not necessarily the inverse of cohesion or an impediment to it. It may be the condition for its potential or its peculiar - and paradoxical - form of existence. For example, aside from serving as an economic wellspring for 
local tyrants, drugs and arms trafficking in Brazilian favelas establishes cooperative networks in an illegal market and articulates social pacts that become a source of identity and belonging for socially invisible youths whose self esteem has been trampled by perverse and multilayered instances of rejection and exclusion. Of course this sort of social cohesion is essentially problematic or perverted in its social meanings. Having said that, however, it is perhaps not unreasonable to take a more process-centered approach to cohesion, one that is relativized and contextualized. It may be useful to conceive of it as a continuum along which fixed points and clear frontiers are not always easily identified.

An empirical example might serve to illustrate this: a community assailed by youth criminal gang violence might arm itself or else lend its support to a group willing to "take justice into its own hands." This has occurred repeatedly in Brazil and Guatemala and is also evident in various forms in Colombia, Mexico and Venezuela. Violence is the motive behind the organization of local society and it provides the language and substance of social mobilization. In this scenario, cohesion derives from violence and is structured as violence. The state is removed, democracy out of focus, legitimacy in tatters. In this case, there is no "cohesion in democracy": it is organized instead against society and democracy.

It is interesting to note, however, that despite these pockets of cohesionwithout-adhesion-to-democratic-institutionality, institutional democracy exists in these societies. And these pockets are not islands set adrift; they have ties to the state and to legality. Organized murderers or hit men, extermination groups and vengeance seekers, militias and informal private security agents pay taxes, vote, run for office, attend church, are consumers, and abide by the rules in many aspects of their lives. It is not unheard of for such individuals to be known and admired by their communities, segments within communities, or sectors of public opinion. What is more, the notion of pockets or isolated gaps in sovereignty pales and is relativized when we shift our gaze in the opposite direction - towards institutions and their agents.

Let us turn our attention to the natural adversaries of the lethal crimes perpetrated by social actors who kill, collectively or individually: the police, prosecutors, defenders, and judges. We will examine the case of Brazil, focusing particularly on the state of Río de Janeiro, where military and civilian police killed 4,329 people from 2003 to 2006 (inclusive). An estimated over $65 \%$ of those murders did not occur during confrontations, in other words, as a legal response to armed resistance by suspects, but 
present clear evidence of having been executions. We are referring, then, to over 2,800 deaths caused by illegal police actions (it is common knowledge that military police combat units in the state of Río de Janeiro stopped accepting surrender in the mid 1990s: one can therefore grasp the magnitude of these figures).

The police, then, rival the murderers, intermingling with them, occupying their space, and taking on exactly the same identity. It is no accident that police officers swell the ranks of extermination groups and are members of organized militias. When are they acting as civil servants at the behest of the state? When are they acting as private individuals?. How to establish clear boundaries? The entire field is swathed in shadows. And the police operate in these shadows by suppressing the sovereignty of the state in territories where they are and lay down the law and separating them from the rule of law and the Constitution. When they intervene as state agents, the weapons used, the timing of the intervention, the popular wisdom that it is the police who behave like that, and the impunity that shelters them - due to the complicity of many other state agents including prosecutors and judges (who go with the flow against the democratic rule of law) - all of these things undermine the credibility of public institutions.

The presence and the absence of the state must therefore be relativized in their meaning and implications both as enclaves of sovereignty and in the juxtaposition of state and violence, institutions and crime.

\section{Organized crime and the patrimonialization of the state}

Organized crime and drug trafficking pose the very real risk of contributing to a perverse "repatrimonialization" of the state in Latin America. Even more so since the illegal nature of such activities only exacerbates the evident danger posed by the entry of the "economy" into "politics." The repatrimonialization process is rooted in an overwhelmingly negative legacy in which a (sometimes) precarious democratic conviction goes hand in hand with institutions operating out of a retrograde and oppressive patrimonialism that propagates and intensifies patterns of inequality, while obstructing development and the deepening of civic values (of equity and liberty).

This disturbing mix alters both sides of the equation: democratic institutions as well as patrimonialism. The former face the dilemma posed by the gap, or even the contradiction, between form and substance, depriving subordinated classes of access to justice and restricting their control over 
representation. The latter is redefined as a crude predatory assault on the state, the citadel par excellence of the public realm. In such a scenario, public corruption causes patrimonialist pacts to become entangled in the clandestine networks widely known as organized crime. In this way, drug trafficking revives, on new foundations and in a new international context, some of the endemic ills plaguing the states in the region.

Note that we are not suggesting that Latin American states have been taken over by organized crime or that patrimonialism is synonymous with organized crime. What we are trying to say is that, as many societies in the region became more complex and democratic institutions more consolidated - insofar as this process has found reasonable conditions to prosper amid pitfalls, setbacks and restrictions - the latter proved incapable of guaranteeing external controls, broadbased participation, transparency and less impunity for "white collar" criminals. This caused a metamorphosis of the traditional patrimonialism that had negatively politicized the economy and obstructed the market: it essentially turned to modern criminal dynamics and found its expression in the form of organized crime, within which public corruption is but one possible example. ${ }^{47}$

When patrimonialism disintegrates into organized crime, the eroding legitimacy of political institutions may give rise to skepticism, apathy, the growing autonomy of the body politic, and the breaking away of bureaucratic-administrative segments. This set of circumstances leaves the state and political representation increasingly removed from what could be termed the effective foundations of the republican popular will. As this was taking place, political representation and state decision-making processes became hostage to private interests, which derailed the reforms historically necessary from the standpoint of the public interest, rational governance, and democratic progress.

To conclude, it could be argued that: (1) patrimonialism and modern capitalism coexist and mutually redefine themselves in Latin America; (2) the loss of strategic space - due to factors that render societies, economies, and political life increasingly complex and impact institutions - - causes patrimonialism to disintegrate into organized crime; (3) the political economy of drugs furthers this process wherever it exerts power and influence; (4) this panorama creates an opportunity, despite the enormous

47 The negative politicization of the economy involved privatizing the public through the installation or maintenance of an institutional structure that legitimized privileges and standardized procedures that preserved and deepened inequalities. 
civilizational risks: in the context we have described, it can stimulate a revitalization of democracy insofar as the struggle to reestablish it requires the construction of order (security and legitimacy) and reducing inequality in access to justice.

\section{The threats of corruption ${ }^{48}$}

There is a widespread perception of rampant corruption in Latin America that impinges on political and economic life, public and private institutions, and social cohesion in general in the countries of the region. Indeed one of the pillars of a cohesive social system is the legitimacy of its political institutions, premised on respect for those to whom society has delegated authority. This legitimacy is what enables the authorities to fulfill their mandates efficiently and with a minimum of coercion. When legitimacy is absent, authority can only be exercised through authoritarianism and violence, whether that means corrupt practices, the cooptation of allies and constituents, or frequently a combination of the two.

Authoritarian regimes are conducive to corruption because of the restrictions imposed on the expression of public opinion, the loss of judicial autonomy and the discretional exercise of power. Corrupt political systems, for their part, always lean in the direction of authoritarianism as a strategy to cover up their proclivity towards the private appropriation of public resources. The authoritarian regimes that predominated in Latin America up until the 1980s were frequently associated with extremely high levels of corruption. In many cases, in the wake of the democratization processes of the 1990s, endemic corruption evolved into "kleptocratic" political regimes that demoralized democratic institutions and created fertile ground for the emergence of new forms of authoritarianism.

One might of course argue that corruption is a universal phenomenon, and this is true. The difference is found less in the degree of corruption in each country - although this is also relevant - than in the degree of impunity. Herein lies the distinction between corruption in Europe and the United States, and corruption in Latin America, which occurs with virtual impunity: those caught in flagrante delicto not only go unpunished

48 This section is based on Simon Schwartzman, "Corrupção e coesão social na America Latina." 
but frequently insist on remaining in public office. More than corruption per se, it is the state of general impunity that causes the public backlash and indignation and has led to the eruption of protests.

\section{Economic corruption and development}

Although corruption affects social cohesion in various ways, its principal effect lies in the way it undermines democratic institutions and public identification with the political system. Technically, economic corruption undercuts healthy price competition and the quality of products and services, thereby hampering economic growth and the distribution of its benefits for society. This has not prevented extremely corrupt societies from achieving high growth rates, China being an excellent example of this. In democratic societies, however, public sector corruption at different levels hampers the development and strengthening of a professional, competent administration, encourages the negative selection of political leaders, and creates a sense of frustration and a rejection of taxes, which are perceived as being tarnished.

Taking the most straightforward approach to the economic issue, the question is whether the existence of corrupt practices in a particular country helps or hinders economic activity and by association, the generation of wealth and economic development. Writing in the 1960s, Nathanael Leff argued that in the absence of a well established legal framework in less developed countries, the payment of a bribe to certain public officials to obtain contracts and authorizations was a rational behavior choice on the part of companies, one that facilitated the flow of economic activity. The bribe was regarded as "grease" for economic transactions; a fee like any other that had to be anticipated in a company's normal transaction costs. In contrast, Rose-Ackerman, among others, has argued that corruption is not grease, but rather "sand": while it may facilitate specific business dealings, corruption reduces the transparency of markets, hampers competition based on efficiency and results, and ultimately breeds inefficiency in the economy and society as a whole. Whichever the case may be, there is strong consensus among economists today that corruption has a significant negative impact on the economies of the affected countries (Mauro, 1997).

There are many explanations for this. When governors make decisions based on private pay-offs, the companies they invite to invest in the country are not always the most efficient or competent, and an extraordinary premium is exacted from them in terms of the uncertainty they will face 
in the form of tax exemptions, monopolies, price controls, and the like. Many firms prefer not to invest under such circumstances, while others are inclined towards short-term speculative investments to the detriment of more mature, long-term projects. If bribing the authorities is a normal practice, taxes are not collected and public services only benefit those who are able to pay for private services to cover their needs. This, in turn, is detrimental to public investment in areas of general public interest such as in education, health, and infrastructure.

Corruption has never been exclusive to poor countries and the literature on the subject is replete with examples of this problem in developed countries (Rose-Ackerman, 1999). This is a very important point. The corruption issue is always associated with moral values and judgments and with the perception that the poorest countries, or their elites, are more corrupt than their counterparts in the developed world. This perception has repercussions for private investments as well as for the cooperation and aid policies of national and international institutions. And it has sparked the endless and largely inconclusive debate over whether the poorest countries are the victims of, or actually responsible for, their own poverty and underdevelopment.

The observation that corruption is not unique to the poorest countries helps chip away at the moral arrogance of many parties to this debate and situates the matter of corruption in the more neutral territory of sociological, political and economic analysis. Most importantly, insofar as it is inherently difficult to know for sure exactly how widespread corruption is, this proviso has the role of projecting this critical issue into the broader sphere of interpretation concerning its real effects. This is particularly significant given that corruption feeds on the large public bureaucracies organized in the dominant patrimonialist tradition in Latin America, in which a whole range of private actions are contingent upon administrative or bureaucratic concessions or licenses.

\section{Political corruption and democracy}

Corruption of a specifically political nature occurs when the "rules of the game" are violated in electoral processes or in the functioning of government institutions. It may take the form of illegal campaign financing or direct electoral fraud, anomalies in legislative or judicial proceedings or in executive actions (vote buying schemes, machinations between the executive and the judiciary, the influence of particular lobbies and interest 
groups over legislative processes and executive actions, etc.). This type of corruption is contingent upon many factors: in part, the ethical culture of each society, but also the make-up of political institutions, the transparency of political processes and government actions, and the force of public opinion and the independent press.

As long as the electoral process depends heavily on private campaign funding, deals between candidates and financial or business groups are virtually inevitable and offer very tangible benefits to financiers, as is the case in Brazil (Claessens, Feijen y Laeven, 2006). So long as executive action relies on constant negotiations with the Congress to enact legislation, dealmaking with respect to positions, votes, and the release of funds is also virtually inevitable. In these areas, there is a fine line between legitimate and corrupt behaviors.

While political corruption occasionally facilitates the participation and access of disenfranchised groups (as was the case of "machine politics" in New York and Chicago), it also helps undermine institutions and contributes to the widening gap between the "mythical codes" of laws, and the operational practices of daily life.

In effect, one way to look at democracy is as a system that formalizes, regulates, and legitimizes the exercise of power, protects minorities, and ensures the right of all sectors of society to participate in electoral races. This conception does not imply that political leaders are literally representatives of the popular will and it acknowledges that many such leaders come from social sectors that are out of reach of the vast majority of the population. But when party and electoral systems work properly, they uphold the principle of representativity, thereby legitimizing this form of governance. At the same time, they are a mechanism for the administration and negotiation of conflicts and disputes, which do not take on the destructive nature observed in countries where the democratic system does not work and is not legitimate. If democracy is to play this role, clear, formal operating rules must be in place and must be observed and respected by the vast majority of the population. Just as important as the formal legality of political and electoral processes is the legitimacy and recognition that society vests in the political system.

Lack of public confidence in the political system creates crisis modes of varying sorts. In many Latin American countries, the deterioration of the traditional democratic order has become the justification for the establishment of populist, plebiscitary regimes, which initially may come across as efficient at distributing resources and social benefits, but ultimately differ very little 
from more typically kleptocratic regimes. Examples of this are the Collor administration in Brazil and the Fujimori government in Peru.

This deterioration also justifies the growing trend among social movements of various sorts to turn to "direct action." Acting in the name of human rights, these groups set out to build or rebuild strong racial, cultural and regional identities among the population. At the same time, they neither recognize the legitimacy of existing democratic institutions nor believe in the need to improve them. Another tack in this regard is the frequent use of the plebiscite to skip over regular legislative procedures or support for other manifestations of "direct democracy." Irrespective of the good or bad intentions of the individuals involved, such movements only accentuate the contemporary political crisis (Schwartzman, 2004: pp.161-180).

Social inequality and disillusionment with career politicians in Latin America has fueled support for politicians who (claim they) are not really politicians, but rather saviors of the fatherland who intend to govern for the good of the people. Even when such leaders are democratically elected, power defined as a space to be conquered by individuals and political groups seeking to take control of the spoils of public resources is still a feature of many democracies on the continent (one which reinforces the inclination towards continuism in power, even at the expense of democratic institutions).

Corruption clearly is not the main cause of all the problems of underdevelopment, inequality, and institutional fragility, although it is associated with, and can contribute to, all of these things. Weakened institutions lend impetus to the search for community identities that are easy to perceive and follow and are not contingent on drawn-out processes of formation and socialization. Religion, race, the tribe, the gang, separately or in combination, allow such identities - often crystallized by charismatic leaders or clinical rationales - to accentuate the dysfunction of the public order.

\section{Corruption, norms and social cohesion}

Economic and political analyses frequently approach corruption as a rational behavior like any other, devoid of moral content. In part, this is a methodological ploy: to leave aside for a moment the values of the analyst in order to better understand the rationales or interests that drive individuals and organizations to engage in corrupt behaviors. We know, however, that in some societies people's behavior is guided by ethical principles which preclude, or at least limit, behaviors that may be considered corrupt, and that this is not the case, or is much less so, in other societies. Using Argentina 
as an example, Luis Moreno Ocampo (2000) refers to the existence of "mythical rules" of ethical behavior. While these rules must not be violated, they manage to coexist fairly smoothly with corrupt "operational codes," which are the ones that actually work. The coexistence of this duality of norms and practices is hardly trivial. Because of the mythical rules, operational behaviors must be discreet, and this gives rise to all sorts of cynical behaviors such as student plagiarism, tax evasion, or "informal" labor contracts. Such behaviors often lead to the tightening of formal rules, which in turn engenders increasingly sophisticated informal practices. This normative duality can be explained, according to the same author, by discrepancies in the different normative systems governing people's lives that allow the operational codes to predominate.

In a more general sense, why do societies establish ethical norms that people tend to obey? Under what conditions do these norms prevail? Under what conditions do they lose meaning and relevance? There are two metaphors to answer these questions, one through the lens of existing institutions and the other through that of the interactions between individuals. The two are often linked. From the standpoint of the overall functioning of society as well as of personal bonds, societies organized around the common good and long-term benefits are contingent upon ethical behaviors that allow people to trust each other. Conversely, societies inclined towards immediate, short-term results tend to exhibit predatory behaviors. At the same time, it is difficult, if not virtually impossible, to sustain ethical behaviors when the institutions responsible for maintaining social order (the police), upholding the law (the judiciary), or regulating business (fiscal officials) can impose systems of payments or bribes that draw the citizen into the corrupt system. This is facilitated in turn by a system of laws so (formally) severe that a public agent only has to hint at a willingness to apply the law for a citizen to understand that it makes more sense to reach an agreement. This constant uncertainty vis-à-vis the law and its enforcers gives rise to an "individualism Latin America style" that we might describe as hyper-reflexive or as an exacerbated individualism: the individual lacks defined parameters for how to behave in his or her dealings with representatives of the law and its regulations. (Should one violate the rules? Corrupt the law enforcement agent? Trust that one possesses the necessary material resources or contacts to "get off"? Obey the law knowing that impunity is the rule?) Individualism in Latin America, then, is more a product of the distortion or transgression of the legal system than an expression of its application (Sorj, 2005a). 
And perhaps herein lies the crux of the matter: how to change the rules of the game when citizens and public officials weave networks of common interests premised on a hypertrophied legal system associated with high levels of inequality ${ }^{49}$ How to break down the complicity of interests, particularly between the middle and upper classes that allows for constant pacts of microcorruption?

\section{The judicial question ${ }^{50}$}

Until recently, Latin American judiciaries were not necessarily considered germane to understanding the political workings in the region. In the wake of democratic transitions - whether due to the exigencies of the transition process itself or those inherent to economic reforms - the region's economic elites, international financial institutions, and significant sectors of the public began to regard judicial institutions as politically and institutionally relevant. This unusual convergence of actors had two consequences. First, it placed the issues of judicial functioning and performance on the political agenda, paving the way for reforms oriented towards the quality and type of services provided. It also led to a judicialization of conflicts as courts and judges were increasingly drawn into public policy and to a growing tendency to use ordinary legal proceedings to lodge complaints and settle social and political demands.

In recent years, these two realities - the first related to the aggiornamento of the judiciary's institutional capacity to perform its functions and the other to the discovery of the justice system by social actors - have informed the evolution of the judiciary and the direction of the academic debate over this issue.

\section{Judicial reforms}

Those concerned with the bureaucratic aspects of the problem focused on the study and implementation of measures that would enhance judicial capacity to respond efficiently and impartially to complaints. The priority

49 See Pablo Sorj (2005) for an exercise in applying economic analysis to the legal system in contexts of widespread corruption and severe social inequality.

50 This section is based on Catalina Smulovitz and Daniela Urribarri, "Poderes judiciales en América Latina. Entre la administración de aspiraciones y la administración del derecho.” 
was on procedural aspects to expedite and ensure the independence of decisions and to lower the thresholds for access to the system. Over the past twenty years, judicial reforms have been undertaken in almost every Latin American country to modify judicial selection procedures, expand the administrative powers of judicial authorities, promote transitions to oral proceedings and public legal representation, and increase the number of actors authorized to bring cases.

As the chart shows, the administration of justice was established as a separate branch of government from the moment each country was constitutionally founded. In the context of judicial reform processes in the 1990s, however, some of the functions originally assigned to the judiciary became autonomous or administratively separate. Efforts to implement the aforementioned reforms in the countries of the region encountered difficulties related to the insufficiency and quality of the data used to assess the problem and the failure to take into account political resistance

\section{Judicial institutions and date of establishment}

\begin{tabular}{l|c|c|c|c|c|c}
\hline & Argentina $^{*}$ & Bolivia & Brazil $^{*}$ & Chile & Guatemala & Mexico $^{*}$ \\
\hline Judicial branch & 1853 & 1826 & 1824 & 1823 & 1825 & 1824 \\
Public Ministry & 1994 & $\mathrm{n} / \mathrm{d}$ & 1993 & 1999 & 1992 & 1993 \\
$\begin{array}{l}\text { Public Defenders } \\
\text { Office }\end{array}$ & 1994 & 2003 & 1994 & 2001 & 1997 & $\mathrm{n} / \mathrm{d}$ \\
$\begin{array}{l}\text { Defender of } \\
\text { the People }\end{array}$ & 1994 & 1997 & & & $1985^{51}$ & $1999^{52}$ \\
$\begin{array}{l}\text { Ombudsman) } \\
\text { Council of the }\end{array}$ & 1994 & 1994 & $\mathrm{n} / \mathrm{d}$ & & $\mathrm{n} / \mathrm{d}$ & 1994 \\
$\begin{array}{l}\text { Judiciary } \\
\text { Ministry of Justice }\end{array}$ & $\mathrm{n} / \mathrm{d}$ & 53 & $\mathrm{n} / \mathrm{d}$ & $\mathrm{n} / \mathrm{d}$ & & \\
$\begin{array}{l}\text { Judicial School } \\
\text { 2002 }\end{array}$ & 1994 & $\mathrm{n} / \mathrm{d}$ & 1994 & 1992 & 1994 \\
\hline
\end{tabular}

$\left.{ }^{*}\right)$ the data correspond to the Federal System; n/d: no data

Source: Prepared by the authors based on the websites of the judicial organs, the Political Database of the Americas - Georgetown University and the Organization of American States, the Report of Justice in the Americas 2004-2005 - CEJA'S, and Pásara (2004 c), in Smulowitz, op.cit.

51 The equivalent in Guatemala is the Human Rights Ombudsman.

52 The equivalent in Mexico is the National Human Rights Commission.

53 The equivalent in Bolivia is the Vice Ministry of Justice and Human Rights. 
to reforms on the part of local judicial and political authorities. These difficulties notwithstanding, the reforms wrought significant changes in the organization, resources, and performance of the region's judiciaries. Institutions such as the Public Ministry, public defender systems, councils of the judiciary and judicial schools were established and the internal organization of the judiciary and procedures for judicial selection and removal were reformed, while the number and types of populations with access to the judicial system was increased.

But the breadth of these reforms must be viewed in relation to the actors of the judicial system, primarily attorneys. The chart below shows the number of attorneys in each of the countries studied. This is relevant inasmuch as litigiousness and ease of access to the system are related to the supply of attorneys. The chart reflects tremendous variation in the ratio of attorneys to the general population. Brazil and Argentina rank first, with approximately 300 attorneys per 100,000 inhabitants, while Bolivia and Guatemala each have fewer than 100 attorneys per 100,000 inhabitants. The presumed relationship between the number of attorneys and litigation levels seems to hold true in these countries.

Advocates of this perspective view the problems besetting the judicial system as essentially linked to a public bureaucracy that has difficulty converting "inputs" into "outputs." It follows, then, that studies on judicial performance and government corrective actions are focused on administrative reforms to enhance performance - particularly measures to reduce the judicial backlog and delays in resolving cases, such as replacing

Number of judges, prosecutors, defenders
and attorneys per 100,000 inhabitants

\begin{tabular}{l|c|c|c|c|c|c}
\hline & Argentina & Bolivia & Brazil & Chile & Guatemala & Mexico \\
\hline Judges & 11.2 & 9.5 & 7.6 & 5 & 6 & $\mathrm{n} / \mathrm{d}$ \\
Prosecutors & 0.8 & 4.5 & $\mathrm{n} / \mathrm{d}$ & 4.2 & 6.9 & $\mathrm{n} / \mathrm{d}$ \\
Defenders & 0.6 & 0.8 & 1.9 & 1.5 & 1.1 & 0.6 \\
Attorneys & 312 & 77 & 279 & 124 & 68 & 196 \\
\hline
\end{tabular}

Source: The data are for the last year available in each case (2003-2005). The information on the number of judges comes from Unidos por la Justicia for Argentina and from the Supremo Tribunal Federal of Brazil, and CEJA's Report of Justice in the Americas for the remaining countries. The data on prosecutors and defenders for all of the countries comes from CEJA's report. The information on the number of attorneys is taken from Revista Sistemas Judiciales No 9, 2005, in Smulowitz, op. cit. 
the inquisitorial system with an accusatory or semi-accusatory one - or to facilitate public legal representation.

It is worth noting, however, that even where progress has been registered, evaluations and opinions of judicial performance are still disappointing. In most countries of the continent, the justice system continues to be plagued by enormous case backlogs, obstacles to access by poor sectors, and impunity associated with powerful political and economic influences over judicial decisions. ${ }^{54}$

Average length of proceedings

\begin{tabular}{|c|c|c|c|c|c|c|}
\hline & Argentina & Bolivia & Brazil & Chile & Guatemala & Mexico \\
\hline Criminal & $\begin{array}{c}1.5 \text { to } 2 \\
\text { years }\end{array}$ & $\begin{array}{l}9 \text { to } 12 \\
\text { months }\end{array}$ & $\mathrm{n} / \mathrm{d}$ & $\begin{array}{c}3 \text { to } 7 \\
\text { months }\end{array}$ & 1.5 years & $\mathrm{n} / \mathrm{d}$ \\
\hline Civil & 2 to 3 years & $\mathrm{n} / \mathrm{d}$ & $\mathrm{n} / \mathrm{d}$ & 509 days & $\mathrm{n} / \mathrm{d}$ & $\mathrm{n} / \mathrm{d}$ \\
\hline
\end{tabular}

Source: The data from Argentina and Chile are taken from CEJA's Report of Justice in the Americas 2004-2005, and those for Bolivia and Guatemala are taken from Marchissio (2004), in Smulowitz, op. cit.

Again, the outcomes of these reforms do not seem to have lived up to expectations. Opinion polls continue to show high levels of public dissatisfaction with judicial performance. Public opinion views the system as unfair, characterized by costly delays and politically-motivated rulings, and far removed from the interests of everyday citizens. The administration of justice is considered untrustworthy, corrupt, slow, costly, and biased in its treatment of the rich and the poor. Even when, as Pásara (2004a) points out, such perceptions may be biased, information as to how the public views the justice system cannot be taken lightly; at the very least, it is worth wondering where such perceptions come from. According to the 2006 Latinobarómetro study, the public assessment of the judiciary in the region is very poor, with an average $38 \%$ approval rate of its performance in Latin America. Among the countries surveyed, only in Brazil does over half of the population approve of judicial performance (53\%) while Argentina is at the other extreme with a public approval rate of only $29 \%$. The study also showed that $66 \%$ of the region's inhabitants believe that the judiciary discriminates against them because they are poor.

54 Averages by type of crime are as follows: theft: 127 days; rape: 171 days; settlements: 193 days; slander: 108 days. 
In synthesis, studies of reform processes point to various sources of problems in their implementation (Pásara, 2004b): (a) Due to the insufficiency and quality of the data used to assess the problem, reforms were concentrated in problem areas that may not have been as serious as they seemed based on a partial reading and on an agenda proposed by international aid entities; (b) insofar as these assessments tended to attribute problems to the existing legal framework, reforms and reformers failed to take into account the political obstacles and resistance to the process on the part of local political and judicial actors. This impeded the development of strategies and networks to support reform implementation.

\section{The judiciary as a space for politics}

Those who view the judicial branch as an alternative venue for political conflicts and its institutions as a strategic resource for political action have a very different interpretation of the matter. While not discounting the relevance of the bureaucratic, functional aspects, these observers stress that the judiciary has in recent years become a space to fulfill the retributory and social aspirations of various social actors. From this standpoint, political and social actors and individuals are finding new ways to make instrumental and experimental use of this venue, transferring to the judicial sphere substantive demands and aspirations that have not been satisfied in the political playing field. In this space, demands become assertions of rights, judges become parties to political disputes, and the law is transformed into the discourse and language of conflicts. This is reflected in a significant increase in judicial litigiousness in the region.

From this perspective, the origin of, and the problems posed by, the judicialization of aspirations cannot be resolved by the more efficient administration of judicial institutions. And this growing judicialization of conflicts poses new and different questions: if expert evaluations and public opinion polls on judicial performance are consistently negative, why does

Rate of litigiousness per 100,0000 inhabitants (Number of cases per 100,000 inhabitants)

\begin{tabular}{c|c|c|c|c|c|c}
\hline Year & Argentina & Bolivia & Brazil & Chile & Guatemala & Mexico \\
\hline 2004 & 10,225 & 2,740 & 8,568 & 12,305 & 2,151 & $\mathrm{n} / \mathrm{d}$ \\
\hline
\end{tabular}

Source: for Argentina, Bolivia, Brazil and Chile: Unidos por la Justicia, 2006, Información \& Justicia. For Guatemala: Report of Justice in the Americas, CEJA'S, in Smulowitz, Op. Cit. 
the judicial caseload continue to grow? Does this mean that performance is less deficient than the evaluations would suggest? Does it mean that a significant segment of the public now regards filing judicial complaints as another tool of political struggle?

Efficiency evaluations concentrated on indicators such as delays and congestion can obscure other uses to which citizens might be putting judicial institutions. For example, if filing a judicial complaint has really become part of a broader negotiation of a conflict, then what appears as delays and congestion in less disaggregated statistics, could be an indication that the resolution of political disputes is being transferred to the judicial sphere.

Recent data on cases presented in civil courts that examine the moment at which backlogged cases became inactive point to this new interpretation (Hammergren, 2002: p.26). The fact that a significant proportion of complaints become inactive early on in the process would seem to indicate that a good number of them are being resolved extrajudicially. This situations invites the notion that political and social actors view legal complaints as just one of several instruments - and the judicial system as just one of the available avenues - for the resolution of disputes. If this is the case, and if actors use the presentation of legal complaints as a strategic tool, then the growing delays and backlog may be indicative of a different use of the judicial institution rather than its inefficiency, thereby reaffirming the existence of a process of judicialization of conflicts.

Recent studies that have scrutinized the history of cases presented in the five countries reveal an aspect of this phenomenon that had been overlooked: the high percentage of cases abandoned soon after they were opened. A study on the Juicio Ejecutivo Mercantil in two courts in the Federal District of Mexico (World Bank, 2002) showed that $80 \%$ of the cases were abandoned by the parties and never resolved, while $60 \%$ of cases became inactive after they had been declared admissible. A study conducted in Brazil indicated that $48 \%$ of executory actions and $51 \%$ of monitory actions were stopped after having been declared admissible by the judiciary, and $20 \%$ of the former were subsequently abandoned..$^{55}$ Only in the Argentine case did the data reflect lower levels of case abandonment prior to resolution.

But this strategy is more ambivalent than would appear at first glance. In effect, if actors presume that the judicial response is going to take time then there is less incentive to use the system as a mechanism to regulate 
and arbitrate conflicts and less chance that actors will resolve their conflicts on the basis of law. This increases the barriers to access and impinges on the social equity of the outcomes. Delays increase obstacles to access by discouraging the use of justice services by those who are not in a position to wait for long periods to get results. It exacerbates social inequity because those who cannot await the results of their legal process are forced to resolve their conflicts in the context of binary relations in which the imbalance of power between the two parties is what ultimately decides the outcome. Therefore, in addition to the problem of judicial efficiency per se, it is also important to recognize its correlation to the greater or lesser degree of equity in the outcomes yielded by the system and of the propensity to actually use it.

Whataretherepercussionsoftheadventofthesenewtypesofinterventions? For one thing, the law has become another strategic instrument for doing politics. According to some authors, this judicialization is allowing citizens to employ the coercive powers of the state to pursue their own interests and therefore should be viewed as a form of citizen engagement in democracy. On the other hand, however, judicialization enables minority actors to intervene and exert influence over public issues without having to reach significant majorities. In this sense, while such interventions make it possible to incorporate issues and actors otherwise excluded from the public debate, the caveat is that it can also have antidemocratic outcomes.

\section{Justice and social cohesion}

How do these two views of the judicial issue relate to social cohesion? From the administrative standpoint, improved judicial performance will reduce obstacles to access and other related factors that conspire against social cohesion will tend to dissipate. On the other hand, and regardless of whether the performance of judicial institutions can actually be improved, social cohesion is contingent on the innovative ways in which actors use the judicial space to claim and demand their integration into the broader political community. As a result, aside from matters specific to administrative aggiornamento, the latter perspective is contingent upon the establishment of conditions (lower thresholds of access, support and legal aid structures) that facilitate the use of this sphere to change the distribution and protection of rights in the political arena.

It is also important to examine the extent to which the judicialization of social life is part of an ambivalent attempt by individuals to establish new 
bonds of trust with institutions. With regard to the judicial issue, how can we ignore the profound distrust expressed in public opinion polls and all of the promises surrounding this renovated resource on the part of court actors? Inequality vis-à-vis the justice system is among the most dramatic and dangerous symptoms when it comes to social cohesion. Not only does it corrode the legitimacy of public institutions, it has an even more profound effect on the very meaning of collective living. The perception of an unfair (not just ineffective) judicial system engenders contradictory feelings that flow easily into political nihilism. Experiences of this type take on even more dramatic overtones in a region wracked by serious problems of violence, organized crime, and corruption. The outcome, as we all know, is a mixture indignation, cynicism and apathy.

But we reiterate the novel aspects of the process currently underway. While the law is hardly - and poorly - enforced, recourse to the legal system is on the rise. And although dominant groups continue to enjoy unabashed impunity, some of their acts, such as certain forms of corruption and human rights violations, are beginning to be punished. Some would say, and rightly so, that the process is still hesitant and painfully slow. Yet the promise is real. At the same time, one cannot expect that the judiciary alone will be able to regenerate state institutions. This is especially true since an overload of expectations concentrated in this branch will ultimately politicize it, and lead to executive and legislative attempts to rein it in.

But taking a closer look, and despite Latin America's secular self-image as a continent with a particularly entrenched culture of transgression, we cannot fail to notice that in recent decades (unprosecuted) public corruption cases are increasingly widespread in other latitudes, while public rejection of such behavior is on the rise in Latin America, owing in large part to the influence of the media. Turning to human rights violations, while the panorama remains poor in many countries, it is also true that public efforts and awareness have a higher profile than in other parts of the world. Our intention, of course, is not to negate the serious pitfalls or the gravity of the problems, but to make sure we do not overlook the virtue of the promise.

\section{Conclusions}

This chapter is clearly a study in contrasts. First, as we have shown, $21^{\text {st }}$ century Latin America has become the theater for real growth in delinquency and criminal acts, as reflected in armed urban violence or the emergence 
of organized crime which, under cover of international networks, severely compromises the legal institutionality of the countries of the region. In some countries, violence and crime are a relentless nightmare that - due to the deficiencies of the state - individuals must face based on their different possibilities to do so. Ultimately too, when individuals take charge of their own security, they end up covering over the institutional gaps (which often are part of the problem, given the porous boundaries between legality and illegality among the very actors charged with law enforcement).

Second, corruption among politicians, high level officials, and the police, coupled with the inefficiency of the judicial system, is high on the public opinion agenda. Whether because it is actually on the rise, or because investigative journalism and the news media are more efficient, and/or because people are more sensitive to such phenomena, corruption plays a key role in political dynamics.

Case by case, corruption corrodes people's trust in institutions, producing cynicism and frustration. It also hampers processes of egalitarian individuation since everyone is potentially dependent on a favor; sooner or later, a well-situated friend or acquaintance will help find a "way out" But something new is insinuating itself into this scenario. Public awareness concerning impunity is on the rise, especially among the middle classes. True, at the moment this heightened sensitivity is often expressed in ambivalent ways: alongside a fatalistic or bitter attitude towards the entrenched secular failure to respect the rules, there are movements in the region, often in the form of collective or individual outbursts that seek to progressively limit impunity for such acts.

These two contradictory realities - the rise in increasingly violent crime and the still incipient attention to certain forms of abuse and corruption - are the fruit of the democratic revolution sweeping the continent. When the symbolic equality among citizens is divested of hope or resources, what emerges are predatory and criminal behaviors along with socially destructive or personally self-destructive attitudes. But that same symbolic equality among citizens is what sometimes triggers demands for respect for the law, and if need be, efforts to defend themselves through the law. The former conspires against social cohesion (especially by giving shape to perverted expressions of micro-cohesion in criminal groups). The latter buttresses social cohesion (since it conveys a modicum of trust in institutions). Which of these synergies will win out is contingent on the nature of the democratic game that takes shape in the region in the coming years. 


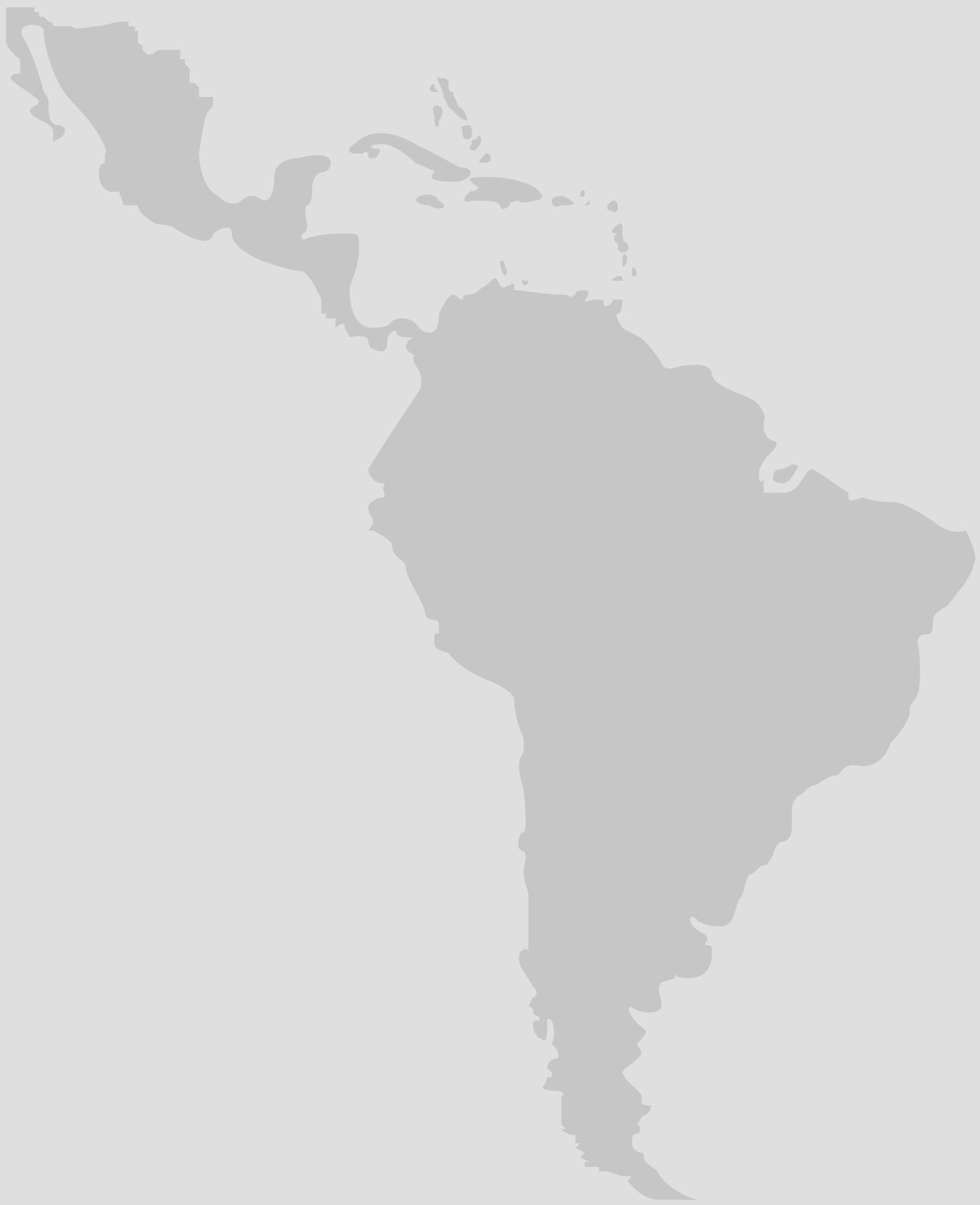




\section{Chapter IV}

\section{State, Nation and Politics at the Dawn of the $21^{\text {st }}$ Century}

\section{Introduction: State and society, a prismatic relationship}

The gulf between the state and much of society has led to conflicting interpretations of their respective roles in Latin American history. For some observers, the state has been the vehicle for order and progress in amorphous societies fragmented by particularistic interests. Others, in contrast, regard the state as a source of patrimonialism and an obstacle to the autonomous development of society and the public space.

Dichotomies rely intrinsically on oversimplification and these conflicting interpretations of the past refer to rural, elitist societies that have little in common with contemporary urban, mass societies. A more painstaking examination of the history of various Latin American countries would reveal that both interpretations are rooted in different circumstances and moments in history. The Latin American state was characterized by its unity, continuity, and organizational stability. Buffeted by constant modernization processes, it promoted modernizing dynamics in the economy. The stability of the state system in the region - which set it apart from other regions helped consolidate a government apparatus that would guarantee territorial and identitary unity. 
In practice, neither the state nor society had a univocal role in setbacks or progress; indeed their interdependence and cross-impacts were reinforced over time. Even so, it is perhaps safe to say that despite the institutional modernization processes underway in many countries, the state is lagging far behind the fast-paced modernization of society with the attendant demands for infrastructure and regulatory systems. Indeed, in many areas, the state is showing signs of collapse. In the 1980s, this was reflected in hyperinflation, in other words, the state's inability to fulfill one of its basic missions: to guarantee the value of its currency and, by extension, people's assets (wages, property). Today this collapse is evident, as we have discussed, in the state's growing inability to protect property, security and above all, life (basic human rights) in the face of growing criminal violence that frequently implicates law enforcement officials.

It comes as no surprise, then, that the state apparatus often proves unable to address the countless, and sometimes new, social and economic pressures confronting it. This has undermined the credibility of the region's welfare States, some barely nascent, and produced a crisis or an inadequacy conducive, as we will see, to the expansion of neo-populist or authoritarian leaders.

But states are facing two additional pressures as well: the first is a plethora of new institutional demands, often spearheaded by ethnic or minority groups, which are putting to the test the age-old equations premised on the system of nation states. Nation states were founded on the positive construction of a narrative that fostered a sense of a community of citizens and on the simultaneous destruction, repression, resignification, or banishment to the private realm of precedent or competing collective identities. The schools, heroes and national holidays, intellectuals, and particularly in Latin America, the media, played critical roles in this protracted construction process. While these disparate factors have not disappeared, the old national narratives are now being assailed by unprecedented institutional pressures from new actors.

But perhaps no other variable offers a better blueprint for the relationship that must be established between the state and society than the phenomenon of consumption. Here we must conclude that the demonization of the market or of the state as mechanisms for ensuring access to public goods and a basic income, which includes the regulation of labor relations, is clouding our ability to grasp what is taking place in Latin America. The challenge for us today is to integrate the market in its role as the main generator of wealth with social policies that modify income distribution without alienating the middle sectors. We must, for example, encourage a balanced debate over 
how to flexibilize labor rights without abolishing them, while integrating the informal sector into the state-regulated economy.

Social policy and the myriad of possibilities for ensuring access to public goods - including the regulation of public service concessions and curbs on oligopolist practices in the private sector administration of public services - cannot be designed by technocrats out of the public eye. But this means that we must revisit the notion that the role of the state is simply to offset the failures of the labor market, as if a labor market could actually exist without state regulation. At the same time, the state's role has to change substantially. Mechanisms for internal oversight and citizen participation in government institutions are required to curb patrimonialism and ensure democratic supervision of government administration and social policy.

Each of these points sheds light on different aspects of a single overarching trend. When it comes to the two major principles of societal integration - the state and the nation - we are not witnessing a dichotomy of "individuals" versus "groups." As in the preceding cases, what we are seeing is an entire spectrum of new expectations which, when conveyed by actors operating with new parameters for action, bring about a transformation of considerable proportions. Even when their demands take dangerous turns, individuals ultimately are expressing a desire for greater recognition as citizens, whether in terms of public policy, symbolic integration, or access to consumption. In any case, symbolic and participatory needs are just as important for social cohesion in democracy as the socioeconomic aspects. And this imperative informs the structure of this chapter. We will address the observable changes and continuities in the state and the specific problems associated with redefining the boundaries between the public and the private in the area of consumption, before turning to the issues of populist temptations and the symbolic mutation of nation.

\section{The State: continuities and challenges}

The State has been, and remains, the main actor in Latin American societies. From independence onward, its role has been fundamental for social cohesion both in its symbolic or national dimensions and in terms of economic and administrative territorial integration. A review of the main trends in the history of the formation of the state can help elucidate the current situation before we delve into the challenges posed by contemporary globalization processes. 


\section{The long journey of the Latin American state $e^{56}$}

The trajectory followed by Latin American countries from their founding to the present reveals a remarkable degree of continuity and relative stability in the state apparatus established in the $19^{\text {th }}$ century. While borders were frequently redrawn, transferring strips of territory from one State to another, the fragmentation caused by international conflicts, civil wars, indigenous uprisings or regional struggles did not - with few exceptions - extinguish previously constituted sovereignties or give rise to new entities. The longevity of the state order in the region has been a salient factor in the continuity of Latin American countries in the international system. Indeed, beginning in the Pre-Colombian era and throughout three centuries of colonialism, state domination was a constant in the meso-American and Andean regions. For example, the policies of various national governments - Peru, Bolivia, Chile, Ecuador and Argentina have had a centripetal effect on large ethnic groups such as the Quechuas and Aymaras, which have been divided among more than one sovereign nation for nearly two hundred years. Because of this, the state has gradually become an inescapable horizon of the social life of these communities and a reference point, albeit a precarious one, for their collective identity.

Alongside this trajectory is an equally longstanding phenomenon which is the flipside of state cohesion and the reason for its survival. There exists an unspoken pact in which the subjected communities acknowledge the state's right to exact tribute and demand service provision, while the state, in turn, is disposed to ensure the conservation and reproduction of the corporate structure of the communities by refraining from direct interference in their internal organization or in the make-up of their authorities. The very structure of the oligarchic authority abetted this division until well into the $19^{\text {th }}$ century. Their own cohesion rooted in family ties and extended family networks, Latin American oligarchs identified much more with the outside world than with the realities in their own countries. This centrifugal focus was strengthened by a caste structure inherited from colonial times that deepened the social gulch, excluding members of indigenous communities from national life, while enabling the power elites to exercise political dominion over the "republic of Indians."

56 This section is based on Antonio Mitre, "Estado, modernización y movimientos étnicos en América Latina." 
In sum, the state as a constant over time and aloof or absent from the social space, is the key to understanding the nature of political domination in the countries produced by colonization.

Another trend that helped consolidate the Latin American political map was a decline in inter-state wars in the $19^{\text {th }}$ and $20^{\text {th }}$ centuries. The rise of U.S. hegemony post World War I played a crucial role in this by buffering the impact of extra-continental conflicts and serving as a moderating force in regional disputes - not to mention its repeated invasions and incursions into what it regarded as its sphere of influence. It also helped that Latin American nationalisms were established belatedly, not in response to foreign domination or conflicts with other states, but fundamentally as levers for industrialization or development projects. By the time this phase was consolidated, throughout Latin America, the "imagined enemy" that is part and parcel of all nationalistic discourse was already embodied by the figure of the Empire - the United States - while for the Republic of the North, the "empire" was first England, then Germany, and later the Soviet Union. In this way, the rabid anti-imperialism south of the Rio Grande paradoxically served as an effective antidote against aggressive nationalism and under conditions of "Pax Americana," had relatively fewer catastrophic consequences from the standpoint of war.

We should note here that many Latin American intellectuals cultivated a pacifist vocation that has spanned two centuries of republican existence. Their philosophy is reflected powerfully in the work of Juan Bautista Alberdi, El Crimen de la Guerra [The Crime of War]. What is more, no Latin American country has ever exercised colonial domination or exploitation over populations and territories outside of its own political jurisdiction.

Contrasting sharply with their inclination towards a relatively peaceful external coexistence is the acute inability of Latin American states to prevent violence within their borders. The face of this violence has changed in recent decades, from one that is primarily political to diverse manifestations grouped loosely under the term "citizen insecurity." The common thread in both incarnations has been the state's chronic inability to control all of the territory under its jurisdiction by ensuring an institutional presence and the rule of law. The emergence of free or liberated territories - an intermittent phenomenon in the history of most countries in the region - is the most acute manifestation of the vacuum left by the state and deepened by the infinite, day to day infractions of the law perpetrated with absolute impunity by members of society. Succinctly put, states evince greater sovereignty facing outward than within their own territories. 
One can infer from these observations that the sustainability of Latin American states in the international system does not seem to be contingent on the degree of domestic cohesion. Indeed, dating back to the struggles for independence, external ties were essential to the constitution and consolidation of states. In order to concentrate power, the forgers of states required access to outside weapons and funding and the resulting bonds of dependence afforded them a source of autonomy from their social base and always scarce local resources. More than merely a financial transaction, indebtedness was a tacit acknowledgment of a sovereignty in the hands of "capitalized coercion."

Similarly, if we examine the correlations between economic opening, bureaucratic expansion and state consolidation, we can see the comparative advantage, during the states' formative stages, of having in place a bureaucratic layer capable of dealing with the foreign sphere. This shaped the economic development of the nascent states and also might explain in large part the differences that would later crystallize in their respective agendas. Theories arguing that the state, on the periphery of the capitalist system, would be the weakest link of foreign domination, accustomed several generations of intellectuals to the notion that there would be an inverse correlation between the level of exposure of economies peripheral to the international market and their degree of political autonomy, with deleterious consequences for the very construction of the state. The study of different historical processes shows that under certain conditions, the opposite is true: economic opening and exposure to the influences of international capitalism can increase a state's regulatory capacity and spur the modernization of its bureaucracy. In the same way, experiences of government reorganization at the behest of hegemonic powers tend to strengthen the autonomy of peripheral states, enhancing their bureaucratic capacity to control particular interests, whether domestic or international.

One of the factors at play here is that, except in crisis situations, the structure of interaction between states is conducive to cooperative behavior, inasmuch as it constitutes, by necessity, a much more stable and durable horizon than that guiding the calculus of private agents and groups. From this standpoint, the final decades of the $20^{\text {th }}$ century marked a shift from a pattern of direct state to state relations towards one characterized by the interference of multiple subjects galvanized, as noted earlier, by a hefty contingent of international agencies and organizations operating in a legal milieu that is less than sensitive to institutions and values associated with the principle of sovereignty. The astonishing level of activity undertaken 
by states, and fragile ones in particular, in the contemporary international arena - leaving aside for a moment ideological differences and geopolitical motivations - seems to point to the need to restore the sovereignty in their relationships with their peers that has been diminished by disaggregatory influences and pressures. An important aspect of the aforementioned strategy is the expansion of the bureaucratic infrastructure needed for the external activities of states, since it requires a lesser investment of time and money than the expansion of the domestic matrix and tends to be an effective formula for obtaining short-term political gains.

Viewed through this lens, the recent wave of nationalizations in the region takes on new meaning, particularly in countries where the sale of state sectors represented not only the privatization of an economic sphere, but also the elimination of an important column of the state's bureaucratic platform and regulatory capacity. On the domestic front, the formation of the industrial system during the national populist era was critical to the consolidation of state autonomy. The expansion of the bureaucratic machinery driven by industrialization expanded the legal and institutional platform of states and afforded them national density. As a result, in countries where the industrialization process was weak or never really took hold, the bureaucratic structure atrophied and the state, more vulnerable than ever to the predatory action of private interests, lacked the social base to sustain itself nationally.

Today, a comparison of the levels of social modernization and industrial development achieved by countries in the region reveals the tensions fueled by intensified demands - a widespread phenomenon that has been compounded by the demonstration effect created by globalized modernity - and the uneven capacity of state systems to process it. This panorama is even more complex in predominantly indigenous regions where the nationpeoples pact incorporated the rural population into state institutions through political parties, trade unions and peasant federations, but did not interfere with the internal organization of the communities.

\section{The State at the crossroads of globalization ${ }^{57}$}

Many of the challenges facing welfare states in the region today must be understood against the backdrop of these historical continuities. In

57 This section is based on Luis Alberto Quevedo, "Identidades, jóvenes y sociabilidad." 
the current context, public policies are hard-pressed to reverse the main currents of globalization or confront major supranational challenges. It has become almost cliché to observe that in the context of territorial redimensioning, problems at the global-regional and local level take on new relevance. Globalization processes erode the political capacity of states, even as transnational networks encroach on the traditional space for doing politics, namely, the national framework (as defined by the concepts of territory and sovereignty).

Several "macro" phenomena have emerged, as complicated as they are varied, in the economic, financial, political, and cultural spheres. Each of these must be addressed separately, always bearing in mind, however, that they are convergent and involve many other processes. While political sovereignty in our countries inevitably still operates within certain spatial parameters, markets and public spaces have swelled to the point that they are no longer localizable. Inasmuch as "space and territoriality no longer serve to symbolize the boundaries of society" (Bolz, 2006), the political sphere tends to lose control - at least partially - over economic and communication processes. One of the ramifications of this is that the nation-state is no longer "the natural repository of the people's trust" (Bauman, 2005) and this, in turn, undercuts its traditional role as a unifying entity.

The limitations placed on the state in the era of globalization (and the need to implement new forms of government intervention) have not, however, tempered citizen expectations vis-à-vis the state. To the contrary. The state is still the target of the most essential demands for protection (even more so when the main actors of the globalized economy seem remote and opaque). In any event, the disaggregatory market trends that emerged - and virulently so - in the region in the 1990s, have frequently demonstrated their scant effectiveness in transforming antiquated public institutions.

Although the outcomes of structural reform policies vary greatly from country to country, in many instances their negative effects became evident at the most primary, reticular social level. In the wake of these failures, many Latin American states were once again called upon to take responsibility for ensuring social cohesion, particularly when the specter of "dissolution" was raised (in the strongest terms). Indeed, ultimately no one turned to the market or civil society organizations in search of cohesion, rather it became incumbent upon the state to recover one of its most classic functions. This is not to say (as we have discussed) that civil society has not 
developed its own strategies for identity, survival, community bonds and economic solidarity in order to subsist. But the hardest task was reserved for public policy, meaning redistributive economic policies, compensatory social policies, and national projects. With the climate favorable for economic growth recovery in recent years, many countries began to take steps in this direction.

The "return to the state" after a decade of pro-market reforms is ambiguous however: society-state relations are marked by distrust toward representatives, and a significant portion of society views the state as a privileged intermediary in its own self-identification as the collective order. One interpretive key to this analysis perhaps might involve deciphering the significance of the coexistence of the "crisis of representativity" and the "demands of the community (or the group)" in each of our countries. This is true whether we are examining the "populist shift" taking place in some countries or the nature of a social conflictivity that produces "impatient" subjectivities organized into "communities of indignation" (Innerarity, 2006). Indeed, what is taking shape seems to be a quest for a more direct relationship between the individual and the state to the extent that traditional interlocutors (trade unions, political parties) have been debilitated, as discussed earlier.

\section{Challenges to the welfare state in Latin America ${ }^{58}$}

It would be a mistake, however, to insinuate that this process is analogous in all Latin American countries. Indeed the challenges for social cohesion have very different impacts depending on the welfare state model in effect. Borrowing from Filgueira's work (1988), we can identify some of these disparities based mainly on the typology proposed by this author in three categories: stratified universalism, dual systems, and exclusive systems.

"Stratified universalism" refers to the combination of broad coverage of social benefits, with substantial differences in terms of the variety, eligibility requirements (retirement age or prerequisites for home financing, for example), and quality of the benefits. Such arrangements are modeled on the corporate welfare systems of continental Europe. The countries that typically follow this type of system are Argentina, Costa Rica, Chile and

58 This section is based on Ruben Kaztman and Luis Cesar de Queiroz Ribeiro, "Metrópoles e sociabilidade: reflexões sobre os impactos das transformações sócio-territoriais das grandes cidades na coesão social dos países da América Latina." 
Uruguay, although the profile of the Chilean welfare state seems to be leaning towards a more liberal model in the Anglo-Saxon tradition. ${ }^{59}$

Filgueira offers Brazil and Mexico as examples of "dual systems." Although residents of the principle urban areas have access to a welfare system of the sort we have described as stratified universalism, social services provide very little coverage to the rest of the population. In these cases, the difference lies in the fact that, politically speaking, "the control and incorporation of lower income sectors has been based on a combination of clientelistic and patrimonialist forms in socially and economically less developed areas and vertical corporativist forms in more developed areas" (Filgueira, 1988).

The category of "exclusive regimes" which according to Filgueira encompasses the rest of Latin American societies with the exception of Panama, are historically characterized by the presence of elites who "appropriate the state apparatus and, sustained by the exportation of primary goods in enclave economies, use the fiscal capacity of those states to extract revenues, without providing the counterpart of collective goods, whether in the form of infrastructure, regulation, or social services. These sorts of social protection and insurance systems consist largely of elitist policies that accord additional privileges to those already in positions of privilege. Typically, professionals, a minority of formal employees and public officials benefit from this model. Much of the population represented in the informal sector, agriculture, and secondary labor is excluded.... Consistent with this panorama, social indicators in these countries are routinely poor and display the highest differentials in regions with varying development levels" (Filgueira, 1998).

It is reasonable to expect that the reaction of societies with more egalitarian socio-cultural patterns (stratified universalism) to trends toward diminished social cohesion triggered by new forms of accumulation will be similar to the reactions observed in more developed countries. In any event, this somewhat simplified classification helps demonstrate the variety of political agendas currently operating in the region.

Most of the countries that succeeded in galvanizing their industries in the past set up social welfare systems that, while not without gaps, benefited significant segments of the urban population. One might predict, then, that those segments would use their past gains as a yardstick for current demands and as the criteria for weighing the advantages and disadvantages of the 
situations they encounter with the advent of new forms of accumulation. Conversely, in exclusive systems, the segmentation caused by new growth modalities probably will meet with less resistance and this will reinforce the profound fragmentation already evident in their cities. The isolation of the urban poor is a more serious and longstanding problem in the latter countries and in many cases is probably intensified by the breakdown of traditional domination models and their intricate relationships of hierarchical reciprocity and moral obligations. ${ }^{60}$ Perhaps for this reason, in countries organized under the exclusive model, the impact that increased isolation due to new growth modalities has had on the urban poor is obfuscated by the fact that these countries had never managed to solve the basic problem of how to universalize social rights. The ability to process and resolve basic social tensions, then, is still latent in these societies and they erupt sporadically in the form of conflicts and violence. Such tensions reflect a difficult negotiation process that was begun, but never concluded, between alternative and conflicting projects for the construction of nationality.

It is necessary, then, to take an equanimous view of the contemporary situation. The interpretation that for decades pointed to a linear and progressive process of granting new rights has, on occasion, run up against the contention that the welfare state has been progressively dismantled in recent decades. An erroneous analysis on all counts. What we have witnessed in recent years is a complex panorama of overlapping processes, in which some rights deteriorate or are eroded in practice, while other important rights and opportunities are granted. National differences notwithstanding, no unilateral interpretation can truly explain the current situation. In any event, these limitations are not unrelated, as we will see below, to the myriad transformations fueled by growing consumption in the region.

60 This is the argument put forth in some studies on Brazil that have sought the reasons for urban violence in the decomposition of the hybrid system of reciprocity historically shaped by conservative or selective modernization, which has not been replaced by rules premised on the rights of citizens. For a discussion of this, see Soares (1997) and Velho (1996). For an interpretation that counters the hypothesis of the crisis of the hybrid system of reciprocity, see Souza (2003). 


\section{Consumption: individual and collective goods ${ }^{61}$}

Markets are not predetermined entities. They emerge in the most diverse forms and are constantly transformed by social and political actors. ${ }^{62}$ At the same time, once they have been institutionally established and consolidated they impose their own dynamics on social actors. Markets are not immutable, however, and to a large extent the history of capitalist societies is the unfolding of social, political and cultural struggles over the mercantilization/demercantilization of social relations and the private/ social content of property, labor relations, what is produced, and how it is distributed.

This is not to say, as Latin American history shows, that all struggles against mercantilization are inherently progressive or, conversely, that more mercantilization is necessarily a regressive phenomenon. Many antimercantilist arguments are associated with romantic-reactionary visions or with the defense of corporative interests or those of groups that benefit from state revenues and monopolies. In turn, greater mercantile freedom can mean more production and income and improved distribution of social wealth. Similarly, consumption may be a source of freedom and self-expression or a source of alienation and a sign of social inequality.

\section{Market and antimarket in Latin America}

To varying degrees in Latin America, "merchant" and "trade" were traditionally associated with the foreigner ("Jewish," "Spanish," "Turkish," "Arab," "Chinese"). These groups did not adhere to the local codes of clientelistic relations and were apt to be stereotyped as ambitious and profit-mongering. The notion that trade had no soul was carried to an extreme in the work of Uruguayan writer José Enrique Rodó, for whom Latin America was guided by spiritual and aesthetic values, while the United States embodied the mercantile world driven by materialistic and quantitative values.

61 This section is based on Bernardo Sorj, "Capitalismo, Consumo y Democracia: Procesos de Mercantilización/desmercantilización en América Latina."

62 As indicated in much of the literature, beginning with Polanyis pioneering book (1944) and including contemporary works in the area of economic sociology such as Granovetter and Swedberg (1992). 
Latin America is not alone in its reluctance to accept the market. As brilliantly explained by Marx and Engels in the Communist Manifesto, the market disorganizes values and traditional systems of domination, solidarity and lifestyles. In most European societies, moreover, the various influences of Catholic, Socialist, and Romantic thought produced a certain distrust of trade and of the figure of the merchant. The United States, and to a lesser extent the United Kingdom, may be the only societies with a predominantly positive view of the market and its attendant values, such as profits, competition, merit, wealth, success, individual consumption and ambition.

In the United States, the market and its values are building blocks for the construction of individual identities and narratives and these values, which are encouraged by the political discourse, give legitimacy to the system. In Europe, despite the growing presence of the market in political discourse, the nation state serves as the repository for common values and the main target of political action. Ostentatious consumption is less apparent. While these disparities are real, they do not translate in practice into diametrically opposed models. Mercantile values and consumism have penetrated deeply into all European societies and in recent decades have even been integrated into the discourse of most political parties. ${ }^{63}$ At the same time, solidarity and opposition to inequality in its most extreme forms have always been present in social relations and the political debate in the United States. ${ }^{64}$

In the wake of the structural reforms of recent decades, in many Latin American countries an eclectic array of actors has forged a broadbased alliance against the "market" (defined as the antithesis of the protector state). It includes segments of the antimercantile Catholic tradition; holdouts of revolutionary socialism that associate working class access to mass consumption with alienation; a brand of nationalism that equates the market with globalization and the latter with the power of the United States; and groups that feel they have been harmed by privatization, often merged with the agendas of social movements critical of different aspects of the mercantilization of social relations.

This broad, complex and often ideologically confusing mix of factors and actors has stoked a powerful antimarket sentiment in some cases mobilized

63 Although, in cases such as France, individualism, meritocracy and competition are present in the civil service career.

64 Even the Sherman Antitrust Act, approved by the United States Congress, was designed to protect against economic power. 
by political discourses with significant authoritarian, nationalistic or statist components. The alliance of antimarket groups has many paradoxical features, uniting as it does the most disparate sectors. These include the poorest groups which experience the market in its crudest and most direct forms in their struggle to develop new survival strategies every day; middle class sectors that have lost government benefits; and NGOs as vehicles for an antiglobalization and antimarket discourse (even though they are themselves a product of globalization).

It has not always been this way. The socialist parties at the start of the $20^{\text {th }}$ century advocated free imports as a way of ensuring urban workers access to cheaper commodities. The movement toward export substitution, however, forged an alliance among trade unions and entrepreneurs, supported byleftist political parties, that shifted the focus from consumption to employment. This fusion sometimes gave rise to a perverse symbiosis through which the business sector (including state-owned enterprises) — waving the banner of nationalism - produced expensive, low quality commodities. It is no coincidence that economic liberalization and privatizations were welcomed, especially by upper and middle classes, which are more sensitive to product quality given the diversity and scale of their consumption as well as their exposure to foreign goods.

Pro-market forces, largely comprised of more modern and cosmopolitan middle income sectors, have found themselves somewhat isolated politically due to their inability to craft a message capable of capturing the imagination of wide swaths of society. The vast majority of the population, from the Rio Grande to Tierra del Fuego, opposes privatization initiatives. There are several reasons for this. First, economic structural reforms failed to make any noticeable difference in social inequality. Moreover, promarket groups constitute a new elite (entrepreneurs, economists, business administrators, attorneys) whose discourse of efficiency and integration into the international system displays little sensitivity toward local conditions and the political and social context. And finally, among the opposition are sectors which were directly harmed, together with the old left which successfully leveraged the symbiology of national sovereignty by linking it with state-owned enterprises.

Social inequality fuels ideological polarization, making it very difficult to develop new political and intellectual discourses that offer a balanced analysis together with proposals for mercantilization/demercantilization processes that ultimately would consolidate democracy with equity and growth. 
The above notwithstanding, consumer protection has increasingly become the focus of a broad spectrum of public agencies responsible for authorizing the release of medications, supervising food hygiene and technical product standards, and enforcing consumer rights. Over the past two decades, many Latin American countries were surprisingly successful in their efforts to pass consumer protection laws. Backed by civil society, these laws have had a significant impact on businesses and have helped to promote the notion of a proactive consumer. ${ }^{65}$

\section{Individual consumption and political dynamics}

The society of mass consumption that has taken shape in Latin America in recent decades has had contradictory effects on the democratization of social relations and social cohesion. Mass consumption, advertising, and the consumer culture have virtually destroyed the symbolic barriers among social classes heretofore cocooned in relatively closed systems of aesthetics, tastes, and consumption patterns. While this transformation clearly has its positive side in the sense of universalizing expectations of access to goods formerly unavailable to much of the population, it has also bred dissatisfaction and frustration.

The old socially stratified culture of consumption was characterized by a certain degree of resignation combined with a solidary acceptance of the destiny of the group and of specific forms of fulfillment and entertainment. The revolution of expectations brought about by the culture of mass consumption encourages egalitarian values, but also contributes to social anomie inasmuch as many aspirations of consumption are not fulfilled and probably never will be. It could be argued that the extreme value placed on access to consumer goods leads to individual aspirations that value inequality, or at least make it more acceptable: everyone believes in the legitimacy of aspiring to consume more and this becomes the justification for consuming luxury items, which in turn become the horizon of common aspirations.

Particularly among the poorest sectors, access to consumer goods requires family strategies in which each member contributes - often using some form of credit - to the purchase of merchandise (a refrigerator, television, DVD, sound system, computer, car). Working class sectors

65 For an examination of the Brazilian case, see Sorj (2000: Chapter III). 
across Latin America increasingly possess such commodities, frequently with the aid of the informal sector which markets brand-name clothing imitations, contraband electronics - particularly from Asia - , and illegal copies of audio-visual materials. The products and styles of the middle and upper classes, then, are now within reach of working class sectors and the poor. And yet, while the radio, television, refrigerator, CD player, and increasingly the cell phone, are accessible to much of the population, other commodities such as a car, cable TV, a computer and the Internet, not to mention international travel, continue to be the privilege of the few.

Consumer goods, by social class (\% of owners)

\begin{tabular}{l|c|c|c}
\hline & \multicolumn{3}{|c}{ Class } \\
\hline Cable TV & $\begin{array}{c}\text { Upper and upper } \\
\text { middle class }\end{array}$ & Middle class & Lower class \\
Landline telephone & 78,6 & 62,4 & 39,2 \\
Mobile telephone & 87,3 & 77,5 & 62,5 \\
Internet access & 90,4 & 81,1 & 66,6 \\
Automobile & 61,5 & 33,3 & 15,8 \\
Motorcycle & 67,9 & 45,3 & 25,3 \\
Washing machine & 27,5 & 9,4 & 7,7 \\
Firearms & 83,0 & 71,1 & 55,0 \\
\hline
\end{tabular}

Source: ECosocial, 2007 (urban populations)

Similarly, widespread access to the communications media reinforces the consumption society by unifying the symbolic universe of the population, which is tuned in to the same flow of advertising and information (although obviously the ability to process the information varies greatly according to educational level). The cultural repertoire, values and tastes of diverse social groups are homogenized since everyone is watching the same television programs. This influences political communication styles and unifies the national space. Meanwhile, "white line" appliances, particularly the refrigerator, facilitate access to the latest consumer food products distributed by the supermarket chains that have popped up in every neighborhood. 
New consumer products influence living and working conditions as well as the styles. The cell phone, for example, eases the logistics of a whole contingent of informal service workers (just as it has come to be used very efficiently by organized crime). But it also facilitates parental contact, especially between working mothers and their children.

As noted in the first chapter, mobile telephone use has expanded enormously among the poor, facilitating a degree of telephone access never achieved by the landline. Internet access, in contrast, remains essentially confined to the middle classes. Bearing a closer resemblance to the United States than to Europe in this regard, access to consumer goods in Latin America is experienced as a symbol of citizenship. It conveys a sense of belonging to society, of participating "as equals" through access to material goods and in particular, to symbolic goods, since the media, and the television in particular as we have noted, create a common space for participation within a single universe of information and culture.

Therefore, while the market remains severely limited as a mechanism for job creation and income generation, it has been highly successful in reducing the prices of certain goods and expanding marketing and credit systems. This is not to say that expanded consumption has create a state of satisfaction. To the contrary, dissatisfaction is a constant in a society of consumption that is perpetually generating new products and feeding the desire to consume them. This is true of young people for whom access to consumer goods is part and parcel of social self-affirmation. At the same time, spiraling consumer expectations and the attendant frustrations are not channeled into collective demands and instead are experienced as an "individual problem."

Let us take a closer look at this last point. Consumption conveys a sense of belonging that differs from the bonds of citizenship created by membership in a particular political group. The citizen-consumer is at once more differentiated and more standardized than the citizen-politician. More differentiated because consumption creates an infinite spectrum of positions and distinctions, quite unlike political citizenship (which ultimately, and only in a more or less transitory way, creates "second class citizens"). But this type of belonging is also standardized because consumption implies entering an overwhelmingly homogeneous shared world not, of course, in terms of goods actually consumed, but definitely in terms of expectations of consumption (in contrast to the universe of the citizen-politician structured, at least from the normative standpoint, around a capacity for critical judgment). 
Despite the commonality in terms of expectations, consumption strongly accentuates the individualization of social actors (owing to the incredible qualitative differentiation in the range of products). The result is an implicit acceptance of inequality even as margins of individual consumption widen. This is perhaps one of the main political ramifications of consumption. Contrary to popular wisdom, consumption in mass society has not been a factor in deindividualization. Indeed, from an historical perspective, mass society and consumption have been driving factors in an individualization process heretofore confined to certain elite groups (Millefiorini, 2005). But the fact that consumption - unlike rights - operates through a diversified and unequal range of products creates a sense of belonging marked from the outset by a structural tolerance toward differences and inequality. The important thing is to participate in consumption, practically and symbolically. This attitude is aptly illustrated by the race toward credit observed among low-income sectors (despite the attendant risk of upsetting individual and family equilibriums).

\section{Public goods and democracy}

The expansion of mercantile relations in Latin America was marked by the colonial legacy of a rentier state - a purveyor of prebends - that created an elite accustomed to privilege, hierarchical relations, and production systems organized around slavery or servitude. During the subsequent period of expanding industrialization, the state continued to serve as a source of revenue and privilege for public sector contractors teamed with politicians. Public resources allocated for social policy primarily benefited the middle sectors and civil servants, although labor struggles did result in certain social benefits for organized working class sectors.

The distributive impact of public revenues can be examined from the standpoint of how they are collected or how they are spent. The more they are derived from direct tax contributions by the richest sectors, the more progressive the tax system. From the distribution standpoint, there are three basic models: the first, a regressive model, transfers public resources unevenly among the different social strata, primarily benefiting the middle and upper sectors. Up until recently, this was the predominant model in most Latin American countries, particularly for resources allocated for education and pensions. The second model, which might be termed neutralprogressive, distributes public resources in a relatively homogeneous manner among social strata. The net result is reduced inequality if the bulk 
of the resources appropriated by the state comes from the richest sectors. The third, or progressive, model channels a relatively larger proportion of public resources towards low-income sectors, thereby reducing social inequality by an even greater margin. Of course if any of these models is to have a relevant impact, the state's revenue collection capacity must account for a significant percentage of the national product.

As stated earlier, the regressive - or low distributive impact - model has predominated throughout Latin American history. At the same time, until recent decades, the state had very little fiscal capacity. The middle and upper classes benefited from public resources through a free education system, particularly at the secondary and postsecondary levels (populated mainly by families possessed of a higher level of cultural capital); through infrastructures that provided poor services in poor neighborhoods and no coverage whatsoever in many rural areas; and through pension systems favorable to public servants.

This situation began to change in recent decades, as the state's revenue collection capacity increased (Brazil approaches the levels of developed countries with a much smaller income tax base) while some social policies began to shift toward the poorest sectors, although in certain areas of public policy, pensions and higher education in particular, the middle and upper sectors still reap the greatest benefits from public resources. Social indicators show significantly wider coverage of basic public utilities such as electricity, piped water and sewage services in many urban sectors, along with broader coverage of electrical and social services in rural areas (ECLAC, 2007c).

Basic education coverage, while still not universal in some countries, has expanded tremendously, although quality remains poor. In the course of this process, the middle sectors frequently moved their children to private schools offering a higher quality education. Access to higher education increased, although in some countries public universities continue to cater to the middle and upper classes, while the poor generally attend private universities, often of dubious quality. Despite pension reforms in many countries, these systems still tend to favor the middle classes and public sector employees in particular. Nonetheless, expanded pension coverage to heretofore excluded populations - such as occurred in Brazil where a universal pension fund was established to cover non-contributing rural sectors and cash transfer policies were instituted - wrought significant improvements in the lives of the poorest families.

Quality of life indicators associated with broader coverage of social policies have shown overall improvement in recent decades: mortality rates 
have dropped and life expectancy and literacy rates have risen. While a systematic country by country study would point to significant differences and, in some instances, negative or violent fluctuations associated with recent economic crises, in most Latin American countries, the level of resources allocated to education and health generally remained stable. And because the state has generally improved its revenue collection ability, public spending in those categories has risen in absolute terms. Nonetheless as Nora Lustig asserts, the state's capacity to serve as a vehicle to offset inequality remains poor in Latin America ${ }^{66}$ While Europe has reduced its Gini index by 15 points ( $5 \%$ through tax impact and $10 \%$ through transfers) the equalizing impact in Latin America has been infinitesimal.

Efforts to promote progressive social policies inevitably pose new social and political challenges. When policies are implemented, for example, to expand primary and secondary education and health coverage to low income sectors, the middle and upper sectors frequently turn to private schools and healthcare systems in search of higher quality services. In the education field, this will ultimately reproduce social inequality due to the gap between the rich and the poor in terms of the cultural resources available at home and at school. By the same token, as the middle sectors withdraw from public services they lose interest in monitoring and advocating for the quality of those services. Tax pressures, meanwhile, are viewed as a divestiture or "an injustice," since these social groups no longer "feel" as if they benefit from public services.

The risk of a fiscal revolt - whether active or passive - by the Latin American middle classes cannot be entirely discarded. Policies that demercantilize only a very few goods and services, particularly if those services exclusively target the poorest sectors, may contribute to a downward spiral in three stages:

- A public service devoted virtually exclusively to the poorest sectors deteriorates rapidly (health, education). The result, which may not seem logically inevitable, does tend to be socio-logically unstoppable.

- Such a situation engenders a powerful sense of frustration among the middle classes, who find themselves relegated to the role of financiers of a service they do not use.

66 "El mercado, el Estado y la desigualdad en América Latina." Presented at the conference titled "Cohesión social, movilidad social y políticas públicas en América Latina", Antigua, Guatemala, July 13 and 14, 2007. 
- Ultimately, the fact that the middle classes are subsidizing services they do not use - and poor quality services at that - fosters a generally critical posture toward those services (which may lead to their further deterioration or elimination).

It might be excessive to speak of a citizenship through consumption as some have done (Sorj, 2000) in Latin America, but the assertion is certainly apt as an indication of the degree to which access to consumer goods has become a linchpin of social engagement in the region. Consumption is a sign of belonging and notwithstanding the underlying disparities and inequality, it conveys a real sense of inclusion.

A dual and constantly overlapping social stratification system is operating in modern societies, much like a double helix, one inside the other: the first is the product of market relations and the second of public relations. They are inextricable (there can be no market in the absence of an institutionalizing state or a viable state in the absence of an efficient market). With major national variations, social relations everywhere are a product of the way in which these two axes overlap and of a whole series of asymmetrical power relations - in function of the sources of economic power or political pacts - among social groups. It is this interface that lends meaning to the division between mercantilized goods and services on the one hand and demercantilized goods-services on the other. This is, in fact, one of the main conflicts in capitalist societies: what should remain in the sphere of market relations? Which goods related to social rights should be demercantilized?

This is a much broader debate in which the unique characteristics observed in Latin America can undoubtedly be attributed to the formidable dual limitation on access to mercantilized and demercantilized consumer goods alike. But the main issue is that in Latin America - here, however, the analysis should differentiate by social good (health, education, transportation), time period and country - demercantilized goods have long benefited primarily the middle sectors while access to the consumption of mercantilized goods, frequently through the liberalization of imports, afforded access to quality goods, albeit in unequal doses, to the middle layers as well as some lower income sectors.

This debate, and its role in social cohesion, is a looming issue in the region. As in many other areas, Latin America must find, in pragmatic terms, a balance between the private sector (mercantilized goods), the public sector (goods somewhere in between the two) and public services (in 
principle, truly demercantilized benefits). The institutional equations will vary substantially in function of the type of welfare state and the national tradition. But for the moment, and despite the political importance of consumption in our societies, the issue has yet to be placed on the table with sufficient clarity.

\section{New political discourses and democracy: a return to populism?}

A decade ago the debate centered around the renaissance of populism in the cases of Carlos Menem in Argentina, Alberto Fujimori in Peru, and Abdalá Bucaram in Ecuador. The inauguration of Hugo Chávez in 1999 and the subsequent unfolding of the "Bolivarian revolution," has reignited and even broadened this discussion. Many analysts are seeing an expansion of a new populism, which the current administrations of Evo Morales in Bolivia and Rafael Correa in Ecuador have joined. There is even talk of a "Venezuelan model" being exported to other countries of Latin America and the Caribbean.

\section{The trajectory of the Chávez administration ${ }^{67}$}

When Hugo Chávez first took office in 1999, he launched a series of reforms to the country's political and economic system. Thus began the so-called Bolivarian revolution and now, after nearly nine years in power, the socialist project of the $21^{\text {st }}$ century is well underway. The rise of Chávez has occurred in a context that has been described as "the conjunction of four factors: the extreme institutional rigidity of bipartisanism that left no room for the participation of new social actors and excluded certain parties by law (the left); poor economic redistribution; weak governance; and the growth, diversification and mobilization of social organizations" (Ramírez, 2006: 39-40).

In broad terms one might argue that the "Chavista" project has evolved through three major stages. The first, from 1999 to mid 2004, was mainly geared towards carrying out the Bolivarian revolution premised on a series

67 This section is based on Francine Jácome, “¿Renovación/resurgimiento del populismo? El caso de Venezuela y sus impactos regionales." 
of political changes which served in practice to concentrate more power in the hands of the president and expand his influence over matters heretofore under the purview of the other branches of government, the armed forces, and the oil industry. Political polarization and conflict intensified during this period.

Chavez's triumph in the August 2004 presidential recall referendum launched a period of radicalization geared towards cementing his control over the economy and mechanisms for citizen participation. This second stage lasted until December 2006, when he was elected for the third time, to another six-year term.

Chavez's re-election with $62.48 \%$ of the vote ushered in the third stage, which began with his declared intention to establish $21^{\text {st }}$ century socialism in the country through what have been called the "five engines" of the revolution. There has been talk of forming a single party of pro government forces. Where analysts previously detected elements of a populist discourse in this project, indicators now point strongly to a course that, while still displaying many characteristics of populism - authoritarian populism to be exact -, increasingly "departs" from the national-popular model and marks a shift towards a more openly authoritarian regime. The Chávez administration appears to be moving in the direction of Castroism. This observation has been reinforced by his active and explicit efforts to export his model by investing funds in other countries of the region to support political groups, business or governments, and by pronouncing judgment on the political situation and events in other nations. In this the Chávez government diverges from traditional populist governments. The latter observed the principle of respect for national sovereignty and refrained from interfering in the affairs of neighboring countries. This posture was one of the pillars of peaceful coexistence in the region in the $20^{\text {th }}$ century (and indeed, it was even construed as a safeguard against United States interventionism).

During the first stage, an early step in the Bolivarian revolution was to convene a Constituent National Assembly to draft the 1999 Constitution. ${ }^{68}$ Throughout this period, and into the second stage, various constitutional reforms modified the institutional framework to create direct interfaces between the people and their leader (Ramírez, 2006). These reforms weakened the elites, political parties and traditional trade unions, while

68 Minorities were not represented proportionately in the assembly, which was dominated virtually across the board by government representatives. 
solidifying state control over civil society. At the same time, however, they seem to have created opportunities for new forms of inclusion and grassroots participation in politics.

Some observers point out that the focus in the earlier stages was on political reform, while economic activities followed an orthodox fiscal and monetary policy, payment of the foreign debt, increased participation of transnational capital, and strengthening imports to respond to the domestic market demand. Public spending rose with the surge in oil prices beginning in 2003-2004 and wealth was redirected through missions targeting disadvantaged sectors. The enormous degree of presidential discretion in the implementation of social policy has been criticized, however, along with the state's growing control over oil policy and the economy, where the financial sector takes precedence over the productive. This approach indicates that the administration socialist rhetoric is accompanied by pragmatism in political and economic decision-making (Ramírez, 2006).

Following his December 2006 reelection, Hugo Chávez declared that the majorities had voted in favor of the $21^{\text {st }}$ century socialism project. What are the characteristics and contents of this new stage? Little information is available, but in Chávez's words, it was to be "native, Christian, indigenous and Bolivarian," and led by the grassroots, essentially the recently created local community councils. It has been stressed that this is to be a new socialist model unlike any of the other experiences that have developed around the world.

The economic proposal for this stage includes respect for private property coupled with a stronger focus on public property, which includes cooperatives and community projects. It also refers to the notion of distributive justice based on a more equitable distribution of the nation's wealth. A third area describes the development of an alternative model of income generation premised on cooperatives, co-management, worker self-management and social production enterprises to promote means of endogenous development and build social capital. Venezuela purportedly will conserve its capitalist economy for anywhere between 2 to 10 years. The short term proposals, therefore, include incentives for private corporations willing to work under the conditions established by the government. Hence, soft credits (with a conditionality that affords many more facilities than normal), changing dollars at the official exchange rate, and tax relief will be available only to businesses that adhere to government policies and not to those that choose to keep operating based on purely mercantile principles. Some of the announcements and activities undertaken during the first 
half of 2007 could point to growing state influence in this sector. Chávez unexpectedly decreed the nationalization and statization of companies in the telecommunications and energy sectors, arguing that they are strategic and therefore should be administered by the state.

The plan in the political sphere includes a transition phase referred to as revolutionary democracy. The importance accorded horizontal power structures is reflected in the pivotal role of the community councils. These groups are structured around a direct relationship between the executive and the communities that circumvents such intermediaries as civil society organizations and political parties. The idea is to build "grassroots power" and some government spokespeople having gone so far as to suggest that these sorts of structures will eventually replace regional and local governments.

\section{A new model for Latin America?}

Two basic questions arise in this context: (1) is the process underway in Venezuela a renovation/resurgence of populism? And (2) is there a "Venezuelan model" that is being assimilated by other regional governments? With regard to the first question, a hegemonic current known as "chavismo" has been gaining impetus in Venezuela since 1999. It has been classified variously has revolutionary, socialist, bonapartist, totalitarian, populist, and military populist, among other terms. As we will describe below, this wide range of conflicting definitions must be understood in the context of time: during the course of its three main stages, the Chávez administration has taken on very different profiles. With respect to the second question, while the leftist populist discourse bears some resemblance in all three cases (Venezuela, Bolivia and Ecuador), that does not necessarily mean a Venezuelan "model" is being applied in the other two countries.

Two points should be made with respect to populist traits in the Venezuelan case. First, by all indications the current process is a hybrid that contains important elements of a populist discourse. Because it is operating in a different national and international reality, however, it does not reflect all of the characteristics associated with classical populism. There are many ways to approach the debate based on how populism is conceptualized, and this has led to disparate perspectives and interpretations of what is currently taking place.

Some observers take the view that there is no new populism. According to this argument, the processes underway in Venezuela and elsewhere in the region today cannot be categorized as populist, because they do not 
share its traditional features, as embodied, for example, in the case of Juan Domingo Perón. "Classical" populism has a number of distinctive characteristics including the inclusion of traditionally marginalized sectors of society, the corporativist character of movements, the polarization of the oligarchy and the people, the rejection of the elites and traditional political parties, nationalism and anti-imperialism, and the rise of a leader-savior. Economic policy included import substitution and nationalization and assigned the state a central role in the economy.

Another viewpoint argues that new forms of populism have emerged - the so-called neopopulism - that do not necessarily share all of the characteristics of traditional populism. From this standpoint, we are seeing populist processes with new contents adapted to the current national and historical realities. These observers point to the disparity between the populist political discourse and the variety of economic strategies actually put into place, which are not all necessarily equal. One of the main arguments from this standpoint is that populist processes may implement a wide range of economic policies, as illustrated by those undertaken by Fujimori and Menem, in contrast to Chávez.

Moreover, in recent years the debate over populism has been enriched by the ways in which this trend it associated with views on the new left in Latin America and the Caribbean. A new current has emerged known as the populist left, in contrast to a new democratic or reformist left. Some would argue that the former is grounded in traditional premises dating back to the middle of the last century and that it has failed to incorporate global and regional changes into its thought and practice, especially after the fall of the Berlin wall. The latter, in contrast, seeks to respond to the current times, developing policies of fairness and social inclusion in the framework of democracy and productive economies that can respond more effectively and efficiently to the needs of citizens.

To summarize, in the context of this debate, it could be argued that certain aspects of the Venezuelan situation from 1999 to 2006 point to a process with populist characteristics (we could mention, for example, messianic leadership/concentration of power; social and political polarization; oligarchy/people; nationalism/anti-imperialist rhetoric; rejection of the establishment/dismantling of democratic institutions; high inflation; statecontrolled economy/nationalizations; clientilistic redistribution; a rise in corruption; and control over the media). But because it is an evolving process, contents and practices are constantly emerging that alter the basic conditions and make it even more difficult to describe. We might assert, 
therefore, that a transition is underway and that Hugo Chávez's reelection and his January 2007 announcements about building " $21^{\text {st }}$ century socialism" might signify a shift towards a more authoritarian, "caudillistic" and militaristic regime, one that eventually might break completely with the traditional Latin American populist mold.

In this sense, and to answer the second question, those who argue that an alleged Venezuelan model is being exported must bear in mind that Ecuador and Bolivia have unique characteristics that in all likelihood would not tolerate a process such as the one underway in Venezuela. While the discourse of the three countries reflects aspects of leftist populism, the contrasting realities will influence how it progresses. For example, the Bolivian Constituent Assembly has yet to draft a new constitution. Given the presence of the opposition, any new constitution will, in all likelihood, be the result of dialogue and negotiation among various political and social sectors. Other factors such as regional concerns and the influence of indigenous and peasant movements also distinguish Bolivia and Ecuador from the Venezuelan situation.

In response to the widespread view that the Venezuelan model has become a beacon in several countries in the region, and the evident fragmentation or polarization of the latter, it is important to recall Manuel Garretón's (2006) assertions. First, one must distinguish clearly between the existence, or not, of "exportable" models, on the one hand, and the nature of the leadership of certain presidents, on the other. Second, it is critical to examine which models could truly solve the internal problems of different countries and the types of alliances that might be established in the context of globalization. In this sense, it is necessary to conceive of a new development model to counter the "neoliberal project," one that identifies strategies to address development processes, means for overcoming inequality, insertion into a globalized reality, and productive transformation.

A regional vision of Latin America must bear in mind that blocs with any hope of having influence on the international plane can only be built around coherent state policies whose long term vision is independent of the political leader in power at a given moment. At this time, only two countries are actually in a position to sustain such a bloc: Mexico and Brazil. Both could play an important role in the future. If they are to do so, the former must extricate from its dependence on the United States and the latter must openly step into its leadership role. In the Andean region, as in the case of Venezuela, more time is required to reestablish the relationship between state and society. 
Despite his aggressive foreign policy, Chávez is hardly in a position to assume this leadership role. As Petkoff asserts, "the manipulation of social resentment, the unnecessary intimidation of the middle class, administrative inefficiency, constant combativeness, the political and social segregation of his foes, and rampant corruption undermine the viability of Chavism as a platform for profound change" (2005a: 126). As Lozano (2005) cautions, building a majority is not tantamount to democratic governance. Political stability is increasingly in jeopardy in Bolivia, Ecuador and Venezuela, creating situations that portend violent conflicts in the short or medium terms should they continue to promote the agendas conducive to deepening polarization and political and ethnic conflictivity that are part and parcel of the populist leftist discourse.

Moving beyond the debates over the political nature of the Chávez administration or its regional export capability, however, it is important to underscore the implications of such movements for social cohesion. It is common knowledge that populist practice offers a rhetorical response to the demands of social inclusion and tends to intensify polarization and weaken democratic institutions, even as it fortifies the leader promising future redemption. This so-called renovation or resurgence of populism has shown that the processes in Latin America and the Caribbean in recent decades have failed in important ways to achieve what we identify as "social cohesion in democracy." As long as this gap persists, it is easy to predict that projects with pronounced populist attributes will garner acceptance and support. And over time, such projects tend to evolve into regimes carried by authoritarian and personalistic leaders who, despite their promises, do not deliver effective, sustainable social cohesion and inclusion.

\section{The crisis of representation, populism and democracy ${ }^{69}$}

Let us take a closer look at this last point. The impact of populism ultimately lies in its ability to build a unit around the pole of "the people" that speaks with a single voice, that of "the leader," while simultaneously establishing an intensely - and irreconcilably — antagonistic relationship with all other forms of political expression: the "anti-people" pole. The outcome is a familiar one: a spiral of mutual repudiation between the two poles that weakens and finally eliminates the forms of negotiation and interchange inherent to a pluralistic democratic system. 
As an expression of a rationale for action that redefines the political space in terms of inclusion/exclusion and friend/enemy, populism is a strictly political phenomenon. It is therefore compatible with the most diverse ideologies - right, left, reactionary, progressive - and economic programs, from distributionist statism to neoliberalism. As a political phenomenon, populism must also be distinguished from certain traits which, while perhaps intrinsic to its nature, do not wholly define it, such as, for example, the personalization of power and anti-institutional behaviors. These sorts of characteristics can occur independently of populism.

The era of mass communication inherently guarantees a tremendous amount of public visibility to those in positions of power. The executive branch has become a pulpit from whence to issue a first person appeal to the entire population. Moreover, any government embarked on sweeping reforms to the status quo can be expected to govern "over the heads" of parties and legislatures and resort to decision-making procedures that hover on the margins of legality. Mutations in the public sphere and reform policies, then, have manifestations in the form and exercise of public power that are far from intrinsic to the phenomenon of populism. Although inseparable from public power, populism very quickly becomes much more than a political style.

In order to pin down the characteristics of populism as a political phenomenon, it is useful to review what sociological literature has to say about its origins. There is consensus that populism has its origins in a crisis of representation in democracy, in other words, the widening gap that by definition separates representatives from the represented as political parties prove patently incapable of mediating between them. Various factors can contribute to this and we can enumerate some of them using Venezuela's current experience as just one of several possible reference points. The inventory of causes includes the inability of political parties to adapt to the challenges posed by the changing rules of the economic game, which translates in practice into unsatisfactory responses to social demands. The growing entropy observed in the older parties also undermines their credibility by weakening their ties to their constituents, even as they prioritize their own survival through the use and abuse of public resources. Finally, there is the problem that broad swaths of the population remain on the sidelines of the political system with little or no participation.

Having said that, the crisis of political representation is a necessary but insufficient condition for populism. Another factor must be introduced to round out the picture: a "crisis on high." Here, a leader emerges who is 
effectively able to project himself as different and distanced from the existing political class. It is this leader who ultimately exploits the virtualities of the crisis of representation. And he accomplishes this by linking unmet demands, political resentment and a sense of exclusion to a unifying discourse that appeals for the rescue of popular sovereignty - which has been hijacked by the political party establishment - in order to mobilize it against an enemy whose specific profile, while it may vary in time ("the oligarchy," "the plutocracy," "foreigners"), always refers to those regarded as responsible for the social and political malaise that is plaguing "the people." In its more complete version, populism implies an operation to suture the crisis of representation by changing the terms of the discourse, creating new identities, and reorganizing the political space through the introduction of an extrainstitutional excision.

Even a cursory look at the "Bolivarian revolution" reveals the conditions conducive to populism that we have just discussed. High among the underlying causes of the crisis of representation was the economic and social disequilibrium brought about the Carlos Andrés Pérez administration's abrupt swing in the direction of market reforms. This set in motion a series of consequences that set the stage for his successor, Rafael Caldera who - though elected as a critic of "neoliberalism" - ended up associated with highly unpopular adjustment policies. At the same time, the consociative political system administered for years by the two main parties - Democratic Action (AD) and the Social Christian Party of Venezuela (COPEI) - was eclipsed, as new political expression's emerged. And significantly, broad swaths of the population were politically alienated, as eloquently illustrated by high rates of voter abstentionism. As to the "crisis on high," we have the 1992 rebellion of young military officers which, despite its failure, thrust its leader, Hugo Chávez, into the public spotlight. There he became the magnet for a diffuse and multifaceted inconformity, combined with intense criticism of the "partidocracy" and a rhetoric of nationalistic exaltation.

The reconstruction of Chavez's political enterprise aptly illustrates the problems posed by populism-cum-regime from the standpoint of democratic institutions. As we have discussed, the agenda of the Bolivarian revolution has progressively concentrated and delegated decision-making powers in the person of its instigator and leader. In these circumstances, the network of balances and controls that distinguish democracy as a constitutional order has deteriorated profoundly. As might be expected, this deterioration has extended to political pluralism, due to the hegemonic ambitions of the new regime, and the retreat of an opposition whose dissent 
brooked no concessions. Against this backdrop, an increasingly polarized public life has overtaken institutional structures, and is expressed today through "town square politics" and the fractious nature of clashing political positions.

Having reached a point in which the signs of authoritarianism are visible, we must take a longer view. And when we do so, what begins to take shape is certainly authoritarianism, but an authoritarianism of the masses. We point this out in order to reintroduce into our discussion a feature that is intrinsic to the current political panorama in Venezuela. We are referring to the experience of participation that the "Bolivarian revolution" has offered to vast grassroots sectors. Politically sidelined until very recently, these sectors have been returned to center stage through the recognition of opportunities and entitlements that have reinforced their sense of belonging to the national community. This is an aspect that should not be overlooked when examining the support that surrounds and sustains Chávez’s leadership.

Writing in 1956 shortly after a similar political experience drew to a close - we are referring here to the populist Perón administration (19461955) - , Gino Germani was able to see beyond the euphoric atmosphere triggered by the restoration of democracy when he asserted:

"According to the generally accepted interpretation, the support of the low income classes was a result of the demagoguery of the dictatorship. One might accept such a generic assertion, except that it is, at the very least, insufficient. What we have to ask ourselves next is what that demagoguery consisted of. Here the common interpretation is what we will term, for brevity's sake, "a plate of lentils." The dictator "gave" the workers a few material advantages in exchange for their freedom. We believe that such an interpretation should be rejected. It is true that the dictator engaged in demagoguery. But what was so effective about that demagoguery was not so much the material advantages but the fact of having given the people the experience (fictitious or real) that they had achieved certain rights and were exercising them. The workers who supported the dictatorship, far from feeling deprived of their freedom, were convinced that they had conquered it. Of course here even with the word freedom we are referring to two different things. The freedom they might have lost was one they never really had: political freedom to operate on the level of high politics, distant and abstract politics. The freedom they believed they had gained was a concrete, immediate 
freedom, one of affirming their rights against foremen and bosses, of feeling more like they were their own bosses."

Of course the composition of Perón's and Chávez’s grassroots following is different (formal employees predominated in the former case) and the two experiences might differ in terms of their accomplishments in the area of rights. But the Germani quotation is intended to draw attention to a particular aspect of the populist phenomenon, namely, the value placed on the self-esteem and protagonism of grassroots sectors: the recognition of their status as first class citizens. Through this lens, populism emerges as an agent of the democratic revolution in progress and a reflection of the growing desire for social horizontality in the region (yesterday in Argentina and in Venezuela today).

Of course just how much of this valuing, this recognition, is genuine and how much is illusory is open to debate. But once the question has been posed, we are compelled to be consistent and to hold it up for comparison with democracy to ascertain whether or not the latter is better situated to produce this valuing and recognition without incurring in the excesses of authoritarianism. In a recent work, Francisco Panizza proposed that populism is the mirror of democracy; a mirror that reveals what the existing democracy is and what it is not. The populist temptations that surface periodically in Latin American countries appear to be showing us that our democracies - with their regular elections, their parties, and their institutional rules - have not succeeded in satisfying the demands for inclusion of significant sectors of the population. We must nonetheless resist reacting as so many others who start off understanding the reasons for populism only to demand indulgence for its policies. We must instead explore the ways in which our democracies might, without renouncing their principles, extend the sense of belonging to cover the entire national community, so that it no longer has to go looking for it elsewhere.

Populism responds to grassroots demands for inclusion with a rhetoric that essentially is an appeal for the future redemption of "the people" from the "forces of evil." This is usually accompanied by a complementary device: the staging of scenes of genuine political communion, marches, mass actions, which are reminiscent of religious rituals and like them, instill in among the participants a sense of mutual acknowledgment and fraternity. With this image in mind it has been said that populism is an expression of community nostalgia. The characterization could be acceptable if it is divested of its pejorative slant to reveal one of populism's advantages over 
democracy: its ability to create "heat" where the routines of democratic rules are "cold." If populism does indeed act as a mirror for democracy, its ability to be effective at this level - in terms of a vision of the future and the experience of participation - seems to contain a message for us: something that transcends the mechanisms for regulating the formation and practice of governments is missing and its absence constitutes, to varying degrees depending on the country, unfinished business in the task of achieving "social cohesion in democracy" in Latin America.

Populism then, is associated with periods of an observable distancing between the state, grassroots demands, and citizens. Its presence (and historically cyclical appearances) is that much more likely in the context of efforts to (re)construct a modern state in relation to the subjectivity of the governed. As we touched on earlier, the aim of populism is to merge "the people" with the state, with the leader acting as the catalyst and, beyond that, to instill in the governed a sense that the state "belongs" to them after a long period of estrangement. Legitimacy - when citizens not only recognize their authorities, but feel that what "their" state "does" is "theirs" too entails a substantial dose of imaginary identification. This identification uses and abuses the metaphor of politics as war in which the opposition becomes the enemy and this ultimately leads to radical polarization and destroys any possibility for negotiation.

Populism often reemerges following a period in which the governed have resented the political system for being particularly disengaged and remote and when the time is ripe for it to be revamped. And therein lies the nature of its two-fold message: it is at once "democratic" (affording individuals a sense of citizenship) and "grassroots" (upholding a community identity denied by the anciens régimes). This symbolic identification process is compatible - as the region's neopopulist experiences have demonstrated beyond a shadow of a doubt - with a wide range of economic policies and social alliances. Populism, in other words operates in the tension between a democratic-plebeian-plebiscitary element and a grassroots-imaginaryauthoritarian element (Martuccelli, Svampa, 1997). There is a very real risk that it will bounce from one extreme to the other: a double-edged sword, and probably the direction that the Venezuelan experience is taking.

That said, and despite its inherent threats, it is important to bear in mind the fundamentally ambiguous nature of populism. In contrast to revolutionary or openly totalitarian movements that outright reject the legitimacy of representative democracy and elections, populism - as a plebiscited authoritarianism of the masses - is constantly demanding those 
very things. So it is possible to predict that it will have a very real presence in the region in the immediate future, at least in a number of countries. Indeed, in view of the weaknesses among social actors described earlier, and the traditional insufficiencies of the state in Latin America, the "return" of populism is certainly one of the potential scenarios on the political agenda. But its "return" is not merely an expression of community nostalgia aptly embodied by the notion of "the people." Populism is also - and perhaps today more than ever - the fruit of the growing expectations of individuals who have seen their dignity as citizens amputated by regimes that failed to offer them inclusion, whether symbolic or economic.

Populism is at once a mirror on the insufficiency of democracy and a pathology of its limitations. But as other national experiences have shown in the region, populism - even when it operates through its trademark mass authoritarianism - has been a powerful factor of political inclusion and beyond that, a paradoxical vehicle for the expansion of citizen individualization, even as it has left deep wounds in the political system that have weakened democracy.

\section{Nation and the challenge of identities}

With the return of populism, the state's shortcomings have been held up for debate and ultimately accentuated. Perhaps even more importantly, the state now finds itself at the heart of diverse processes led by a wide array of actors, that call into question - for the first time in region's history in any real sense - the boundaries and meanings of nation. The nodal point, as we will demonstrate, is found in an eclectic array of social demands, all seeking legal recognition and a particular set of rights.

\section{Nation and the challenges of the $21^{\text {st }}$ century: an introduction ${ }^{70}$}

Even as it suppressed the memories of indigenous peoples, Africans, and emigrants, the nation-building process in Latin America created a common space in which the concept of citizenship could emerge: a space of equals, regardless of origin, class, religion or race. This was an inherently conflictive process since different social groups appropriated the notion of

70 This section is based on Bernardo Sorj, "Reconstrucción o Reinvención de la Nación: la Memoria Colectiva y las Políticas de de Victimización en América Latina." 
citizenship - of equal members with the same rights within a national community - to advance their own versions of the common good. The process by which an image (or images) of nation is shaped, therefore, is one of constant reinvention involving citizen participation and state action. Memories of the precolonial, colonial, oligarchical, national-statist past are not consecutive phases along a continuum, but rather layers that sometimes remain dormant in the collective memory only to resurface with a new meaning, to be employed in new discourses.

New social demands assail the image of nation underlying the political discourse, and do so with an impact that is more forceful even - as an abundance of literature has emphasized - than globalization's effect of weakening national identity and memory in search of new sub- and supranational identities. This analysis is no doubt essentially correct. Even so, it underestimates the processes through which globalization recreates the national conscience, this time in the framework of a more cosmopolitan vision. Nations, and their elites in particular, have always developed their national image using their relative standing in the international social order as their yardstick. In the context of globalization this yardstick has come to be shared by the entire population.

We are living in a time of reflexive nationalism. One in which information about other national realities is widely disseminated through various audio-visual communication systems and in all manner of indexes about each country's ranking in areas such as human development, corruption, freedom of the press, democratization, environmental protection and so forth. These images of the quality of life in the outside world increasingly define a country's self-image as well as its expectations, which are shaped less by past events than by its current status relative to other nations. In this way, globalization transforms the national image and in a way reinforces it, while simultaneously provoking a new social clash over its meaning.

In response to the new realities and challenges posed by globalization, the nation finds itself under reconstruction, and what we are now observing in Latin America are the initial symptoms of that process. Globalization reaches into every household, but not in the same way. For the children of the elites and the middle classes, the outside world is a tangible reality experienced through regular tourist travel abroad, learning foreign languages, university programs in the United States or Europe and eventually a good job in one of those countries. For poorer sectors, in contrast, it is comprised of images on a television screen: worlds of ideal consumption that in the best case scenario might be attained through illegal migration. We are experiencing 
a disconnection between the middle classes and lower income sectors with respect to the symbolic value of nation. While nation as a reference point is on the decline for the former, for upwardly mobile working class sectors the best living conditions remain contingent on the nation state. And in this sense, ethnic identities are one of the resources available particularly now that political party systems and trade unions have lost their ability to effectively channel social demands.

The national identity that has undergone an outright mutation corresponds to the nationalist-statist period: this was the national identity that offered an integrating discourse to middle and low-income sectors throughout the $20^{\text {th }}$ century, with varying degrees of success depending on the country. What is currently at stake in the public space is not so much alternative proposals for development models as the capacity to mobilize discourses that appeal to public sensibilities through collective identities in which actors find symbolic recognition. The obstacles many face in their efforts to become fully integrated individuals in a society of global consumption engenders collective discourses that afford new forms of recognition, including those of a religious or ethnic nature. Collective identity must therefore be viewed as a political resource that enables certain groups, and their elites in particular, to negotiate with the state for access to positions or goods.

Similarly, the current process of reconstructing the national memory in Latin America cannot be reduced to a mere overhaul of dichotomies such as national vs. foreigner or state-driven vs. market-driven economies. Ethnic identities involve much more complex processes than might appear on the surface. As we have seen, religions originally associated with Brazilian Afrodescendents are now mainly sustained by whites and mulattos, while grassroots sectors are in the midst of a genuine revolution of religious beliefs, owing in particular to the rise of evangelical cults, which predominate, for example among Mexican indigenous groups and broad sectors of the urban poor in Brazil.

In the context of structural reforms, governments initially embraced policies on ethnic identity and legal pluralism, possibly because such forms of symbolic recognition did not seem to entail any significant cost or weaken class loyalties. These policies were implemented without consideration for the enormous costs they might have for national cohesion and democratic institutions.

In this new Latin America in which collective identities are wearing away the old cohesive ideologies of the $20^{\text {th }}$ century, the national-statist tradition 
is reappropriating the discourse of victimization with the contemporary trappings of ethnic and racial awareness. Yet this discourse is a potentially ambiguous one in that it could deepen democracy in social relations or else destroy national identity and memory constructed around a utopian mestizo-centered horizon. Although this horizon was never actually achieved, it did set a course that enabled Latin American societies to avoid fratricidal interethnic conflicts.

\section{Ethnic policies and citizenship ${ }^{71}$}

An important new development in the current period is that the indigenous issue can largely be addressed as a matter of new citizens' rights. Let us take the cases of Bolivia, Ecuador, Colombia and Chile as empirical examples with which to trace a comparative vision of indigenous proposals and the ways in which they are processed by societies and by national states.

The indigenous issue refers to the citizenship status of the descendents of native populations established before the conquest, most of whom now rank among the poorest and most stigmatized groups on the socioeconomic scale (with respect to the rights and duties that circumscribe their inclusion as members of the political community). The fundamental question has to do with the substance of that citizenship: should indigenous peoples have the same rights as others or should they have special rights as descendents of the originary peoples?

From this optic, the indigenous issue is part of a national issue that does not display Irredentist tendencies, at least not up to the present. While some groups self-identify as nations and emphasize autonomy, their demands tend to relate to local or regional self-government within existing states. Far from advocating separatism, most indigenous movements are trying to redefine their situation in the nation states where they reside. Their quest, however, is not a homogeneous one: there is an enormous amount of variation among. indigenous movements, demands, and strategies. We must therefore begin with the premise that the indigenous struggles in each country have unique characteristics that reflect the influence of factors such as geography, demographic and socioeconomic structures, the history of indigenous-state relations, and local political and cultural traditions.

That said, demographics seems to be a key factor, one that bifurcates the indigenous issue. In cases where native groups constitute only a small minority,

71 This section is based on León Zamosc, "Ciudadanía indígena y cohesión social." 
the issue is treated as a matter of survival. In contrast, in countries where these groups represent a majority or a significant percentage of the population, it becomes more a matter of effective equality in representational rights.

Two cases illustrate the first variant. In Colombia, where all of indigenous groups combined make up just $2 \%$ of the population, their national organization's stated goals related to territoriality, autonomy and cultural preservation. In the early 1990s, when the political class sought to restore its legitimacy by modernizing institutions and offering amnesty to guerrilla members and concessions to low income sectors, the indigenous movement took advantage of the opening to win seats in the Constituent Assembly and secure the recognition of a wide range of cultural rights, territorial autonomy and representational quotas in political institutions. Similarly, Chile's Mapuche population accounts for approximately $5 \%$ of its inhabitants. In response to Pinochet regime's decree privatizing communal lands, the Mapuche began to articulate demands for territorial autonomy. The conflict became more radicalized beginning in 1998 when the indigenous organizations launched an offensive that has featured land occupations and harassment of forest and mining industries. The "concertation" [coalition] governments have reacted to such actions with repression, including the application of antiterrorism laws. The Mapuche coordinating committee [Coordinadora Mapuche] continues to demand recognition as a people, self-determination and control over territory and resources, thus far to no avail.

What do these examples tell us about the situation of minority indigenous populations? They are small groups, concentrated in well demarcated, remote areas, who have been subjected to an invasion by the state, settlers, and large corporations hoping to exploit the local natural resources. Facing the loss of control over - and devastation of - their ecological habitat, the trampling of their culture by mainstream society, and even the risk of extinction, their demands hone in on the conditions that will ensure their survival: control of territories, the autonomy to self-govern, and protection of their lifestyles and culture. Chile's response is indicative of the state's instinctive reflex to reject initiatives that undermine its sovereignty, limit its freedom of action over natural resources, or call into question hegemonic concepts of citizenship and nation. The Colombian case confirms that a convergence of special conditions is required to compel Latin American countries to be generous with their native minorities.

Moving on to the second variant, in which indigenous groups make up the largest sectors of the population, the struggle for equal standing can take one of two tacks. The first of these is the consociational alternative in which 
ethnicity or nationality is the primary element for organizing the state around collective rights and for distributing government functions and power among autonomous groups (Belgium, the Netherlands, and Switzerland are examples of this model). The other possibility, premised on equality derived from individual citizens rights, is a universalistic state in which ethnicity is neutralized insofar as it is not considered a basis for political organization and freedom of expression for sociocultural diversity is guaranteed.

With this in mind, we will concentrate on two cases in which indigenous populations have significant demographic influence. The Quechuas, Aymaras and other smaller groups account for over half of the total population of Bolivia. The 1952 agrarian reform classified them as Bolivian peasants, thereby creating the basis for a hybrid identity that combines peasant and indigenous identifications with that of belonging to the Bolivian nation. What really politicized the indigenous issue was the electoral alliance forged in the 1990s between the National Revolutionary Movement (MNR) and a party of indigenous intellectuals that put Gonzalo Sánchez de Lozada in office, with Aymara native Víctor Hugo Cárdenas as his vice-president. This administration implemented a pro-market reform program and declared multiculturalism. The model, however, disintegrated in the wake of public protests and the electoral ascent of the Movement toward Socialism (MAS).

This process represented a dramatic shift towards the politization of the indigenous issue. Initially the political elite had used it as a rallying cry to garner support for its platform. In response, the peasant and worker confederation (CSUTCB), the coca-growers and their party, the MAS, incorporated the issue into their own discourse, not so much to demand special rights, but rather to reaffirm the country's native roots and the grassroots aspiration for access to an egalitarian and participatory form of citizenship. The success of this formula was evident in the mass protests and in unprecedented voter support for Evo Morales. Hence, the attempt from above to co-opt what was inherently indigenous led to the gestation of a project that established indigenous legitimacy as an identitary pillar of the nation and mobilized it for nationalist and grassroots purposes. In this project, whose fate is currently at stake in the Constituent Assembly, the solution to the indigenous issue seems to lie in the direction of a plurinational state that combines the universalist principle of egalitarian individual rights with recognition of the collective rights of originary groups (through a system of regional and local autonomous structures that would include indigenous territorial units). 
Native populations in Ecuador account for 15\% to 20\% of the population, mainly Quichuas from the Sierra and various smaller Amazonic groups. Their confederation, known by the acronym CONAIE, has been unique in Latin America in terms of its ability to coordinate protests at the national level. It was therefore ideally situated to spearhead grassroots struggles against neoliberalism and it played a key role in the downfall of two presidents (Abdala Bucaram and Jamil Mahuad). CONAIE has melded peasant and grassroots demands with indigenous aspirations such as plurinationalism, bilingualism, representation in government and territorial autonomy. Its Pachakutik party obtained $10 \%$ of the seats in the 1997 Constituent Assembly, thereby ensuring that the resulting constitution would include cultural rights and provisions on territoriality and participation in government that would lay the legal groundwork for a certain degree of autonomy. But rather than pressuring for implementation of these objectives, the indigenous movement focused on consolidating its political protagonism in the country, even joining in the Lucio Gutiérrez administration. The latter's pro-market shift put an end to the alliance, however, and CONAIE was left severely debilitated.

More recently, following the electoral victory of populist President Rafael Correa, the indigenous movement recovered some of the terrain lost during the mobilizations for a new Constituent Assembly. Today the Ecuadorian political system is in a state of collapse and a completely new scenario is unfolding. It is a complicated moment for the indigenous movement, which must ensure its place in the Constituent Assembly and redefine its objectives with respect to its place in national politics and its rights under the new Constitution.

To summarize, most of the indigenous peoples in Bolivia and Ecuador are peasant farmers who experience their class and ethnic identifications as part of a single identity and who come from a long history of integration as "second class citizens." In this context, their demands do not veer towards universalism or towards consociationalism in their purest forms. They are directed, rather, towards a midpoint characterized by truly egalitarian citizens' rights together with collective rights in the form of safeguards for cultural differences and prerogatives such as autonomy for those groups wishing to exercise it. Going beyond the discourse and platforms to focus on the driving forces behind the mass protests, we could argue in both cases that demands associated with territoriality and autonomy are less pressing compared to countries with small indigenous populations. 
Indeed, in Bolivia and Ecuador demands related to territoriality appear to be more germane to Amazonic groups than to the principal Andean groups. The latter have tended to mobilize, not around ethnic issues in the strictest sense, but rather around the broader national issues such as state economic policies and governance. Clearly their main motivation is not the need to close ranks on themselves, entrench themselves in their territories and surround themselves with protective barriers to survive as indigenous peoples. To the contrary, their struggles have to do with overcoming marginalization and getting involved in politics to "indigenize" Bolivia and Ecuador: to ensure that institutions, culture, the distribution of economic and political power, and public life in general reflect the reality of countries in which the majority, or a large sector, of the population is indigenous. In the final instance, they want to be included in the nation state with a status of effective citizen equality.

What are the implications of the indigenous issue for social cohesion? As we have noted, the government authorities must be widely viewed as legitimate if cohesion is to buttress a democratic system. This legitimacy, however, is not derived from the absence of conflict but rather the presence of mechanisms to resolve conflict in a manner that all sectors might consider balanced. Moreover, the normative consensus must inspire a sense of belonging among all citizens, which is only possible when its contents reflect the cultural diversity of a particular society.

With this in mind, the vicissitudes of social cohesion must be regarded as an arrival point in an ongoing process that begins with the initiatives of actors interacting in pursuit of their interests and aspirations. These interactions, which nearly always include a healthy dose of conflict, are processed by political institutions and frequently lead to modifications of citizens' rights and duties. Since people's identifications, as well as the legitimacy of institutions, are contingent upon the content of citizenship, those modifications are bound to have repercussions for social cohesion. This is the process that must be examined in order to grasp the many derivations of the indigenous issue in Latin America.

From the moment the indigenous issue becomes politicized (in other words, when it acquires a public profile as something that is at stake in political interactions), the way in which it is addressed has important ramifications for social cohesion. Specifically, social cohesion is strengthened when society and the state resolve the indigenous issue through commitments that are acceptable to the indigenous populations. Conversely, social cohesion is 
fractured when the matter is simply ignored or when attempts to resolve it fail to take into account their aspirations.

The logic of this thesis is particularly clear in countries where native peoples make up a significant portion of the national population. Numerous recent studies have shown that these populations experience the worst conditions in terms of income, poverty, nutrition, and levels of education and health. For generations, they have been subjected to discrimination and racism in daily life and to the cultural homogenization policies of consecutive governments. Against this backdrop, the politicization of the indigenous issue has created a situation in which entire sectors of the population are unable to identify themselves with the nation, feel that they belong to it, or regard its institutions as legitimate. Therefore, and particularly taking into account that they are generally inclined towards equality rather than separatism, the pressure brought to bear by indigenous groups to redefine their situation must be interpreted as a redemptive drive towards integration and strengthening social cohesion. This is a matter which, as we discussed in the first chapter, also has a tangible influence on every day social relations.

What we now observe in countries such as Bolivia, Ecuador, Guatemala - and perhaps Peru in an incipient fashion - is the political processing of this issue. Countries with small native groups that refuse to recognize their territoriality and autonomy argue that, because they represent a miniscule percentage of the population, there is no reason for the state to make exceptions that would undermine the legal order and national unity or for it to waive its sovereign prerogative to exploit natural resources for the benefit of all citizens, just to protect such a tiny minority. Governments instead propose to solve the difficulties facing indigenous groups through assistential programs designed to more fully integrate them into national society. But it is precisely the historical failure of such solutions, compounded by the threat of extinction, that compel native peoples to insist on the need for self-determination. Moreover, the fact that these indigenous groups comprise such small sectors does not mean that the problem of social cohesion does not exist, since they are clearly not "insignificant" at the regional or local levels.

The Mapuche in Chile, for example, have a demographic presence in four out of thirteen regions of the country and are the majority in a good number of districts [comunas]. The situation is comparable in other countries, such as Mexico, Honduras, Costa Rica and El Salvador, that have proven resistant to the demands of their indigenous minorities. Significantly, the 
fact that Colombia, Venezuela, Panama and Nicaragua have recognized the territoriality and autonomy of native peoples has not caused the legal order or national identity to collapse, nor has it put an end to the exploitation of natural resources.

Despite the importance of law, however, the indigenous issue cannot be solved by the justice system. The conditions that give rise to relations of inequality cannot be changed solely through legal advances. Judicial systems, for their part, frequently run into concrete difficulties in their efforts to integrate traditional cultures that do not espouse the creed of individual rights. Indeed, while legislation to benefit ethnic identities can clearly mitigate situations of inequality, it may also pose new problems when, for example, communities exercise their rights to solidify oligarchic structures or when collective rights are pitted against individual rights. A clear illustration of these sorts of tensions is found in proposals for the official recognition of customary law, which frequently is at odds with principles of women's equality and equal participation in community decision-making processes.

\section{Multiculturalism and democracy: beyond the rhetoric of diversity ${ }^{72}$}

The tension between two legal traditions - customary and liberal — with respect to the indigenous issue merits a closer look. Are we not facing a losing battle, a twist on Weber's "war of the gods," which sooner or later will inevitably undermine social cohesion in any form? To answer this question it is helpful to provide an empirical element, a fundamental one, the importance of which will only be apparent at the end of this section. We begin with an assertion: among all population sectors, integration processes into the dominant culture have never been as strong as they are today. Put simply: new generations of indigenous youth are less likely to speak the ancestral language, dress differently or participate in community rituals. Concomitantly, and also a sign of the times, they do not deny their origins, but rather view them a source of affirmation and dignity. In sum, these young people are protagonists in a long-term process to transform stigmatized identities into ethnic identities of which they can be proud. We will return to this in the conclusion. Suffice it to note here that new social

72 This section is based on Juan Carlos Torre, "Populismo y Democracia." 
demands, while expressed in collective identitary terms, are essentially the fruit of a democratizing dynamic and an aspiration for dignity demanded by individual members of those minority groups. More than a simple dichotomy of "individual" rationales versus "minority" rationales, we are facing a unique dialectic between the affirmation of minority rights and individual democratic aspirations.

If this is not taken into account, one inevitably falls into an interpretation that juxtaposes, with no way out, a multiplicity of demands revolving around the realization of individual plans on one side and the recognition of particular communities on the other. But let us examine for a moment the tensions that this contradiction seems to introduce into the public debate.

It is often said that Latin American democracies are only halfway there: they offer political freedoms and yet they have not created the conditions ex ante that would ensure the effective enjoyment of those freedoms. Put more succinctly, they do not guarantee citizens access to basic levels of well-being and protection under the law and in consequence, poverty and legal defenselessness constitute formidable obstacles to the autonomy, and hence the freedom, of broad swaths of the population. This interpretive key is defective, however, in that it fails to do justice to the importance of this recognition of political equality as a social expectation and as a political opportunity.

First, this recognition is important as a social expectation because it spotlights the chasm between the formal existence of political rights and the lack of civil and social rights, which serves as an incentive to actively increase aspirations. Social mobilization is rooted in the struggle for congruence between reality and discourse. Where there is congruence - whether due to the effective enjoyment of the full spectrum of citizens' rights (in this case institutional pressure would be more likely than mobilization) or because the denial of rights is generalized - the result is usually withdrawal punctuated by sporadic eruptions rather than sustained mobilization.

Second, recognition of political equality expands the structure of opportunities by providing access to resources conducive to collective action. It is safe to say that in comparable situations of unmet aspirations, some political contexts are conducive to political action, while others discourage it. The political contexts relevant to the present discussion are democratic ones, in which political rights create opportunities for participation that evolve, in turn, into platforms for mobilizations to demand expanded citizenship. 
Based on these elements, the question becomes to what degree, and under what conditions, can marginalized sectors use their political rights as a battering ram to conquer their civil and social rights. In our understanding, a framework of multicultural policies to benefit indigenous populations is an apt illustration of propitious conditions. This would appear to be confirmed by a widely recognized fact: the policies we are referring to were developed in the context of the "third wave" of democratization which reached the coasts of Latin American countries in the early 1980s.

Put into perspective, the path of institutional reforms revolving around the citizenship status of indigenous populations unfolded in several stages. In the first stage, "redemocratization" had the effect of raising the public profile of ethnic exclusion and discrimination against indigenous populations. This triggered an expectation of recognition among these groups which, in turn, created the potential for social mobilization.

In the second stage, the potential for mobilization was realized, as a structure of favorable opportunities opened up. Here the common denominator - notwithstanding the variations among countries - was a common awareness of the transformative power of collective action. Favorable opportunities included those of an institutional nature, such as the administrative and fiscal decentralization processes launched in the context of pro-market policies. As decision-making power was passed down through decentralization, local indigenous communities were able to be more proactive with their initiatives. Other favorable opportunities were of a political nature, such as those created by the constitutional assemblies held in several countries: the open, competitive airing of their debates offered these disadvantaged sectors more advantageous conditions to articulate demands and exert influence.

A third and final stage, which spanned the 1990s in the framework of intense mobilizations, consisted of the adoption of multicultural policies to benefit groups now referred to as the "originary peoples" of Latin America by virtue of their recent recognition. In the 1990s, then, policies of multicultural citizenship began to modify the "monocultural, monoethnic, monolingual" characteristics of Latin American countries. As a result, many countries, to varying degrees, have recently introduced a number of collective rights for indigenous populations, such as: bilingual education, collective ownership of communal lands, the official status of customary law, and forms of territorial self-governance and differentiated political representation.

Within the array of institutional reforms triggered by multicultural policies, however, there is one that brings into sharp relief the problematic 
implications we alluded to earlier. We are referring to the defense and protection of the uses and customs of indigenous populations. How then, are we to approach an intercultural dialogue? For a dialogue to be productive there must be a space of intersection between the parties involved. The problem arises, however, precisely with regard to the existence and extent of this space of intersection when we have the cultural diversity advocates on one side and the charter of rights in the liberal tradition being raised on the other. It is always possible to invoke, as is often done, the need to combine diversity and unity by granting special rights that acknowledge the demands of historically marginalized communities, based on a common foundation of universal rights applicable to all members of a nation-state.

This has been the script for many of the institutional reforms that recognize the public status of customary law, while clarifying that this public status is subject to "compatibility" with the guarantees enshrined in the country's legal system. Would not this compatibility requirement, however, diminish customary law by subjecting it to the "quality control" of a normative framework premised on universal and individualistic liberal principles? In practice, the prudential caveats accompanying the adoption of multicultural policies - such as the compatibility requirement - allow the public authorities to interfere in the life of the communities by means of ulterior regulations. Excuses abound, such as the punitive practices of indigenous populations which permit harsh physical punishment, for example. What is the appropriate course to take when confronted with such practices, in which communities judge and punish their members pursuant to norms that clash with the individual judicial guarantees that those individuals enjoy in the liberal tradition?

The normative logic governing multicultural policies suggests a response in terms of the appropriate course to take. Positive discrimination favoring marginalized groups usually goes hand in hand with the stipulation that the public authorities not interfere with their ancestral practices. Ideally, the public authorities will impose few or no restrictions on the way in which communities treat their own members. When it comes down to concrete options, the compatibility clause does not really offer a solution to the dilemma we raised earlier. And it does not offer one because any external interference to safeguard the rights of the individuals in jeopardy might be criticized as an attack on the cohesion and identity of the communities. In practice, the multiculturalist sermon usually recommends that the public authorities accommodate the communities to the highest extent possible in the name of respect for cultural diversity. In its most orthodox versions, 
this posture extols the autonomy of indigenous groups because it safeguards their uses and customs, and also because defending this autonomy helps put another dent in the old patterns of cultural hegemony.

In such circumstances it is understandably difficult to organize and further an intercultural dialogue. Would it be a mistake to consider cultural visions as "perpetual prisons" destined to reproduce themselves, blind and deaf to the challenges posed by the ever-changing environment and by the exposure to alternative scripts? In any case, how can we not be sensitive to the risks of an essentialist identitary nature entailed by a legal tradition that incorporates certain cultural practices in an ahistorical manner, and holds them up as untouchable aspects of a tradition?

But there are still other risks whose negative consequences should not be overlooked. We are referring to the risks incurred by asking the public authorities to refrain from defending the freedom and autonomy of persons, so as not to throw a wrench in the intercultural dialogue. Specifically, the authorities are asked to set aside legal guarantees of a liberal bent in certain areas of the national territory and to tolerate the frequent violation of those guarantees by the uses and customs of indigenous populations. These risks should not be underestimated in a region such as Latin America, where legal guarantees have been - and are - regularly trampled, whether by authoritarian regimes or by every day micro-authoritarianisms.

Caught between customary rights and liberal law, the question of the citizenship status of indigenous populations would circumscribe a field of insurmountable conflict. But these opposing principles, which reify customary law (and identity) as well as the liberal legal tradition, fails to take into account the empirical element with which we began this section: underlying ethnic demands is an affirmation of dignity on the part of social actors who are themselves increasingly integrated into the dominant national culture (even in their resistance to it). Most of the movements we are discussing are organized in the name of liberal laws, rather than in opposition to them. And contrary to what identitary essentialism would like to impose, it is within these movements, and not only as an intromission from without, that schisms and disagreements arise among those espousing different interpretations of the tradition. Among them - as so many women indigenous voices demonstrate - are unabashed proponents of individual life against the dictates of a time-frozen tradition. 


\section{Types of victimization discourse}

The victim, in principle, is the individual or social group considered to have suffered an injustice. As a political discourse, victimization is not just a conceptual elaboration on an objective situation. It is a complex construct that determines who is to blame and their motivations, who has been victimized and how they should reconstruct their own history based on that circumstance, and what alternatives exist to resolve the situation.

We can distinguish two types of victimization discourses: alterophobic and self-centered. The important thing in alterophobic discourse is the identification of the "culprit" and the judgment concerning the damages incurred. Its goal may be the destruction of the enemy or demands for reparations. The underlying rationale for alterophobia is articulated based on the pure versus the impure (whether in its secular or religious form) in which contact with the impure party must be avoided, combated and, where possible, eliminated. In self-centered victimization the locus of the victim is subject to an affirmation of inherent values rather than a devaluing of the other and to a project to reconstruct his humanity, which is mainly contingent on his capacity to mobilize his own resources.

These differences have a tremendous impact in terms of democratic politics and with respect to their consequences. The alterophobic discourse turns politics into a war in which people cast their lot with rival camps and those associated with the enemy are by definition illegitimate and may be excluded from the public space at any time. The self-centered discourse, while still agonistic in nature, emphasizes the need to join forces to build a common project that is expansive and forward looking.

These models never appear in their purest form in practice and political discourses can flow back and forth between the two or mutate over time. The trend towards an antidemocratic agonistic discourse is usually associated with blaming the "enemy" for all contemporary evils and devaluing the opposing discourse based not on arguments but on the characteristics of the messenger ("bourgeois," "unpatriotic," "white," etc.).

This trend is no stranger to nationalism, particularly in its most reactionary forms. Neither are the communist and revolutionary traditions exempt from an alterophobic victimization policy, as seen in certain third-worldist discourses in which imperialism theories cast the blame on advanced countries for their backwardness. Victimization was - and continues to be - part of the baggage of the Latin American leftist culture, even though in the $20^{\text {th }}$ century socialist tradition, the solution did not lie in reparation 
policies but rather in expelling imperialism and rebuilding society. Today the leftist culture of victimization has been updated by a discourse in which peoples become the victims of globalization and neoliberalism.

This sort of discourse is also evident among certain sectors of the power elite in Latin America when they condemn the activities of international NGOs. Similarly, it is observed among business sectors who resort to alterophobic victimization to secure government protection from international competition or engage in self-centered victimization ploys in their attempts to claim a new sphere of action from the patrimonialist state.

\section{The racialization of Brazil? ${ }^{73}$}

National cultures and mythology are based on historical experiences and on the political and social processes that reinforce or transform them. The dominant class in $20^{\text {th }}$ century Brazil did not attempt to invoke its European origins to distinguish itself from the rest of the native or immigrant population. The negative relationship with the past hampered the formation of a "traditional" elite that derived its prestige from its "deep roots" and was presumably the embodiment of nationality. Similarly, the immigrant-driven economic protagonism of Sao Pablo, the cosmopolitanism of Río de Janeiro, and the absence of wars or relevant external enemies - along with strong economic growth and the social and geographic mobility of the population for much of the $20^{\text {th }}$ century - converged to eliminate or weaken any potentially xenophobic leanings or tendencies to romanticize the past.

The ideology of "Brazil, the country of the future," came into vogue in the 1950s with the emergence of the middle classes created by the industrialization and modernization process. During this period, the social mobility of the emergent social strata was based on levels of economic growth rarely achieved in other countries. Confident in the capacity of industry, science and technology to ensure social progress, these strata not only eschewed racial ideology, they valued popular expressions mainly associated with the black population and even absorbing them into their art forms. At the same time, the new ideologies attempted to explain Brazil's ills based exclusively in reference to economic and political processes, leaving aside the race issue completely. While the ideal of "whitening" society is still

73 This section is based on Bernardo Sorj, "Deconstrucción o reinvención de la Nación: La memoria colectiva y las políticas de victimización en América Latina”; see also, Demétrio Magnoli "Identidades raciais, sociedade civil e política no Brasil." 
evident in practice, the underlying ideological discourse was delegitimized and replaced by a Brazilian culture that affirms its multiple roots.

Today this vision of forming a new forward-looking tropical civilization that integrates diverse cultural traditions is being assailed by NGOs and militant groups self-identified as representatives of the "black movement," with considerable backing from international foundations, in particular the Ford Foundation. These groups advocate affirmative action policies - which they argue would benefit the black population concentrated among the poorest social strata - while criticizing the notion of racial democracy as a sham. Their intention is to rewrite Brazilian history, eliminating references to such complex processes as mestizaje, cultural syncretism, and the value placed on African culture that left a powerful imprint on the history of the $20^{\text {th }}$ century. These groups find it necessary to reconstruct the national memory with an emphasis on the period of slavery, the suffering of the black population, and the advantages that European immigrants ostensibly enjoyed at the start of the $20^{\text {th }}$ century.

The idea is to construct a new historic actor, the figure of the AfroBrazilian with its own memory as a victim of history, imitating the United States model. And yet the latter model is grounded in an historic reality that has very little in common with the Brazilian historical-cultural reality. There are enormous discrepancies between the U.S. and Brazilian realities. African Americans in the United States were integrated into the European culture through their conversion to the evangelical church, in which context they constructed their memory of slavery based on the story of the exodus from Egypt. In Brazil, there is no memory of slavery since it never produced a collective narrative handed down from generation to generation. For African Americans in the United States, Africa is a mythological construct that serves as a point of reference to affirm their differences, without any substantive content. In contrast, African religions were kept alive in Brazil and adapted to the local culture and, as mentioned earlier, today Brazilians of all stripes participate in them. The Catholic Church, with its considerable syncretic capacity, ultimately assimilated rituals of African origin. In this way, Brazilian culture openly absorbed African elements, whether in its music, its cuisine, the martial art known as capoeira, recreational activities, and religious beliefs. In doing so, it recognizes its African roots, not as a myth about its origins but as a daily practice.

Mestizaje, however, is a long-term process that began at the start of the colonization period and left as its legacy a society in which most of the population has black, indigenous and European ancestry. What might seem 
obvious in other countries such as the United States, where the principle of a single drop of blood determines the "race" to which one belongs, in Brazil, an extensive nomenclature has grown up around skin color (along with hair and eye color) in which dozens of distinct labels vary from region to region and the boundaries between categories are blurred.

The difficulties of racializing social relations therefore even has its practical side. For example, universities that have established affirmative action policies for black students have been faced with dramatic situations in their efforts to define who qualified as black. Recently, a pair of identical twins submitted their applications to the relevant university committee: one was accepted while the other was not.

This is not to say that racism - among dominant sectors and low-income sectors alike - and a derogatory self-image of blacks do not exist in Brazil. But the myth of racial democracy precluded the formation of groups in the mold of the Ku Klux Klan or institutionalized forms of apartheid (even in the slavocratic era, mulattos occupied high level positions in white society and free blacks owned slaves).

How is it possible then that the Parliament is currently debating a law that runs counter to the construction of an apparently consolidated national identity? There are, as we have already indicated, various interest groups involved (intellectuals who believe that in lieu of a class struggle a racial struggle will serve, NGOs who fuel a discourse that affords them resources and social status, government officials who believe that these sorts of policies are cost-free and high in political benefits) but important as they may be, it would clearly be a mistake to attribute the profile of this issue solely to their actions. Indeed, demands and attitudes of this sort reflect an increasingly prevalent frame of mind in public opinion, which has lost confidence in the future due to the lack of economic growth and social mobility. Paradoxical as it might seem, contemporary criticism of the Brazilian nation probably is fueled more by an uncertain future than a hidden past.

This is not just a word game. Moving past the political rhetoric, differences of opinion are organized, in fact, around the most effective way to surmount the inequalities afflicting certain social groups. For some, this means putting into practice individualistic affirmative action policies that can only be justified by an historical revision of the national memory. Other observers, in contrast, hold that the memory of racial democracy - indissolubly a utopian project and an every day experience - must serve as underlying premise for revisiting universalist policies that can effectively reduce inequalities. 
As it pursued and radicalized policies originally designed under the government of Fernando Henrique Cardoso, the Lula da Silva administration became mired in affirmative action programs that necessitated the legal definition of racial identities in Brazil. The most ambitious example of this undertaking, the racial equality bill [Estatuto de la Igualdad Racial] stipulates the compulsory racial classification of every Brazilian through the mandatory identification of "race" on all documents generated in the health and education, employment and social security systems. ${ }^{74}$ The new racial categories include the newly created legal figure of "Afro-Brazilian," which compulsorily lumps together self-declared "blacks" along with other color gradations such as "mulatos" and "pardos." In this way, an official collective identity is established irrespective of the way in which each citizen would prefer to define him or herself. Indeed there are several controversial aspects to this law. Indigenous populations do not have the same status as the "blacks." Mestizos, of which there are several types in Brazil, are eliminated as a category with the right to exist as a discreet identity, even though that is how they regard themselves. Other social groups not defined by skin color who have been subjected to exploitation and exclusion for centuries, and up until recently, such as the northeasterners from the dry areas, have simply were simply been erased from the new racialized history.

In any event, the "racialization" of Brazil has engendered a movement comprising intellectuals and activists with diverse party affiliations seeking to block approval of the law. While recognizing the existence of racial prejudice and the need to combat it, they argue that the introduction of the race category as a criterion for social policy is an aberration, both because it means introducing race (which only exist for racist world views) as a category and because this measure will destroy the long and arduous process of building racial democracy, which is a political horizon, but also an actual component of Brazilian sociability. If affirmative action policies prosper in Brazil, what could be at stake is the future of Brazilian social cohesion organized around multicultural tolerance and the capacity to assimilate diversity and syncretism. 


\section{Conclusions: from technocratic reformism to democratic reformism?}

A certain polarization has developed in the past decade between two analytical approaches implicitly or explicitly associated with the political models and experiences on the continent. In some countries, pro-market reforms - which are often justified and facilitated politically by hyperinflation - were associated with the dismantling of the state and had an especially punishing impact on the poorest sectors. This model, which we term technocratic-reformist, emphasizes structural reforms to ensure fiscal accountability and transparency, monetary stability and less state interference in certain market mechanisms. Its social policies are guided by principles of efficiency and targeted towards the poorest sectors.

The second approach, which we will call statizing-nationalist, advocates a return to nationalism, a decisive role for the state in the economy, the protagonism of social movements, and direct grassroots participation, which is controlled to the extent possible by the central authorities. It develops in an agonistic manner in opposition to, and as a condemnation of, "neoliberalism" and globalization identified with United States imperialism.

In many aspects, the second model we have described constitutes a step backward in the direction of authoritarianism, central authority control over popular movements, and the crowding and suffocation of the economy by a state whose spending practices are not grounded in its productive base. Its current appeal in the region, however, is symptomatic of serious problems with the reformist-technocratic vision. These problems can and must be addressed if the technocratic-reformist model is to become a political vision capable of articulating a vision of the future that motivates society as a whole.

What are the main shortcomings of the technocratic-reformist model, whose main mouthpieces have been international agencies in general and a large percentage of economists in particular (who often paid a high cost in terms of their local legitimacy)? When political life is reduced to public policy and social life to abstract socioeconomic categories, leaving to the market problems of employment, labor relations, and the integration of the informal sector, it is impossible to construct a political project with which the poorest sectors can identify. An impoverished economicistic vision of politics went hand in hand with the impoverishment of the social realm. Society was abbreviated into categories of income distribution, poverty and social inequality. Any interest in individual action was reduced to the value 
placed on entrepreneurship, and communityboiled down to the instrumental and extremely limited concept of social capital. The technocratic-reformist discourse condensed the defense of the symbolic dignity of the poor into the category of excluded sectors demanding compensatory social policies.

Due in part to an understandable reaction to the old nationalism and statism, technocratic reformism impoverished the political discourse and was generally insensitive to the dimension of constructing a national project. By reducing politics to public policy implementation and efficient resource administration, it ignored the issues and values associated with nation and symbolic inclusion, which are fundamental even in terms of forming public officials identified with, and committed to, the common good.

This chapter highlights the dangers inherent to reducing politics to strictly administrative or economic matters. Modern societies also require efforts to search for collective meaning. The notion of politics in contemporary societies is indivisible from a project capable of distributing the material benefits of the economic system together with a shared values and beliefs system. This assertion, of course, is not intended to pit the need for effective public policies against the development of a political discourse, or a greater sensitivity to the need for symbolic integration against the need to reduce poverty and misery. To the contrary, it assumes that all of these dimensions must be integrated in the interest of consolidating democracy on the continent. Indeed, the current state of affairs is due in large part to the dissociation between a political approach reduced only to economic needs or only to symbolic or cultural imperatives. Social cohesion in democracy requires the intersection of both of these dimensions.

Democratic political life is always constructed, and constructs, around a project of nation. In this context, individuals and social groups find common values, while the state proposes the rules of the game with which citizens identify and which foster a sense of being part of a shared destiny and a national community. This, in turn, confers a sense of dignity and selfrecognition.

In the context of this inexorable imperative of social cohesion, the main shortcoming of technocratic reformism is that it failed to invest sufficient resources in the construction of its symbolic legitimacy. This means that we must develop new political visions that conjugate a vision of nation with democratic values in its intersection with globalization processes. It also means recognizing a society in which individuals demand greater opportunity for personal fulfillment along with respect for the dignity of each and every person. In sum, it is a matter of moving from technocratic 
reformism to democratic reformism. Only a transition of this nature will afford the region a durable and sustainable political project.

In the real social world, symbolic and associative needs are just as important as the socioeconomic dimensions, and the distribution of public goods cannot be dissociated from the discursive form and substance of how, to whom, and why these goods are distributed. What is more, an integrative approach such as this should not be limited to those who receive goods, but should target sectors with greater purchasing power who must also identify with a project aimed at greater social equity.

In all societies, this sense of nation is mainly rooted in longstanding cultural structures that are periodically updated by political and cultural clashes. In this, Latin America is no exception. But the fragility of the democratic political culture in most of countries on the continent engenders spasmodic, unstable processes fraught with ups and downs. In this framework, the pitfalls of the region's welfare states, consumptionrelated issues, populist temptations, and the reactivation of identitary demands pose major challenges for social cohesion that can only be met by the introduction of a new political project. Here it is useful to recall that "developmentalism" was about national progress and integration and the value placed on labor, a new political and cultural discourse around which the most varied economic policies were designed in an ad hoc fashion. Technocratic reformism reversed the formula. Developmentalism will only be successfully replaced by a new vision of nation that offers more space for the broad expression of new forms of individuation sustained by a state capable of expressing the new demands of society. 


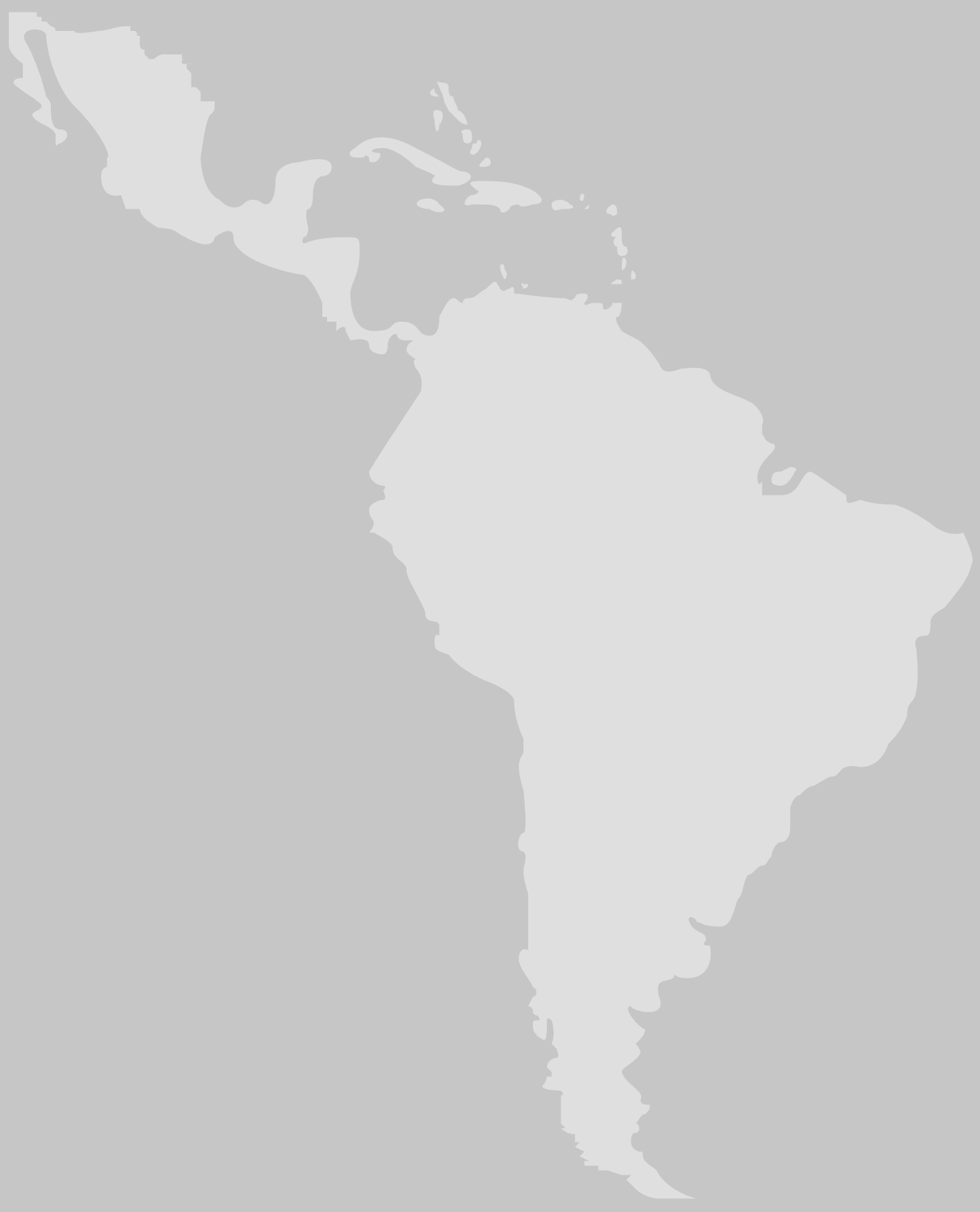




\section{, | | General Conclusions}

As seen in the preceding chapters, trends observed in contemporary capitalist societies across the world are operating in Latin America, albeit with the particular characteristics shaped by its history, developmental levels and social structures. What is more, a specific process is underway in the region associated with the dialectic between the expectations and initiatives of social actors in a general framework of democratization of social relations. The challenge that social cohesion represents for presentday institutions and politics must be understood in the framework of this two-tiered analytical reality.

\section{Latin America: comparative structural similarities}

What are the trends in the region, common to other parts of the world, which were accelerated by the impact of the demise of communism, new globalization processes, transformations of productive systems and the new information and communication technologies? They can be summarized conceptually as individuation, dedifferentiation and deinstitutionalization.

Individuation generally refers to the study of the major historical processes that shaped the production of individuals in modern times. In the context 
of Latin America today, however, it involves the accentuation of individual idiosyncrasies and a context in which decisions are increasingly transferred to individuals in a culture devoid of fixed values and references points. Individuals are increasingly responsible for decisions about the meaning of their place in the world, their survival strategies, and their negotiations with their social surroundings in the absence of clear, pre-established rules or normative systems. The expansion of the space for individual action does not mean, however, that institutions have simply stopped functioning. To the contrary, weakened norms, values and traditional bonds of solidarity fuel demands for public regulation, social policy and formal contractual relations in spheres heretofore considered within the confines of private life. This has led to the increasing judicialization of social relations.

Individuation in Latin America takes on the unique characteristics we described at length in the preceding chapters. To these we must add the characteristics of the labor market where individuals' social positions and roles are less univocal relative to other, more advanced, societies. Although we were unable to go into depth about the employment issue, it too is critical to the discussion. Pluriactivity is common practice in many countries of the region, mostly among low-income sectors but also among middle sectors. This means that in one's lifetime, one might engage in a plurality of "occupations" involving myriad "identities" (it is not uncommon, for example, for a formal worker to go through periods of informal work, or for a salaried employee to "round out" his or her income by taking an outside job). Both phenomena describe an atmosphere in which social cohesion is organized based on greater societal porosity.

Individuals are bound by their social context. Obviously the same options are not available to a poor Latin American considering emigrating to a developed country to work under precarious or illegal conditions, compared to a middle class youth who is wondering whether or not to study at a foreign university and then remain abroad to work with a multinational corporation. The same is true of illegal acts, since a poor criminal can anticipate a very different fate than a rich one: the former is liable to be convicted without an adequate defense, while the resources of the rich infractor will ensure access not only to ample legal support, but also to the possibility of leveraging funds or contacts to corrupt police or court officers if need be. Indeed, what we have here is a research agenda on the complex relations between individuation and social stratification.

By the dedifferentiation of social subsystems, we mean the erosion of the boundaries that divide them, and the interpenetration and colonization 
of different spheres of power (for example, the influence of economic power on scientific research, the influence of the judiciary or the media on political decisions, the weakened ethics inherent to each profession or public function, and the growing presence in public life of topics previously confined to the private realm). But in Latin America, added to this first tier of blurred boundaries is a historic legacy in which social subsystems were always low density and enjoyed little autonomy, especially because the culture of transgression and the imposition of economic and political power significantly undermined the autonomy of the public authorities. Latin America, then, faces the dual challenge of building autonomous social subsystems in contexts in which a new capitalist culture is weakening them.

Deinstitutionalization (or perhaps detraditionalization) refers to the erosion of the foundational values of modernity and of the dominant ideologies of the $20^{\text {th }}$ century (family, work, homeland, progress) and the forms of socialization and representation associated with them (school, universal draft, trade unions, political parties, universal ideologies), which have been replaced with more gelatinous and fluid forms of sociability and solidarity. Tradition is no longer a beacon for action and actors must base their behaviors on new criteria that require an increasingly larger does of reflexivity. Here again the challenges for the region are manifold, since the penetration of the universalist values of modernity, particularly through the school system, was highly deficient, although this varied enormously from country to country (the chasm between Uruguay and Bolivia comes to mind, for instance).

These three processes are interconnected. Individuation influences, and is the result of, dedifferentiation and deinstitutionalization processes and vice versa. In Latin America these trends are overdetermined by the legacy of pervasive inequality and poverty and a patrimonialist state. The dynamic of dedifferentiation, for example, is particularly influenced by the rampant corruption that destroys the autonomy of state subsystems, by an informal sector that erects a parallel economy behind the state's back, and by violence that increasingly privatizes security. Prominent among deinstitutionalization processes is the crisis of traditional political party systems and the emergence of collective actors with politically fragmented, and fragmenting, demands. Similarly, dictatorships and hyper-inflation, in their moment, left an indelible imprint on social processes that is still felt today in political culture and institutions.

We are confronted, then, with the challenges of $21^{\text {st }}$ century modernity arriving on the heels of a past with few virtues to recommend it, by way of 
processes marked by the extreme fragility of the public space and social inequality. It is important to understand just how these trends operate as we reflect on the enormous challenges lining the path to democratic consolidation in the region. The new winds blowing hamper institutionbuilding processes, yet also bring with them fresh potential for the development of a democratic culture.

More individuation means more autonomy and personal initiative and the constant questioning and negotiation of social relations and this widens the chasm between the individual subjective world and society. Compounding this is the waning influence of the major social adhesives of the $20^{\text {th }}$ century. Ultimately we are experiencing a deinstitutionalization of the old values that paves the way for new associative and symbolic cultures. Young people today, for example, reorganize into new patterns of sociability, beliefs and solidarity in which consumption, the cultural industry and new forms of religiosity occupy an important space. The few existing ethnographic descriptions of these patterns, however, have yet to be fully integrated into political and sociological analysis.

Secular utopias are in a state of collapse. The breakdown of collective visions of the future brings enormous pressure to bear on individuals, who become the main vehicles for the construction of meaning in their lives, a circumstance that alters the way collective demands are expressed. The latter, as we have discussed, are often expressed in the lexicon of human rights, of demands on the state, or of group victimization constructed around a reference to a current or past injustice. Although these demands and forms of victimization may lead to reparations and more effective insertion into the modern world, they also create new sources of tension and social fragmentation.

\section{Latin America: the surprise of democracy from the ground up}

Yet along with these trends - which resemble those observed in other regions of the world - we must consider another, extremely powerful aspect, one which serves as the foundation for many of the conclusions of this book. Latin America has experienced - is experiencing - an unprecedented democratic transformation. What is radical and new about this process can be described based on three elements: (a) the structural depth of the process; (b) its progressive spread to every social group; and 
(c) the fact that society and culture, rather than the political-institutional sphere, are at the heart of this transformation. Let us briefly examine each one of these points.

First, while this democratization process partially coincides with the restoration of democracies in the 1980s, it represents a radical departure from the past in that it has genuinely emerged as the fruit of a series of structural factors. Through processes of urbanization, globalization, expanded educational coverage and new communication systems - but also due to structural reforms - Latin American societies have became more individualized and democratized than ever before. Despite an apparent status quo that might be conveyed by certain inequality and poverty indicators, the social fabric, association patterns and symbolic universes have undergone profound changes in Latin America. Indeed, social life has changed more dramatically than the state or the economy as society has become more porous and dynamic. This includes progress in gender relations and in the recognition of ethnic diversity. The democratization of symbolic universes and expectations, together with the questioning of traditional authorities and a generally reinforced antiauthoritarian culture, inform one of the most profound revolutions witnessed in Latin America in recent decades. As we have seen, it has had powerful implications at all institutional levels, from the family, to the school, to relations with the established authorities. This transformation, which we will return to momentarily, has a tremendous liberating potential, but also poses risks for social cohesion.

Second, this democratization is not confined to regime changes (from authoritarian to democratic) nor is it only perceptible in certain social categories. As we have seen, an egalitarian desire is palpable across social boundaries and permeates all social actors, albeit with varying levels of intensity. Traditionally vertical relations progressively give way to more horizontal forms whose vigor and demands are tangible in the workplace, in gender, intergenerational, and inter-ethnic relations, and in public interactions including, of course, relations with the political authorities. Here again, this process is both promising and problematic. While the old social cohesion based on patrimonial and hierarchical ties has been largely destabilized, it has yet to be completely replaced with a form of social cohesion rooted exclusively in equality. That notwithstanding, and in marked contrast to the recent past, the democratic transformation has been massive and widespread. Tocqueville is no longer a foreign author in Latin American countries. But the version that is taking root is unique and goes hand in hand with another civil religion - human rights discourse 
- and other vehicles for social organization, values and social practices (the mass media, expectations of individual and collective consumption, transgressions of the law).

Third, and defying many predictions, society and culture, rather than political systems (and the democratic transition associated with an alleged "third wave"), are the driving force behind this democratizing process. This is clearly one of the reasons that the democratic transformation, despite its depth and breadth, has yet to be sufficiently theorized and noticed on the continent. The traditional assumption in Latin America was that changes in the direction of democracy would come from the political realm, or at least the economy and no one ever really gave serious thought to the possibility that it could come from culture and society. And yet, as we have endeavored to show systematically throughout this study, the opposite has occurred. Culture and society have become democratized, in their demands and in their forms, more deeply and more robustly than the political system and even many institutions.

Thedemocracythatwasmeanttohavearrived "fromabove" hasmaterialized "from below," unquestionably with characteristics, "deformations" and ramifications associated with a less than virtuous institutional substratus. The state has been hard-pressed to adjust to this new reality and confronted with a citizen-driven revolution, the political discourse often seems to be trailing behind. This transformation, for example, requires new fiscal demands in the form of taxes and a closer link between public spending and citizens' sense of belonging and control of government. All of which, needless to say, makes corruption increasingly less acceptable. A series of factors that engenders new and deeply-rooted frustrations today, but could auger a new type of citizen relation tomorrow.

In any event, this democratizing tension is at the heart of a dialectic between two processes - expectations and initiatives - which we have repeatedly emphasized throughout his study. On the one hand, across Latin America today citizens' expectations have risen significantly (in terms of more horizontal social relations, higher levels of consumption, symbolic participation in nation, and of course, rights). On the other, and despite the many institutional shortcomings described herein, equally visible in the region is a proliferation of individual initiatives and opportunities for action. Of course these supplemental actions (relative to the past) do not occur uniformly (not all actors take equal advantage of them) and there is quite a bit of variation among them (some rely more on individual capacities while others leverage collective resources and 
still others combine the two, as we saw in our discussion of emigration). In any event, the dialectic elicits institutional responses and gives rise to radically different social phenomena depending on the particular milieu, or country, or actors involved. Sometimes, the combined effect of these two factors portends clearly democratizing forms of progress, while in others, the chasm between them translates into very real and profound dangers. The inherent ambivalence of this dialectic generally complicates efforts to anticipate the direction changes will take. Only using very broad strokes and contextual empirical reviews as controls, were we able to design three overarching equations:

- The first scenario produced by this dialectic occurs when expectations rise without a corresponding increase in the ability of actors to realize them. This was one of the historical roots of the populism of the 1960s (when the demands overloaded the political system). It is, as we have pointed out, one of the causal factors behind expanding violence and organized crime in the region, and (albeit with different trappings) the return to populism and victimization processes. As in the past, this vision embodies the fear of the "masses." But where some would interpret this as an overarching process, our study accords it only partial relevance.

- The second equation - almost as the inverse of the preceding scenario - occurs when increased expectations are accompanied by, or find an outlet in, opportunities for overwhelmingly individual action. More forcefully put: until very recently, this possibility was simply ignored in the region given the prevailing paternalistic vision of social actors. From the standpoint of social cohesion in democracy, it is a response imbued with an insurmountable ambivalence. While it is now possible to find individual solutions to collective challenges (emigration, horizontalization of the social bond, new individual uses for community resources, and creativity thanks to the culture of new social ties), it also can impede the search for solutions to certain problems that necessarily must be collective or public. In this sense, unmitigated praise for individual initiative is an ideological trap. The real increase in practical initiative on the part of actors in Latin America clearly enables them to individually bridge institutional gaps (and this occurs in all ambits of social life), It cannot under any circumstances, however, constitute a political horizon in the long term. 
- Finally, the social and cultural depth of the dialectic between growing expectations and greater capacity for action by individual actors invites us to look beyond the mere individual solution of collective problems towards a new basis for the intersection between institutions and individuals. This is clearly the virtuous circle that should serve as our guidepost in the coming years. Institutions should not blame individuals, nor tie their hands. To the contrary, institutions must be structured in such a way as to effectively bolster the initiatives of actors, so as to foster a new type of bond between the two. The individual does not exist in opposition to institutions. The individual, in his or her constitutional fragility, is the product of a way of making society. The political debate in the region and the long tradition of ideological rivalry between collectivism and individualism often cloud the essential and inextricable link between the affirmation of collective institutions on one side and the expansion of individual autonomy on the other. Unquestionably, as this study shows, this virtuous circle is far from a reality in Latin America. But the foundations have been laid. And in some arenas, admittedly under critical modalities at the moment (let us consider, for example, the growing recourse to law), some positive signs are beginning to emerge. It is important to understand that the consolidation of institutions cannot be accomplished to the detriment of the growing capacity for individual action, but must instead be rooted in that capacity, and indeed must encourage it.

Latin America is having serious problems translating new social patterns at the institutional level. This matter should receive concerted attention in the coming years. In effect, the disconnect between institutions and the social reality, between the legal country and the real country, has long been remarked in the region. The general assumption has been that the former (under foreign influence) were way "ahead" of the latter (and the atavisms of our societies). That line of reasoning rings false today, at least in part. The transformation of the social bond and the growing relevance of citizens' demands have been such that, at the moment, individuals and society have the feeling that they are "ahead" of their institutions. The latter are at once the compulsory and indispensable channel for individual complaints and the eternal obstacle to the translation of their aspirations.

The future of democracy will be written by associating and developing the virtuous circle between institutions and individuals. This association 
involves the reconstruction of authority among people - politicians, public officials, and citizens - in the context of social relations that demand a differential of expertise and positions of authority, and in the sphere of norms and laws. This issue is at the heart of all contemporary modern societies. In Latin America, however, it is aggravated by the loss of respect for authority associated with corruption, by a culture of transgression and low educational levels. One of the main challenges for the social sciences in Latin America, and for the design of democratic political projects, is to think about how to construct authority on democratic foundations. But what keeps many of the region's intellectuals from addressing this issue is the tendency to mechanically equate the issue of authority with that of authoritarianism or "the right." Avoiding the subject, however, does nothing avert the constant danger that the "lack of authority" will fuel authoritarian temptations.

\section{A new challenge for social thought}

The difficulty of reaching consensus on the situation of social cohesion on the continent largely stems from this new state of affairs. Is there more or less social cohesion today than before? The construction of "objective" indicators is an attempt to answer this type of question, yet fails to address its precursor, which is: exactly what is the nature of social cohesion? If this question is not answered, one ends up supposing that social cohesion can be chronologically measured and compared using the same indicators, as if we were dealing with the same entity in each case. In the endeavor to discern the qualitative dimensions of this phenomenon - in our case what has actually changed in Latin America with these democratic winds that are blowing - have inclined us towards an historical interpretation of the transformation in progress.

We are ill-prepared, however, to contemplate this challenge. Why? Because the desociologization and depolitization of Latin American social thought due to the invasion of economism somehow blocked interdisciplinary dialogue. We have only a poor grasp of the new social dynamics on our continent. Most contemporary analyses and studies of political systems conclude that they are in "crisis," yet have not managed to identify alternative dynamics and projects to reorganize the political system. Latin American critical social thought is struggling to reinvent itself following the crisis of its underlying paradigms (its vanguardism in the 
1960s and 1970s, interpreting the will of the people and, in recent decades, the desire to simply be an expression of social movements (Sorj, 1989).

With its unilateral emphasis on distributive aspects and its excessive and not always rigorous application of the concepts of inclusion/exclusion, social thinking has neglected to address the issues and needs of the middle classes, which constitute the linchpin of stability and social cohesion. To give just one example, these sectors are the backbone of the workings of public institutions, but this role requires a certain ethos in which members of the middle layers see themselves as the defenders of the common good of the nation. In the past, of course, this sense of national inclusion created mechanisms for the exclusion of other social groups. This was particularly the case when the middle classes, ethnocentrically decided that they (and their interests) were the embodiment of "decency" and "civilization." But we must bear in mind that during the developmentalist period in many Latin American countries, the sense of being part of the construction of a nation facilitated the establishment of institutions imbued with the "aura" of public service. Today, in contrast, much of this middle class ethos is concentrated in extragovernmental organizations linked to international agendas that are more frequently engaged in condemning the state, and the rest are sick of politics and are even losing the positive connotation of belonging to the nation.

We must reflect on the complex relationships between state, society and the political system in order to design development strategies with equity, particularly in democratic contexts. The power of classical Cepaline thought lay not in an economic policy paradigm but in its intellectual underpinnings, in its sensitivity to the historic specificities and social dynamics of the region.

Inequality and poverty, for example, are statistical conglomerations that tell us little, very little, about the social lives, associative worlds and construction of meaning in contemporary Latin American societies. The same is true of categories such as social inclusion and exclusion. There is no question that limited access to social services or to opportunities in the labor market contribute in crucial ways to the construction of a sense of exclusion. Yet this assumes a pre-existing inclusion in terms of expectations of access to equality. And this feeling is not elicited by a mechanical relationship with socioeconomic indicators. Feelings of exclusion, frustration and social anomie are present in sectors with the highest social welfare indicators (ostensibly the "included"). The included/excluded dichotomy has often left the middle classes out of the analysis of social dynamics, even though they are one of the pillars of political life in the region. 
We must therefore understand the new ways of organizing symbolic and associative universes in Latin America. Since the way in which expectations are developed by social actors, and the individual and collective strategies they employ to realize them, are not expressed mechanically or exclusively in the form of demands upon the political system. Social expectations channeled through new associative groups (whether religious or cultural), the expectations and realities associated with emigration, virtual communities, music, alcohol or drug use, gang membership and organized crime - none of these fit into the simple dichotomy of integrated/excluded. In response to the many facets of social cohesion, Latin American social thought must revitalize its theoretical imagination and carry forward the work of its classical theorists.

\section{Reinstitutionalizing politics}

To conceive of politics in modern societies is, in the first instance to conceive of a collective project capable of creating a sense of a shared set of values and beliefs, even as people pursue their individual interests. Democratic politics is built on and builds a project of nation in which individuals find shared values, a sense of being part of a shared destiny and a national community with which they identify positively and in which they find elements of dignity and self-recognition, a project that simultaneously recognizes the legitimacy of the diverse interests and world visions held by groups and individuals. In Latin America, social cohesion in democracy must be processed by institutions able to absorb and express conflicts as a constitutive and legitimate part of the social order and incorporate them into the heart of social life.

Where do we begin to work a change that can produce quality institutions and policies in which citizen participation and oversight are not reduced to voting or to periodic outbursts of dissatisfaction? The struggle against dictatorship led us to overestimate the capacity of civil society, which has established itself in democracy as a demander of the state rather than a mechanism for political representation capable of articulating transformative visions of power relations and distribution systems. The radical state/ market dichotomy is not overly helpful either. When the synthesis between nation and politics does not take place in programmatic terms and through transparent institutionalized mechanisms for political representation, the task is transferred to circumstantial leaders who give voice to the frustrated 
desires of the community. Politics becomes the byproduct of leaders able to catalyze these grassroots aspirations, and the destinies of our countries are ultimately held hostage to each new election.

We must refocus the debate on societal models that the contemporary political realm has proven incapable of expressing. This means giving some thought to the reorganization of systems for social participation, political party representation, and political discourses. Public policy debates (an imperative) can elicit clear and objective evaluations of how to optimize scarce resources with clearly defined objectives. However, the debate over models of society entails openly addressing conflicts of interests and differing visions of what constitutes a desirable society and what is within the realm of the possible. Obviously the politics underlying different models of society cannot find expression in the absence of coherent and viable public policies. That said, the space for debate over what type of society is desirable absolutely cannot be reduced to a laundry list of public policies, no matter how inspired. Politics, especially in a region such as Latin America, cannot ever be reduced to social engineering.

This does not mean a return to millenarian approaches in which society must be reinvented in each election, or the development of "projects" for nation wherein lie the solution to all problems. To the contrary, it has to do with approaching politics as an ongoing process, one in which alternative solutions to specific problems are offered up for public debate in the context of a normative vision that understands that society is permeated by mutually legitimate conflicts of interest.

How to move in this direction? We do not believe that orthodox/ heterodox or state/market dichotomies are useful in crafting creative alternatives for development strategies. As indicated in the preceding chapter, we must revitalize the technocratic-reformist model, which - at least in some of its versions - had the merit of focusing on fiscal accountability and transparency, monetary stability, a reduction of the state's clientelistic interference in market mechanisms, recognition of the role of the private sector, and social policies targeting the poorest sectors. Devoid of a policy of meaning, however, this technocratic-reformism ran into serious limitations.

The new political discourse must appeal not just to the "people" or the "masses," but also to individuals, addressing them as responsible citizens capable of effective oversight of state actions. In order to reconstruct political institutions in particular we must revisit the relations between the individual, networks, and pyramids (that is, hard nuclei of power such 
as the state and large corporations). A higher degree of individuation and the proliferation of fluid networks do not mean that power centers have disappeared. Instead, they have undergone a dual transformation, at the internal level and in relation to their surroundings. State structures must be increasingly permeable to citizen interaction and oversight or they run the risk of becoming obsolete. In this sense, it is essential to break out of the current perception that the only ones paying taxes are formal sector employees and entrepreneurs. All products available for consumption are taxed and therefore everybody pays taxes (especially since income taxes account for only a minimal percentage of tax revenues in most systems in the region). It is critical to disabuse the middle and upper classes of the notion that they have to be the only financiers of the state, while fostering among lower income sectors a sense of their role in this task. These two elements are essential to expanding a citizen conscience that is more willing to contribute to public spending in the region. Here too the virtuous circle is found in the intersection between collective institutions and individual initiatives.

\section{Citizen inclusion, nation and social cohesion in democracy}

The unilateral value placed on the market, coupled with social policies proffered as little more than compensatory measures to fill its gaps, diminish society as a whole as well as the symbolic dimensions of politics and public goods and service-provision. In Latin America we are far from identifying totally with an individualistic, market-centered culture capable of creating a sense of community - indeed it is difficult to imagine our ever doing so. This is not only attributable to the obvious limitations of the market today (and its failure to offer most citizens a sense that the opportunities and recompense it has to offer are fair). It is also due to the fact that the republican tradition and the role of the protector-state (with powerful paternalistic connotations) are deeply embedded aspects of our culture which we must address if they are to change.

The national culture is part of the common good in a society. It is an intangible and immeasurable source of richness whose value is renewed, empowered, devalued, or destroyed by the actions of citizens and political leaders. This is particularly true when it is transformed into xenophobic nationalism. Paradoxically, globalization processes have left citizens increasingly conscious of the nation in which they live, and not only 
because of the impact of new communications media. When international institutions following cosmopolitan agendas established indicators to rank countries in the international system, they reinforced each individual's sensitivity to the relative "value" of his or her own society. This new reflexive nationalism can be a factor in diminishing the sense of value of the national society or else a potentially galvanizing and motivating force for citizens.

To move in this direction we must develop - in a collective effort that demands the participation of each social sector in its unique sphere of action (social scientists, decision-makers, politicians, civil society) - new political discourses capable of engendering nonxenophobic nationalistic projects and new forms of associativism and participation that reinforce (or reconstruct) the institutional system. Latin America arrived at democracy by default, largely due to the crisis of authoritarian regimes. The time has come to give it a content with which society can identify.

To begin with, this requires a better understanding of the societies in which we live: the conflicts and social cohesion they produce and the opportunities available for discourse and for political actors who are the conduits between society and the state. We cannot forget that while social cohesion and democracy can lead to a fruitful synthesis, it can also, as has oft occurred on the continent, set us on yet another collision course.

Conceiving strategies for social transformation unquestionably includes developing more effective and socially just public policies. Even more crucial, however, is our ability to identify the historic moment and the social structures in our countries upon which to construct new alliances and discourses for new types of consensus which, translated into political action, will lead to the transformation of the state.

On the threshold of this new century, Latin American nations must react to agendas mainly set by the countries to the north. There is nothing historically new or intrinsically unworthy about this. The objective is to successfully confront the challenges thrown our way, but not the discourse they are wrapped in and still less the specific solutions. In Latin America (except perhaps for a few countries) issues of ethnic belonging as an alternative to, or in confrontation with, national participation are not really on the table today. What is at stake and affects people's sense of national dignity and pride is not their identification with the nation but their identification with political institutions. While there is a lot of room for improvement in terms of integrating indigenous populations and combating prejudice and racism, the problems of belonging in Latin America are not the same as those faced in Europe or the United States, for example. The 
challenges we face essentially reflect broader social schisms that affect all citizens, albeit unequally: enormous inequalities, limited opportunities for decent employment, violence, and the shortcomings of public institutions, which cause many to emigrate and others to withdraw from, and exhibit increasing cynicism towards, democratic institutions.

A narrow public policy focus tends to overlook something equally important in modern democratic societies and that is the development of visions/projects for society with which most citizens can identify and which make them feel as if democracy is a central value in their lives. This has increasingly less to do with creating a new collective actor imbued with political and organizational density and more with collective capacity and the design of common goal-oriented projects. There will be no social cohesion without a broadbased political debate over projects that deepen democracy on the continent. In order to achieve this, we must move beyond our nostalgia for a past that is not coming back as well as the apologist celebration of the new. 


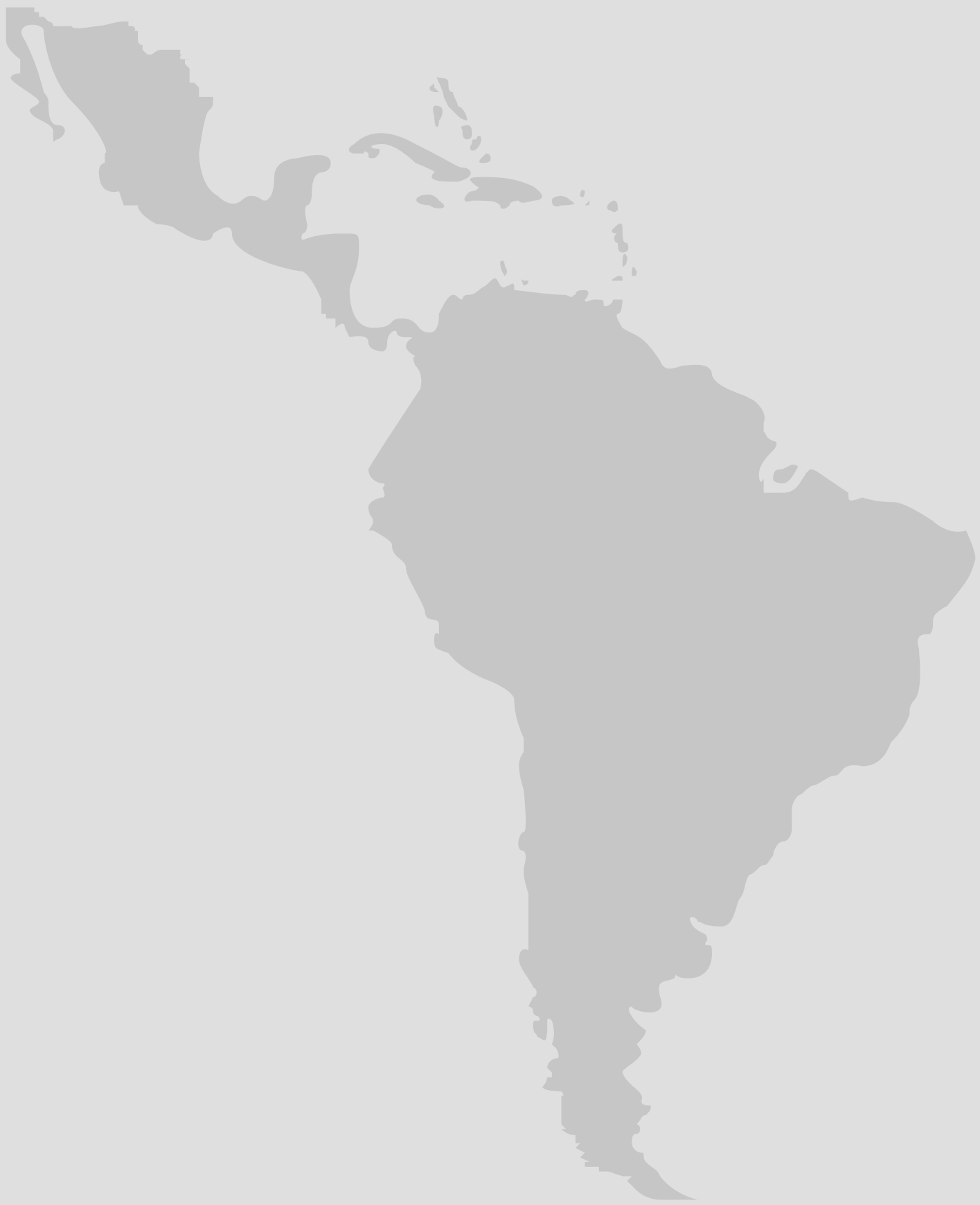




\section{Annex 1 \\ Background to the Concept of Social Cohesion}

The predominant concept of social cohesion in the current international debate was developed in the 1990s by the European Union as part of a political discourse imbued with an essentially normative-evocative meaning that seeks to define a desirable horizon for society. ${ }^{75}$ The notion of social cohesion synthesizes in a way the central values of solidarity and equality in the European model. It contrasts sharply with the Anglo-Saxon model, which is regarded as steeped in more individualistic values and less concerned with distributive aspects or the state's role as guarantor of the common good. ${ }^{76}$

Underlying the European Union's concerns with social cohesion are its changing productive base and demographics in recent decades, its insertion into globalization processes and the attendant impact on job

75 The concept of social cohesion is defined as "the capacity of a society to ensure the welfare of all its members, minimizing disparities and avoiding polarization. A cohesive society is a mutually supportive community of free individuals pursuing these common goals by democratic means." http://www.coe.int/T/E/social_cohesion/social_policies/03.Strategy_for_ Social_Cohesion/

76 http://216.239.51.104/search?q=cache:InbhfFfic4YJ:www.notre-europe.eu/en/axes/ competition-cooperation-solidarity/works/publication/how-to-enhance-economic-andsocial-cohesion-in-europe-after-2006/+definition+european+commission+social+cohesion $\& \mathrm{hl}=\mathrm{pt}-\mathrm{BR} \& \mathrm{ct}=\mathrm{clnk} \& \mathrm{~cd}=10 \& \mathrm{gl}=\mathrm{br}$ 
creation/unemployment and the distribution of wealth and opportunities, and challenges to the welfare state. ${ }^{77}$ These changes provoke social tensions which, in turn, jeopardize "social cohesion." In synthesis, European social cohesion has to do with the specter of the immediate past which it hopes, in some way, to preserve.

As the concept of social cohesion became increasingly central to the European Union's discourse, criteria and indicators were developed to measure it. Known as the Laeken indicators, they deal mainly with distributive variables (employment, income, access to public services). ${ }^{78}$ In this way, the notion of social cohesion, a normative framework, became operational and therefore a target for public policies intended to influence the indicators.

In sum, the concept of social cohesion is associated with a specific political context that evokes what is regarded as a desirable state of affairs relative to the status quo ante. As such, social cohesion is not set up as an interpretative framework for reality in the sense of proffering a theory and an analytical framework for social dynamics.

The concept of social cohesion is clearly part of sociological tradition: it is featured prominently in the work of Émile Durkheim and later revisited, though not always under the same name, in the functionalist tradition. The concept of social cohesion adopted by the European Union, however, claims no intellectual affiliation with that current of thought. It is essentially a normative reference associated with operational criteria revolving around indicators (employment, health, etc.) which are selected by public debate, politicians, and technocracies.

Can the operational instrument developed in the European Union be applied to the Latin American reality? We think not. Our history and social realities are very different and we must therefore come up with an analytical and political translation of the concept of social cohesion for our region. Moreover, a legitimate question to pose is: why introduce into the Latin American debate a concept that risks becoming the new fad, one that in a sense superimposes itself on pre-established normative concepts (such as full citizenship or democracy with equity) and others involving

77 Gosta Esping-Anersen et alli, Why We Need a New Welfare State, Oxford, Oxford University Press, 2002.

78 http://eur-lex.europa.eu/LexUriServ/LexUriServ.do?uri=CELEX:52002DC0551:ES:HTML http://circa.europa.eu/Public/irc/dsis/ssd/library?l=/task_force_esec/1617_april_2007/ improvementsdoc/_EN_1.0_\&a=d 
relatively similar indicators (such as the Human Development Index, for example)? We believe that the value of addressing the issue of social cohesion in Latin America lies in its potential to focus the debate on social and cultural dynamics after decades of hegemonic thinking centered on economic issues.

This is not to say that the issue of social cohesion cannot be addressed following parameters similar to those developed by the European Union. In this case the aim would be to design public policies around indicators of social cohesion associated with issues that have been widely debated in recent decades (growth, inequality, poverty, technological innovation, fiscal policy). In the second scenario, which is our choice in the present discussion, the subject of social cohesion can be taken as an opportunity to introduce into the public debate a fresh vision of the directions our societies are taking and new ways to approach public policy-making and democratic consolidation. These two viewpoints are not mutually exclusive. To the contrary, they could stimulate a rich dialogue over the paths to follow in the region.

If it is true that the concept of social cohesion requires more sensitivity to, and the effective inclusion of, social, political and cultural issues, one might conclude that a return to an interdisciplinary dialogue is required, one that incorporates the contributions of the various disciplines in the social sciences. This means galvanizing economists, sociologists, political scientists, anthropologists and historians in an effort to discover the many nuances evoked by the concept of social cohesion (societies that value democracy and equity and transmit a sense of belonging and dignity to their citizens). It is not so much a matter of developing a theory of social cohesion as placing this concept at the service of a multidisciplinary examination of the social processes underway in Latin America. In this sense, while progress in the area of definitions and indicators, such as those developed by ECLAC, represent an important contribution, they also run the risk of declaring resolved conceptual problems that require further theoretical and empirical development. ${ }^{79}$ The challenge, in particular, is to

79 See Social Cohesion: Inclusion and a Sense of Belonging in Latin America and the Caribbean, ECLAC, 2007, http://www.eclac.org/cgi-bin/getProd.asp?xml=/publicaciones/xml/4/27814/ P27814.xml\&xsl=/tpl/p9f.xsl\&base=/tpl/top-bottom.xsl ; Ana Sojo y Andras Uthoff (editors) Cohesión social en América Latina y el Caribe: una revisión perentoria de algunas de sus dimensiones, 2007, http://www.eclac.org/cgi-bin/getProd.asp?xml=/publicaciones/ xml/8/28198/P28198.xml\&xsl=/dds/tpl/p9f.xsl\&base=/cooperacion/tpl/top-bottom.xsl 
make sure that the concept of social cohesion is not treated merely as a new label on a container with the same contents and methodologies as always, with their essentially economic bias.

Sociocultural dynamics tend to be overlooked in the reports of international agencies or only included when they have a specific economic purpose, as is the case with "social capital," or in the form of public opinion surveys. One of the reasons for this absence is that when handled in an intellectually responsible manner, sociocultural dynamics require a sensitivity to, and acknowledgement of, the diversity of national histories in which values and symbolic universes acquire specific meanings that are hard to quantify and generalize. This ultimately conspires against the analyses developed by international organizations whose vocation is to come up with generalizable and quantifiable solutions, sometimes at the expense of the complex webs and the particularities of national histories.

This is not to say that Latin America is not a legitimate subject for comparative research. To the contrary, in addition to their similar or parallel historical processes, the same political and ideological winds periodically blow across the continent. Yet these winds blow across a wide variety of topographies and therefore their effects cannot be generalized. Sensitivity to the diversity of national societies must include the recognition that social processes affect different social and generational groups differently. For this reason, our analysis focused mainly, although not exclusively, on the large metropolis and the most dynamic sectors, as that is where social problems and emergent trends are revealed more explicitly.

\section{Social cohesion in democracy: change and social conflict}

The analysis of social cohesion in Latin America must elucidate its relationship with democracy. In Europe, democracy is a consolidated fact, while in our countries a question mark still remains. That is why we prefer to speak of social cohesion in democracy to describe more precisely the challenge we face in the region. By referring to social cohesion in democracy we can also distinguish more clearly between the analytical and normative dimensions of the concept. Why is this so?

As social theory teaches us, all societies generate some form of cohesion. Otherwise they would not exist. But the mechanisms for social cohesion vary based on the history and type of society. In complex societies, this is reflected 
in the existence of universes of beliefs and values shared, to varying degrees, by all members of society, and by systems of authority rooted in consensual norms and coercive systems that ensure the functioning of the established order. Mechanisms of social disintegration are also many and varied. They may be the product of exclusion, anomic violence or authoritarian ideologies. While the social vectors may vary enormously the end result is an inability to trust in the capacity and legitimacy of democratic institutions.

If every society has, by definition, social cohesion, then what is at stake from the standpoint of the operative value of the concept is the degree of social cohesion in a society in function of particular objectives. For the purposes of this study, the issue at hand is social cohesion in democracy. That is, of the processes and mechanisms that might weaken or strengthen the belief in democratic values and practices as a way to resolve social conflicts and advance the common good.

Social cohesion in modern times cannot be dissociated from social change and from social conflict. Modern societies are in constant mutation which means that some forms of sociability are always disintegrating and giving way to new mechanisms for integration in which citizen participation and demands play a critical role.

In established democracies, as in Europe for example, the legitimacy of social conflict and the existence of channels to resolve demands are considered an acquis. This is not the case in our societies, where political systems feature enormous limitations and easily become channels for authoritarian solutions, and where the state itself, rife with flaws and antidemocratic components, is part of the problem.

The analysis of social cohesion in Latin America must therefore include an understanding of processes of change and social conflict, as well as the mechanisms through which they are expressed and resolved. The analysis of social cohesion in democracy, therefore, centers around the social transformations in progress and the challenges they pose for democratic institutions. This means expanding the analytical and normative horizon of social cohesion beyond (but inclusive of) public policy, to encompass the functioning of political and cultural systems. The analysis is framed, then, around nations as the space reserved for the functioning of the political system and the state, in the context of globalization.

In order to develop this perspective we must first present the historical framework that circumscribes the potential for social cohesion in democracy - which implies paying particular attention to the diversity of political models and forms of social conflict. 


\section{Political models}

Most assessments of the region - due to the limitations of the official and semi-official institutions that produce them - do not refer explicitly and directly to the current dominant political models and discourses. Yet this aspect is critical to understanding the political reality of the continent. If structural socioeconomic conditions can cause antidemocratic trends to emerge, they only do so through the presence of concrete political models advanced by specific actors. We cannot forget, then, that while poverty and social inequality are the foundational substratus upon which political dynamics are constructed, what ultimately destroys democracies are antidemocratic movements, ideologies and political leaders - which mobilize and polarize the imagination and the political debate - and that anticorruption movements were the main factor that brought down several presidents in the region over the past decade.

As a consequence of the preceding point, we understand that social cohesion has to do not only with the most adequate or effective public policies - which are clearly crucial and have certainly been mentioned herein - but also requires us to ask ourselves about the mechanisms for the symbolic and political mobilization of citizens, which are a prerequisite for the possibility (or impossibility) of public policies and state reforms. Any examination of public policies requires a more nuanced understanding of the sectors they target. The poor, for example, are not a statistical conglomerate but rather heterogeneous social actors with active and creative survival strategies that are not always in sync with the official plans. The informal sector (from housing to work), for example, is much more than the lack of alternatives in the formal sector. It is built out of the constant search for niches and opportunities made possible by the absence, or fragility, of government regulations. It encompasses everything from constructions with no urban development plan to the diversion of electricity, potable water or cable TV; from mini-contraband to arms and drugs trafficking or illegal collective transportation. Moreover, the legalization of these activities is not always an obvious, possible or desirable course from the standpoint of the participating actors.

What is more, some policies such as those governing cash transfers, for example, can undermine democratic consolidation if they are not implemented with the necessary care. It is therefore not just a matter of what is delivered, but how, and the way in which it is received by social actors. We must also address the challenge that the impact of public policies 
is of variable duration. Some policies may have an impact only in the long term, while society is demanding more immediate responses.

\section{Cohesion and social conflict}

All of these elements must be borne in mind insofar as they define the ultimate aim of this book: to deepen the debate over the possibilities for consolidating democratic political projects on the continent. The analysis of social cohesion means striving to understand the myriad social dynamics of integration and of conflict, which are legitimate and critical components of the construction/transformation of mechanisms for social cohesion in democratic societies. In this sense, it is not possible to characterize the specific contents of social cohesion based on a priori definitions. For example, the definition of social cohesion - according to ECLAC (2007a), "the dialectical relationship between established mechanisms of social inclusion exclusion and citizens' responses, perceptions and attitudes towards the way in which these operate..." - implies a theory and an empirical analysis of what is meant by "citizens" and "established mechanisms of inclusion/ exclusion," and of the content of this dialectical relationship, in other words the intermediaries that relate what is established to the institutive actions of social actors.

The included/excluded dichotomy leads to a unilateral vision of the construction of social cohesion in that it fails to take into account the entirety of processes that traverse society. All of these processes are fundamental to the construction of social cohesion and they cannot be reduced to issues of social inclusion/exclusion. They generally involve a direct correlation between the objective criteria of inclusion/exclusion (usually socioeconomic and schooling indicators) and the subjective dimensions of social cohesion. Of course, limited access to social services, income and opportunities in the labor market frequently are keystones in the construction of a sense of social exclusion. But this relation is not mechanical and we cannot overlook the category of relative deprivation (for example, the expectations and feelings of inclusion or exclusion of a recent migrant originally from a rural setting are not the same as those of a generation born and raised in the city), nor can we assume that feelings of exclusion, frustration and social anomie are not present among sectors with better indicators of social wellbeing.

This assumption concerning the centrality of social exclusion does not correspond to the historical reality of the continent or other regions, where 
many social movements that have questioned democratic institutions had middle class roots. Today, feelings of frustration among the middle classes - which generally are associated with generalized corruption and the inability of the state to protect life and property - erode social cohesion around democratic values. The importance of this issue for democratic consolidation should not be underestimated: as we pointed out earlier, most of the social mobilizations that brought about the removal or the impeachment of ten presidents in recent years revolved around reports of corruption, while in many countries the main issue concerning much of the population is insecurity associated with violence.

Similarly, reducing social inclusion to its purely economic dimensions does not permit us to assign the proper weight, for example, to the danger that informal labor poses for the consolidation of democratic institutions. While the informal sector sometimes facilitates survival strategies - and for some sectors can even yield higher incomes than those they would obtain in the formal sector - its very existence strengthens a culture of illegality and is generally associated with Mafia-like structures of control that foster corrupt relations with the law enforcement officials responsible for suppressing their activities.

The interrelations between social cohesion and inclusion/exclusion are, therefore, complex, as an abundance of sociological studies have shown and as our study has tried to demonstrate in more depth specifically with regard to Latin America. Societies whose cohesion revolves around egalitarian values can intensify feelings of exclusion among individuals and groups who would be considered acceptable in other contexts. In certain cases, greater economic inclusion can increase feelings of symbolic and political exclusion and, conversely, greater symbolic inclusion can intensify feelings of economic exclusion. In sum, the objective and subjective dimensions of inclusion/exclusion are complex and require theoretical and empirical analyses sensitive to the historical formation of values systems in each society.

In general, analyses of social cohesion guided by the included/excluded dichotomy tend to consider institutional integration mechanisms (usually employment and social policy) as the main, or even the only, factor of integration, against which individual leanings are juxtaposed. This vision generally only considers the family (and more recently, ethnic group) as a factor of integration, leaving aside other associative forms through which 
individuals find solidarity and meaning in their lives. ${ }^{80}$ Without excluding social policy and the workplace, which are of course critical, we have tried to identify the dynamics of the new (and old) universes of meaning and individual strategies of solidarity and belonging (including religion, party, trade union, music, virtual communities, emigration, neighborhood, drug use, violent gangs, civil society organizations, and affinity groups) which are key intermediaries in relations between the individual and the market/state and producers of social cohesion that cannot be reduced to the included/ excluded dichotomy.

80 We recall that in all of his works, Émile Durkheim stressed the central role that these intermediary levels between the individual, the state and the market play in social stability and the construction of meaning. 


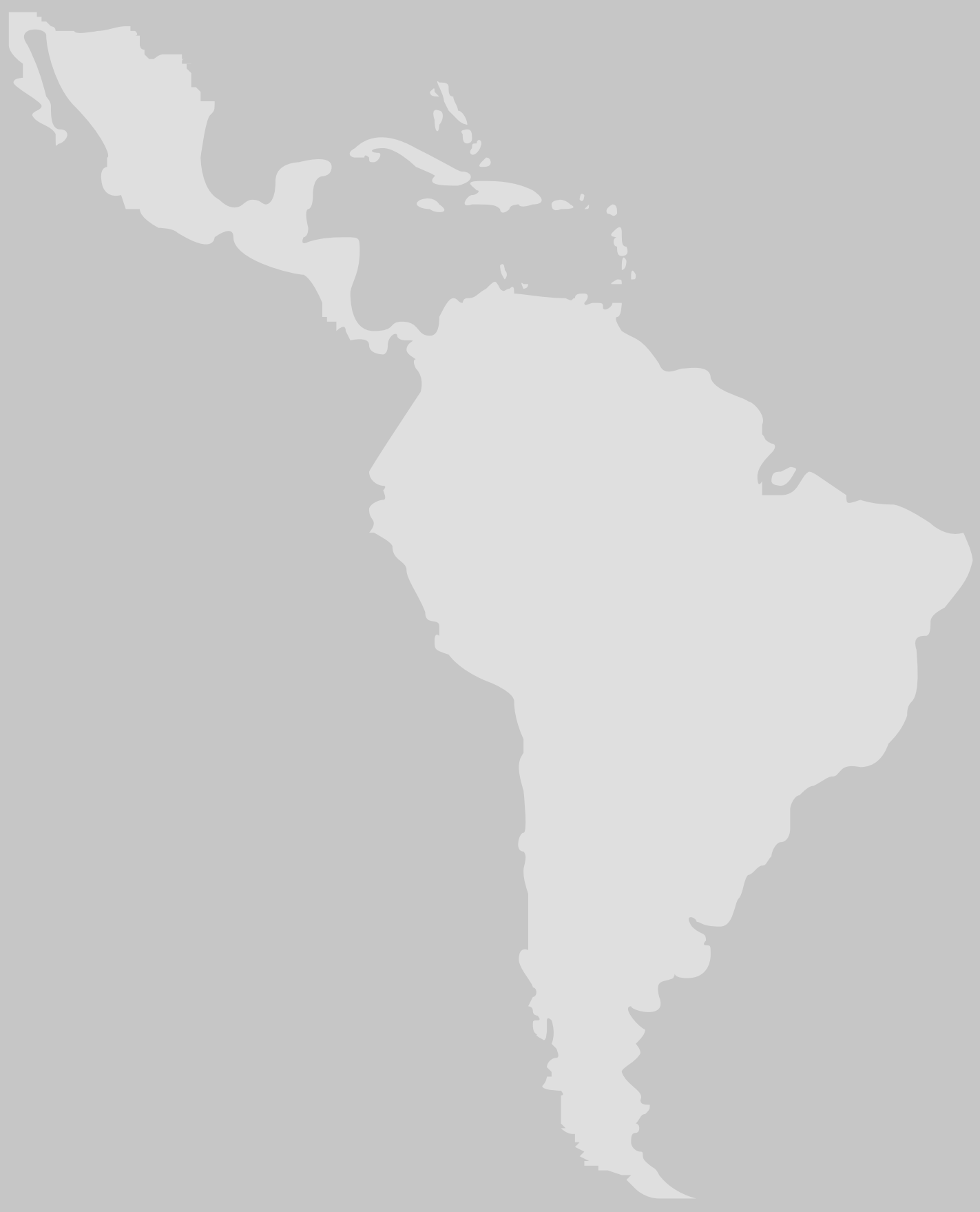




\section{Annex 2}

\section{1 । | | List of contributions}

Cardoso, Adalberto; Gindin, Julián (2007), "Relações de Trabalho, Sindicalismo e Coesão Social na América Latina”, São Paulo, iFHC.

Julio Cotler: Comentarios a un grupo de papers, São Paulo, iFHC.

Dreyfus, Pablo G.; Fernandes, Rubem Cesar (2007), "Violencia urbana armada en América Latina: otro conflicto", São Paulo, iFHC.

Jácome, Francine, “Renovación/Resurgimiento del Populismo? El Caso de Venezuela y sus impactos regionales" (2007), São Paulo, iFHC.

Kaztman, Ruben; Ribeiro, LuizCesar de Queiroz(2007), "MetrópoleseSociabilidade: reflexões sobre os impactos das transformações sócio-territoriais das grandes cidades na coesão social dos países da América Latina”, São Paulo, iFHC.

Larreta, Enrique Rodríguez (2007), "Cohesión Social, Globalización y Culturas de la Democracia en América Latina”, São Paulo, iFHC.

Magnoli, Demétrio (2007), "Identidades raciais, sociedade civil e política no Brasil", São Paulo, iFHC, São Paulo, iFHC.

Mitre, Antonio (2007), "Estado, Modernização e Movimentos Étnicos na América Latina”, São Paulo, iFHC.

Mustapic, Ana Maria (2007), "Del malestar con los partidos a la renovación de los partidos”, São Paulo, iFHC. 
Oro, Ari Pedro (2007), "Religião, Coesão Social e Sistema Político na América Latina”, São Paulo, iFHC.

Quevedo, Luis Alberto (2007), “Identidades, Jóvenes y Sociabilidad - una vuelta sobre el lazo social en Democracia”, São Paulo, iFHC.

Peralva, Angelina (2007), "Globalização, migrações transnacionais e identidades nacionais", São Paulo, iFHC.

Schwartzman, Simon (2007), “Coesão Social, Democracia e Corrupção”, São Paulo, iFHC.

Smulovitz, Catalina; Urribarri, Daniela (2007),, "Poderes Judiciales en América Latina. Entre la administración de aspiraciones y la administración del derecho", São Paulo, iFHC.

Soares, Luiz Eduardo; Messari, Nizar (2007),, "Crime organizado, drogas, corrupção pública -observações comparativas sobre Argentina, Brasil, Chile, Colômbia, Guatemala, México e Venezuela”, São Paulo, iFHC.

Sorj, Bernardo (2007), "Capitalismo, Consumo y Democracia: Procesos de mercantilización/desmercantilización en América Latina”, São Paulo, iFHC.

Sorj, Bernardo (2007), “Deconstrucción o reinvención de la Nación: La memoria colectiva y las políticas de victimización en América Latina”, São Paulo, iFHC.

Szmukler, Alicia (2007), "Culturas de Desigualdad, Democracia y Cohesión Social en la Región Andina”, São Paulo, iFHC.

Torre, Juan Carlos (2007), “Cohesión-Populismo”, São Paulo, iFHC.

Vaillant, Denise (2007, "Educación, socialización y formación de valores cívicos”, São Paulo, iFHC.

Yúdice, George (2007), "Medios de Comunicación e Industrias Culturales, Identidades Colectivas y Cohesión Social”, São Paulo, iFHC.

Zamosc, Leon (2007), “Ciudadanía indígena y cohesión social”, São Paulo, iFHC. 


\section{| | | | Bibliography}

Acero Velásquez, Hugo (2006), Situación de la violencia y delincuencia de Venezuela y concentración delincuencial en Caracas, Caracas, Available at http://www.comunidadesegura.org/files/active/0/diagnostico_violencia_y_ delincuencia_Venezuela_y_Caracas.pdf

Anheier, Helmut; Katz, Hagai (2003), "Mapping Global Civil Society." En Global Civil Society 2003. Editado por M. Kaldor et al, Yearbook 2003, The Center for the Study of Global Governance. Available at http://www.lse.ac.uk/Depts/ global/yearbook03chapters.htm

APC, La Asociación para el progreso de las Comunicaciones (2005), Monitor Politicas TIC y Derechos en Internet en América Latina y El Caribe. Available at: http://lac.derechos.apc.org/es.shtml?apc=se_1

Araujo, Katia (2006), Estudio de la noción de derecho y vías y posibilidades para su defensa en los sectores de menores recursos, Santiago, OXFAM.

Avila, Leonardo de la Torre (2006), No llores, prenda, pronto volveré: migración, movilidad social, herida familiar y desarrollo, La Paz, PIEB/IFEA.

Bolz, Norbert. (2006), Comunicación mundial, Buenos Aires, Katz.

Briceño León, Roberto (2002), "La Nueva Violencia Urbana de América Latina", Sociologías, № 8, 34-51.

Briceño León, Roberto (2006), Violence in Venezuela: Oil Rent and Political Crisis, Caracas, Lacso.

Buarque de Holanda, Sérgio (2006), Raízes do Brasil, São Paulo, Companhia das Letras. 
Bauman, Zygmunt (2005), Identidad, Madrid, Losada.

Campero, Guillermo (2000), Respuestas del sindicalismo ante la mundialización: el caso de Chile, Lima, ILO.

Cardoso, Adalberto Moreira (2004), Industrial Relations, Social Dialogue and Employment in Argentina, Brazil and Mexico, Geneva, ILO, Employment Strategies Papers, No. 7.

Cardoso, Adalberto; Gindin, Julián (2007), "Relações de Trabalho, Sindicalismo e Coesão Social na América Latina”, São Paulo, iFHC.

Carranza, Marlon (2005), "Detention or Death: Where the 'Pandillero' Kids of El Salvador are Heading." In Dowdney, Luke, Neither War, nor Peace: International Comparisons of Children and Youth in Organized Armed Violence, Rio de Janeiro, COAV, Viva Rio, ISER, IANSA.

Castells, Manuel (1998), La société en réseaux, Paris, Fayard.

CEJA/JSCA - Justice Studies Center of the Americas (n/d), Report of Justice in the Americas 2004-2005, Reports on Argentina, Bolivia, Brazil, Chile, Guatemala and Mexico. Available at www.cejamericas.org

Cheresky, Isidoro. (ed.), (2007), La politica después de los partidos, Buenos Aires, Prometeo.

CIA (2007), The World Fact Book, Available at https://www.cia.gov/cia/publications/ factbook/fields/2122.html.

Claessens, Stijn; Feijen, Erik and Laeven, Luc (2006), Political Connections and Preferential Access to Finance: the Role of Campaign Contributions, Washington, DC, University of Amsterdam, World Bank and CEPR.

Cook, Maria Lorena, The Politics of Labor Law Reform: Comparative Perspectives on the Mexican Case, Paper presented at the Latin American Studies Association Conference, Chicago, Illinois, September, 1998.

Cruz, Miguel (2006), El Salvador, en La Cara de la Violencia Urbana en América Central, San José, Fundación Arias para la Paz y el Progreso Humano, 105-162.

Da Matta, Roberto (1978), Carnavais, malandros e heróis, Rio de Janeiro, Zahar.

De la Garza, Enrique. (1990), "Reconversión industrial y cambio en el patrón de relaciones laborales en México." En La modernización de México. Editado por A. Anguiano, México, UAM.

De León, Carmen Rosa; Sagone, Itziar (2006), Guatemala. En La Cara de la Violencia Urbana en América Central, San José, Fundación Arias para la Paz y el Progreso Humano, 163-200.

Dreyfus, Pablo (2002), Border Spillover: Drug Trafficking and National Security in South America, Geneva, Doctoral Dissertation, Institut Universitaire de Hautes Études Internationales (IUHEI).

Dreyfus, Pablo; Fernandes, Rubem Cesar (2007), "Violencia urbana armada en América Latina: otro conflicto", São Paulo, IFHC. 
Dubet, François; Martuccelli, Danilo (2000), ¿En qué sociedad vivimos?, Buenos Aires, Losada.

Dupas, Gilberto (2001), Economia global e exclusão social, São Paulo, Paz e Terra.

Durkheim, Emile (1893), De la division du travail social: étude sur l'organisation des sociétes supérieures. Paris, F. Alcan.

Durkheim, Emile (1995), La división del trabajo social I, Madrid, Akal. Available at: http://sociologia. fsoc.uba.ar/documentos/lecturan/durkheim_division_ trabajo1.pdf

ECLAC (2007a), Social Cohesion, Inclusion and a Sense of Belonging in Latin America and the Caribbean, United Nations, Santiago. Available at: http:// www.eclac.org/cgi-bin/getProd.asp?xml=/publicaciones/xml/4/27814/ P27814.xml\&xsl=/tpl/p9f.xsl\&base=/tpl/top-bottom.xsl.

ECLAC (2007c), Social Panorama of Latin America, United Nations, Santiago.

ECosocial (2007), Available at http://www.ecosocialsurvey.org/inicio/index.php

Esping Andersen, Gosta (1990), The Three Worlds of Welfare Capitalism, New Jersey Princeton University Press.

Esping Andersen, Gosta (1999), Social Foundations of Post Industrial Economies, Oxford, Oxford University Press.

Esping-Anersen, Gosta et al (2002), Why We Need a New Welfare State, Oxford, Oxford University Press.

Etchemendy, Sebastián; Collier, Ruth Berins (2007), Down but Not Out: Union Resurgence and Segmented Neocorporatism in Argentina (2003-2007); Mimeo.

Fajnzylber, Pablo; Lopez, Humberto (2007), “Cerca de casa: impacto de las remesas en el desarrollo de América Latina”, Banco Mundial.

Fernandes, Rubem Cesar; Nascimento, Marcelo de Sousa (2007), Mapping the Divide, Armed Violence and Urbanization in Brazil; Geneva, Small Arms Survey.

Filgueira, Fernando (1998), "El nuevo modelo de prestaciones sociales en América Latina: residualismo, eficiencia y ciudadanía estratificada.” En Ciudad y Política. Editado por B.Roberts, San Jose de Costa Rica, LACSO/SSRC,.

Finkelievich, Susana; Prince, Alejandro (2007), El (Involuntario) Rol Social de los Cibercafés, M. S.

French, John (2004), Drowning in Laws: Labor Law and Brazilian Political Culture, Chapel Hill and London, University of North Carolina Press.

Frith, Simon (2003), "Música e Identidad." En Cuestiones de identidad cultural. Editado por S. Hall y P. du Gay., Buenos Aires, Amorrortu.

Fundación Arias (2006), “Análisis Regional." En La Cara de la Violencia Urbana en América Central, San José, Fundación Arias para la Paz y el Progreso Humano, 1-58. 
García Canclini, Néstor et al (1991), Públicos de arte y política cultural: un estudio del II Festival de la ciudad de México, México, Universidad Autónoma Metropolitana-Iztapalapa / Departamento del Distrito Federal.

Garretón, Manuel (2006), “Modelos y liderazgos en América Latina." Nueva Sociedad, No 205, Buenos Aires, 103-113.

Gasparini, Leonardo; Cruces, Guillermo et al (2007), "Informe de consultoría Proyecto CIEPLAN-IFHC sobre Cohesión Social” Sección 1: Selección de indicadores socioeconómicos para América Latina, São Paulo iFHC, CEDLAS, Universidad Nacional de La Plata.

Germani, Gino (1968), Política y Sociedad en una época en transición: de la sociedad tradicional a la sociedad de masas, Paidos, Buenos Aires.

Giddens, Anthony (1990), The Consequences of Modernity, Cambridge, Polity Press.

Gil, Sandra Araujo (2004), “Inmigración latinoamericana a España: estado de la cuestión.” Revista Global, N 5.

Girola, Lídia (2005), Anomia e individualismo, Barcelona, Anthropos.

Granovetter, Mark (1995), Getting a Job: a Study of Contacts and Careers, Chicago, University of Chicago Press.

Granovetter, Mark; Swedberg, Richard (1992), The Sociology of Economic Life, Boulder, Westview Press.

Halbwachs, Maurice (1971), La topographie légendaire des évangiles en Terre Sainte, 2a. ed, Paris, PUF.

Hammergren, Linn (2002), Uses of Empirical Research in Refocusing Judicial Reforms: Lessons from Five Countries, World Bank, Washington DC. Available at http://www1.worldbank.org/publicsector/legal/UsesOfER.pdf

Hirschman, Albert (1970), Exit, Voice and Loyalty, Cambridge, Harvard University Press.

Huntington, Samuel (1996), Political Order in Changing Societies, New Haven, Yale University Press.

Innerarity, Daniel (2006), El nuevo espacio público, Madrid, Espasa Calpe.

Jácome, Francine (2007), “¿Renovación/resurgimiento del populismo? El caso de Venezuela y sus impactos regionales”, São Paulo, iFHC.

Kaldor, Mary et al (2003), Global Civil Society 2003, Yearbook 2003, The Center for the Study of Global Governance, Available at http://www.lse.ac.uk/Depts/ global/yearbook03chapters.htm

Katzman, Ruben; Ribeiro, Luiz Cesar de Queiroz (2007), “Metrópoles e sociabilidade: reflexões sobre os impactos das transformações sócioterritoriais das grandes cidades na coesão social dos países da América Latina”, São Paulo, iFHC. 
Kruse, Tom; Escobar de Pabón, Silvia (2005), "La industria manufacturera boliviana en los noventa." Serie: Avances de investigación No 25. La Paz, Centro de Estudios para el Desarrolo Laboral y Agrario (CEDLA).

Larreta, Enrique Rodríguez (2007), “Cohesión Social, globalización y culturas de la democracia en América Latina”, São Paulo, iFHC.

Lechner, Norberto (1999) "Los condicionantes de la gobernabilidad democrática en la América Latina de fin de siglo." En Los noventa, Política, sociedad y cultura en América Latina y Argentina de fin de siglo. Editado por D. Filmus, Buenos Aires, FLACSO-EUDEBA.

Leff, Nathaniel (1964), "Economic Development through Bureaucratic Corruption” American Behavioral Scientist, v.8, No 3, 8-14.

Lisboa, Marcos de Barros; Viegas, Mônica (2000), "Desesperança de vida: homicídio em Minas Gerais, Rio de Janeiro e São Paulo, 1981 a 1997”, Ensaios Econômicos da EPGE, № 383.

Lopez, Luiz (2007), En quête d'identité: mondialisation, figures de la féminité et conflits sociaux à la frontière Mexique Etats-Unis. Tésis de Doctorado de Sociologia. Paris, CADIS/EHESS.

Lozano, Wilfredo (2005), "La izquierda latinoamericana en el poder", Nueva Sociedad, No 197, Buenos Aires, 129-145.

Lustig, Nora (2007), "El mercado, el Estado y la desigualdad en América Latina", Paper presentado en el Taller Cohesión social, movilidad social y políticas públicas en América Latina, Antigua, Guatemala, julio.

Luz, Daniel (2007), ¿Es la prevención de la violencia armada una cuestión de desarrollo? El caso de El Salvador, San Salvador, mimeo.

Magnoli, Demetrio (2007), "Identidades raciais, sociedade civil e política no Brasil", São Paulo, iFHC.

Marchissio, Adrián (2004), La duración del proceso penal en la República Argentina. A diez años de la implementación del juicio oral y público en el sistema federal argentino, Fundación Konrad Adenauer y Ministerio Público Fiscal (Available on the websites of both institutions), February 2004.

Marramao, Giacomo (2006), Pasaje a Occidente: filosofía y globalización, Buenos Aires, Katz.

Martuccelli, Danilo (2007), Cambio de rumbo, Santiago, LOM.

Martuccelli, Danilo (2002), Grammaires de l'individu, Paris, Gallimard.

Martuccelli, Danilo; Svampa, Maristella (2007), "Las asignaturas pendientes del modelo nacional-popular. El caso peruano." En Nación y nacionalismo en América Latina, Editado por J. González, Buenos Aires, CLACSO.

Martuccelli, Danilo; Svampa, Maristella (1997), La plaza vacía, Buenos Aires, Losada. 
Mauro, Paolo (1997), “The Effects of Corruption on Growth, Investment and Government Expenditure: a Cross-Country Analysis."En Corruption and the Global Economy. Editado por K.A. Elliot., Washington, DC, Institute for International Economics.

Merton, Robert K. (1957), Social Theory and Social Structure, Glencoe, Ill., Free Press.

Millefiorini, Andréa (2005), Individualismo e società di massa, Roma, Carocci.

Ministère des Affaires Etrangères, France, Available at http://www.diplomatie. gouv.fr/

Mitre, Antonio (2007), “Estado, modernização e movimentos étnicos na América Latina”, São Paulo, iFHC.

Montero, Lourdes (2005), "Los nuevos mundos del trabajo. El empleo asalariado en Bolívia." Serie Documentos y trabajo, No 31, La Paz, Centro de Estudios para el Desarrolo Laboral y Agrario (CEDLA).

Mustapic, Ana Maria (2007), “Del malestar con los partidos a la renovación de los partidos”, São Paulo, iFHC.

Nino, Carlos. (1992), Un país al margen de la ley, Buenos Aires, Emecé.

Nugent, Guillermo (1998), Composición sin título, Lima, Friedrich Ebert Stiftung.

O’Donnell, Guillermo (1984), ¿Y a mi qué me importa? Notas sobre sociabilidady política en Argentina y Brasil, Buenos Aires, CEDES.

Ocampo, Luis Moreno (2000), "Structural Corruption and Normative Systems: the Role of Integrity Pacts." In Combating Corruption in Latin America. Edited by J.S. Tulchin and R. H. Espach. Washington, D.C, Baltimore. Published by Woodrow Wilson Center Press. Distributed by Johns Hopkins University Press.

IOM, INEI, DIGEMIN (2006), Peru: Estadísticas de la Migración Internacional de los Peruanos, 1990-2005. Lima.

Oro, Ari Pedro (2007), "Religião, coesão social e sistema político na América Latina”, São Paulo, iFHC.

Pásara, Luis (2004a), “Lecciones ¿aprendidas o por aprender?” En En busca de una justicia distinta. Editado por L. Pásara., Justicia Viva, Lima Perú.

Pásara, Luis (2004b), Reformas del sistema de justicia en América Latina: cuenta $y$ balance, Instituto de Investigaciones Jurídicas de la UNAM, México. Available at www.info.juridicas.unam.mx/inst/evacad/eventos/2004/0902/ mesa11/278s.pdf

Pellegrino, Adela (2003), "La migración internacional en América latina y el Caribe." Serie Población y Desarrollo, Nº 35, Santiago do Chile, CEPAL/BID.

Peralva, Angelina (2007), "Globalização, migrações transnacionais e identidades nacionais", São Paulo, iFHC.

Perroud, Mélanie (2006), "Dekasegi/Dekasseguis: des travailleurs brésiliens au Japon.” Diasporas, histoire et sociétés, $\mathrm{N}^{\circ}$ 9, 138-150. 
Petkoff, Teodoro (2005), “Las dos izquierdas." Nueva Sociedad, No 197, Buenos Aires, 114-128.

Phebo, Luciana (2005), "Impacto da arma de fogo na saúde da população no Brasil”, En Brasil: as armas e as vítimas. Editado por R.C. Fernandes. Available at http:// www.desarme.org/publique/media/vitimas_armas_impacto_saude.pdf

Polanyi, Kart (1994), The Great Transformation, Boston, Beacon Press.

Portocarrero, Gonzalo (2004), Los rostros criollos del mal, Lima, Red para el desarrollo de las ciencias sociales en el Perú.

Putnam, Robert D. (2001), Bowling Alone: the Collapse and Revival of American Community, New York, Touchstone.

Quevedo, Luis Alberto (2007), “Identidades, jóvenes y sociabilidad: una vuelta sobre el lazo social en Democracia”, São Paulo, iFHC.

Ramírez, Franklin (2006), “Mucho más que dos izquierdas." Nueva Sociedad, No 205, Buenos Aires, 30-44.

Roberts, Kenneth (2007), From the 'End of Politics' to a new 'Left Turn': the Repoliticization of Social Exclusion in Latin America, Paper presented at the Conference on Globalization, Diversity and Inequality in Latin America, University of Pittsburgh.

Rose-Ackerman, Susan (1999), Corruption and Government: Causes, Consequences, and Reform. Cambridge, UK: Cambridge University Press.

Rose-Ackerman, Susan; Kornai, János (eds.) (2004), Building a Trustworthy State in Post-socialist Transition, New York, Palgrave Macmillan.

Salas, Carlos; De la Garza, Enrique (eds.) (2006), La situación del trabajo en México. Available at http://docencia.izt.uam.mx/egt/publicaciones/libros/actlst06/ indice.htm.

Sallum Jr., Brasílio (1996), Dos generais à Nova República, São Paulo, Hucitec.

Schwartzman, Simon (2007), “Coesão social, democracia e corrupção”, São Paulo, iFHC.

Schwartzman, Simon (2004), Pobreza, exclusão social e modernidade: uma introdução do mundo contemporáneo, São Paulo, Augurim Editora.

Smulovitz, Catalina; Urribarri, Daniela (2007), "Poderes judiciales en América Latina: entre la administración de aspiraciones y la administración del derecho", São Paulo, iFHC.

Soares, Luiz Eduardo; Messari, Nizar (2007), "Crime organizado, drogas, corrupção pública: observações comparativas sobre Argentina, Brasil, Chile, Colômbia, Guatemala, México e Venezuela”, São Paulo, iFHC.

Soares, Luiz Eduardo (1997), "A duplicidade da cultura brasileira." En O malandro e o protestante: a tese weberiana e a singularidade cultural brasileira. Editado por J. Souza, Brasília, Editora UnB.. 
Sojo, Ana; Andras Uthoff (eds.), Cohesión Social en América Latina y el Caribe, una revisión perentoria de algunas de sus dimensiones, CEPAL, (2007), United Nations, Santiago, Available at http://www.eclac.org/cgi-bin/getProd. asp?xml=/publicaciones/xml/8/28198/P28198.xml\&xsl=/dds/tpl/p9f. $\mathrm{xsl} \&$ base $=/$ cooperacion/tpl/top-bottom.xsl

Sorj, Bernardo (2007a), “Capitalismo, Consumo y Democracia: Procesos de mercantilización/desmercantilización en América Latina”, São Paulo, iFHC.

Sorj, Bernardo (2007b), "Deconstrucción o reinvención de la Nación: la memoria colectiva y las políticas de victimización en América Latina”, São Paulo, iFHC.

Sorj, Bernardo (2006), "Internet, Public Sphere and Political Marketing: Between the Promotion of Communication and Moralist Solipsism.” Rio de Janeiro: The Edelstein Center for Social Research, Working Paper 2.7, Available at http://www.bernardosorj.com/pdf/wp2_english.pdf

Sorj, Bernardo (2005a), La Democracia Inesperada, Buenos Aires, Prometeo/ Bononiae.

Sorj, Bernardo (2005b), "Sociedad Civil y Relaciones Norte-Sul: ONGs y Dependencia”, Centro Edelstein de Investigaciones Sociales, Working Paper 1, Rio de Janeiro, Available at http://www.centroedelstein.org.br/espanol/ wp1_espanol.pdf

Sorj, Bernardo (2000), A Nova Sociedade Brasileira, Río de Janeiro, Jorge Zahar.

Sorj, Bernardo (1989), "Crises e horizontes das ciências sociais na América Latina”, Novos Estudos CEBRAP, № 23.

Sorj, Bernardo; Guedes, Luís Eduardo (2006), Internet y pobreza, Editora Unesco /Ediciones Trilce, Montevideo.

Sorj, Pablo (2005), Economic Analysis of Widespread Corruption and Optimal Law Enforcement, Stanford Law School, April.

Souza, Jessé (2003), A construção social da subcidadania: para uma sociologia política da modernidade periférica, Rio de Janeiro, Editora da UFMG/IPUERJ.

Stiglitz, Joseph. (2002), Globalization and its Discontents, New York y London, W. W. Norton and Company.

Szmukler, Alicia (2007), "Culturas de desigualdad, democracia y cohesión social en la Región Andina”, São Paulo, iFHC.

Tönnies, Ferdinand; Loomis, Charles Price (2002), Community and Society. Mineola, N.Y., Dover Publications.

Torre, Juan Carlos (2007), “Cohesión-Populismo”, São Paulo, iFHC.

Touraine, Alain (1988), La parole et le sang, Paris, Odile Jacob.

UNDP (2000), Human Development Report, Bolivia, La Paz.

US Department of State, Available at http://www.state.gov/g/drl/rls/irf/2001/5594.htm 
Velho, Gilberto (1996), "Violência, reciprocidade e desigualdade.” En Cidadania e Violência. Editado por G.Velho y M. Alvito. Rio de Janeiro, UFRJ/FGV.

World Bank (2002), The Juicio Ejecutivo Mercantil in the Federal District Courts of Mexico: a Study of the Uses and Users of Justice and Their Implications for Judicial Reform. Poverty Reduction and Management Unit, Latin America and the Caribbean, Report No. 22635-ME.

World Health Organization (WHO) (2002), World Report on Violence and Health, Geneva.

Yúdice, George (2007), "Medios de comunicación e industrias culturales: identidades colectivas y cohesión social", São Paulo, iFHC.

Zapata, Francisco (1993), Autonomía y subordinación en el sindicalismo latinoamericano, México, Fondo de Cultura Económica.

Zamosc, Leon (2007), “Ciudadanía indígena y cohesión social”, São Paulo, iFHC.

\section{Internet sites}

http://www.venezuelanalysis.com/articles.php?artno=1151

http://www.overmundo.com.br

http://www.sindipecas.org.br

http://eur-lex.europa.eu/LexUriServ/LexUriServ.do?uri=CELEX:52002DC0551: ES:HTML.

http://circa.europa.eu/Public/irc/dsis/ssd/library?l=/task_force_esec/1617_april_ 2007/improvementsdoc/_EN_1.0_\&a=d

http://www.camara.gov.br/sileg/integras/359794.pdf

http://www.coe.int/T/E/social_cohesion/social_policies/03.Strategy_for_Social_ Cohesion/

http://216.239.51.104/search?q=cache:InbhfFfic4YJ:www.notre-europe. eu/en/axes/competition-cooperation-solidarity/works/publication/ how-to-enhance-economic-and-social-cohesion-in-europe-after$2006 /+$ definition + european + commission + social + cohesion $\&$ hl $=$ pt $\mathrm{BR} \& \mathrm{ct}=\mathrm{clnk} \& \mathrm{~cd}=10 \& \mathrm{gl}=\mathrm{br}$ 


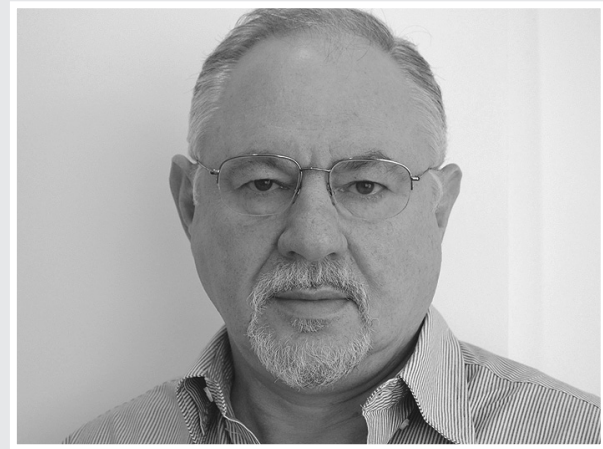

BERNARDO SORJ (www.bernardosorj.com), Uruguayan by birth and a naturalized Brazilian citizen, is the director of the Edelstein Center for Social Research and a professor of sociology at the Federal University of Río de Janeiro. He has been a visiting professor at several universities in Europe and the United States. $\mathrm{He}$ is the author of over 100 articles and 20 books, which have been published in English, Spanish, Portuguese and French, including Latin America's Elusive Democracies (published in English, Spanish and Portuguese), A Nova Sociedade Brasileira, (Rio de Janeiro, Jorge Zahar, 2001), Internet y Pobreza (Montevideo, Trilice/UNESCO, 2006) and A Construção Intelectual do Brasil Contemporâneo (Rio de Janeiro, Jorge Zahar, 2002).

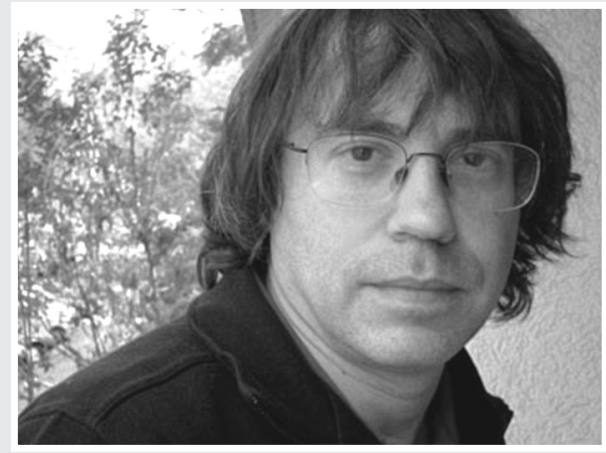

Danilo Martuccelli, a Peruvian native, currently resides in France and is a professor of sociology at the Universidad de Lille 3. He is the author of 15 books and 100 chapters and articles published in specialized journals. His books include Sociologies de la modernité (Gallimard, 1999), Grammaires de l'individu (Gallimard, 2002), La consistance du social (P.U.R., 2005), Forgé par l'épreuve (Armand Colin, 2006), En la plaza vacía (with Maristella Svampa Ciudad, Editora, 1997), and more recently, Cambio de rumbo in LOM, Chile (2007). He has lectured at universities in France and other European countries, and throughout Latin and North America. 